Gustavo Adolfo Patiño Alvarez

\title{
Caracterização Analítica de Carga de Trabalho Baseada em Cenários de Aplicações Multimídia
}

Tese apresentada à Escola Politécnica da Universidade de São Paulo para obtenção do título de Doutor em Engenharia Elétrica

São Paulo

2013 
Gustavo Adolfo Patiño Alvarez

\section{Caracterização Analítica de Carga de Trabalho Baseada em Cenários de Aplicações Multimídia}

Tese apresentada à Escola Politécnica da Universidade de São Paulo para obtenção do título de Doutor em Engenharia Elétrica

Área de Concentração:

Microeletrônica

Orientador:

Prof. Dr. Wang Jiang Chau

São Paulo

2013 
Este exemplar foi revisado e alterado em relação à versão original, sob responsabilidade única do autor e com a anuência de seu orientador.

São Paulo, 31 de janeiro de 2013.

Assinatura do autor

Assinatura do orientador

Patiño Alvarez, Gustavo Adolfo

Caracterização analítica de carga de trabalho baseada em cenários de aplicações multimídia / G.A. Patiño Alvarez. -ed.rev. -- São Paulo, 2013.

$240 \mathrm{p}$.

Tese (Doutorado) - Escola Politécnica da Universidade de São Paulo. Departamento de Engenharia de Sistemas Eletrônicos.

1. Multimídia (Aplicações) 2. Carga de trabalho 3. Análise de desempenho 4. Sistemas embutidos 5 . Modelo analítico 6. Modelos de computação I.Universidade de São Paulo. Escola Politécnica. Departamento de Engenharia de Sistemas Eletrônicos II. t. 
Dedicado a dos grandes familias, cuna primera de mi ser: Mis familias Álvarez Bedoya y Patiño Restrepo. 
Lee,

entiende,

escribe,

verifica,

y crea! 


\section{AGRADECIMENTOS}

Ao meu orientador, Prof. Dr. Wang Jiang Chau, pela oportunidade de fazer doutorado sob sua orientação, participando do trabalho acadêmico e de pesquisa no grupo de Sistemas Eletrônicos Integrados e Software Aplicado (GSEIS). Graças à oportuna orientação do Prof. Wang foi possivel moldar a tese, focando sempre na qualidade do projeto de doutorado.

Aos meus colegas de grupo com que compartilhei tantos "cafezinhos", refeições no "bandejão", e inúmeras conversas interessantes sobre as diferenças culturais dos nossos países: Peru, Colômbia e Brasil. Agradeço a amizade do Jorge, Mary, Mario, Carlos, Jonas, Joel e Cristopher, quem nos últimos anos fizeram ainda mais agradável os longos dias de trabalho na sala e no lab. Do mesmo modo, agradeço aos meus amigos Jenny e Valdomiro cuja jovem família me recebeu sempre de braços abertos, como mais um membro da família.

Agradeço ao Prof. Marius Strum pela amizade oferecida nos últimos anos, assim como pelas breves conversas sobre vários dos temas considerados na realização da presente tese.

Aos meus amigos e amigas, brasileiros, colombianos, e de outras nacionalidades, com quem compartilhei tantos momentos agradáveis, interessantes e de crescimento pessoal durante os anos que fiquei em São Paulo. Faço extensivo o meu agradecimento à Universidade de Antioquia e aos professores Eduard Rodríguez, Claudia Isaza, Edinson Aedo e Eugenio Duque. Igualmente apresento minha gratidão aos meus pais Hernando e Cristina, minhas irmãs Claudia e Leidy, e a minha namorada Verônica Andrade.

Aos professores da banca de defesa pelo interesse e pela paciência em ler o texto da tese.

À CAPES pelo financiamento desse trabalho através de bolsa de doutorado; e à Escola Politécnica pelos auxílios econômicos recebidos através do Programa de Apoio à Pós-Graduação (PROAP) para viagens e a compra de equipamento de computação. 


\section{TABELA DE CONTEÚDO}

1.1 Metodologias de Projeto no nível de Sistemas 21

1.1.1 DOMÍNIO DA PLATAFORMA

1.1.2 Paralelismo no Nível de Tarefa

$\begin{array}{ll}\text { 1.1.3 MAPEAMENTO } & 25\end{array}$

1.1.4 AVALIAÇão do DeSempenho no Nível de Sistemas 26

1.2 Projeto baseado em Cenários 28

1.2.1 CENÁRIOS DE CASOS DE USO

1.2.2 CENÁRIOS de APLICAÇão 28

$\mathbf{1 . 3}$ Motivação $\quad \mathbf{3 0}$

1.3.1 ANÁlise De DeSEMPENHo BASEAdo Na Modelagem da CARGa de TRABalHo 30

1.3.2 Modelagem Para ANÁlise de DeSEMPENHo PaRa AplicaÇões em MultimídIa 31

1.3.3 Projeto baseado em CenárIOS 33

1.3.4 ABORDAGEM INTENSIVA DE SOFTWARE

1.4 OBJETIVOS

1.4.1 OBJetivo Geral 36

1.4.2 OBJETIVOS ESPECÍFICOS 36

1.5 CONTRIBUIÇÕES

1.5.1 CARACTERIZAÇÃO DA EXECUÇÃO DAS TAREFAS DE UMA APLICAÇÃO 38

1.5.2 MODELO DE EVENTOS
1.6

1.6 ORganizaÇÃo da TESE $\quad 40$

2. MODELOS FUNDAMENTAIS E TÉCNICAS DE DESEMPENHO

2.1 Modelo da Aplicação $\quad \mathbf{4 4}$

2.1.1 Modelo de FluXo SínCRONO de Dados 44

2.1.1.1 Grafo Direcionado $\quad 45$

2.1.1.2 Grafo de Fluxo de Dados $\quad 45$

2.1.1.3 Grafo de Fluxo Síncrono de Dados 46

2.1.2 GRAFo Homogêneo de Fluxo SínCRONO de Dados 47

2.1.3 Propriedades ANaLíticas dos GRAFOS DE SDF 48

2.1.4 Modelagem Da APLICAÇÃO BASEADA EM SDF 49

2.1.5 Modelo de Fluxo Ciclo-Estático de Dados 52

2.1.6 Modelo de Fluxo SínCrono de Dados, Atento a Cenários 54

2.1.6.1 Modelo de SDF Atento a Cenários baseado em Cadeias de Markov 56

2.1.6.2 Modelo de SDF Atento a Cenários baseado em uma Máquina de Estados Finitos 57

2.1.7 COMPARAÇão de MOdelos de FLUXO de DAdOS [STUIJK07] 
2.1.8 MOdELOS DINÂMICOS DE EVENTOS DISCRETOS 62

2.1.8.1 Grafos de Eventos Temporizados 64

2.2 ANÁLISE DE DESEMPENHO $\quad \mathbf{6 6}$

2.2.1 ANÁLISE DE DESEMPENHO MOdULAR (MPA) 66

2.2.1.1 Modelo do Ambiente $\quad 67$

2.2.1.2 Modelo de Elemento Arquitetural 68

2.2.1.3 Componentes Abstratos e o Real-Time Calculus 69

2.2.2 Modelo de CURVAS de SeRVIços 71

2.2.2.1 Generalização de Curva de Serviço $\quad 72$

2.2.2.2 Concatenação fim-a-fim de um conjunto de sistemas 73

2.2.2.3 Teoria de sistemas sob a visão da Álgebra de Min-Plus 74

2.2.3 ANÁLISE DE DESEMPENHO EM MOdeLOS DE SDF 76

2.2.3.1 Análise de Vazão 76

2.2.3.2 Espaço de Estado de Grafos de SDF 76

2.2.3.3 Espaço de Estado na Execução Autotemporizada 82

2.2.3.4 Comportamento Transitório e de Regime Estacionário em SDF [KUMAR09] 84

3. CARACTERIZAÇÃO DA APLICAČ̃̃OO

3.1 ANÁLISE TEMPORAL

3.2 ANÁLISE DO PIOR-CASO [WILHELM08]

$\begin{array}{lll}3.2 .1 & \text { PROBLEMÁtICA } & 87\end{array}$

3.2.2 CLASSIFICAÇÃO DAS ABORDAGENS 90

3.2.2.1 Estimação Dinâmica 90

3.2.2.2 Análise Estática 93

3.2.3 MOdelagem da MICRO-ARQUitetURA 96

3.2.3.1 Dependência de Contexto nos Tempos de Execução 97

3.2.3.2 Anomalias de Temporização

3.2.4 ANÁlise de ROtAS DE EXECUÇão do Código de SOFTWARE 99

3.2.5 CÁlCULO dA EStIMATIVA WCET 100

3.2.5.1 Métodos de Estimação Baseados em Estrutura 101

3.2.5.2 Métodos de Estimação Baseados em Rotas 102

3.2.5.3 Enumeração Implícita de Rotas 102

3.2.6 FeRRAMENTA DE ANÁlISE dO WCET: CHRONOS 103

3.3 CaracterizaÇÃo da Carga de TRABalHo 105

$\begin{array}{llr}\text { 3.3.1 TRABalHos CorRELATOS } & 105\end{array}$

$\begin{array}{ll}\text { 3.3.2 CuRVas de Carga de TRabalho } & 107\end{array}$

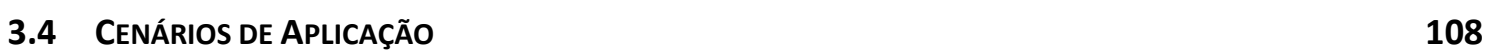

3.5 Curvas de Caracterização de Variabilidade 108

$\begin{array}{lll}\text { 3.5.1 DEFINIÇÕES PRELIMINARES } & 109\end{array}$

3.5.2 DEFINIÇÕES DE TIPOS DE VCC EM APLICAÇÕES MULTIMÍDIA [MAXIAGUINE05] 110

3.5.2.1 Curvas de Chegada Baseadas em Eventos 111

3.5.2.2 As curvas de Consumo 111

3.5.2.3 Curvas de Exigência de Execução 112

3.5.2.4 Curvas de Produção 113 
3.5.2.5 Curvas de Serviços Baseadas em Recursos

3.5.2.6 Curvas de Taxa de Tipo

3.5.2.7 Curvas de Serviços Baseadas em Eventos e Curvas de Chegada Baseadas em Recursos 114

4.1 Metodologia de Projeto Orientado a Atores $\mathbf{1 1 6}$

4.1.1 PROJETO BASEAdO EM INTERFACES 117

4.1.2 TRABalHos CORRELATOS 118

4.1.2.1 Interfaces de Tempo Real 118

4.1.2.2 Análise de Desempenho Composicional de Sistemas de Fluxo de Dados Cíclicos 122

4.1.2.3 Interfaces de Atores Temporais 124

4.2 DESCRIÇÃo de ATORES

$\begin{array}{lll}4.2 .1 & 125\end{array}$

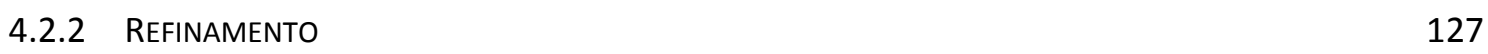

$\begin{array}{lll}4.3 & \text { RePRESENTAÇão de FluXo de Dados } & \mathbf{1 2 8}\end{array}$

4.3.1 SemÂntica de MaX-Plus PaRa RePRESENTAÇ̃̃o de SDFs 129

4.3.1.1 Álgebra Max-Plus 131

4.3.2 RepresentaÇão de GRafos de SDF atravÉS de Matrizes MaX-Plus 137

4.3.3 EXECUÇão AUTOTEMPORIZADA REPRESENTADA NA ÁLGEBRA DE MAX-PLUS 141

4.3.3.1 Análise Espectral 143

5. MODELO ANALÍTICO DE EVENTOS BASEADO EM SADF E CURVAS DE CENÁRIOS $\quad 145$

5.1 MOdelo De ESPAÇO DE ESTADO PARA GRAFOS DE SDF 146

$\begin{array}{lll}\text { 5.1.1 ESPAÇO DE ESTADO DOS GRAFOS DE SDF } & 147\end{array}$

5.1.2 SoluçÃo aO Modelo de ESPAÇO de Estado EM GRAFOS DE SDF 148

5.1.2.1 Resposta Homogênea e Resposta Forçada ou de Regime Estacionário. 149

5.1.2.2 Função de Transferência 151

5.1.2.3 Resposta ao Impulso 151

5.1.3 AVALIAÇão DE DESEMPENHO BASEAdA EM GRAFOS DE SDF 152

5.1.3.1 Vazão 152

5.2 ESPECIFICAÇÃO DE UM MODELO DE ESPAÇO DE ESTADO PARA SADF 157

$\begin{array}{lll}\text { 5.2.1 MODELO DE SADF } & 158\end{array}$

5.2.2 AUTÔMATO DE MAX-PLUS PARA SADF 161

5.2.3 Modelo de SADF COMO UM Modelo Linear em MaX-Plus 162

5.2.4 ESPAÇO DE ESTADOS EM SADF 163

5.2.5 SOLUÇÃO AO ESPAÇO DE ESTADOS EM SADF 163

5.2.5.1 Resposta Homogênea e Resposta Forçada 165

5.3 CURVAS DE CARACTERIZAÇÃo DE VARIABILIDADE PARA GRAFOS DE SADF 166

5.3.1 CuRVAS DE CARGa DE TRABalHo baSEADAS EM CenÁRIOS 167

5.3.2 CURVA DE SERVIÇO BASEADA EM CENÁRIOS 169

$\begin{array}{lll}5.4 & \text { AVALIAÇÃO DE DESEMPENHO BASEADO EM GRAFOS DE SADF } & 173\end{array}$ 
5.4.1 MOdelo de VAZÃo

5.4.2 VAzÃo em Grafos de SADF SEM Atores de ENTRAdA E de SAída 174

5.4.3 VAZÃo em Grafos de SADF COM ATORES de ENTRAdA E de SAÍdA 178

6.1 Fluxo de Caracterização da Carga de Trabalho 184

6.2 ANÁlISE de DESEMPENHO baSEado em REal-TIME CalCULUS 189

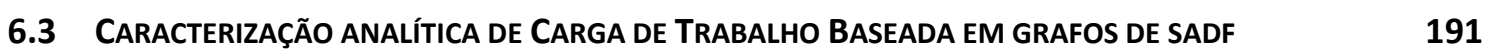

$\begin{array}{ll}\text { 6.4 CASO DE USO } & 194\end{array}$

6.4.1 DECODIFICADOR JPEG 194

6.4.2 ANÁLISE DE DeSEMPENHo BASEAdo EM REAL-TIME CaLCULUS 199

6.4.2.1 Resultados 201

6.4.3 ANÁLISE DE DESEMPENHO BASEADO EM SADF 202

6.4.3.1 Modelo de SADF do Decodificador JPEG 202

6.4.3.2 Espaço de Estados do grafo SADF sem entradas externas 204

6.4.3.3 Espaço de Estados do grafo SADF com entrada externa 208

$\begin{array}{ll}\text { 6.4.3.4 Autômato de Max-Plus para SADF } & 210\end{array}$

6.4.3.5 Curvas de Carga de Trabalho baseada em Cenários 213

6.4.3.6 Curva de Serviço baseada em Cenários 213

\begin{tabular}{lr} 
CONCLUSÕES & 215 \\
\hline
\end{tabular}

REFERÊNCIAS BIBLIOGRÁFICAS $\quad 218$

\begin{tabular}{lr} 
ANEXO I & 229 \\
\hline
\end{tabular}

$\begin{array}{lr}\text { I.1. SiStemas Lineares Clássicos } & 229\end{array}$

I.1.1. RESPOSTA DE ESTADO HOMOGÊNEA 229

l.1.2. RESPOSTA FORÇADA 230

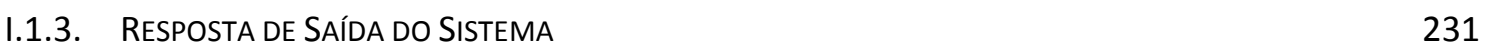

I.1.4. MATRIZ de TRANSIÇÃO DE ESTAdOS 231

\begin{tabular}{lr} 
ANEXO II & 232 \\
\hline
\end{tabular}

II.1. Sistemas LINEARES Discretos E VARIANTES No TEMPO 232

II.1.1. RESPOSTA HOMOGÊNEA 232

$\begin{array}{lr}\text { II.1.2. RESPOSTA FORÇADA } & 233\end{array}$

\begin{tabular}{lr} 
ANEXO III & 235 \\
\hline
\end{tabular}

III.1. ESPAÇO DE ESTAdo Linear EM MAX-Plus 235

$\begin{array}{lr}\text { III.2. TRANSFORMADA T } & 237\end{array}$ 


\section{TABELA DE FIGURAS}

Figura 1.1: Metodologia do diagrama-Y para a Exploração do Espaço de Projeto [ZHU10]....... 22

Figura 1.2: Um exemplo de uma arquitetura MPSoC [MAXIAGUINE05] ................................... 24

Figura 1.3: Um exemplo de uma arquitetura MPSoC [MARCULESCU04] ...................................26

Figura 1.4: Um cenário de sistema é a combinação entre uma Instância MPSoC e um cenário de

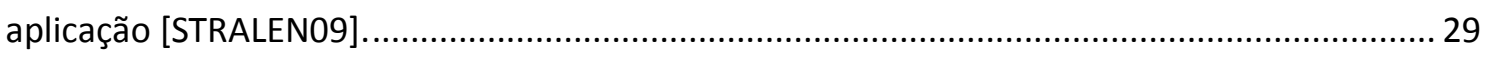

Figura 1.5: Um exemplo de um modelo de uma aplicação streaming [ZHU10] .......................... 33

Figura 1.6: Fluxo de projeto para análise de uma aplicação seguindo a caracterização e modelagem propostas neste projeto de doutorado.......................................................... 41

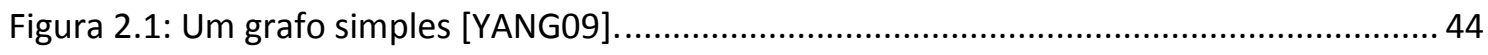

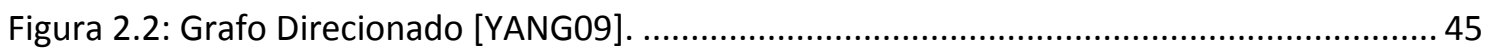

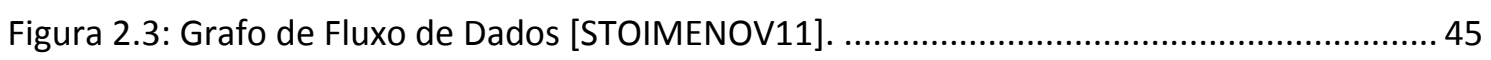

Figura 2.4: Grafo de Fluxo Síncrono de Dados [YANG09] ...................................................... 47

Figura 2.5: Grafo Homogêneo de Fluxo Síncrono de Dados [YANG09]. ...................................... 47

Figura 2.6: Modelo HSDF de um Codec de MPEG-4 [GEILEN11a]............................................... 50

Figura 2.7: Exemplo do problema da capacidade de um buffer, em um grafo de tarefas de

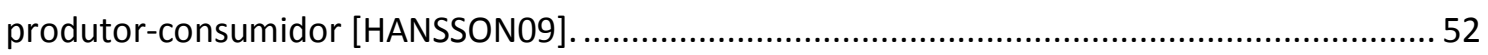

Figura 2.8: Comparação de MoCs de Fluxo de Dados [STUIJK07] ................................................. 58

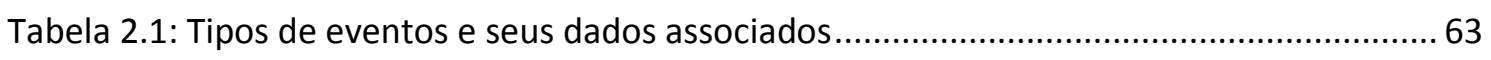

Figura 2.9: Um TEG simples, definido com dois lugares (places), duas transições de entrada $\boldsymbol{u} \mathbf{1}$

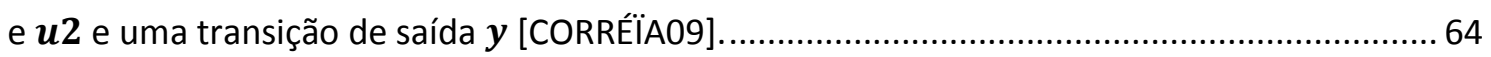

Figura 2.10: Visão geral da abordagem de Análise Modular de Desempenho (MPA)

[WANDELER06a] .66

Figura 2.11: Atraso e Backlog obtidos a partir da curva de chegada e curva de serviço

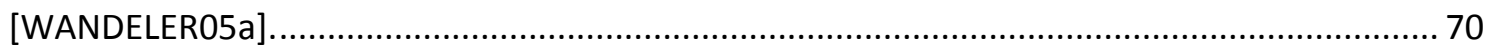

Figura 2.12. Um sistema de filas, como curva de serviço $\boldsymbol{S}(\boldsymbol{t})$, chegadas $\boldsymbol{A}(\boldsymbol{t})$ e saídas $\boldsymbol{D}(\boldsymbol{t}) \ldots 72$

Figura 2.13: Conjunto de sistemas em série que pode ser combinado em um único sistema pela

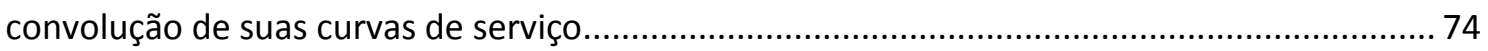

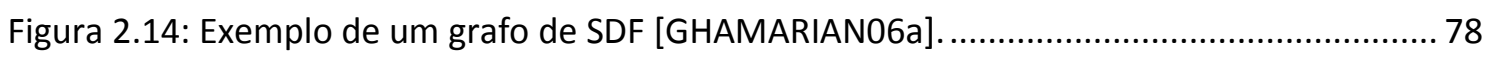

Figura 2.15: Execução autotemporizada do exemplo da Figura 2.14 [GHAMARIAN06a]............ 83

Figura 2.16: Grafo de SDF em estado transitório [KUMAR09] .................................................. 84

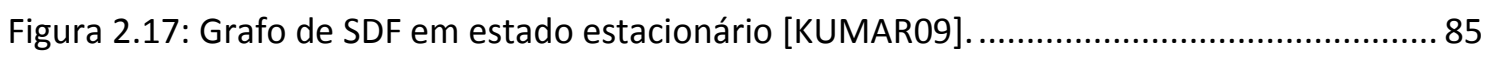

Figura 3.1: Noções básicas concernentes à análise temporal de sistemas [WILHELM08].......... 88

Figura 3.2: Principais componentes da Análise Temporal [WILHELM08] .................................... 94

Figura 3.3: Metodologias diferentes para o cálculo do limite do WCET [ERMEDAHL03] .......... 101 
Figura 3.4: Um exemplo de análise estática de código e seu respectivo CFG 105

Figura 3.5: Algumas VCCs utilizadas para modelar a carga de trabalho de aplicações multimídia

[MAXIAGUINE05]. 110

Figura 4.1: Um componente abstrato simples $\boldsymbol{F}$ e sua representação de interface adaptativa [WANDELER06b]. 120

Figura 4.2: Visualização do problema avaliado pela metodologia de Análise de Desempenho

Composicional de Fluxo de Dados Cíclicos [STOIMENOV11] ................................................... 124

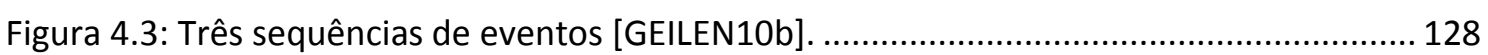

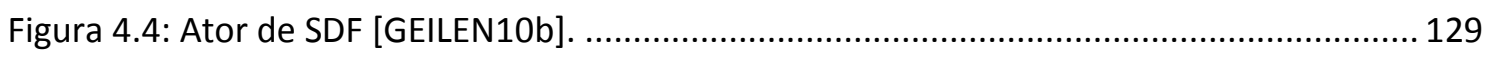

Figura 4.5: Rastro de eventos para o ator SDF da Figura 4.4 [GEILEN10b]............................. 129

Figura 4.7: Exemplo de uma execução autotemporizada de um grafo de SDF [GEILEN09]..... 131

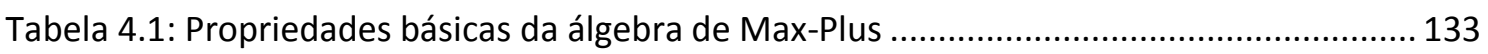

Figura 4.8: Grafo de precedência para a Matriz A [RAISCH09] .............................................. 137

Figura 4.9: Representação em Max-Plus de um grafo de SDF [GEILEN10b] ............................. 137

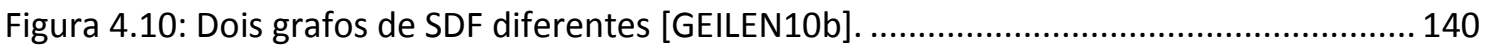

Figura 5.1: Representação em Max-Plus de um grafo de SDF [GEILEN10b] . ............................ 148

Figura 5.2: Exemplo de um grafo de SADF [GEILEN10a] ...................................................... 159

Figura 5.3: Exemplo do grafo da Figura 5.2 para a sequência de cenários aaab [GEILEN10a]. 159

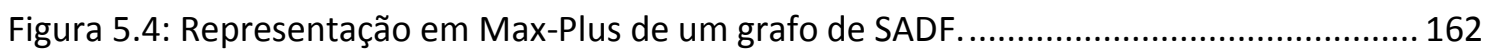

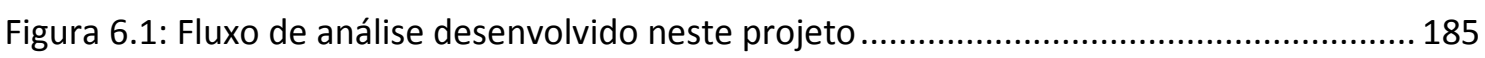

Figura 6.2: Exemplo de um código $C$ e seu respectivo CFG obtido usando Rose [ROSE12] ..... 187

Figura 6.3: Algoritmo baseado em análise estática de rotas para encontrar as rotas de execução dos códigos-fonte das tarefas de uma aplicação..................................................... 188

Figura 6.4: Fluxo de análise de desempenho baseado em Real-Time Calculus........................ 190

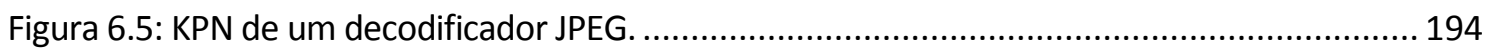

Figura 6.6: CFG do código-fonte da tarefa CC do JPEG da Figura 6.5 ..................................... 196

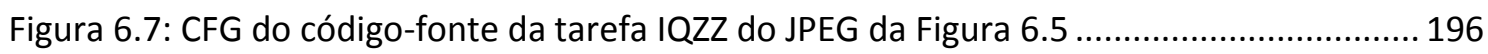

Figura 6.8: CFG do código-fonte da tarefa RASTER do JPEG da Figura 6.5 …............................ 197

Figura 6.9: Sequência de eventos (ou marcadores) de entrada para o decodificador JPEG. ... 198

Figura 6.10: Autômato de eventos para o fluxo de eventos de entrada, como aquele da Figura

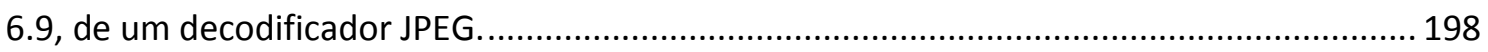

Figura 6.11: Curvas de carga de trabalho para a tarefa Demux do decodificador JPEG........... 200

Figura 6.12: Grafo Marcado do decodificador JPEG ......................................................... 200

Tabela 6.4: Atrasos e requisitos mínimos de buffer para o decodificador JPEG.......................... 201

Figura 6.14: Modelo de SADF do Decodificador JPEG sem entradas nem saídas ...................... 203

Tabela 6.5: Tempos extremos de execução para a tarefa RASTER ........................................... 203

Tabela 6.6: Tempos extremos de execução para a tarefa IQZZ ................................................. 203

Tabela 6.7: Tempos extremos de execução para a tarefa IDCT .................................................. 204

Tabela 6.8: Tempos extremos de execução para a tarefa VLD. ................................................... 204

Tabela 6.9: Tempos extremos de execução para a tarefa CC. ................................................... 204

Tabela 6.10: Tempos extremos de execução de cada tarefa em relação aos diferentes cenários

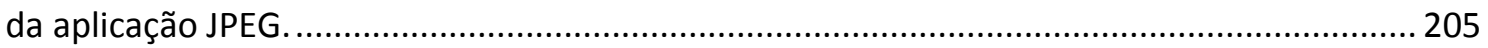

Figura 6.15: Modelo de SADF do Decodificador JPEG com entrada $\boldsymbol{x}$ e saída $\boldsymbol{y}$. ........................ 209

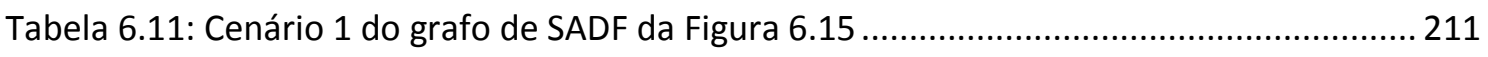

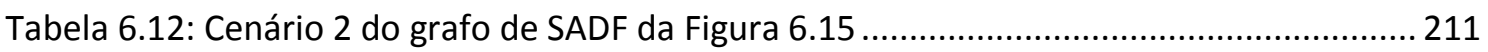




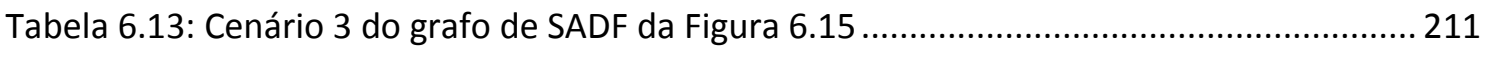

Tabela 6.14: Cenário 4 do grafo de SADF da Figura 6.15 ........................................................ 211

Tabela 6.15: Cenário 5 do grafo de SADF da Figura 6.15 ...................................................... 212

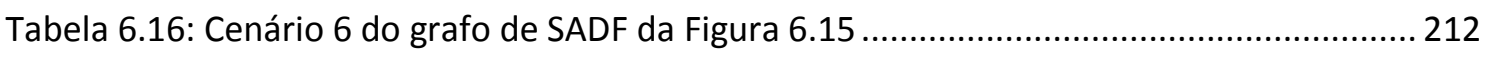

Tabela 6.17: Cenário 7 do grafo de SADF da Figura 6.15 ....................................................... 212

Tabela 6.18: Cenário 8 do grafo de SADF da Figura 6.15 ....................................................... 212

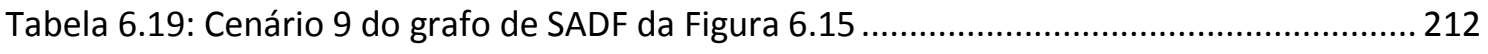

Tabela 6.20: Cenário 10 do grafo de SADF da Figura 6.15 ....................................................... 212

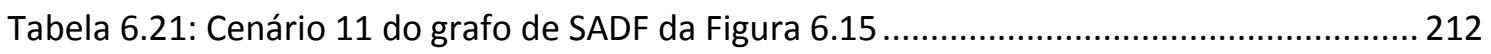

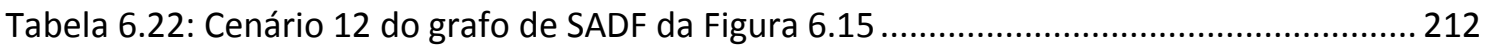

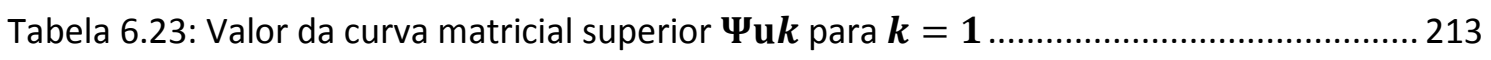

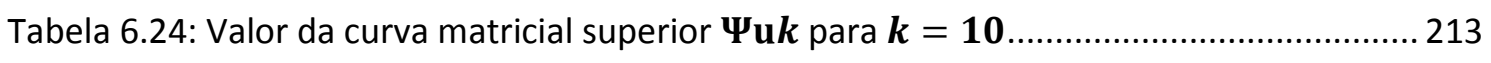

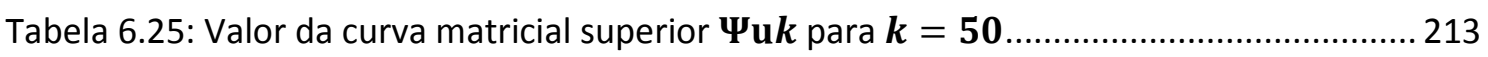

Figura 6.16: Curvas de serviço baseadas em cenários para o decodificador JPEG $(\boldsymbol{k}=\mathbf{1} \ldots \mathbf{1 0})$.

214

Figura 6.17: Curvas de serviço baseadas em cenários para o decodificador JPEG $(\boldsymbol{k}=\mathbf{1} . . \mathbf{5 0})$.

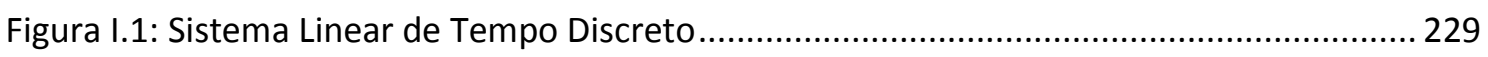




\section{LISTA DE ABREVIAÇÕES}

\begin{tabular}{|c|c|}
\hline APG & : Application Graph \\
\hline AST & : Árvore Sintática Abstrata \\
\hline BCET & : Best Case Execution Time \\
\hline BDF & : Boolean DataFlow \\
\hline CFG & : Control Flow Graph \\
\hline CPU & : Central Processing Unit \\
\hline CSDF & : Cyclic-Static Dataflow \\
\hline DRAM & : Dynamic Random Access Memory \\
\hline DSP & : Digital Signal Processor \\
\hline DMA & : Direct Memory Access \\
\hline FIFO & : First Input First Output \\
\hline FP & : Política de escalonamento de Prioridade Fixa \\
\hline FSM & : Finite State Machine \\
\hline FSM-SADF & : FSM-based Scenario Aware Synchronous Dataflow \\
\hline HSDF & : Homogeneous Synchronous Dataflow \\
\hline ILP & : Integer Linear Programming \\
\hline IPET & : Implicit Path Enumeration \\
\hline KPN & : Kahn Process Network \\
\hline MCM & : Maximum Cycle Mean \\
\hline
\end{tabular}




\begin{tabular}{|c|c|}
\hline MCR & : Maximum Cycle Ratio \\
\hline MOPC & : Modo de Operação do Pior-Caso \\
\hline MPA & : Modular Performance Analysis \\
\hline MPSoC & : Multiprocessor System-on-Chip \\
\hline MoC & : Model of Computation \\
\hline NoC & : Network on-Chip \\
\hline $\mathbf{P E}$ & : Processing Element \\
\hline PN & : Petri Net \\
\hline $\mathbf{R P}$ & : Rede de Petri \\
\hline RTI & : Real-Time Interfaces \\
\hline RTC & : Real-Time Calculus \\
\hline SDF & : Synchronous Dataflow \\
\hline SDFG & : Synchronous Dataflow Graph \\
\hline SADF & : Scenario Aware Synchronous Dataflow \\
\hline SoC & : System-on-Chip \\
\hline TDMA & : Time division multiple Access \\
\hline TEG & : Timed Event Graph \\
\hline VHDL & : VHSIC Hardware Description Language \\
\hline vCC & : Variability Characterization Curves \\
\hline WCEP & : Worst Case Execution Path \\
\hline WCET & : Worst Case Execution Time \\
\hline WFQ & : Weighted Fair Queuing \\
\hline
\end{tabular}




\section{RESUMO}

As metodologias clássicas de análise de desempenho de sistemas sobre silício (System on chip, SoC) geralmente são descritas em função do tempo de execução do pior-caso $^{1}$ das tarefas a serem executadas. No entanto, nas aplicações do mundo real, o tempo de execução destas tarefas pode variar devido à presença dos diferentes eventos de entrada que ativam o sistema, colocando uma exigência diferente de execução sobre os recursos do sistema.

Geralmente, um modelo da carga de trabalho é uma parte integrante de um modelo de desempenho utilizado para avaliar o desempenho de um sistema. O quão bom for um modelo de carga de trabalho determina em grande medida a qualidade das soluções do projeto e a precisão das estimativas de desempenho baseadas nele. Nesta tese, é abordado o problema de modelar a carga de trabalho para o projeto de sistemas de tempo-real cuja funcionalidade envolve processamento de fluxos de multimídia, isto é, fluxos de dados representando áudio, imagens ou vídeo.

O problema de modelar a carga de trabalho é abordado sob a premissa de que uma caracterização acurada do comportamento temporal do software embarcado permite ao projetista identificar diversas exigências variáveis de execução, apresentadas para os diversos recursos de arquitetura do sistema, tanto na operação individual do conjunto de tarefas de software, assim como na execução global da aplicação, em fase de projeto.

A caracterização do comportamento de cada tarefa foi definida a partir de uma análise temporal dos códigos de software associados às diferentes tarefas de uma aplicação, a fim de identificar os múltiplos modos de operação que o código pode apresentar dentro de um processador. Esta caracterização é feita

\footnotetext{
${ }^{1}$ Termo conhecido na literatura como o WCET (Worst-Case Execution Time).
} 
através da realização de uma análise estática das rotas do código executável, de forma que para cada rota de execução encontrada, estimam-se os tempos extremos de execução (WCET e $\mathrm{BCET})^{2}$, baseando-se na modelagem da microarquitetura de um processador on-chip. Desta forma, cada rota do código executável junto aos seus respectivos tempos de execução, constitui um modo de operação do código analisado.

A fim de agrupar os diversos modos de operação que apresentam um grau de semelhança entre si de acordo a uma perspectiva da medida de processamento utilizado do processador modelado, foi utilizado o conceito de cenário, o qual diferencia o comportamento de cada tarefa em relação às entradas que a aplicação sob análise pode receber.

Partindo desta caracterização temporal de cada tarefa de software, as exigências da execução global da aplicação são representadas através de um modelo analítico de eventos. O modelo considera as diferentes tarefas como atores temporais de um grafo de fluxo sincrono de dados, de modo que os diferentes cenários de operação da aplicação são definidos em função dos tempos variáveis de execução identificados previamente na caracterização de cada tarefa. Uma descrição matemática deste modelo, baseada na Álgebra de Max-Plus, permite caracterizar analiticamente os diferentes fluxos de eventos entre a entrada e a saída da aplicação, assim como os fluxos de eventos entre as diferentes tarefas, considerando as mudanças nas exigências de processamento associadas aos diversos cenários previamente identificados. Esta caracterização analítica dos diversos fluxos de eventos de entrada e saída é a base para um modelo de curvas de carga de trabalho baseada em cenários de aplicação, e um modelo de curvas de serviços baseada também em cenários, que dão lugar a caracterizar o dinamismo comportamental da aplicação analisada, determinado pela diversidade de eventos de entrada que podem ativar diferentes comportamentos do sistema em fase de execução.

\footnotetext{
${ }^{2}$ Do inglês: Worst-Case Execution Time e Best-Case Execution Time
} 


\section{ABSTRACT}

Classical methods for performance analysis of Multiprocessor System-on-chip (MPSoCs) are usually described in terms of Worst-Case Execution Times (WCET) of the executed tasks. Nevertheless, in real-world applications the running time of tasks varies due to different input events that trigger the system, imposing a different workload on the system resources.

Usually, a workload model is a part of a performance model used to evaluate the performance of a system. How good is a workload model largely determines the quality of design solutions and the accuracy of performance estimations based on it. This thesis addresses the problem of modeling the workload for the design of real-time systems which functionality involves multimedia streams processing, i.e, data streams representing audio, images or video.

The workload modeling problem is addressed from the assumption that an accurate characterization of timing behavior of real-time embedded software enables the designer to identify several variable execution requirements that the individual operation of the software tasks and the overall execution of the application will present to the several system resources of an architecture, in design phase.

The software task characterization was defined from a timing analysis of the source code in order to identify the multiple operating modes the code can exhibit within a processor. This characterization is done by performing a static path analysis on the code, so that for each given path the worst-case and bestcase execution times (WCET and BCET) were estimated, based on a microarchitectural modeling of an on-chip processor. Thus, every execution path of the code, with its estimated execution times, defines an operation mode of the analyzed code. 
In order to cluster the several operation modes that exhibit certain degree of similarity according to the required amount of processing in the modeled processor, the concept of scenario was used, which differentiates every task behavior with respect to the several inputs the application under analysis may receive.

From this timing characterization of every application task, the global execution requirements of the application are represented by an analytical event model. It describes the tasks as timed actors of a synchronous dataflow graph, so that the multiple application scenarios are defined in terms of the variable execution times previously identified in the task characterization. A mathematical description of this model based on the Max-Plus Algebra allows one to characterize the different event sequences incoming to, and exiting from, the application as well as the event sequences between the different tasks, having in count changes in the processing requirements associated with the various scenarios previously identified. This analytical characterization between the input event sequences and the output event sequences states the basis for a model of scenario-based workload curves and a model of scenariobased service curves that allow characterizing the behavioral dynamism of the application determined by the several input events that activate several system behaviors, in the execution phase. 


\section{Capítulo 1}

\section{INTRODUÇÃO}

A presente tese trata sobre sistemas embarcados, definidos como sistemas de computação desenvolvidos para executar uma ou várias funções dedicadas enquanto interagem com o mundo fisico. Exemplos de projetos que tradicionalmente têm sido alvo dos sistemas embarcados são as usinas nucleares, os sistemas de transporte ferroviário, a eletrônica automotiva e de aviação, o controle de tráfego aéreo e as telecomunicações; porém, hoje os sistemas embarcados também estão sendo incluídos em redes de sensores sem fio, sistemas de multimídia, telefones celulares, tablets, consoles de jogos, leitores de livros eletrônicos, sistemas de automação de prédios, e muitos outros.

O projeto de praticamente qualquer sistema embarcado começa a partir da definição da gama pretendida de aplicações para o sistema. Posteriormente, os projetistas tentam especificar o sistema a fim de ele suportar as aplicaçõesalvo, da forma mais eficiente e econômica possivel. Os projetistas otimizam a arquitetura do sistema $^{3}$ com base em critérios como custo, tamanho, desempenho e energia do sistema. Neste processo, conhecer as características da carga de trabalho que as aplicações-alvo vão impor à arquitetura é essencial para chegar a uma solução arquitetural ótima.

Estas características de carga de trabalho que são importantes em um contexto de projeto determinado podem ser capturadas em um modelo de carga de trabalho. Utilizar tal modelo é uma prática bem estabelecida no projeto de sistemas de computação e avaliação de desempenho [MAXIAGUINE05]. Um modelo de carga de trabalho serve para caracterizar

\footnotetext{
${ }^{3}$ Arquitetura do sistema é o conjunto interligado e especificado de componentes de um sistema, como processadores, periféricos de I/O, meios de comunicação, etc.
} 
formalmente a carga de trabalho, e com base nesta caracterização, distinguir entre diferentes cenários de carga. Esta caracterização representa uma entrada importante no projeto da arquitetura do sistema e no processo de otimização. Além disso, um modelo de carga de trabalho é indispensável durante o projeto de várias políticas de gestão de recursos e estratégias de adaptação por parte da arquitetura, na fase de execução.

Tipicamente, o modelo da carga de trabalho também é uma parte integrante de um modelo de desempenho utilizado para avaliar o desempenho do sistema. O quão bom for um modelo de carga de trabalho determina em grande medida a qualidade das soluções do projeto e a precisão das estimativas de desempenho baseadas nele. Em muitos contextos de projeto de sistemas de computação, encontrar um modelo apropriado de carga de trabalho representa um problema dificil. Nesta tese, é abordado o problema de modelar a carga de trabalho para o projeto de sistemas de tempo-real no nível de sistemas, cuja funcionalidade envolve processamento em tempo-real de fluxos multimídia, isto é, fluxos de dados representando áudio e vídeo.

\subsection{METODOLOGIAS DE PROJETO NO NÍVEL DE SISTEMAS}

Devido à alta complexidade de projeto e custo de produção, novas metodologias de projeto no nível de sistemas têm surgido para lidar com a crescente pressão do tempo de colocação no mercado. Entre estas metodologias, duas alternativas promissoras são: o esquema do diagrama-Y 4 [BALARIN03, KIENHUIS97] e o projeto baseado em plataforma [KEUTZER00]. Ambos propõem a ortogonalização (isto é, a separação de interesses) da aplicação e da plataforma, e usam um procedimento de mapeamento explícito a fim de relacionar os modelos da aplicação com plataformas de arquitetura. Esta separação permite aos projetistas mapear uma série de instâncias do modelo da aplicação em uma plataforma de arquitetura, e vice-versa, de modo mais eficiente.

\footnotetext{
${ }^{4}$ Este diagrama-Y para a exploração do espaço de projeto [BALARIN03] é diferente do diagrama-Y apresentado por Gajski [GAJSKI94] para descrever níveis de abstração e domínios de descrição de sistemas.
} 
A Figura 1.1 mostra o esquema do diagrama-Y, o qual tem sido muito utilizado para a exploração do espaço de projeto no coprojeto de hardware/software (Hardware/Software Codesign). Ele representa uma metodologia onde os modelos da aplicação são especificados como redes de blocos funcionais baseados em modelos de computação (MoCs) [JANTSCH03, KAHN74, LEE98]. Independentemente disto, as plataformas de arquitetura são caracterizadas como instâncias de modelos parametrizados de uma arquitetura. Para avaliar o mapeamento de modelos de aplicação em plataformas de arquitetura, uma ferramenta chave para a avaliação de desempenho, suportada em simulação ou em métodos analíticos, é explorada. A partir dos números de desempenho resultantes, o projetista pode propor melhorias em três questões centrais dentro do projeto sendo desenvolvido: a plataforma, a aplicação e as decisões de mapeamento (questões que são sinalizadas como pequenas lâmpadas na Figura 1.1). Tal processo de projeto é iterativo até que os critérios requeridos sejam satisfeitos. O esquema do diagrama-Y encaixa-se em vários níveis de abstração das aplicações e das plataformas.

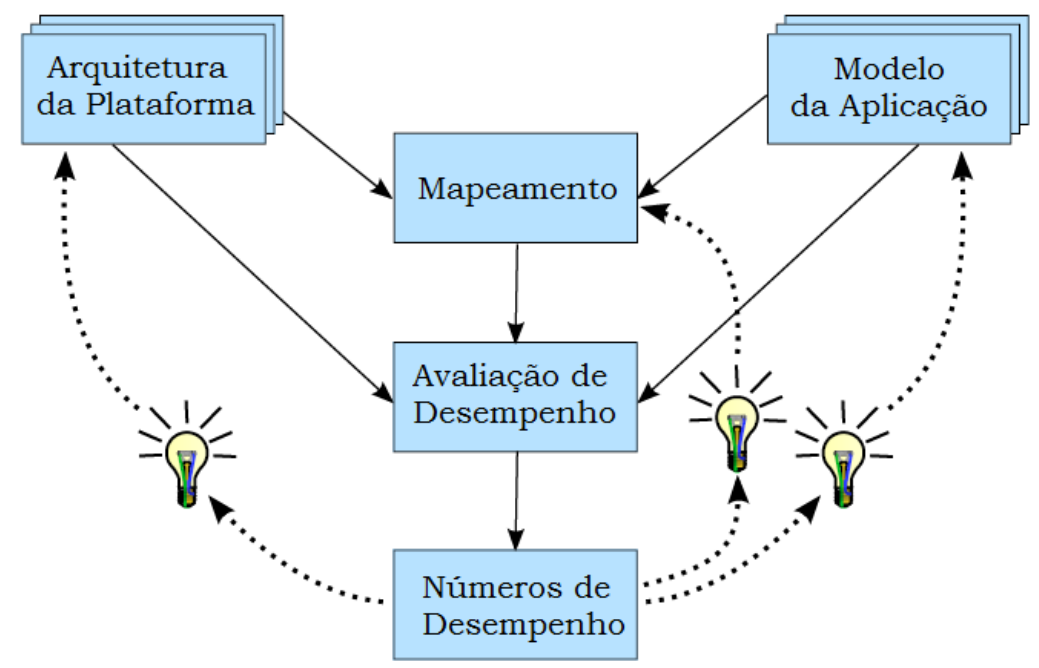

Figura 1.1: Metodologia do diagrama-Y para a Exploração do Espaço de Projeto [ZHU10].

A avaliação de desempenho na fase inicial de projeto é importante para a tomada de decisões fundamentais do projeto, antes que recursos sejam investidos em implementações detalhadas do sistema. Em particular, o papel da avaliação de desempenho no fluxo de projeto é duplo: por um lado, a avaliação de desempenho é utilizada como uma validação, ou mesmo um instrumento de certificação, após o projeto no nível de sistema ser concluído. 
Por outro lado, ela orienta o projetista para encontrar soluções eficientes em um espaço de projeto potencialmente enorme, e, portanto, lhe oferece suporte na tomada antecipada de decisões cruciais dentro do fluxo de projeto.

\subsubsection{Domínio da Plataforma}

Impulsionadas pelos requisitos da aplicação e sustentadas pelos avanços tecnológicos, as arquiteturas dos sistemas embarcados estão sendo projetadas para conter uma composição de diversos elementos de processamento paralelo (por exemplo, múltiplos processadores, barramentos, memórias, periféricos, etc), integrados em um único chip. Tais arquiteturas de sistemas de multiprocessamento heterogêneo sobre silício (Multiprocessor System-on-chip, $\mathrm{MpSoC}$ ) têm um potencial para proporcionar um alto desempenho $\mathrm{e}$ flexibilidade, de modo eficiente relacionado ao custo e à energia. Desta forma, os computadores embarcados para processamento de multimídia estão sendo, cada vez mais, implementados como MpSoCs. Há muitos exemplos de MpSoCs de multimídia, observados tanto na indústria como na academia [DUTTA01, ISHIWATA03, IWASAKI03, STRIK00, TALLA04]. A maioria deles segue o padrão de projeto mostrado na Figura 1.2.

Entretanto, em muitos casos, esse potencial é difícil de ser percebido devido à insuficiência de métodos e ferramentas que possam agilizar o processo de projeto de arquiteturas MPSoC a fim de produzir resultados de alta qualidade. Esse problema resulta, em grande medida, da incapacidade dos modelos tradicionalmente utilizados no projeto no nivel de sistemas para capturar com precisão as características importantes da carga de trabalho multimídia impostas sobre as arquiteturas MPSoC como um resultado do processamento de fluxos de mídia.

Um MPSoC típico multimídia contém um número de processadores programáveis de software (CPUs, DSPs, processadores de mídia, etc), coprocessadores parcialmente programáveis, módulos de hardware de função fixa e dispositivos periféricos (por exemplo, blocos de entrada/saída de vídeo e áudio). Esses componentes computacionais estão interligados por uma infraestrutura de comunicação intrachip, a qual pode abranger vários tipos de barramentos, pontes, controladores de acesso direto à memória (DMA), memórias distribuídas, e outros componentes de comunicação. Seguindo o 
paradigma de redes intrachip (Network-on-chip, NoC) [KUMAR03, DALLY01], a infraestrutura de comunicação intrachip pode se assemelhar a uma rede de computadores de larga escala, envolvendo conceitos tais como roteadores, switches, protocolos, filas de comunicação, etc. A rede de comunicação intrachip pode ter uma arquitetura complexa consistindo em várias sub-redes interligadas por pontes, tal como mostrado na Figura 1.2.

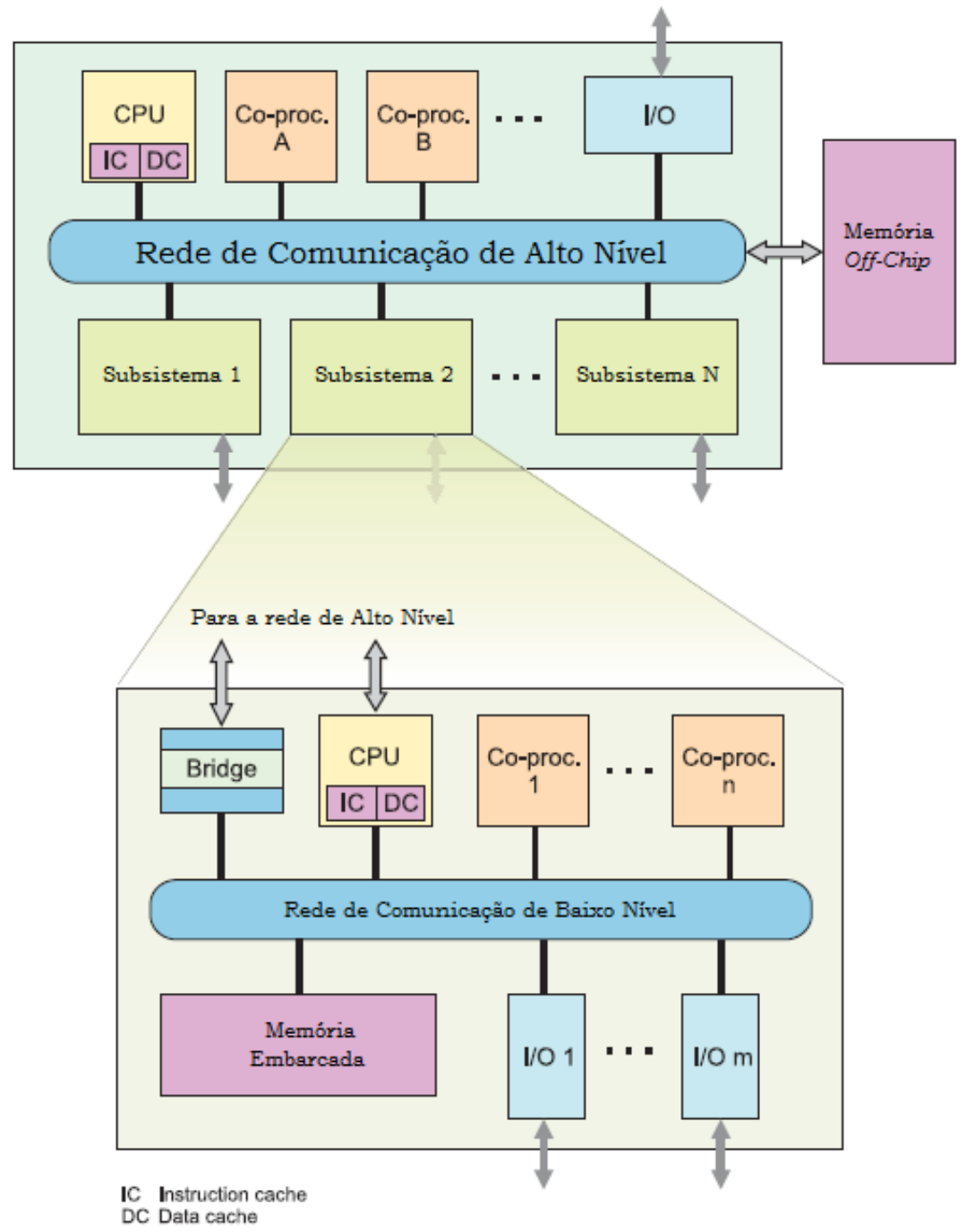

Figura 1.2: Um exemplo de uma arquitetura MPSoC [MAXIAGUINE05].

Uma sub-rede (rede de baixo nível) combina dentro de um cluster restrito (subsistema) componentes computacionais que possuem comunicação intensa. Desta forma, o tráfego de comunicação local entre os componentes do subsistema é isolado da troca de dados no nível do sistema, a qual tem lugar através de uma rede intrachip de alto nivel. 


\subsubsection{Paralelismo no Nível de Tarefa}

Um dos grandes desafios que surge, quando é feito o mapeamento de uma aplicação para uma plataforma MPSoC, é dividir a carga da aplicação em múltiplos processadores. Existem duas formas disponíveis para paralelizar a aplicação e dividir a carga em mais de um processador: o paralelismo no nível de tarefa (também conhecido como pipelining) e o paralelismo no nivel dos dados. No primeiro caso, cada processador recebe uma parte diferente de uma aplicação a fim de ser processada, enquanto que no segundo caso, os processadores operam sobre a mesma funcionalidade da aplicação, porém, com dados diferentes. Até certo ponto, estas abordagens são ortogonais e podem ser aplicadas isoladamente ou em combinação.

\subsubsection{Mapeamento}

A metodologia de exploração do espaço de projeto apresentado no diagrama-Y da Figura 1.1 descreve uma ortogonalização de interesses referente ao projeto e análise da aplicação feita separadamente do projeto e análise da plataforma, de modo que o procedimento de mapeamento relaciona os diferentes modelos desenvolvidos representando a aplicação, com os elementos de computação e de comunicação planejados como componentes da plataforma alvo.

Desta maneira, este mapeamento pode implicar diferentes niveis de refinamento referente ao nivel progressivo de detalhe da funcionalidade da aplicação atribuída aos respectivos recursos de computação e comunicação da plataforma, tal que de acordo ao nível de refinamento considerado, é possível falar de um mapeamento de computação seguido de um mapeamento da comunicação, de modo que este último considera maior detalhe na atribuição de recursos e na avaliação de desempenho executada [MARCULESCU04]. A Figura 1.3 apresenta uma visão mais detalhada do diagrama-Y da Figura 1.1.

A caracterização temporal da aplicação, a avaliação das exigências de processamento (carga de trabalho) das tarefas da aplicação nos recursos de HW, e a identificação da possivel geração de dados na ativação de cada tarefa da aplicação, são atividades necessárias dentro do mapeamento no domínio da computação, que permitem uma primeira abordagem da avaliação parcial do desempenho do sistema em fase de projeto. Posteriormente, quando um nível de refinamento maior é considerado ao se fazer o mapeamento no domínio da 
comunicação, aspectos como o volume de comunicação, as taxas de transferência de pacotes, tamanho dos buffers, e a carga de trabalho colocada sobre o meio de comunicação (conexões baseadas em barramentos, conexões ponto a ponto, ou em uma estrutura de comunicação de rede intrachip), precisam ser considerados para uma nova e mais refinada avaliação de desempenho. Tal forma é utilizada para determinar se a combinação entre aplicação-arquitetura satisfaz as restrições de projeto impostas na especificação do sistema [MARCULESCU04, LAHIRIO0].

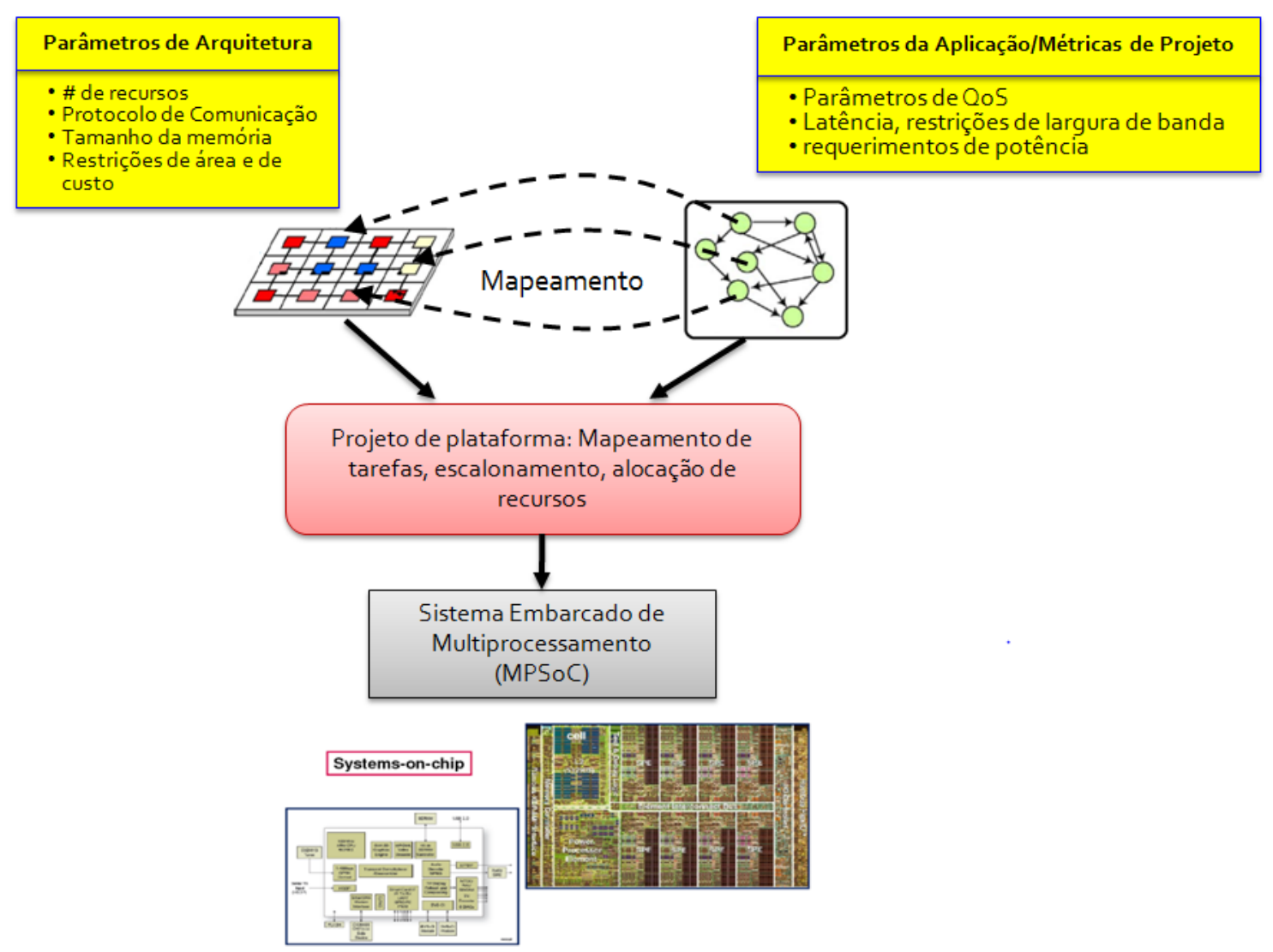

Figura 1.3: Um exemplo de uma arquitetura MPSoC [MARCULESCU04]

\subsubsection{Avaliação do Desempenho no Nível de Sistemas}

Dadas as rigorosas exigências de muitos domínios de aplicação, torna-se claro que a avaliação do desempenho de um sistema embarcado é altamente importante no processo de projeto. Em particular, não só a exatidão funcional das computações realizadas pelo sistema é relevante, mas também o desempenho do sistema em termos dos tempos de resposta ou o consumo de 
energia (entre outros aspectos de desempenho), de modo que eles também precisam ser garantidos.

Como visto anteriormente, ao se considerar diferentes niveis de refinamento no mapeamento entre a aplicação e a arquitetura, múltiplas rodadas da avaliação de desempenho serão necessárias a fim de se aperfeiçoar as estruturas de computação e de comunicação do sistema sobre as quais a aplicação especificada será executada. O desempenho na computação nos processadores será o primeiro a ser avaliado, logo após executar o mapeamento dos aspectos computacionais da aplicação e, posteriormente, o desempenho da comunicação será avaliada considerando-se a carga de trabalho que os recursos de computação e de processamento colocam sobre a estrutura de comunicação.

Note-se que para sistemas embarcados a distinção entre requisitos funcionais (comportamental) e não-funcionais (desempenho) é algo nebulosa. Por exemplo, em um sistema de tempo-real, um resultado correto, porém, que chega mais tarde (ou mesmo antes) do que o especificado, pode levar a uma falha do sistema. Do mesmo modo, em um dispositivo móvel operado por bateria, o consumo excessivo de energia pode comprometer o tempo de operação requerido do dispositivo e, portanto, a sua funcionalidade. Diferentes aspectos de desempenho podem ser relevantes para um sistema embarcado de hardware/software. Os mais comuns são:

- Propriedades temporais (por exemplo, os tempos de resposta e as latências fim-a-fim).

- Requisitos de memória (por exemplo, tamanhos dos buffers).

- O consumo de energia.

A qualificação ou a quantificação do comportamento do sistema em relação a uma ou várias destas métricas é geralmente referida como a avaliação do desempenho ou análise de desempenho. A avaliação de desempenho de sistemas embarcados é essencialmente diferente da avaliação de desempenho dos computadores de propósito geral. Em particular, devido às exigências restritivas de muitos domínios de aplicação (por exemplo, restrições de temporeal rígido), os projetistas de sistemas embarcados frequentemente não podem 
depender das caracterizações médias ou estocásticas do desempenho de um sistema. Em vez disso, é preciso uma identificação dos limites seguros do desempenho do melhor-caso e do pior-caso.

\subsection{PROJETO BASEADO EM CENÁRIOS}

\subsubsection{Cenários de casos de Uso}

Uma tendência importante nos modernos sistemas de mídia eletrônica é que eles estão se tornando mais interativos, oferecendo interfaces de usuário com a possibilidade de abrir, reorganizar e fechar diferentes apresentações de vídeo/áudio, sessões de telecomunicações, etc. Os sistemas interativos são caracterizados por múltiplas combinações possíveis de tais atividades, conhecidas também como casos de uso.

Em geral, uma aplicação é associada com uma atividade que é iniciada e interrompida, em tempo de execução, por eventos provenientes de ações do usuário ou do ambiente. Uma aplicação de streaming de mídia pode ser dividida em algumas tarefas e representada por um grafo que modela a comunicação entre as tarefas. Os grafos de tarefas de diferentes aplicações são combinados para formar um caso de uso. Além disso, algumas aplicações podem estar em modos de uso diferentes que podem ser chaveadas devido às ações do usuário.

Como visto anteriormente, do ponto de vista de hardware, a divisão de cada aplicação em diferentes tarefas permite que elas sejam mapeadas na fase de projeto em diferentes processadores dentro de uma plataforma MPSoC, o qual leva que o chaveamento das ações do usuário, referentes a cada caso de uso, sejam também distribuídas ao longo da plataforma selecionada.

\subsubsection{Cenários de Aplicação}

Nesta tese, o conceito de cenários de aplicação [GHEORGHITA08] será utilizado no contexto do dinamismo na execução da aplicação definida pela diversidade de eventos de entrada que podem ativar diferentes comportamentos do sistema em fase de execução. Deste modo, um cenário de aplicação descreve o uso dado ao sistema embarcado. Essa descrição de uso pode ser implícita ou explícita. Um exemplo de uma descrição de uso implícita 
é o conjunto de parâmetros de entrada da aplicação. Uma descrição explícita pode ser dada sob a forma de um rastro (trace) representando o comportamento da aplicação. Quando o cenário de aplicação é acoplado com uma instância MPSoC, o resultado é um cenário de sistema (ver Figura 1.4). Além de uma descrição de utilização, um cenário de sistema também leva em consideração o custo do sistema. Esse custo do sistema inclui métricas como o número de ciclos de processador, a utilização da memória ou a energia dissipada. Estes custos costumam ser utilizados para reduzir o número total de cenários de aplicação, agrupando os cenários que possuem custos parecidos.

Esta é a principal diferença entre os cenários de aplicação e os cenários de caso de uso. Assim como um cenário de caso de uso só descreve o sistema embarcado do ponto de vista do usuário, um cenário de aplicação é baseado na perspectiva do projetista em relação ao sistema embarcado. No caso de um reprodutor MP4, por exemplo, o usuário só pode ver os botões e a tela de LCD para ouvir a música ou assistir o vídeo. A arquitetura e as aplicações dentro do reprodutor MP4 só podem ser vistos pelo projetista de modo que ele consegue identificar os diversos cenários de aplicação. $O$ beneficio dos cenários de aplicação é que o correspondente cenário de sistema dá a possibilidade de otimizar o custo do sistema embarcado, estática e dinamicamente (por exemplo, em termos de velocidade ou consumo de potência).

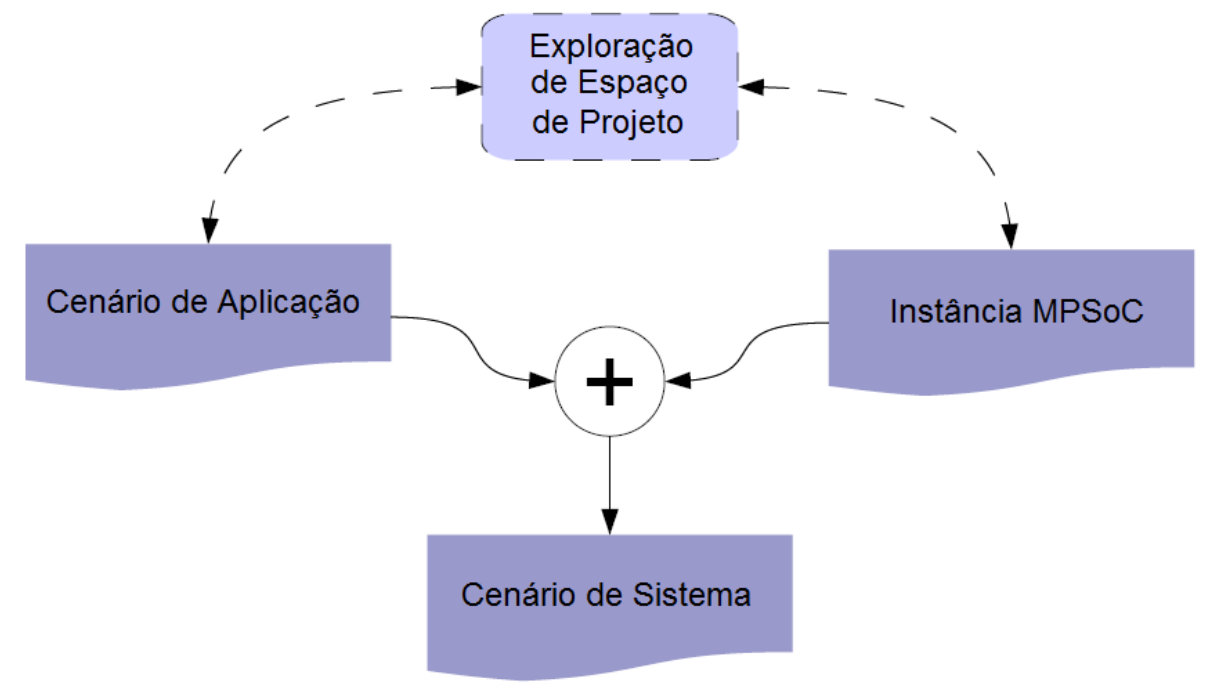

Figura 1.4: Um cenário de sistema é a combinação entre uma Instância MPSoC e um cenário de aplicação [STRALENO9]. 
Existem dois tipos de cenários de aplicação: cenários de intra-aplicação e inter-aplicação. Os cenários de intra-aplicação são cenários que descrevem o comportamento (ou modos de operação) de uma única aplicação, tal como a reprodução de música em mono ou em estéreo. Isto pode ser descrito de várias maneiras tais como os parâmetros de entrada utilizados na aplicação, ou o rastro (trace) de instruções executadas. Por outro lado, os cenários de interaplicação descrevem o comportamento de múltiplas aplicações. A maneira mais óbvia de descrever o comportamento de múltiplas aplicações é indicar quais aplicações podem ser executadas simultaneamente.

\subsection{MOTIVAÇÃO}

Considerando uma metodologia de projeto no nível de sistemas baseada na ortogonalização da aplicação e da plataforma, o estado de arte avaliado para este trabalho de doutorado esteve focado na modelagem da aplicação, visando caracterizar o comportamento temporal das tarefas individuais de aplicações multimídia, assim como a modelagem do fluxo de dados dentro da aplicação. O trabalho teve como premissa que tal fluxo de dados pode ser visto como um fluxo de eventos temporais que representam a carga de trabalho que cada tarefa irá impor ao recurso de hardware onde a tarefa será mapeada dentro da plataforma.

\subsubsection{Análise de Desempenho baseado na Modelagem da Carga de Trabalho}

Hoje em dia a principal tendência na avaliação de desempenho de sistemas embarcados complexos de tempo-real -no nivel de sistemas- depende da simulação. Mesmo que a simulação possa retornar estimativas de desempenho muito precisas, sua cobertura é limitada apenas aos casos de carga de trabalho que sejam simulados. Desta forma, conseguir uma boa cobertura exige múltiplas rodadas de simulação usando cenários, cuidadosamente escolhidos, de carga de trabalho representativos. Além disso, muitas vezes os simuladores precisos exibem altos tempos de execução, fazendo com que a simulação seja uma abordagem ineficiente dentro de ciclos rápidos de exploração do espaço de projeto.

Independentemente de quantos, e quais, cenários de carga de trabalho sejam simulados, a simulação nunca poderá alcançar, em um tempo razoável, a 
cobertura total requerida para a verificação do desempenho. Devido a isto, simulações não podem ser utilizadas, por exemplo, para verificar se um sistema embarcado satisfaz as restrições temporais impostas para todos os cenários possíveis de carga de trabalho. Tal verificação é possível usando abordagens analiticas formais que executam uma análise de desempenho do pior-caso, ou seja, retornando limites de desempenho do pior-caso.

A análise do desempenho de pior-caso usa um modelo de desempenho que representa uma abstração que engloba todos os estados e comportamentos do sistema, e todos os cenários possiveis de carga de trabalho. A análise do desempenho pode, portanto, fornecer a cobertura total requerida para a verificação do desempenho. Além disso, é tipicamente mais rápida do que a simulação. No entanto, devido à complexidade tanto das arquiteturas analisadas como das respectivas cargas de trabalho, é extremamente dificil encontrar abstrações apropriadas do sistema que conduzam a limites precisos (isto é, acurados) de desempenho do pior-caso.

\subsubsection{Modelagem para Análise de Desempenho para Aplicações em Multimídia}

As aplicações multimídia estão se tornando cada vez mais complexas, e ávidas de capacidade de computação, a fim de atender as exigências do consumidor. $\mathrm{Na}$ hora de assistir televisão, por exemplo, o processo de decodificação de vídeo potencialmente continua por horas -uma hora é equivalente a 180.000 quadros de vídeo a um ritmo modesto de 50 quadros por segundo (fps)-. Os televisores de alto desempenho costumam fornecer uma taxa de atualização de até $100 \mathrm{fps}$, de modo que a tendência é de um maior incremento desta taxa. $\mathrm{O}$ mesmo acontece para um fluxo de áudio que normalmente acompanha o vídeo. A plataforma tem de trabalhar continuamente para obter a saída desejada pelo usuário.

A fim de garantir que este alto desempenho possa ser satisfeito pela plataforma, o projetista precisa ser capaz de modelar os requisitos da aplicação. Na ausência de um bom modelo, é muito dificil saber previamente se o desempenho da aplicação pode ser satisfeito em todos os casos, de modo que uma simulação extensiva, e vários testes, costumam ser necessários. 
Deste modo, uma boa modelagem da aplicação é essencial por dois principais motivos:

- Prever o comportamento das aplicações em um hardware específico sem sintetizar realmente o sistema, e

- Sintetizar o sistema após uma solução viável identificada a partir da análise.

Entre os MoCs utilizados para modelar as aplicações multimídia, os modelos de fluxo de dados tem provado ser um instrumento muito útil para capturar as propriedades de tais aplicações [JANTSCH03, POPLAVKO03, STUIJKO7]. As aplicações típicas de multimídia consistem de um conjunto de tarefas (ou processos) que precisam ser realizadas enquanto dados são transferidos ou comunicados entre elas. Este conjunto de tarefas deve ser realizado de forma iterativa, sendo que uma quantidade fixa de dados é consumida e produzida por cada execução de uma tarefa.

Os grafos do modelo de computação de Fluxo Síncrono de Dados, SDF, conhecidos simplesmente por grafos de SDF (Synchronous Dataflow Graphs, SDFG), têm sido tradicionalmente utilizados na modelagem de aplicações de Processamento Digital de Sinais (PDS) [KUNG87, RENFORS81]. Devido à semelhança estrutural entre as aplicações de PDS e as aplicações multimídia, os grafos de SDF também fornecem um bom grau de expressividade para modelar aplicações multimídia [STUIJK05, POPLAVKO03, STUIJK07]. Além disso, o modelo de SDF tem um grande potencial de análise para medir métricas exatas de desempenho as quais são muito importantes na avaliação do comportamento do pior-caso dos sistemas. Esta combinação de expressividade e potencial de análise faz que o modelo de SDF seja muito interessante no domínio das aplicações multimídia para sistemas embarcados.

Nos grafos de SDF, os processos são executados seguindo uma orientação a dados, e também se comunicam uns com os outros através de canais FIFO. A concorrência na aplicação é expressa explicitamente. Um modelo de SDF de uma aplicação com três camadas de pipeline é representado na Figura 1.5. Neste grafo, os nós denotam os processos concorrentes de computação, e os arcos, associados com FIFOs, denotam os canais de comunicação com armazenamento definido por buffers. Em cada execução ou disparo, os 
processos $(p)$ lêem tokens $(m)$ dos FIFOs da sua entrada ( $s$ ), operam (computam) sobre os dados em uma quantidade específica de tempo, e emitem os tokens ( $n$ ) resultantes para os FIFOs da sua saida (s). A quantidade de tokens de entrada (saída) é fixa em cada disparo de um processo, e é chamada de taxa de entrada (saída). Quando todas as taxas de entrada (saída) são iguais a 1 dentro do grafo, o modelo de SDF é chamado modelo de SDF homogêneo (HSDF). Um modelo geral de SDF pode ser convertido em um modelo de HSDF equivalente [SRIRAM00], porém esta transformação aumenta drasticamente o número de processos, motivo pelo qual não é recomendado para modelar aplicações de alta complexidade.

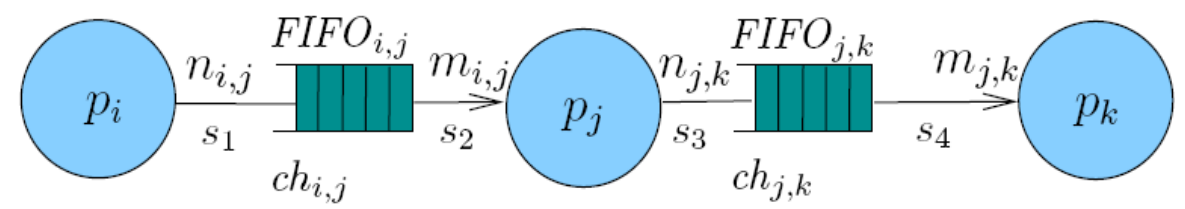

Figura 1.5: Um exemplo de um modelo de uma aplicação streaming [ZHU10].

Como uma alternativa ao MoC genérico de SDF não-temporizado [LEE87a], o modelo de SDF temporizado [GOVINDARAJANO2, STUIJK06] foi proposto para analisar as propriedades temporais das aplicações e/ou do sistema. No entanto, a limitação deste modelo encontra-se na incapacidade de representar tempos variáveis de execução no conjunto de atores que representam as tarefas da aplicação, de modo que todo o universo de execuções desta aplicação é representado por um único cenário de execução, geralmente referido como aquele do pior-caso. Isto leva a que qualquer medida de desempenho, ou caracterização da carga de trabalho, esteja frequentemente distante daquela que a aplicação irá realmente a apresentar uma vez ela seja implementada em uma plataforma de hardware.

\subsubsection{Projeto baseado em Cenários}

Em muitas aplicações modernas de streaming, tais como codecs de áudio e vídeo com esquemas avançados de compressão de dados, o comportamento de um codificador ou decodificador pode mostrar muito mais dinamismo do que o comportamento possivel de ser efetivamente representado com um grafo de SDF [GEILEN10a]. Um exemplo simples é um decodificador de áudio MPEG-1, camada 3, comumente conhecido como MP3. Ele divide um fluxo de áudio estéreo em quadros de $26 \mathrm{~ms}$ e pode empregar cinco esquemas diferentes de 
codificação para um quadro, dependendo do conteúdo de áudio. Os diferentes modos de operação utilizam sub-bandas de diferentes tamanhos (blocos curtos vs blocos longos) ou uma mistura de ambos, parcialmente independentes em relação aos canais de áudio da esquerda e direita. O modelo de SDF não pode capturar tal mudança dinâmica entre esses tipos de quadros, exceto se for utilizando um modelo excessivamente pessimista, o qual seria muito conservador para qualquer tipo de quadro [GEILEN10a].

O MoC de Fluxo Síncrono de Dados, Atento a Cenários (Scenario Aware Synchronous Dataflow, SADF), explora a abordagem de projeto baseado em cenários de Gheorghita et al. [GHEORGHITA06]. Nesta abordagem, o comportamento dinâmico de uma aplicação é visto como uma coleção de comportamentos diferentes, chamados cenários ou modos de operação, que ocorrem em alguma ordem possivel, conhecida ou desconhecida. Cada cenário por si só é relativamente estável e previsivel em relação ao desempenho e ao uso de recursos, e podem ser tratados por métodos tradicionais de análise. O SADF explora o comportamento estático dos cenários. Ele modela o comportamento de cada cenário com um grafo de SDF. Os grafos de fluxo de dados dos diferentes cenários podem ser diferentes em todos os aspectos (por exemplo, as taxas de comunicação ou nos tempos de execução). Isto torna possível explorar o comportamento dinâmico das aplicações procurando economizar recursos, enquanto garantias de tempo são fornecidas.

$\mathrm{Na}$ presente tese, argumenta-se que o comportamento dinâmico das aplicações multimídia está relacionado com a variabilidade de diversos parâmetros da carga de trabalho, de modo que esta variabilidade é a propriedade chave para ser capturada em um modelo de carga de trabalho no projeto de sistemas embarcados. Desta forma, na tese é proposto um modelo de carga de trabalho capaz de capturar com precisão a natureza dinâmica da carga de trabalho, que se relaciona por sua vez, com o comportamento dinâmico de uma aplicação representada pelos diferentes cenários modelados no MoC de SADF. A tese demonstra as vantagens do modelo de carga de trabalho proposto, em relação aos métodos convencionais, quanto à caracterização da carga. Além disto, o modelo permite o desenvolvimento de uma metodologia de análise de desempenho -no nível de sistemas- baseada em uma identificação automática dos cenários representativos de carga de trabalho de cada tarefa de software 
que compõe a aplicação, em uma arquitetura de um microprocessador on-chip previamente escolhido para a implementação do sistema.

Este modelo abre a oportunidade para uma análise de desempenho mais precisa das plataformas de execução distribuídas, sob a presença de cargas de trabalho de aplicações multimídia caracterizada pela variabilidade de diversos parâmetros. A utilidade do modelo de carga de trabalho proposto é demonstrada e avaliada através de uma série de estudos de casos que envolvem comparações com modelos de simulação detalhados.

\subsubsection{Abordagem Intensiva de Software}

Nos últimos anos, as funções a serem implementadas em sistemas embarcados tornaram-se tão numerosas e complexas que o tempo de desenvolvimento passou a ser mais dificil de se prever e controlar. Esta complexidade, em conjunto com as especificações constantemente em evolução das aplicações, tem forçado os projetistas a considerarem implementações que possam ser alteradas rapidamente. Por esta razão, e também dado que os ciclos de fabricação de hardware são cada vez mais caros e demorados, a implementação em software da funcionalidade das aplicações tem se tornado cada vez mais habitual e utilizada. Visto que frequentemente o código-fonte das aplicações já está disponível de alguma maneira em um formato escrito, a tendência na implementação da funcionalidade dos sistemas embarcados é da reutilização dos códigos das diferentes aplicações. Esta abordagem garante uma melhora na qualidade, e no tempo de colocação no mercado, dos produtos criados por uma determinada empresa de base tecnológica, maximizando assim seus respectivos lucros [FRAKES05]. A maioria destas aplicações é escrita em linguagens de alto nivel a fim de se evitar a dependência a qualquer tipo de arquitetura de hardware e aumentar a produtividade dos projetistas.

Depois de identificar a gama de aplicações pretendidas para um determinado sistema, os projetistas realizam a especificação do hardware do sistema para que ele suporte as restrições de cada aplicação e os requisitos do produto final, da forma mais eficiente e econômica possível. Desta forma, o projetista otimiza a arquitetura do sistema com base em critérios como custo, tamanho, desempenho e energia do sistema. Neste processo, conhecer as características 
da carga de trabalho, que o conjunto de aplicações definidas vai impor aos recursos da arquitetura, é essencial para chegar a uma solução arquitetural ótima.

\subsection{OBJETIVOS}

Dadas as motivações apresentadas na seção anterior, os objetivos procurados ao longo deste trabalho de doutorado foram:

\subsubsection{Objetivo Geral}

Especificar e implementar uma metodologia de caracterização analítica temporal de aplicações multimídia orientada a avaliar diferentes propriedades do mapeamento no nível da computação dentro de um fluxo de exploração do espaço de projeto.

\subsubsection{Objetivos Específicos}

I. Caracterizar estaticamente o comportamento temporal variável de cada tarefa de uma aplicação multimídia, dada sua especificação em códigosfonte, que irão ser compilados para um conjunto de processadores onchip dentro de uma plataforma MPSoC. Será composta por processadores do tipo MIPS, considerando-se um conjunto diverso de eventos temporais que definirão a ativação de cada tarefa dentro da aplicação. O objetivo de caracterizar este comportamento temporal pode ser dividido em vários objetivos específicos:

1. Extrair os múltiplos modos de operação, assim como a estimação dos tempos extremos de execução, a fim de conhecer a carga de trabalho de processamento colocada por cada tarefa sobre o processador on-chip.

2. Agrupar os possiveis modos de operação da aplicação em vários cenários de execução, com base na exigência variável de processamento requerida pelas diferentes tarefas da aplicação multimídia. Esta exigência variável requerida constitui a carga de trabalho que o software embarcado coloca em cima dos recursos de hardware de computação e processamento. 
3. A partir do objetivo anterior, outro objetivo será modelar a carga de trabalho total, representada através de fluxos de eventos temporais, que cada cenário de execução da aplicação irá colocar na plataforma de hardware depois da fase de mapeamento.

II. Modelar o software embarcado das aplicações multimídia, através do uso de uma extensão do modelo de SDF conhecida como Fluxo Síncrono de Dados, Atento a Cenários (Scenario Aware Synchronous Dataflow, SADF).

1. Especificar um modelo analítico da transferência de eventos na aplicação, dado um conjunto de cenários de execução, e dada a estimação dos tempos variáveis de execução de cada tarefa, relacionados com sua operação nos diferentes cenários.

2. Especificar uma metodologia de análise de desempenho, focada unicamente na avaliação da vazão na transferência de eventos entre cada tarefa, considerando-se um mapeamento só no domínio de computação, sem se considerar o mapeamento no nível da comunicação entre a aplicação e os recursos de hardware associados à estrutura de comunicação da plataforma selecionada. Métricas como a latência, jitter e outras não foram consideradas dentro da metodologia desenvolvida neste projeto de doutorado.

3. Avaliar a metodologia proposta e os modelos desenvolvidos neste trabalho usando como caso de uso um decodificador MJPEG/JPEG, cuja computação é mapeada em um conjunto de processadores Simplescalar de uma plataforma Multi-Core, na qual os recursos de hardware para computação referem-se só a tais processadores. A estrutura de comunicação desta plataforma não é considerada nos modelos e na metodologia desenvolvida.

\subsection{CONTRIBUIÇÕES}

O trabalho desenvolvido na presente tese orienta-se a propor uma metodologia de análise de desempenho dentro do mapeamento no domínio da computação, o qual se refere ao nivel progressivo de detalhe da funcionalidade da aplicação 
atribuída aos respectivos recursos de computação de uma determinada plataforma selecionada, seguindo o diagrama-Y apresentado na Figura 1.1.

Atividades como a caracterização temporal da aplicação, a avaliação das exigências de processamento das tarefas da aplicação nos recursos de HW, e a identificação da possível geração de dados na ativação de cada tarefa da aplicação, são atividades necessárias dentro do mapeamento no domínio da computação. Deste modo, considerando estas atividades requeridas em tal mapeamento, as contribuições entregues neste projeto de doutorado podem ser divididas em função de dois grandes problemas tratados ao longo do tempo investido no doutorado: a caracterização das tarefas de uma aplicação baseada na análise estática dos modos de operação, e a especificação e implementação de um modelo de eventos temporais que caracteriza a carga de trabalho de uma aplicação multimídia, suportado na análise estática dos múltiplos cenários de aplicação. Nas seguintes subseções apresentam-se as respectivas contribuições referentes a estes problemas.

O mapeamento no nível da comunicação não faz parte do escopo de estudo apresentado nesta tese, de maneira que maiores trabalhos devem ser desenvolvidos em trabalhos futuros a fim de estender a metodologia de análise proposta na tese para cobrir também análises e caracterizações da carga de trabalho considerando aspectos de comunicação inerentes tanto à aplicação como à plataforma.

\subsubsection{Caracterização da execução das tarefas de uma aplicação}

A caracterização das unidades de processamento on-chip está fortemente relacionada à caracterização das tarefas que são executadas por cada um dos processadores selecionados para o projeto do SoC. Tal caracterização de tarefas foi definida a partir da análise dos códigos de programa associados a cada tarefa, a fim de identificar os múltiplos cenários que definem os diferentes comportamentos ou modos de operação de um processador. Neste contexto, as contribuições do presente projeto são:

- Uma solução completamente analítica para o problema de se caracterizar as tarefas de uma aplicação multimídia que possuem exigências variáveis de execução, sendo a caracterização feita através 
da realização de uma análise estática das rotas do código executável de cada tarefa, encontrando seus múltiplos modos de operação. Para cada modo encontrado, estimam-se os tempos extremos de execução (WCET e BCET), baseando-se na modelagem da microarquitetura de um processador on-chip.

- Uma ferramenta que, a partir da análise estática do código-fonte e executável de cada tarefa, permite identificar e extrair os múltiplos modos de operação, assim como a estimação dos tempos extremos de execução, a fim de se conhecer a carga de trabalho de processamento colocada por cada tarefa sobre um processador on-chip.

\subsubsection{Modelo de Eventos}

Em relação ao modo como a aplicação é executada e distribuída nas suas múltiplas tarefas em diferentes processadores on-chip, e considerando os múltiplos cenários de operação de cada tarefa, definidos em função dos diferentes eventos recebidos como entrada, a aplicação multimídia é modelada seguindo um modelo de computação baseado em SADF. Ele permite descrever a dependência temporal das diferentes tarefas em função dos tempos de execução associados ao processador on-chip escolhido para o sistema em fase de projeto. Neste contexto, as contribuições do presente projeto são:

- Uma solução completamente analítica ao problema de modelar a geração de eventos em uma aplicação multimídia que irá ser implementada em um conjunto de processadores on-chip escolhidos para o projeto de um determinado sistema, apresentando assim as especificações temporais e de carga de trabalho colocadas pela aplicação nos recursos de uma plataforma MPSoC.

- Uma ferramenta que segue a metodologia de caracterização analítica temporal de aplicações multimídia e de análise de desempenho desenvolvida neste trabalho de doutorado, focando unicamente na avaliação da vazão na transferência de eventos entre cada tarefa da aplicação, considerando-se o mapeamento só no domínio de computação, sem se considerar aspectos do mapeamento no nível da comunicação. A avaliação de métricas como a latência, jitter e outras não é parte das contribuições deste trabalho, sendo preciso que a 
metodologia seja estendida em trabalhos futuros para permitir a avaliação deste tipo métricas, e outras referentes ao mapeamento entre os componentes de comunicação do modelo da aplicação e a estrutura de comunicação da plataforma multi-core.

- Tal ferramenta permite especificar um modelo temporizado de transferência de eventos na aplicação, a partir das informações de cenários de cada tarefa, e da estimação do tempo de execução dos blocos básicos de instruções executados dentro de cada processador onchip.

\subsection{ORGANIZAÇÃO DA TESE}

Em relação aos objetivos anotados para este trabalho, a Figura 1.6 apresenta um fluxo de análise que resume os diferentes tópicos tratados na tese. Estes tópicos estão relacionados com a descrição dos capítulos da tese dada nos parágrafos seguintes:

Capitulo 2: Modelos Fundamentais e Técnicas de Desempenho. O objetivo desse capítulo será introduzir os modelos baseados em fluxo de dados, assim como uma breve introdução ao estado da arte nas técnicas de desempenho baseadas nesse tipo de modelos, com a idéia de apresentar as bases teóricas que sustentam um modelo analítico de desempenho e mais contribuições deste trabalho de doutorado.

Capítulo 3: Caracterização da Aplicação. Este capítulo apresenta a análise temporal necessária para caracterizar o comportamento temporal variável de cada tarefa de uma aplicação, em função dos diferentes tipos de eventos ou dados de entrada, que a aplicação pode receber como entrada. Esta caracterização é fundamental para definir os parâmetros temporais utilizados no modelo analítico da aplicação baseado em cenários.

Capitulo 4: Modelagem Baseada em Atores Temporais. Este capítulo apresenta a metodologia analítica e matemática usada para caracterizar os fluxos de eventos de saída de cada tarefa, dado o respectivo fluxo de eventos de entrada, dentro do modelo de SDF definido para representar cada cenário de aplicação, considerando uma modelagem orientada a atores temporais. 
Caracterização da entrada e de

Capítulos

recursos de processamento

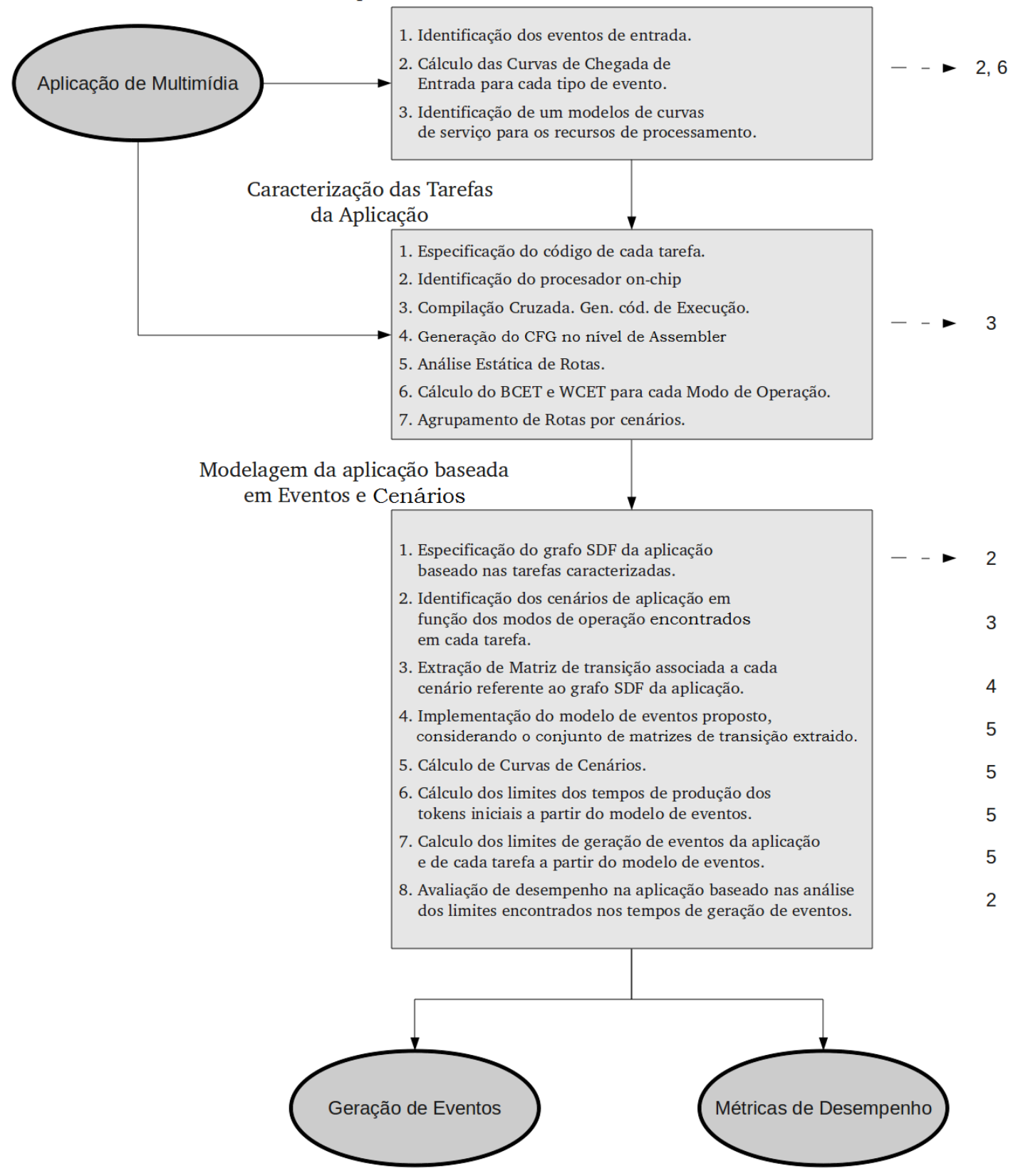

Figura 1.6: Fluxo de projeto para análise de uma aplicação seguindo a caracterização e modelagem propostas neste projeto de doutorado.

\section{Capitulo 5: Especificação de um modelo de eventos temporais baseado em SADF para a descrição de carga de trabalho de aplicações multimídia.}

Este capítulo descreve as contribuições referentes à especificação de um modelo de eventos definido para descrever a carga de trabalho gerada pela execução de uma aplicação multimídia. Ela é dividida em diferentes tarefas que possuem um comportamento temporal variável, o qual define um conjunto de cenários modelado por um grafo de SADF, o qual é interpretado e analisado 
matematicamente como um modelo linear, no espaço de estado da Álgebra de Max-Plus, variante no tempo devido à presença dos múltiplos cenários. A especificação do modelo segue a metodologia de orientação a atores temporais descrita no capítulo 4.

Capitulo 6: Casos de uso para o modelo de eventos desenvolvido e diferentes caracterizações da carga de trabalho de uma aplicação multimídia. Neste capítulo são apresentados os casos de uso desenvolvidos para testar a metodologia de caracterização estática da execução das tarefas de uma aplicação multimídia, assim como a implementação do modelo analítico de eventos temporais utilizado para descrever a geração dos eventos gerados e processados durante a execução da aplicação multimídia. 


\section{Capítulo 2}

\section{MODELOS FUNDAMENTAIS E TÉCNICAS DE DESEMPENHO}

O projeto de sistemas embarcados está se tornando cada vez mais complexo devido a um grande número de casos de uso, plataformas heterogêneas de multiprocessamento, e aplicações cada vez mais complexas e dinâmicas. A fim de gerenciar essa complexidade, uma série de tendências tem emergido nos últimos anos.

O projeto baseado em modelos (Model-based Design) [LEE98] é uma proposta desenvolvida para projetar plataformas e aplicações de maneira que os sistemas possam ser concebidos a partir de modelos simples e abstratos, e que o projeto obtido (automaticamente) possua garantias de se comportar de acordo com o modelo, e seguindo um desempenho previsível. As plataformas devem ser tão divisíveis em blocos quanto possivel [SANGIOVANNIO1] e o modelo da aplicação o suficientemente simples, de modo que sua análise seja possível, servindo também como ponto de partida para um caminho de síntese dentro de um fluxo de projeto. Modelos estáticos e relativamente simples são utilizados para esses propósitos, tendo como exemplo o Grafo (Homogêneo) de Fluxo Síncrono de Dados, ou os autômatos de estados finitos. As aplicações modernas, no entanto, são mais dinâmicas do que aquelas que podem ser capturadas por esses modelos, que incorrem em alto grau de superestimação e em suposições muito pessimistas. Os modelos utilizados neste processo frequentemente capturam aspectos tanto do comportamento da aplicação como da plataforma na qual as aplicações serão mapeadas, assim como 
aspectos relacionados ao impacto de outras aplicações que eventualmente estarão em disputa pelos recursos e a arbitragem destes recursos.

\subsection{MODELO DA APLICAÇÃO}

Um modelo de computação (MoC) é uma abstração de um sistema computacional. Ele define o modo como os processos concorrentes de computação interagem. É possivel utilizar determinados MoCs para analisar as diversas propriedades dos sistemas embarcados, tais como a exatidão funcional e o desempenho. Nesta tese, as aplicações são baseadas em modelos de fluxo síncrono de dados (SDF) [LEE87a, BILSEN96]. A seguir, vários tipos de modelos de fluxo de dados serão apresentados, a fim de contextualizar o uso dos modelos de SDF neste trabalho.

\subsubsection{Modelo de Fluxo Síncrono de Dados}

O MoC de Fluxo de Dados Síncrono (SDF- do inglês, synchronous data-flow) [LEE87a] tornou-se um modelo popular para a modelagem de aplicações multimídia. O MoC de SDF se encaixa bem com as características de streaming e pipelining destas aplicações, de modo que ele pode capturar muitas decisões de mapeamento e restrições de recursos, permitindo se fazer uma análise temporal e do uso de recursos, dentro do fluxo de projeto. Esta seção apresenta tanto as definições de grafos como a terminologia que será necessária no decorrer deste capítulo. Inicialmente, define-se um grafo $G$ como um par ordenado $G=(V, E)$, onde $V$ é um conjunto de nós e $E$ é um conjunto de ramos [YANG09]. A Figura 2.1 apresenta um grafo com três nós $(A, B e C)$ e dois ramos $(A, B)$ e $(A, C)$.

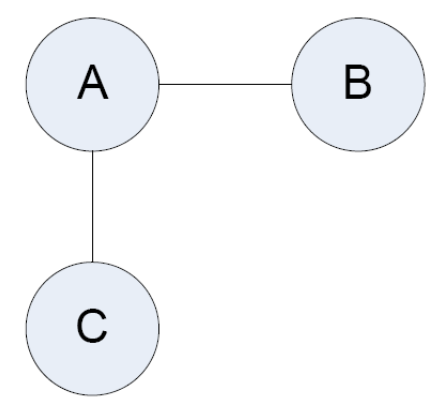

Figura 2.1: Um grafo simples [YANG09]. 


\subsubsection{Grafo Direcionado}

Um grafo direcionado é um grafo $G=(V, E)$ onde cada arco é um par ordenado $\left(v_{1}, v_{2}\right)$, onde $v_{1}, v_{2} \in V$. Para um arco $e=\left(v_{1}, v_{2}\right) \epsilon E$, diz-se que ele é direcionado de $v_{1}$ para $v_{2}$, de modo que $v_{1}$ é a fonte de $e$, e $v_{2}$ é o seu destino. A Figura 2.2 apresenta um exemplo de um grafo direcionado composto por três nós $(A, B$ e $C)$ e dois $\operatorname{arcos}(A, B)$ e $(A, C)$. [SRIRAMOO].

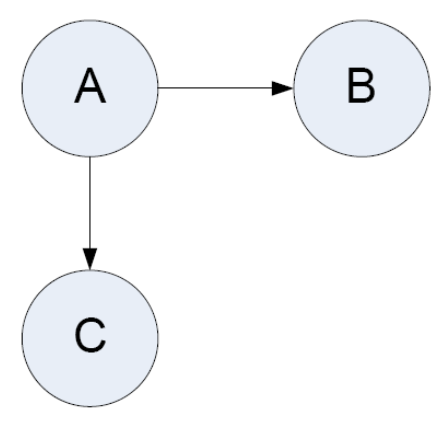

Figura 2.2: Grafo Direcionado [YANG09].

\subsubsection{Grafo de Fluxo de Dados}

Um grafo de fluxo de dados é um grafo direcionado onde os nós, definidos agora como atores ou processos, representam computação e os arcos representam canais FIFO (First-In First-Out). Um grafo de fluxo de dados $(V, E, M)$ é definido como um conjunto de atores $v \in V$ e uma série de canais $e \in E$, onde $E \subseteq V \times V$.

A Figura 2.3 apresenta um exemplo de um grafo de fluxo de dados. Como mostrado no exemplo, cada canal tem associado um número de tokens iniciais $M: E \rightarrow \mathbb{R}^{\geq 0}$, ou seja, $m_{i j} \in \mathbb{R}^{\geq 0}$ indica o número de tokens associados com o canal $e_{i j}=\left(v_{i}, v_{j}\right)$ que conecta o ator $v_{i} \in V$ com o ator $v_{j} \in V$. Este número de tokens é muitas vezes referido como a condição, ou atraso, inicial de cada canal [KAUNZLI07, STOIMENOV11].

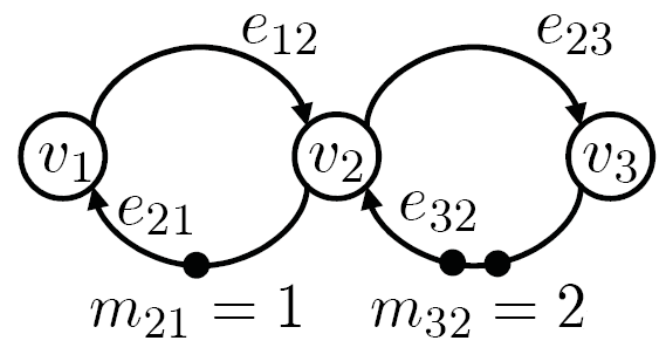

Figura 2.3: Grafo de Fluxo de Dados [STOIMENOV11]. 
O termo "token" é utilizado em um sentido muito geral. Ele deve ser interpretado como qualquer quantidade de dados, não necessariamente inteiros. Deste modo, ele é capaz de modelar sistemas sob uma configuração baseada em fluxos, ou em eventos discretos. Este conceito é útil para atribuir portas de entrada e de saída para cada ator $v_{i} \in V$. Denota-se à porta de entrada do $v_{i}$ associado ao canal $e_{j i}=\left(v_{j}, v_{i}\right)$ como $(j, i)$, e à porta de saída associada ao $e_{i k}=\left(v_{i}, v_{k}\right)$ como $(i, k)$.

Quando um ator é ativado pela disponibilidade de dados que utiliza, diz-se que o ator foi disparado. O disparo de um ator compreende três etapas: primeiro, o ator consome tokens das suas entradas; a seguir, o ator executa a computação; e finalmente, o ator produz tokens para todas as suas saídas.

\subsubsection{Grafo de Fluxo Síncrono de Dados}

O Grafo de SDF é um modelo restrito de fluxo de dados proposto por Lee e Messerschmitt [LEE87a]. No modelo de SDF, cada ator consome/produz o mesmo número fixo de tokens em cada arco de entrada/saída, em cada disparo. Um ator dispara sempre que todos seus arcos de entrada tenham tokens suficientes para uma ativação do ator. Pode haver dependências de dados ao longo das iterações, sendo estas dependências modeladas com tokens iniciais nos arcos FIFO. O atraso de um arco é representado por uma função $d(e)$, a qual, para um arco $e$, retorna o número inicial de tokens armazenados neste arco.

A Figura 2.4 apresenta um exemplo de um grafo de SDF, composto pelos atores $(A, B e C)$, e os $\operatorname{arcos} e_{1}=(A, B)$ e $e_{2}=(A, C)$. Em cada disparo do ator $A$, ele produz dois tokens no arco $e_{1}$ e um token no arco $e_{2}$. Os atores $B$ e $C$ disparam se tiverem pelo menos um token disponivel nos respectivos arcos de entrada. O grafo apresenta um atraso no arco $e_{1}, d\left(e_{1}\right)=1$, representado pelo token inicial armazenado nele, e nenhum atraso no arco $e_{2}, d\left(e_{2}\right)=0$, visto que não tem tokens iniciais armazenados neste arco.

O modelo clássico de SDF é não-temporizado. No entanto, existe uma extensão do SDF na qual um tempo de execução fixo está associado com cada ator [SRIRAM00]. Esta extensão torna o modelo acessível à análise temporal. Nesse caso, define-se a função $t\left(a_{i}\right)$ como o tempo de execução de ator $a_{i}$, associado ao nó $i$. 


\section{Definição - Iteração:}

Uma iteração de um grafo de SDF é uma sequência de disparos de atores, de modo que o grafo é levado de volta à sua distribuição inicial de tokens. Considere-se como um exemplo o grafo de SDF apresentado na Figura 2.4. Uma iteração deste grafo é uma sequência de disparos dos seus respectivos atores, de modo que o grafo novamente ficará com um token no arco $(A, C)$, e zero tokens no arco $(A, B)$.

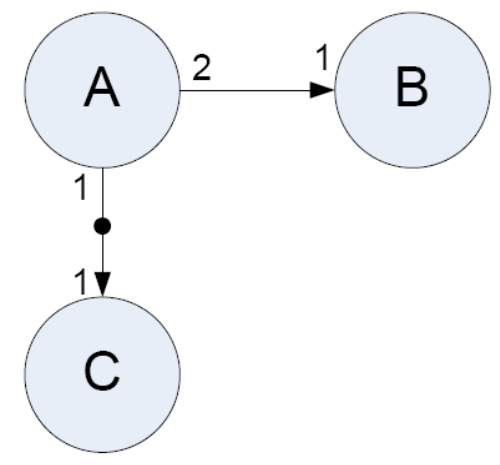

Figura 2.4: Grafo de Fluxo Síncrono de Dados [YANG09].

\subsubsection{Grafo Homogêneo de Fluxo Síncrono de Dados}

Um grafo de SDF no qual cada ator consome (e produz) apenas um token de cada uma das suas entradas (e saídas) é chamado de Grafo Homogêneo de Fluxo Síncrono de Dados (Homogeneous Synchronous Dataflow, HSDF) (ver Figura 2.5). [SRIRAM00].

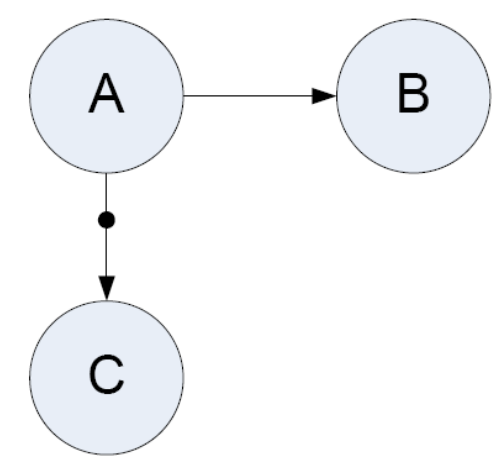

Figura 2.5: Grafo Homogêneo de Fluxo Síncrono de Dados [YANG09].

Um ator do grafo de HSDF dispara quando tem um, ou mais tokens, em cada um de seus arcos de entrada. Neste caso, um único token de cada entrada do 
ator é consumido. Quando o ator termina o disparo, um token é produzido em cada um de seus arcos de saída. Na representação gráfica dos grafos HSDF, podem-se omitir as taxas de produção e de consumo, visto que todas elas serão iguais a 1, como mostrado na Figura 2.5.

Uma iteração de um grafo de HSDF é aquela quando todos os atores desse grafo tenham sido disparados uma vez. A função $s(i, k)$ indica o tempo na iteração $k$ em que o ator $a_{i}$ é disparado. O número da iteração é contado a partir de 0 , de modo que a iteração $k$ equivale à execução $(k+1)$ do ator $a_{i}$. O valor de atraso do arco do ator $a_{i}$ para o ator $a_{j}$ é dado por $d(i, j)$, e $t\left(a_{i}\right)$ é o tempo de execução do ator $a_{i}$. Dentro do grafo de HSDF, define-se a seguinte regra básica:

$$
s(j, k) \geq s(i, k-d(i, j))+t\left(a_{i}\right)
$$

Esta regra significa que para um arco com ator fonte $a_{i}$ e ator destino $a_{j}$, o tempo de início do ator $a_{j}$ deve ser posterior ao tempo final de execução do ator $a_{i}$ de um número prévio de iterações equivalente ao número de atrasos $d(i, j)$.

\subsubsection{Propriedades Analíticas dos Grafos de SDF}

Um grafo de SDF pode ser compactamente representado pela sua matriz de topologia $\Gamma$. A matriz representa a estrutura do grafo, e contém uma coluna para cada vértice e uma linha para cada arco dentro do grafo. O valor de entrada do elemento (coluna $m$, linha $n$ ) na matriz corresponde ao número de tokens produzidos pelo ator $a_{m}$ sobre o arco $n$. Se o ator $a_{m}$ consome tokens a partir do arco $n$, o valor da entrada do elemento $(m, n)$ é negativo. Além disso, se o ator $a_{m}$ não produzir nem consumir tokens do arco $n$, o valor da entrada do elemento $(m, n)$ é definido como zero. Por exemplo, a matriz de topologia do grafo da Figura 2.4 é

$$
\Gamma=\left[\begin{array}{ccc}
2 & -1 & 0 \\
1 & 0 & -1
\end{array}\right]
$$

onde os atores $A, B$ e $C$ são numerados como 1,2 e 3 , e os $\operatorname{arcos}(A, B)$ e $(A, C)$ são numerados como 1 e 2 . 


\section{Definição - Vetor de repetição:}

O vetor de repetição $q$, para um grafo de $\operatorname{SDF}$ com $s$ atores, é um vetor coluna de dimensão $s$, o qual tem a propriedade de que se cada ator $i$ é invocado um número de vezes igual à entrada $i$ deste vetor $q$, então o número de tokens em cada arco do grafo de SDF permanece inalterado. Além disso, $q$ é o menor vetor inteiro para o qual esta propriedade se aplica.

Teorema 2.1: O vetor de repetições $q$ de um grafo de SDF, com taxas de amostragem consistentes, é o menor vetor inteiro no espaço nulo da sua matriz de topologia. Isto é, $q$ é o menor vetor inteiro tal que,

$$
\Gamma q=0
$$

Para o exemplo da Figura 2.4, q é igual a $\left[\begin{array}{l}1 \\ 2 \\ 1\end{array}\right]$. Mais detalhes e demonstrações podem ser encontrados em [SRIRAM00].

O vetor de repetições indica quantas vezes cada ator deve ser executado para trazer o grafo de volta para sua distribuição inicial de tokens. Neste exemplo, para levar o grafo de volta à distribuição inicial de tokens, isto é, zero tokens no arco $(A, B)$ e um token no arco $(A, C)$, os atores $A$ e $C$ devem ser executados uma vez, e o ator $B$ deve ser executado 2 vezes.

Com o vetor de repetições, pode-se definir uma iteração de um grafo de SDF como uma sequência de disparos de atores tal que cada ator no grafo se execute um número de vezes igual a sua entrada correspondente no vetor de repetição.

\subsubsection{Modelagem da Aplicação baseada em SDF}

Utilizado na modelagem de uma aplicação, o grafo de SDF pode modelar a execução de uma aplicação, baseada em fluxo de dados, sobre uma plataforma real. O grafo da Figura 2.6 representa o comportamento de desempenho da 
parte crítica de um decodificador de vídeo MPEG-4 mapeado em uma plataforma SoC composta por dois processadores ARM7, P1 e P2, rodando a 100MHz. P1 serve como a máquina principal de computação. P2 serve como um controlador de memória para calcular os endereços e acessar a memória grande de vídeo contendo os dados na forma de cada objeto encontrado dentro do vídeo [POPLAVKO07]. O grafo captura o processamento de três tipos diferentes de blocos de imagem, em conjunto com a etapa de prefetching dos dados requeridos de uma memória através de uma rede intrachip. Os atores do grafo representam as computações individuais da aplicação. Com cada ativação de um ator, ele consome e produz quantidades fixas de tokens nos canais FIFO. Tal como foi explicado previamente, o ator só pode se ativar se há um número suficiente de tokens nos canais do qual ele recebe informação. Visto que as taxas de produção e consumo estão omitidas, o grafo representado corresponde a um HSDF, de modo que cada taxa é igual a 1.

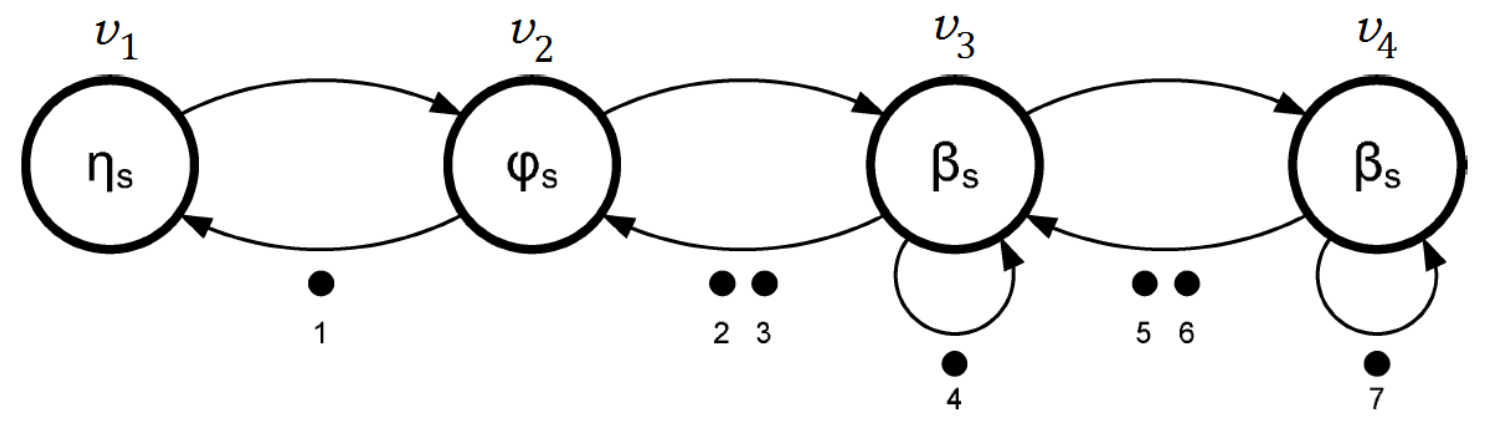

Figura 2.6: Modelo HSDF de um Codec de MPEG-4 [GEILEN11a].

Em geral, no grafo de SDF, os tokens capturam as dependências entre os atores que estão se ativando, de modo que na modelagem de determinada aplicação, estas dependências podem se originar não só pela dependência de dados, mas também pela dependência devida a recursos compartilhados. No caso da Figura 2.6, estas dependências são indicadas pela quantidade de tokens iniciais do grafo, sete no total.

Igualmente, os atores nem sempre representam computações reais, podendo ser utilizados para modelar comunicação ou sincronização, por exemplo, a fim de expressar escalonamentos mais complexos [LEE87b, SRIRAM00]. No caso do exemplo da Figura 2.6, os atores modelam a comunicação sobre uma rede intrachip [POPLAVKO07]. 
$\mathrm{Na}$ representação da computação relacionada às tarefas da aplicação, as ativações de atores precisam da definição de um parâmetro temporal. No modelo de SDF, as ativações dos atores são modeladas com um tempo de execução constante, o qual é tipicamente definido como um limite superior maior do que o tempo de execução real da computação correspondente na aplicação real. Dado que o modelo de computação de SDF é monotônico (isto é, uma ativação prévia, ou curta, de um ator não pode levar a uma ativação posterior do ator), é possível utilizar tempos de execução do pior-caso dentro do modelo a fim de obter um limite superior sobre os tempos reais de ativação e os tempos de produção de dados da aplicação real. No caso do grafo da Figura 2.6, os tempos de execução dos atores $\varphi_{S}$ e $\beta_{S}$ são constantes (independente dos diferentes cenários da aplicação) e $\eta_{s}$ varia para três cenários $s_{1}, s_{2}$ e $s_{3}$, relacionados aos três tipos diferentes de blocos de imagem [POPLAVKO07].

O grafo da Figura 2.6 modela essencialmente um pipeline de leitura de dados do ator $v_{1}$ tal que os dados resultantes do processamento são armazenados no ator $v_{4}$. Os tokens são blocos de vídeo de $16 \times 16$ pixels. O ator $v_{1}$ modela a decodificação da entropia do bloco de vídeo, executada por um processador $P 1$, tal que a leitura da memória de vídeo, para o bloco de vídeo de referência, é feita por um processador $P 2$ definido para operar como um controlador de memória. Essas operações são envolvidas em um só ator uma vez que a aplicação MPEG-4 não permite a execução em paralelo destas operações. (Observe-se que eles não poderiam ser mapeados no mesmo processador devido à restrição de que $\mathrm{P} 2$ seja só um controlador de memória). O ator $v_{2}$ envia os resultados da decodificação através de um canal de rede para o processador $P 2$. O ator $v_{3}$ modela o canal de rede e o ator $v_{4}$ modela $\mathrm{o}$ armazenamento da saída na memória de vídeo, executado pelo processador $P 2$ em um caminho separado de execução.

Os arcos entre $v_{2}, v_{3}$ e $v_{4}$ modelam dois buffers FIFO com um espaço de dois tokens para cada buffer. As reservas do nivel de processamento de computação e de comunicação estão ajustadas de modo que ambos os processadores estejam plenamente carregados (no pior dos casos), e a carga seja devidamente equilibrada. Por exemplo, equilibrar as reservas dos atores $v_{3}$ e $v_{4}$ conduz à definição de um mesmo atraso (tempo de execução) $\beta_{S}$ para ambos. 


\subsubsection{Modelo de Fluxo Ciclo-Estático de Dados}

Um grafo de Fluxo Ciclo-Estático de Dados (Cyclic-Static Dataflow, CSDF) [BILSEN96] é um grafo direcionado $\boldsymbol{G}=(\boldsymbol{V}, \boldsymbol{E}, \boldsymbol{\delta}, \boldsymbol{\tau}, \boldsymbol{\pi}, \boldsymbol{\gamma}, \kappa)$, que consiste de um conjunto finito de atores $V$, e um conjunto de arcos direcionados, $\boldsymbol{E}=$ $\left\{\left(\boldsymbol{v}_{\boldsymbol{i}}, \boldsymbol{v}_{\boldsymbol{j}}\right) \mid \boldsymbol{v}_{\boldsymbol{i}}, \boldsymbol{v}_{\boldsymbol{j}} \in \boldsymbol{V}\right\}$. Os atores são sincronizados pelos tokens transferidos ao longo dos arcos.

A Figura 2.7 apresenta um exemplo de um grafo de tarefas de produtorconsumidor [HANSSON09], com o respectivo modelo de CSDF na parte superior da Figura. Neste exemplo uma tarefa $\boldsymbol{t}_{\boldsymbol{p}}$ comunica-se através de um buffer, com capacidade $\boldsymbol{d}$, com uma tarefa $\boldsymbol{t}_{\boldsymbol{c}}$. Se o buffer estiver cheio, $\boldsymbol{t}_{\boldsymbol{p}}$ é bloqueado; e se o buffer estiver vazio, $\boldsymbol{t}_{\boldsymbol{c}}$ é bloqueado.

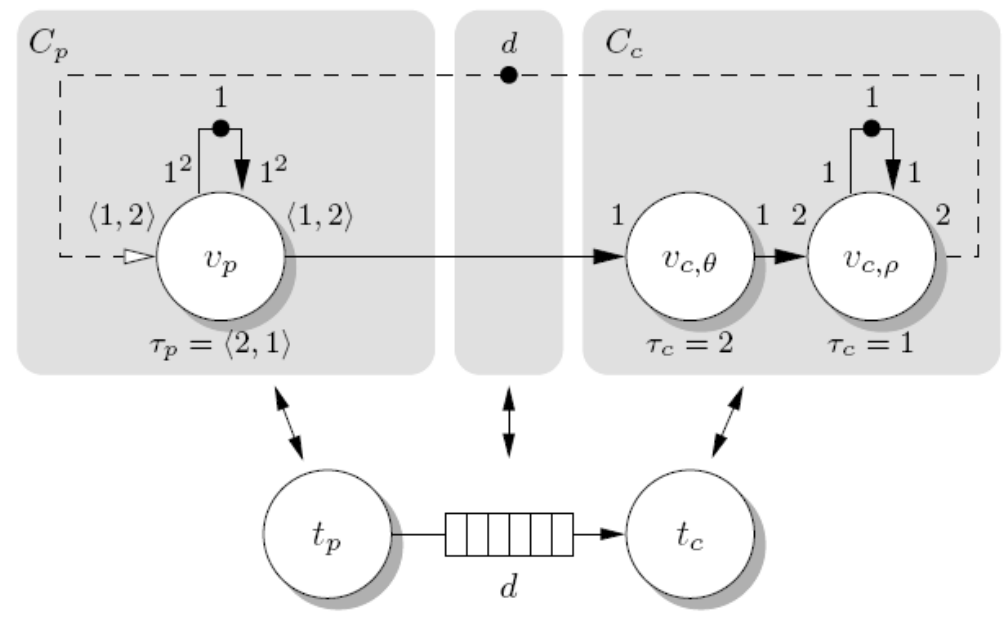

Figura 2.7: Exemplo do problema da capacidade de um buffer, em um grafo de tarefas de produtor-consumidor [HANSSON09].

Tal como mostrado na Figura, o grafo de fluxo de dados pode ser dividido em componentes, definindo assim uma partição do grafo, de modo que o componente $\boldsymbol{C}_{\boldsymbol{p}}$ modela a tarefa $\boldsymbol{t}_{\boldsymbol{p}}$, e o componente $\boldsymbol{C}_{\boldsymbol{c}}$ modela a tarefa $\boldsymbol{t}_{\boldsymbol{c}}$. Neste caso, a fim de representar a quantidade de espaço disponível do buffer, o modelo também inclui um arco de $\boldsymbol{C}_{\boldsymbol{c}}$ para $\boldsymbol{C}_{\boldsymbol{p}}$ indicando que o buffer tem $\boldsymbol{d}$ lugares disponiveis para a comunicação entre $\boldsymbol{t}_{\boldsymbol{p}}$ e $\boldsymbol{t}_{\boldsymbol{c}}$. Este tipo de arco é representado por setas tracejadas [HANSSON09].

Nesta Figura, os tokens que modelam o fluxo de dados fluem do ator $\boldsymbol{v}_{\boldsymbol{p}}$ ao ator $\boldsymbol{v}_{\boldsymbol{c}, \theta}$ e $\boldsymbol{v}_{\boldsymbol{c}, \rho}$; enquanto que os tokens que modelam a disponibilidade de espaço 
no buffer fluem do $\boldsymbol{v}_{\boldsymbol{c}, \theta}$ ao $\boldsymbol{v}_{\boldsymbol{p}}$. Desta forma, o grafo $G$ tem uma disposição inicial de tokens $\boldsymbol{\delta}: \boldsymbol{E} \rightarrow \boldsymbol{N}$, como apresentado pelo único token nos auto-arcos de $\boldsymbol{v}_{\boldsymbol{p}}$ e $\boldsymbol{v}_{\boldsymbol{c}, \rho}$, e os tokens $\boldsymbol{d}$ nos arcos entre eles.

Um ator $v_{i}$ tem $\boldsymbol{\kappa}\left(v_{i}\right)$ fases diferentes de execução, com $\mathbf{\kappa}: \boldsymbol{V} \rightarrow \boldsymbol{N}$, e transições de fase a fase, em um modo cíclico. Um ator é habilitado para disparar quando o número de tokens que serão consumidos está disponivel em todos seus arcos de entrada. O número de tokens consumidos pelo ator $\boldsymbol{v}_{\boldsymbol{i}}$ em um disparo $k$ é determinado pelo arco $\boldsymbol{e}=\left(\boldsymbol{v}_{\boldsymbol{j}}, \boldsymbol{v}_{\boldsymbol{i}}\right)$ e a fase atual do ator que consome token, $\boldsymbol{\gamma}: \boldsymbol{E} \times \boldsymbol{N} \rightarrow \boldsymbol{N}$, e, portanto, é igual a:

$$
\boldsymbol{\gamma}\left(\boldsymbol{e},\left((k-1) \bmod \boldsymbol{\kappa}\left(v_{i}\right)\right)+1\right) \quad \text { tokens }
$$

O número especificado de tokens é consumido atomicamente desde todos os arcos de entrada quando o ator inicia seu disparo. Com a consideração de um auto-arco (com tokens), o número de disparos simultâneos de um ator é restrito. Isto é utilizado no grafo do exemplo da Figura 2.7, onde $\boldsymbol{v}_{\boldsymbol{c}, \theta}$ modela a latência, ou seja, não tem um auto-arco, e o ator $\boldsymbol{v}_{c, \rho}$ modela a vazão, isto é, pode consumir e produzir tokens a uma determinada taxa.

O tempo de resposta $\boldsymbol{\tau}\left(\boldsymbol{v}_{\boldsymbol{i}}, \boldsymbol{f}\right), \boldsymbol{\tau}: \boldsymbol{V} \times \boldsymbol{N} \rightarrow \boldsymbol{R}$, é a diferença entre o tempo final e o tempo inicial da fase $\boldsymbol{f}$ do ator $\boldsymbol{v}_{\boldsymbol{i}}$. O tempo de resposta do ator $\boldsymbol{v}_{\boldsymbol{i}}$, no disparo $\boldsymbol{k}$, é portanto:

$$
\boldsymbol{\tau} \boldsymbol{\tau}\left(\boldsymbol{v}_{\boldsymbol{i}},\left((\boldsymbol{k}-1) \bmod \boldsymbol{\kappa}\left(\boldsymbol{v}_{\boldsymbol{i}}\right)\right)+1\right)
$$

Quando o ator $\boldsymbol{v}_{\boldsymbol{i}}$ finaliza, ele atomicamente produz o número especificado de tokens em cada arco de saída $\boldsymbol{e}=\left(\boldsymbol{v}_{\boldsymbol{i}}, \boldsymbol{v}_{\boldsymbol{j}}\right)$. O número de tokens produzidos em uma fase é denotado por $\boldsymbol{\pi}: \boldsymbol{E} \times \boldsymbol{N} \rightarrow \boldsymbol{N}$. No exemplo da Figura 2.7, $\boldsymbol{v}_{\boldsymbol{p}}$ tem a sequência de tempo de resposta $\boldsymbol{\tau}_{\boldsymbol{p}}=\langle\mathbf{2}, \mathbf{1}\rangle$ e $\boldsymbol{v}_{\boldsymbol{c}, \theta}$ tem a sequência de tempo de resposta $\boldsymbol{\tau}_{\boldsymbol{c}, \theta}=\langle\mathbf{2}\rangle$. Neste grafo, $\boldsymbol{v}_{\boldsymbol{p}}$ consome e produz dois tokens na primeira fase a partir dos arcos, e para os arcos, de $\boldsymbol{v}_{c, \theta}$ e $\boldsymbol{v}_{\boldsymbol{c}, \rho}$, respectivamente. Por brevidade, a notação $\boldsymbol{x}^{\boldsymbol{y}}$ denota um vetor de dimensão $\boldsymbol{y}$, no qual cada elemento tem valor $\boldsymbol{x}$. No exemplo, isto é visto no auto-arco de $\boldsymbol{v}_{\boldsymbol{p}}$, onde $\mathbf{1}^{2}=\langle\mathbf{1}, \mathbf{1}\rangle$. 
Para o arco $e=\left(\boldsymbol{v}_{i}, \boldsymbol{v}_{\boldsymbol{j}}\right)$, define-se $\boldsymbol{\Pi}(\boldsymbol{e})=\sum_{\boldsymbol{f}=\mathbf{1}}^{\boldsymbol{\kappa}\left(\boldsymbol{v}_{\boldsymbol{i}}\right)} \boldsymbol{\pi}(\boldsymbol{e}, \boldsymbol{f})$ como o número de tokens produzidos em um periodo ciclo-estático, e $\boldsymbol{\Gamma}(\boldsymbol{e})=\sum_{\boldsymbol{f}=\mathbf{1}}^{\boldsymbol{\kappa}\left(\boldsymbol{v}_{\boldsymbol{i}}\right)} \boldsymbol{\gamma}(\boldsymbol{e}, \boldsymbol{f})$ como o número de tokens consumidos em um período ciclo-estático. Também definese a topologia de ator $\boldsymbol{\Psi}$ como uma matriz $|\boldsymbol{E}| \times|\boldsymbol{V}|$, onde:

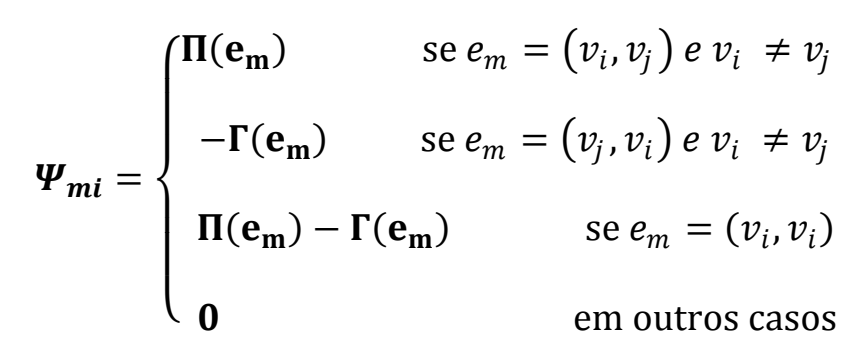

Se a ordem de $\boldsymbol{\Psi}$ é $|\boldsymbol{V}| \mathbf{- 1}$, então um grafo conectado de CSDF é definido como consistente [BILSEN96]. Para um grafo de CSDF consistente, existe um agendamento finito (não vazio) que retorna o grafo para sua disposição original de tokens. Desta forma, a implementação representada pelo modelo precisa de buffers de capacidade finita.

Define-se o vetor $\boldsymbol{s}$ de dimensão $|\boldsymbol{V}|$, para o qual $\boldsymbol{\Psi}_{\boldsymbol{s}}=\mathbf{0}$, e que determina as frequências de disparos relativas do período ciclo-estático. O vetor de repetição $q$ do grafo de CSDF determina as frequências de disparos relativos dos atores e é dado por:

$$
\mathbf{q}=\boldsymbol{\Lambda} \mathbf{s} \quad \operatorname{com} \quad \boldsymbol{\Lambda}_{i k}=\left\{\begin{array}{lr}
\boldsymbol{\kappa}\left(\boldsymbol{v}_{\boldsymbol{i}}\right) & \text { se } i=k \\
\mathbf{0} & \text { em outros casos }
\end{array}\right.
$$

Portanto, a taxa de repetição $q_{i}$ do ator $v_{i}$ é o número de fases de $v_{i}$, dentro de um período ciclo-estático, multiplicado pela frequência de disparo relativa do período ciclo-estático. Para o exemplo da Figura 2.7, o vetor $s$ é definido como $\left[\begin{array}{lll}2 & 6 & 3\end{array}\right]^{T}$, e o vetor de repetição é $q=\left[\begin{array}{lll}4 & 6 & 3\end{array}\right]^{T}$.

\subsubsection{Modelo de Fluxo Síncrono de Dados, Atento a Cenários}

Uma nova tendência, que emerge como uma extensão ao projeto baseado em modelos, é o projeto baseado em cenários [GHEORGHITA08, YANG02, MAMAGKAKIS07, GEILEN10a]. Nesta abordagem, o comportamento dinâmico de uma aplicação é visto como uma coleção de comportamentos diferentes (ou cenários) que ocorrem em uma ordem arbitrária, mas onde cada cenário é 
suficientemente estático e previsível em relação ao desempenho e ao uso de recursos, motivo pelo qual podem ser tratados por métodos tradicionais. No entanto, alguns dos problemas do projeto baseado em modelos foram substituídos pela predição da ocorrência de cenários e pela habilidade de lidar com as transições entre tais cenários.

Trabalhos como [STUIJK08, GEILEN10a] apresentam diferentes técnicas para modelar e analisar sistemas de modo a capturar o seu comportamento, expressado como uma coleção de cenários, sendo cada cenário representado através de um grafo de SDF. Aspectos dos vários grafos de SDF podem ser diferentes dentro dos múltiplos cenários, como, por exemplo, os tempos de execução, as taxas de comunicação, ou mesmo, a estrutura de cada grafo. As dependências entre cenários subsequentes são capturadas por tokens que são transferidos de um grafo para outro. O modelo apresentado nessa abordagem mostra a possibilidade de se capturar naturalmente o pipelining de cenários subsequentes. A base matemática da técnica apresentada corresponde ao uso da álgebra de Max-Plus, a qual fornece as ferramentas matemáticas necessárias para descrever sistemas baseados em atrasos e sincronização.

O estado da arte da análise baseada em cenários [GHEORGHITA08, YANG02, GEILEN10a, STUIJK08] lida geralmente com código sequêncial, tal como o grafo de SDF, e não com aplicações concorrentes. A análise baseada em cenários foi aplicada em Poplavko et al. [POPLAVKO07] para grafos de HSDF com tempos variáveis de execução por cenário. Nesse trabalho, os autores propõem que o número e tipos de cenários, chaveados ao longo de um período a ser executado, sejam incorporados ao fluxo de entrada de vídeo, referente ao componente de codificação em uma aplicação MPEG-4. Nesse caso, é mostrado que, para esquemas avançados de codificação de vídeo, a modelagem baseada em diferentes tipos de cenário permite uma estimativa muito melhorada do tempo de execução do pior-caso, com custos computacionais geralmente acessiveis. Uma estimativa mais acurada do desempenho do pior-caso é obtida através da análise de todas as transições de um cenário $s$ para um cenário $t$. No entanto, quando o número de cenários é grande, a complexidade da análise necessária cresce, bem como a sobrecarga no fluxo de dados. 
A análise tradicional de SDF está geralmente focada em comportamentos de longo prazo tal como a taxa média de transferência ou vazão média (Average Throughput). No entanto, ao considerar mudanças de cenário em grafos de $\mathrm{SDF}$, a aplicação representada é executada só durante uma quantidade finita de tempo, de modo que o comportamento transitório resulta sendo de mais interesse que o comportamento médio de longo prazo. Neste sentido, Moreira e Bekooij [MOREIRA07] analisam o comportamento transitório de grafos de SDF a fim de estudar estritamente a execução periódica de grafos e sua respectiva latência. Igualmente, em [GEILEN10a] é apresentado um algoritmo para analisar o comportamento transitório e de regime estacionário de um SDF, de modo que também seja possível analisar as mudanças de comportamento entre múltiplos cenários (ver seção 2.2.3.4).

Em vista de que as taxas constantes com que os tokens são produzidos ou consumidos definem a execução de cada SDF nas iterações, é possivel dizer que tais iterações são a granularidade natural para definir os diferentes cenários, tanto do ponto de vista da aplicação, como do ponto de vista de análise de desempenho. Tal granularidade não impede que a execução das iterações subsequentes possa sobrepor-se no tempo. De fato, é muito comum que na execução dinâmica de uma aplicação - representada por uma implementação em pipeline - cenários diferentes possam ser ativados simultaneamente.

\subsubsection{Modelo de SDF Atento a Cenários baseado em Cadeias de Markov}

Uma das extensões do modelo de SDF, o Fluxo Síncrono de Dados Atento a Cenários (Scenary-Aware Data-Flow, SADF) [THEELEN06] considera que a ordem de ocorrência dos diferentes cenários é ditada por uma cadeia de Markov, tal que a ordem possivel em que os cenários acontecem é estocástica. Os diferentes cenários podem ter tempos de execução diferentes, ou distribuições de tempo de execução iguais, para cada ator; igualmente podem ter diferentes taxas de comunicação, e alguns atores podem ficar inativos em um, ou em mais cenários.

Esses SADFs podem ser analisados estocasticamente e para o comportamento do pior-caso. A vazão média do longo prazo pode ser calculada, bem como as estatísticas de ocupação dos buffers. Os resultados exatos podem, em 
princípio, ser obtidos por técnicas de exploração do espaço de estado; ou uma simulação pode ser usada para se obter melhores aproximações quando os modelos tornam-se demasiado grandes para uma análise precisa. Visto que a análise não é feita por composição de cenário como no trabalho [GEILEN10a], o espaço de estado que precisa ser analisado pode, ocasionalmente, se tornar altamente proibitivo.

\subsubsection{Modelo de SDF Atento a Cenários baseado em uma Máquina de Estados Finitos}

O projeto [STUIJK08] introduz outra extensão para o MoC de SADF, o qual pode ser utilizado para modelar uma aplicação em conjunto com seus diferentes cenários. Esse novo MoC é chamado de Fluxo Síncrono de Dados, Atento a Cenários baseado em Máquina de Estados Finitos, (Finite State Machine-based Scenario-Aware Data-Flow, FSM-based SADF). O MoC de SADF baseado em FSM é uma versão restrita da MoC de SADF [THEELEN06] apresentado na subseção anterior 2.1.6.1. Estas restrições tornam a análise do comportamento temporal de um modelo de SADF baseado em FSM mais rápido do que em um modelo geral de SADF. No entanto, o resultado da análise pode ser menos acurado devido às abstrações feitas na FSM incluída no primeiro destes modelos.

\subsubsection{Comparação de Modelos de Fluxo de Dados [STUIJK07]}

Esta seção foi feita de uma tradução livre da seção 4.7 da tese de doutorado de [STUIJK07].

Como foi visto até agora, existem vários MoCs de fluxo de dados. Esses MoCs diferem na sua expressividade e concisão, analisabilidade e eficiência na implementação [STUIJK07]. A expressividade e a concisão de um modelo indicam quais sistemas podem ser modelados, e quanto esses modelos são simples ou resumidos. Por exemplo, o comportamento de um decodificador H.263 pode ser representado por um modelo de SDF consistindo de 4 atores. Alternativamente, o mesmo comportamento pode ser modelado com um modelo de HSDF contendo 4754 atores, ilustrando que o modelo anterior é mais sucinto. Claramente, a construção do modelo de SDF é mais fácil do que a construção do grande modelo de HSDF. Além disso, algumas propriedades (por exemplo, comportamento dependente de dados) podem ser modeladas em 
alguns MoCs de fluxo de dados, mas não em outros, o que é uma diferença quanto à expressividade.

O segundo aspecto que diferencia os MoCs é a sua analisabilidade. A analisabilidade de um MoC é determinada pela disponibilidade de algoritmos de análise, e do tempo de execução requerido por um algoritmo quando aplicado em um grafo com um determinado número de nós, independente do MoC considerado. O terceiro aspecto que é relevante quando se comparam MoCs é a sua eficiência na implementação. Isto é influenciado pela complexidade do problema de escalonamento e o tamanho (do código) dos agendamentos resultantes.

Nesta seção, os MoCs de fluxo de dados mais importantes são comparados nesses três aspectos acima mencionados. O resultado desta comparação pode ser visualizado na Figura 2.8. O objetivo da comparação é apresentar a motivação para a escolha feita nesta tese para se modelar uma aplicação através de SDFs.

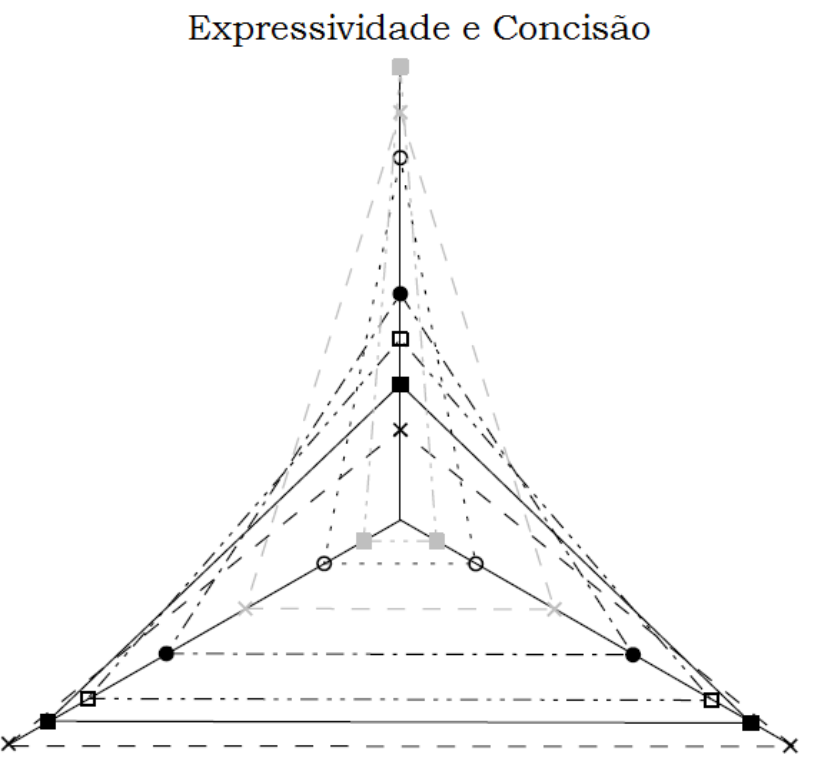

Analisabilidade

Eficiência na Implementação

$\times$ HSDF / Grafos Marcados

$\circ \mathrm{BDF}$

- SDF / Grafos Marcados Ponderados

$\times$ SADF

- Grafos de Computação

- KPN

- $\mathrm{CSDF}$

Figura 2.8: Comparação de MoCs de Fluxo de Dados [STUIJK07]. 
Os dois primeiros MoCs de fluxo de dados considerados são o de HSDF e o de SDF [LEE87a, POPLAVKO07]. É interessante observar que tais modelos correspondem a duas subclasses do modelo de Rede de Petri, MoC de propósito geral bem conhecido, não limitado a fluxo de dados, e com uma ampla literatura científica e de divulgação [PETRI62, REISIG98]. Tais subclasses são os Grafos Marcados [COMMONER71] e os Grafos Marcados Ponderados [TERUEL92], respectivamente. A literatura de Redes de Petri pode fornecer arcabouços teóricos e algoritmos de análise aplicáveis tanto a modelos de SDFs como de HSDFs.

A diferença importante entre os modelos de SDF (ou Grafos Marcados Ponderados) e de HSDF (ou Grafos Marcados) é que o primeiro MoC pode lidar com dependências de multitaxa, fazendo-o mais sucinto. No entanto, os algoritmos de análise existentes para o modelo de HSDF, para propriedades como a vazão ou a latência, têm complexidade de tempo polinomial. Por outro lado, os algoritmos de análise para o modelo de SDF têm uma complexidade de tempo não-polinomial. Isto implica que a analisabilidade deste é menor. O fato de que estes MoCs suportem dependências multitaxa faz com que seus agendamentos, e o problema de escalonamento, também sejam mais complexos. Desta forma, sua eficiência de implementação é menor do que aquela de um grafo modelado com HSDF.

Karp e Miller introduziram em 1966 o modelo chamado de Grafo de Computação [KARP66], para o qual, igual ao grafo de SDF, os atores consumem e produzem uma quantidade fixa de tokens em cada disparo, e os arcos podem conter tokens iniciais. Para cada porta de entrada de um ator, um parâmetro de limite é adicionado, indicando que ao ator conectado só é permitido disparar, se o número de tokens no arco é pelo menos igual ao limite anotado. Um grafo de SDF pode ser visto como um grafo de computação onde esse limite é igual ao número de tokens consumidos pela porta de entrada durante um disparo. Karp e Miller [KARP66] proporcionam condições necessárias e suficientes para a "vivacidade" (liveness) de um grafo de computação. A "vivacidade" indica que todas as partes do grafo podem ser executadas, frequentemente, de modo infinito. Nesse artigo, os autores mostram também as condições sob as quais o tamanho do buffer nos arcos permanece limitado ao executar um grafo de computação. Condições semelhantes existem também para o grafo de SDF. Em [GHAMARIANO6b], 
todas as condições necessárias e suficientes para a "vivacidade" e limitação de um modelo de SDF são dadas.

A distinção feita no modelo do grafo de computação entre o número de tokens necessários para um ator disparar, e o número real de tokens consumidos por um disparo, não torna este modelo mais expressivo do que o modelo de SDF, mas sim mais sucinto. No entanto, isso faz com que as condições sob as quais um ator pode ser agendado (disparado) sejam mais complexas. Pela mesma razão, os algoritmos de análise costumam ser mais complexos.

Uma propriedade importante dos MoCs discutidos até agora é que a taxa na qual os atores consomem tokens das suas entradas, e produzem tokens nas suas saídas, é constante. O MoC de CSDF [BILSEN96, LAUWEREINS94] relaxa essa restrição. Nesse modelo, a taxa de ativação de uma porta pode mudar entre disparos subsequentes. A sequência das taxas da porta deve ser finita e repetida periodicamente. Utilizando o algoritmo de [LAUWEREINS94], qualquer grafo de CSDF pode ser convertido em um grafo de HSDF equivalente. Isso garante que um agendamento periódico, de ordem estática, possa ser construído para um grafo de CSDF.

Isto também mostra que o CSDF não é mais expressivo que o SDF, porém é mais simples e compacto para certos aspectos. A complexidade dos agendamentos em um CSDF será tipicamente maior que o agendamento que resulta de um SDF com um número igual de atores. Técnicas existentes de análise baseadas em espaço de estado para SDFs podem ser estendidas para CSDFs considerando as sequências de taxas como parte de cada estado. Já que os CSDFs contêm mais informação nos seus estados quando comparados com os SDFs, os algoritmos de análise serão mais lentos.

Não é possível modelar um comportamento dependente de dados em qualquer dos MoCs discutidos até agora. Isto torna impossivel expressar a propriedade de que um ator possa escolher entre duas entradas, em função do valor de um token em uma terceira entrada. O MoC de Fluxo Booleano de Dados (Boolean Data-Flow, BDF) permite a modelagem desse tipo de comportamento dependente de dados. Esse modelo foi introduzido por Lee em [LEE91] e estudado extensivamente por Buck em [BUCK93]. O BDF estende o SDF com um mecanismo de chaveamento e de seleção. 
A chave copia os dados que lê da sua entrada para uma das suas saídas, tendo como variável de decisão o valor do token de controle Booleano. Igualmente o seletor lê dados de uma das suas entradas, baseado no valor de um token de controle, e copia esses dados para sua saída. A chave e o seletor introduzem um comportamento dependente de dados, o qual faz com que o grafo de BDF não seja, em geral, analisável em fase de projeto. $O$ comportamento dependente de dados torna também impossivel construir um agendamento de ordem-estática para um BDF.

Portanto, um mecanismo de agendamento em fase de execução deve ser utilizado ao implementar uma aplicação modelada com um BDF. Isto faz a implementação de um BDF ser menos eficiente do que qualquer um dos MoCs mencionados previamente. O modelo de SADF é outro MoC de fluxo de dados que permite a modelagem e análise de comportamento dependente de dados [THEELEN06]. Em um grafo de SADF as taxas dos atores são dependentes de dados e controladas por um ator de controle. Tanto o modelo BDF e o modelo de SADF são Turing-completos, implicando que ambos podem modelar o mesmo comportamento. No entanto, um grafo de SADF será frequentemente mais simples que um grafo de $\mathrm{BDF}$ modelando o mesmo comportamento funcional, visto que os atores de controle no SADF permitem a modelagem de estruturas de controle mais complexas do que a simples chave e o seletor do modelo BDF.

Recentemente, um número de algoritmos de análise foi desenvolvido para grafos SADFs [GEILEN10a]. Esses algoritmos têm uma complexidade de tempo não-polinomial, NP. O tempo de execução destes algoritmos é maior que o tempo requerido para executar um algoritmo de análise similar ao aplicado sobre um CSDF ou um SDF igualmente dimensionados. Isto acontece porque tipicamente mais comportamentos diferentes são possiveis de modelar em um $\mathrm{SADF}$, e todos esses comportamentos precisam ser analisados. O SADF pode ser parcialmente agendado em fase de projeto, e deve ser parcialmente agendado em fase de execução.

O MoC de Rede de Processos Kahn (KPN) foi proposto por Kahn em [KAHN74]. Neste modelo, os processos se comunicam uns com os outros pelo envio de dados através de arcos. Um processo pode escrever em um arco sempre que necessitar. Quando o processo tenta ler de um arco que está vazio (sem 
dados), ele se bloqueia, e deve esperar até que o dado esteja disponível. A quantidade de dados lidos de um arco pode ser dependente de dados, permitindo-se assim modelar qualquer função contínua, das entradas do KPN até as saídas do KPN, com um número arbitrariamente pequeno de processos. A continuidade corresponde informalmente à propriedade dos fluxos de dados de que uma entrada extra só pode levar a uma saída extra (não menos). De fato, o modelo de KPN é suficientemente expressivo para capturar com precisão todas as transformações de modelos de fluxos dependentes de dados. Isto implica que não é possivel analisar propriedades tais como a vazão ou os requisitos de buffer de um KPN sem considerar todas as entradas possiveis. Cada entrada pode exigir um agendamento diferente. Desta forma, o agendamento em fase de execução deve ser utilizado quando um KPN é implementado.

Um MoC que seja utilizado em um fluxo de projeto, orientado a prever o desempenho do sistema, deve ter técnicas de análise suficientemente rápidas. Além disso, o modelo deve permitir uma implementação eficiente visto que a aplicação modelada no $\mathrm{MoC}$ deve ser realizada em uma plataforma, enquanto minimiza-se o uso de recursos. A modelagem de aplicações no MoC utilizado também deverá ser tão simples quanto possivel, a fim de permitir que os projetistas descrevam as diferentes aplicações da maneira mais natural.

O primeiro requisito é cumprido pelo $\mathrm{HSDF}, \mathrm{SDF}$, grafos de computação e o CSDF. O MoC HSDF não foi escolhido dado que os respectivos modelos das aplicações reais podem se tornar muito grandes. Considere-se, por exemplo, o descodificador H.263 discutido no começo desta seção, cuja análise levaria a algoritmos muito demorados para serem úteis na prática, apesar da sua complexidade de tempo polinomial.

\subsubsection{Modelos Dinâmicos de Eventos Discretos}

Em principio, um evento é algo que ocorre durante a execução de uma aplicação, de modo que qualquer alteração em um sistema pode ser definida como um evento. Como uma noção básica do conceito de evento, neste trabalho será utilizada a seguinte definição amplamente aceita na literatura [KRANZLMÜLLEROO]: 


\section{Definição - Evento:}

Um evento é definido como uma ação sem duração que ocorre em um ponto específico no tempo e muda o estado de um processo.

Desta forma, um evento é caracterizado como uma expressão para a mudança de estado de uma aplicação. Isso enfatiza a declaração dada acima, de que um evento pode realmente ser a ocorrência de qualquer coisa, ou, para ser mais preciso, pode expressar qualquer mudança de estado que ocorre durante a execução da aplicação. Note-se que a mudança de estado é descrita pelo acontecimento do novo estado, ou melhor, quando o novo estado inicialmente ocorre. Assim, um evento não pode fornecer informação alguma sobre o estado prévio, embora ele identifique a transição do estado prévio ao estado atual.

Além disso, um evento é um item virtual, uma vez que não precisa de tempo algum para a sua existência, porém ele define o instante em que algo acontece. Ele existe apenas para marcar um determinado acontecimento ao longo do tempo [KRANZLMÜLLER00]. A tabela 2.1 apresenta alguns exemplos de eventos que podem acontecer dentro de uma aplicação.

\begin{tabular}{|c|c|}
\hline Evento & Dados envolvidos \\
\hline Início de um processo & Parâmetros de entrada... \\
\hline Terminação de um processo & Resultados, parâmetros de saída... \\
\hline Envio de mensagem & Fonte, destino, tipo de mensagem, parâmetros... \\
\hline Recepção de mensagem & Fonte, destino, tipo de mensagem, parâmetros... \\
\hline Falha & Número do processo, número da falha, dados da falha... \\
\hline Evento/ação definida pelo usuário & Valor retornado do evento \\
\hline Gerador de números aleatório & Nome do arquivo, modo de acesso, tamanho do buffer... \\
\hline Abrir arquivo & Manipulador do arquivo \\
\hline Fechar arquivo & Manipulador do arquivo, registro que foi lido \\
\hline Leitura de arquivo & Manipulador do arquivo, registro a ser escrito \\
\hline Escrita a um arquivo & Tipo de mensagem, conteúdo das mensagens em espera \\
\hline Inspeção de mensagens em espera & Eventos relacionados ao sistema \\
\hline Eventos do sistemas & Eventos temporários requeridos para a depuração \\
\hline Eventos de depuração & \\
\hline
\end{tabular}

Tabela 2.1: Tipos de eventos e seus dados associados 


\subsubsection{Grafos de Eventos Temporizados}

Um Grafo de Eventos Temporizados (TEG, Timed Event Graph) é uma Rede de Petri (RP) ${ }^{5}$ na qual cada lugar (place da RP) tem exatamente uma transição de entrada e uma transição de saída [RAISCH09]. É possível escrever as equações lineares de estado do grafo sob uma notação de operações $(\min ,+)^{6}$ ou $(\max ,+)^{7}$ que descrevem os disparos das transições de um TEG enquanto ele segue a semântica de execução "Just In Time”. Para se obter um modelo linear, é possivel associar para cada transição $x$, uma função counter, a qual é um mapeamento $\mathbb{Z} \rightarrow \mathbb{Z}_{\text {min }}, \quad t \mapsto x(t)$, que oferece o número de vezes que a transição $x$ tenha sido disparada até o tempo $t$; ou paralelamente uma função dater, a qual é um mapeamento $\mathbb{Z} \rightarrow \mathbb{Z}_{\text {max }}, k \mapsto x(k)$, que oferece o momento no tempo do seu $k$-ésimo disparo. Visto que nos Sistemas Dinâmicos de Eventos Discretos ${ }^{8}$ (Discrete Event Dynamic Systems, DEDS) os estados são finitos e o tempo é discreto [BACCELLI01, COHEN89], considera-se que as funções daters e counters têm valores inteiros. Isto fica ilustrado através do seguinte exemplo:

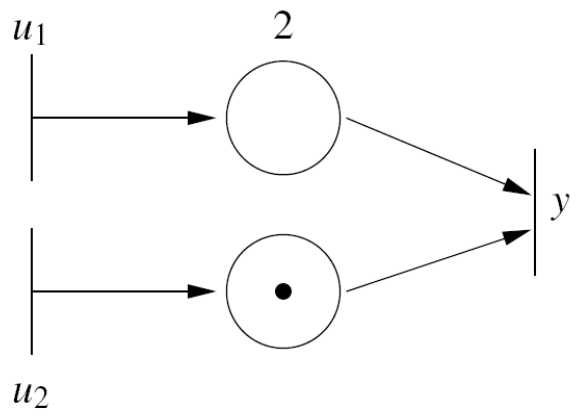

Figura 2.9: Um TEG simples, definido com dois lugares (places), duas transições de entrada $u_{1}$ e $u_{2}$ e uma transição de saída $y$ [CORRÉİA09].

Considere-se o TEG da Figura 2.9. O comportamento da transição y é descrito como se segue:

- Como uma função dater definida como:

\footnotetext{
${ }^{5}$ Também é comum denotar as Redes de Petri como PN, se referindo ao termo em inglês Petri Nets.

${ }^{6}$ Conhecida também como operação ou Álgebra de Min-Plus [CORRÉİA09].

${ }^{7}$ Conhecida também como operação ou Álgebra de Máx-Plus [CORRÉİA09].

${ }^{8}$ Tais como sistemas flexíveis de produção, redes de telecomunicações, sistemas de multiprocessamento, redes ferroviárias, sistemas inteligentes de transporte, redes de computadores, entre outros.
} 


$$
\begin{aligned}
y(k) & =\max \left(u_{1}(k)+2, u_{2}(k-1)\right) \\
& =2 \otimes u_{1}(k) \oplus u_{2}(k-1) \text { Em notação de Max-Plus }{ }^{9}
\end{aligned}
$$

Nste caso, $y(k)$ indica que o tempo de disparo da transição $y$ será definido pelo maior dos tempos de produção dos tokens que chegam de cada lugar de entrada da transição $y$. Os tokens do lugar mais acima terão um tempo correspondente ao tempo da transição $u_{1}$, mais duas unidades de tempo que demora o lugar em liberar o seu respectivo token de saída. Igualmente, os tokens do lugar mais abaixo terão um tempo de produção correspondente ao tempo da transição $u_{2}$ adiantado em uma iteração $(k-1)$, devido ao token inicial armazenado neste lugar [COHEN89].

- Ou, como uma função counter definida como:

$$
\begin{aligned}
y(t) & =\min \left(u_{1}(t-2), u_{2}(t)+1\right) \\
& =u_{1}(t-2) \oplus 1 \otimes u_{2}(t) \quad \text { Em notação de Min-Plus }{ }^{10}
\end{aligned}
$$

Neste caso, $y(t)$ indica que o número de vezes que a transição será ativada até o tempo $t$ dependerá do lugar de entrada com o menor número de tokens disponiveis para serem consumidos pela transição $y$. Assim, o lugar mais acima terá disponivel a quantidade de tokens gerados pela transição $u_{1}$ em um tempo $t-2$; e o lugar mais abaixo terá um número disponivel de tokens dado pela quantidade de tokens geradas pela transição $u_{2}$, mais um token inicial previamente armazenado neste lugar. Visto que a transição só poderá disparar enquanto houver tokens disponiveis nos seus lugares de entrada, a quantidade de tokens gerados pela transição y será igual ao número de vezes que a transição disparar, o que é igual ao número de tokens daquele lugar que tiver a menor quantidade de tokens até o tempo $t$ [COHEN89].

\footnotetext{
${ }^{9}$ Seção 4.3.1.1, desta tese.

${ }^{10}$ Referência [CORRÉİA09].
} 


\subsection{ANÁLISE DE DESEMPENHO}

\subsubsection{Análise de Desempenho Modular (MPA)}

A Análise de Desempenho Modular (Modular Performance Analysis, MPA) [WANDELER06a] é uma abordagem que constrói um modelo de desempenho de um sistema, capturando as propriedades dos seus diferentes elementos, de modo tal que o modelo pode ser empregado para análise utilizando a metodologia de Real-Time Calculus.

Real-Time Calculus baseia-se no arcabouço teórico chamado Network Calculus [BOUDEC01], o qual permite aos projetistas especificar um sistema como um modelo matemático, e avaliar as principais restrições de desempenho tais como o atraso end-to-end. Esta teoria é baseada na álgebra MinPlus (min, +), e é proposta principalmente para a análise de desempenho de sistemas determinísticos, especialmente para a análise do "pior-caso". Real-Time Calculus estende os conceitos básicos de Network Calculus para o domínio de sistemas embarcados de tempo real [THIELEOO].

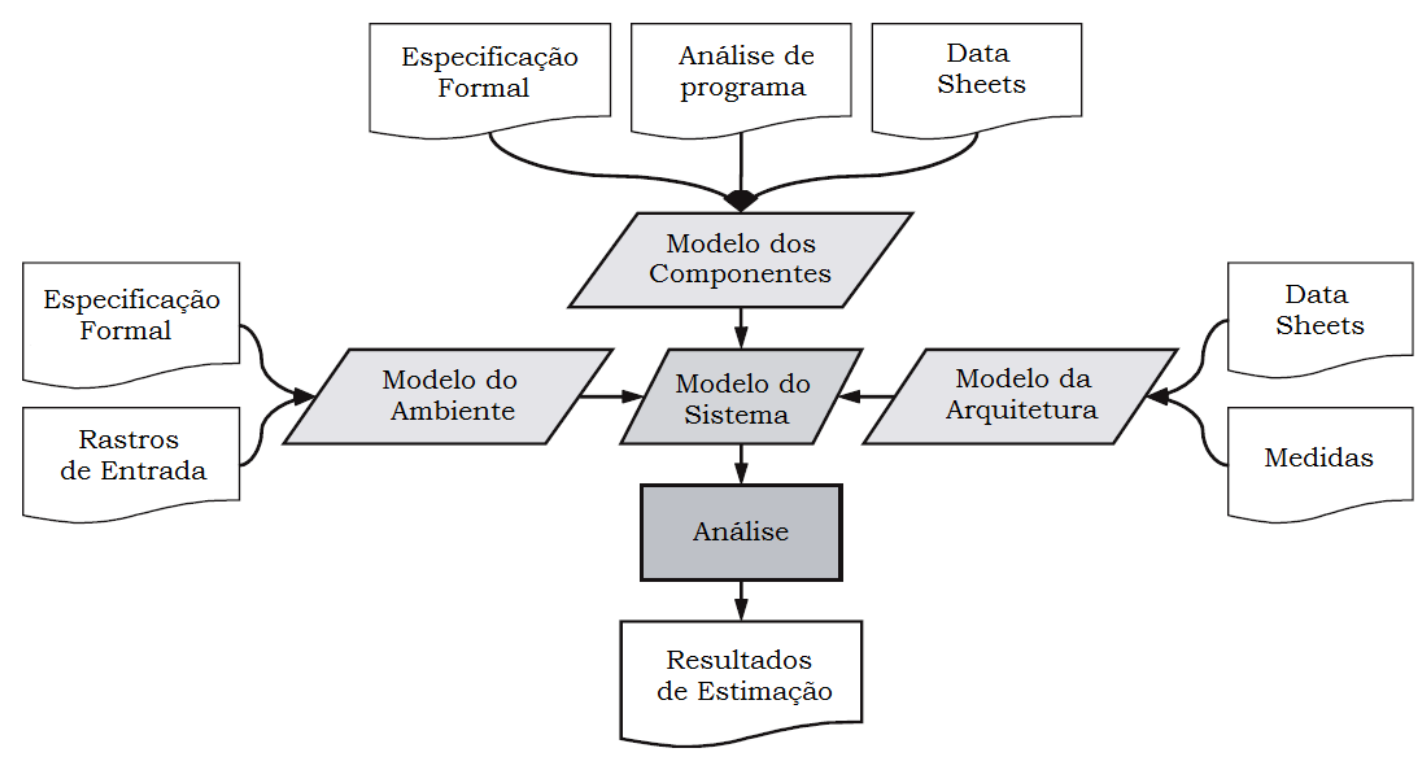

Figura 2.10: Visão geral da abordagem de Análise Modular de Desempenho (MPA) [WANDELER06a].

A Figura 2.10 apresenta uma visão geral da abordagem de MPA [WANDELER06a], onde os modelos de desempenho são construídos usando três elementos básicos abstratos: as curvas de chegada, que modelam o ambiente (fluxos de eventos que chegam e saem); as curvas de serviço, que 
modelam a capacidade dos recursos (Modelo da Arquitetura); e os componentes abstratos, os quais definem a semântica de execução da tarefa dentro do sistema (Modelo do Componente). As seções a seguir dão uma breve introdução a estes elementos básicos e aos métodos de análise.

\subsubsection{Modelo do Ambiente}

\subsection{O Modelo de Fluxo de Eventos}

Em um fluxo de eventos, cada evento tem um tempo relacionado ao momento de sua ocorrência. Além disso, é possivel definir uma classificação de diferentes tipos de eventos para todos os eventos que podem ser encontrados em um fluxo de entrada, de modo que no modelo do sistema as atividades e exigências de recursos criadas por um determinado evento dependerão do seu respectivo tipo de evento. Essa informação temporal abstrata de um fluxo de eventos é capturada utilizando o conceito de curvas de chegada, superior e inferior [CRUZ91].

Definição - Curvas da chegada: Seja $R[s, t)$ o número de eventos que chega dentro de um fluxo de eventos, no intervalo de tempo $[s, t)$. Então, $R$ e as curvas de chegada inferior e superior, $\overline{\boldsymbol{\alpha}}^{\boldsymbol{l}}$ e $\overline{\boldsymbol{\alpha}}^{\boldsymbol{u}}$, estão relacionados uns com outros pela seguinte desigualdade:

$$
\overline{\boldsymbol{\alpha}}^{l}(\boldsymbol{t}-\boldsymbol{s}) \leq R[\boldsymbol{s}, \boldsymbol{t}) \leq \overline{\boldsymbol{\alpha}}^{u}(\boldsymbol{t}-\boldsymbol{s}), \quad \forall \boldsymbol{s}<\boldsymbol{t} \quad(2.4)
$$

Onde $\overline{\boldsymbol{\alpha}}^{l}(\mathbf{0})=\mathbf{0}, \overline{\boldsymbol{\alpha}}^{\boldsymbol{u}}(\mathbf{0})=\mathbf{0}$

A informação de temporização dos modelos padrões de eventos - tais como o modelo periódico, periódico com jitter, periódico com rajada, esporádico, ou de qualquer fluxo de eventos com um comportamento temporal conhecido - pode ser representada por uma escolha apropriada de $\overline{\boldsymbol{\alpha}}^{\boldsymbol{l}}$ e $\overline{\boldsymbol{\alpha}}^{\boldsymbol{u}}$ [CHAKRABORTY03]. Além disso, também é possivel determinar os valores de $\overline{\boldsymbol{\alpha}}^{\boldsymbol{l}}$ e $\overline{\boldsymbol{\alpha}}^{\boldsymbol{u}}$ correspondentes a qualquer rastro (trace) de eventos arbitrários e de dimensão finita obtidos, por exemplo, a partir da observação ou simulação. 
Definição - Autômato de Eventos: Um autômato de eventos $F_{\sigma}$ é uma tupla $\left(S, S_{0}, \Sigma, T\right)$, onde $S$ é um conjunto de estados, $S_{0} \subseteq S$ é um conjunto de estados iniciais, $\Sigma$ é um conjunto de tipos de eventos, e $T \subseteq S \times \Sigma \times S$ é um conjunto de transições [WANDELER05a, WANDELER05b]. O sistema começa em um estado inicial, e, se $s \stackrel{\sigma}{\rightarrow} s^{\prime}$ então um evento $\sigma$ pode ocorrer no fluxo de eventos, levando a uma mudança de estado de $s$ para $s^{\prime}$.

A informação funcional de um fluxo de eventos pode ser obtida a partir de sua especificação formal, ou, algumas vezes, também pode ser possível descobrir padrões de sequência em um rastro (trace) de eventos, de dimensão finita, os quais podem ser transformados em um autômato de eventos.

Quando é dado um modelo de fluxo de eventos como aquele definido na seção anterior, descrito por $\overline{\boldsymbol{\alpha}}^{\boldsymbol{l}}, \overline{\boldsymbol{\alpha}}^{\boldsymbol{u}}$ e $F_{\sigma}$, será então inferido que em qualquer intervalo de tempo de comprimento $\Delta$, pelo menos $\overline{\boldsymbol{\alpha}}^{\boldsymbol{u}}(\Delta)$, e no máximo $\overline{\boldsymbol{\alpha}}^{\mathrm{l}}(\Delta)$, número de eventos estarão chegando dentro do fluxo, e que a possível sequência de eventos de chegada estará limitada por corridas apropriadas de comprimento $\Delta$, dada pelo autômato de eventos $F_{\sigma}$.

\subsubsection{Modelo de Elemento Arquitetural}

Dado um fluxo de dados que atravessa um sistema que contém um único elemento de processamento (PE), seja $A$ sua função cumulativa de chegada (isto é, $A(t)$ é o número de itens de dados que chegaram até o tempo $t$ ); e seja $D$ a função cumulativa de partida do fluxo, definida de forma semelhante pelo número $D(t)$ de itens que deixaram o $\mathrm{PE}$ até o tempo $t$, o sistema fornece uma curva (minima) de serviço $\boldsymbol{\beta}, \boldsymbol{D}(\boldsymbol{t}) \geq \boldsymbol{A} \otimes \boldsymbol{\beta}{ }^{11}$.

A fim de se caracterizar as capacidades de processamento do sistema, é possivel usar $\boldsymbol{C}[\boldsymbol{s}, \boldsymbol{t})$ para representar o número de unidades de processamento, ou de comunicação, disponíveis a partir de PE no intervalo de tempo $[\boldsymbol{s}, \boldsymbol{t})$, de modo que as curvas de serviço inferior e superior, $\boldsymbol{\beta}^{\boldsymbol{l}}$ e $\boldsymbol{\beta}^{\boldsymbol{u}}$, obedeçam a desigualdade:

\footnotetext{
${ }^{11}$ No contexto de Real-Time Calculus e Álgebra Min-Plus, esta operação corresponde à convolução $(f \otimes g)(t):=\inf _{0 \leq \tau \leq t}\{f(\tau)+g(t-\tau)\}$ [BOUDEC01].
} 


$$
\beta^{l}(t-s) \leq C[s, t) \leq \beta^{u}(t-s), \quad \forall s<t
$$

Onde $\boldsymbol{\beta}^{l}(\mathbf{0})=\boldsymbol{\beta}^{\boldsymbol{u}}(\mathbf{0})=\mathbf{0}$.

Casos particulares de curvas de serviço são as funções de pico de taxa, com taxa $r$ (o sistema pode processar $r$ itens por unidade de tempo, e $\boldsymbol{\beta}(\boldsymbol{\Delta})=\boldsymbol{r} \bullet \boldsymbol{\Delta}$ ), e as curvas de serviço de atraso puro com atraso $d: \boldsymbol{\beta}(\boldsymbol{\Delta})=\mathbf{0}$ se $t<d$, e $\boldsymbol{\beta}(\boldsymbol{\Delta})=+\infty$ em outros casos [WANDELER05a]. A combinação dessas duas curvas de serviço dá uma função de taxa-latência:

$$
\beta: t \rightarrow R(\Delta-T)^{+}
$$

onde a+ denota $\max (\boldsymbol{a}, \mathbf{0})$.

As curvas de serviço de um recurso podem ser determinadas utilizando databooks, usando propriedades derivadas analiticamente, ou usando medições. No caso mais simples de um processador sem carga, tanto as curvas do recurso superior e inferior são iguais a uma função de pico de taxa, representada por linhas retas $\boldsymbol{\beta}^{\boldsymbol{u}}(\boldsymbol{\Delta})=\boldsymbol{\beta}^{\boldsymbol{l}}(\boldsymbol{\Delta})=\boldsymbol{f} \cdot \boldsymbol{\Delta}$, onde $f$ é igual à frequência do processador, isto é, o número de ciclos de processamento disponiveis por unidade de tempo [WANDELER05a].

Uma maior discussão sobre o modelo geral de Curva de Serviço é dada na seção 2.2.2, a fim de colocar as bases do modelo de curvas de serviços baseadas em cenários proposto na seção 5.3 .2 do capítulo 5 .

\subsubsection{Componentes Abstratos e o Real-Time Calculus}

Os componentes abstratos são os blocos básicos para a construção de um modelo de desempenho de um sistema. Eles modelam as tarefas da aplicação em um sistema concreto e definem a semântica de como as tarefas da aplicação são executadas nos elementos arquiteturais. Ao mesmo tempo, eles também constroem as bases para a análise de desempenho.

Uma semântica de execução muito comum para as tarefas de uma aplicação em sistemas embarcados é a computação preemptiva gananciosa (Greedy Preemptive Computation), onde um componente é ativado pelos eventos de um fluxo de eventos de entrada. Uma tarefa pré-conhecida é instanciada com cada chegada de um evento a fim de processar o evento de entrada, e as tarefas 
ativas são processadas em ordem FIFO, enquanto elas ficam restritas pela disponibilidade de recursos.

$\mathrm{Na}$ abordagem apresentada, os componentes concretos são modelados por componentes abstratos com um conjunto de relações internas que transformam as curvas de chegada, $\alpha$, e as curvas de serviço, $\beta$, em curvas de chegada de saída $\alpha^{\prime}$, e em curvas de serviço $\beta^{\prime}$, de acordo com a semântica de execução do componente concreto.

Em Real-Time Calculus, o atraso máximo $\boldsymbol{d}_{\max }$ experimentado por um fluxo de eventos com uma curva de chegada superior $\alpha^{u}$, que é processada em um componente abstrato com semântica de computação pré-emptiva, e com uma curva de serviço inferior, $\boldsymbol{\beta}^{\boldsymbol{l}}$, é limitado pela distância horizontal máxima entre $\boldsymbol{\alpha}^{\boldsymbol{u}}$ e $\boldsymbol{\beta}^{\boldsymbol{l}}$ [WANDELER06a] dado por:

$$
d_{\text {max }} \leq \sup _{t \geq 0}\left\{\inf \left\{\tau \geq 0: \alpha^{u}(t) \leq \beta^{l}(t+\tau)\right\}\right\}
$$

Analogamente, o espaço máximo de buffer $\boldsymbol{b}_{\max }$ que é necessário para armazenar esse fluxo de eventos é delimitado pela distância vertical máxima entre $\boldsymbol{\alpha}^{\boldsymbol{u}}$ e $\boldsymbol{\beta}^{\boldsymbol{l}}$ [WANDELER06a] dada por:

$$
b_{\max }=\sup _{\lambda \geq 0}\left\{\alpha^{u}(\lambda)-\beta^{l}(\lambda)\right\}
$$

A Figura 2.11 apresenta graficamente as relações entre $\alpha, \beta, d_{\max }$ e $b_{\max }$.

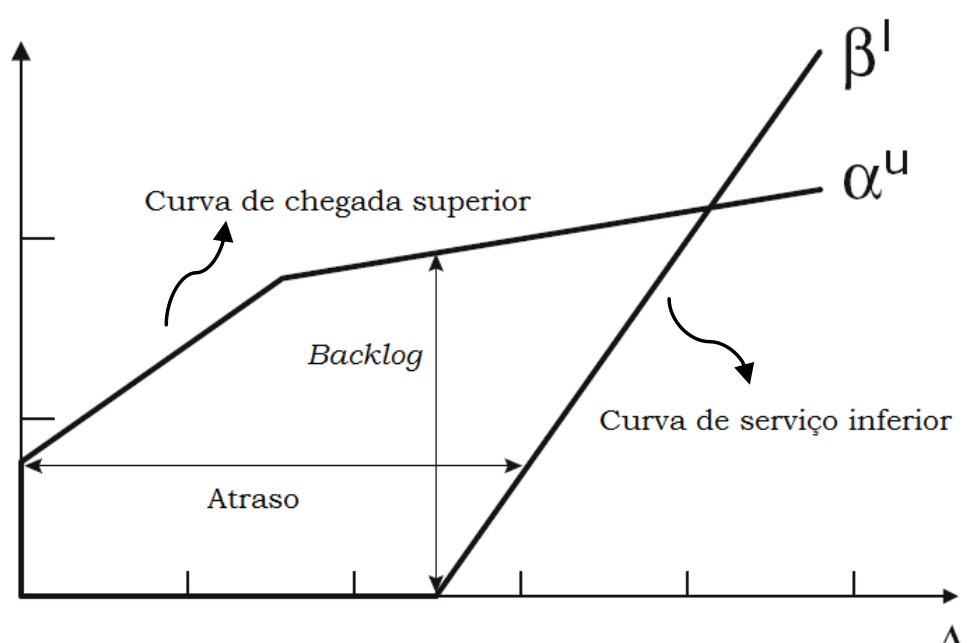

Figura 2.11: Atraso e Backlog obtidos a partir da curva de chegada e curva de serviço [WANDELER05a]. 
É possivel conectar componentes abstratos em uma rede de acordo com o modelo do sistema que é obtido após o mapeamento e o agendamento de várias aplicações sobre uma arquitetura de sistema. Os fluxos de eventos que saem dos componentes abstratos (tarefas) podem ser conectados a uma entrada de fluxo de eventos de outro componente e, de modo semelhante, a capacidade de recurso que não é consumida por um componente abstrato pode ser conectada à entrada de recurso de um componente abstrato de prioridade mais baixa. Em conjunto com os modelos de todos os recursos do sistema (curvas de serviço) e fluxos de eventos que entram (curvas de chegada), o modelo de desempenho de um sistema completo é obtido.

\subsubsection{Modelo de Curvas de Serviços}

Nos últimos anos, as curvas de serviços têm se mostrado um modelo poderoso e versátil para análise de desempenho dos elementos de rede, tais como escalonadores, enlaces e formadores de tráfego, e até redes inteiras de computadores como a Internet. A elegância do conceito de curva de serviço é devida às fórmulas intuitivas de convolução que determinam as saídas de dados de um sistema a partir da suas entradas e da sua curva de serviço (como mencionado na seção 2.2.1.2).

Esta relação fundamental constitui a base do modelo de Network Calculus [BOUDEC01] e o relaciona com a teoria de sistemas clássicos, no entanto, sob uma visão matemática diferente chamada de Álgebra Min-Plus (também conhecida como Álgebra Tropical [SIMON88]) ${ }^{12}$. Tal como na teoria de sistemas clássicos, a força particular da convolução Min-Plus é a capacidade de concatenar um conjunto de sistemas ao longo de uma rota de rede. Isto facilita a noção de Curva de Serviço de Rede, a qual tem a expressividade para caracterizar redes inteiras através de uma única função de transferência [MARKUS10].

O modelo de curva de serviço descreve os elementos da rede, como roteadores, escalonadores e enlaces, usando funções do tempo que especificam o serviço que é oferecido pelo elemento durante um intervalo de tempo definido. De modo semelhante à teoria de sistemas, as curvas de serviços podem ser vistas

\footnotetext{
${ }^{12}$ A álgebra de Min-Plus foi desenvolvida na década dos 80's pelo matemático e cientista da computação Imre Simon (Prof. da USP, 1984-2002). Com o tempo a álgebra de Min-Plus tem recebido também o título de "Álgebra Tropical", só como uma referência ao Brasil.
} 
como a resposta ao impulso de um sistema linear. Na álgebra Min-Plus, a saída de dados de um elemento de rede pode ser calculada a partir da convolução da função de chegada e a curva de serviço do sistema. Esta forma de convolução é significativa, uma vez que ela estabelece um arcabouço geral para a análise de redes inteiras. Os sistemas individuais ao longo de uma rota de rede podem ser facilmente concatenados pela convolução das suas curvas de serviço, produzindo uma curva de serviço de rede que especifica o serviço disponivel fim-a-fim.

Intimamente relacionada com a álgebra Min-Plus é a álgebra Max-Plus, a qual é detalhada no livro de Baccelli et al. [BACCELLIO1], sendo apresentada brevemente na seção 4.3.1.1 da presente tese.

\subsubsection{Generalização de Curva de Serviço}

O modelo de Network Calculus define o conceito de curva de serviço $S(t)$ para modelar o serviço que é fornecido por um sistema. A noção de curva de serviço foi introduzida em [PAREKH93], e ainda mais generalizada e formalizada em [MARKUS10]. Diz-se que um sistema, tal como o mostrado na Figura 2.12, oferece $S(t)$ como uma curva de serviço, se para todo $t \geq 0$ ela satisfaz:

$$
D(t) \geq \min _{\tau \in[0, t]}\{A(\tau)+S(t-\tau)\}=: A \otimes S(t)
$$

onde $A(t)$ é a função acumulativa de chegada, $D(t)$ é a função acumulativa de saída, e o operador $\otimes$ é referido como a convolução Min-Plus. As curvas de serviço têm se mostrado um modelo útil para uma variedade de sistemas frequentemente utilizados em redes de computadores [MARKUS10].

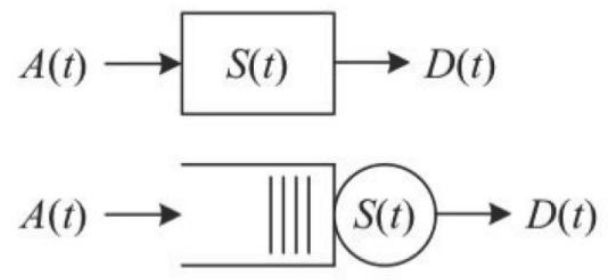

Figura 2.12. Um sistema de filas, como curva de serviço $S(t)$, chegadas $A(t)$ e saidas $D(t)$.

No caso de um enlace com taxa constante $R$, a curva de serviço corresponde a $S(t)=R \cdot t$. Além deste exemplo, a função de Latência-Taxa $S(t)=R[t-T]^{+}$, onde $[x]^{+}=\max \{0, x\}$, pode ser usada para modelar um enlace com capacidade 
$R$ e atraso de propagação $T$, ou um escalonador como aquele chamado de Enfileiramento Justo Ponderado (Weighted Fair Queuing, WFQ) que atribui uma taxa de $R$ a certa classe de tráfego sujeita a uma latência $T$ [STILIADIS98].

Visto que a Eq.(2.8) fornece um limite inferior para o processo de saída, a curva de serviço definida é também chamada frequentemente de curva inferior de serviço. Do mesmo modo, as curvas superiores de serviço podem ser definidas para fornecer um limite superior nas saídas. Se um sistema implementa $S(t)$ tanto como a curva inferior e a curva superior de serviço, a Eq.(2.8) considera só a componente de igualdade, e $S(t)$ é referida como uma Curva Exata de Serviço. Exemplos de sistemas que implementam uma curva exata de serviço são aqueles mencionados previamente de enlaces de taxa constante $S(t)=R \cdot t$ e os escalonadores Latência-Taxa $S(t)=R[t-T]^{+}$ [STILIADIS98], mencionados também na seção 2.2.1.2.

\subsubsection{Concatenação fim-a-fim de um conjunto de sistemas}

Uma propriedade muito importante de Network Calculus é a extensão do conceito de curva de serviço de um único sistema, para um número arbitrário de sistemas em série. Isto facilita uma aplicação imediata dos resultados obtidos em nós isolados, tais como os valores de limites de desempenho mostrados antes, para as redes inteiras.

O processo de saída de um conjunto de dois sistemas com curvas de serviço $S_{1}$ e $S_{2}$, respectivamente, pode ser calculado através da inserção recursiva, tal que $D(t) \geq\left(A \otimes S_{1}\right) \otimes S_{2}(t)$. Visto que a convolução Min-Plus é uma operação associativa, é possivel escrever $D(t) \geq A \otimes\left(S_{1} \otimes S_{2}\right)(t)$. Por extensão, segue que uma rede composta de $n$ curvas de serviço $S_{i}, \operatorname{com} i=1 \ldots n$ em série, como mostrado na Figura 2.13 é equivalente a um único sistema com curva de serviço:

$$
S_{\text {net }}(t)=S_{1} \otimes S_{2} \otimes \cdots \otimes S_{n}(t)
$$

onde $S_{n e t}$ é referido como a curva de serviço da rede. Devido a comutatividade da convolução Min-Plus, a ordem de sistemas não tem nenhum efeito sobre a curva de serviço da rede, de modo que, por exemplo, dado um enlace gargalo, a sua localização dentro da rede não importa. 


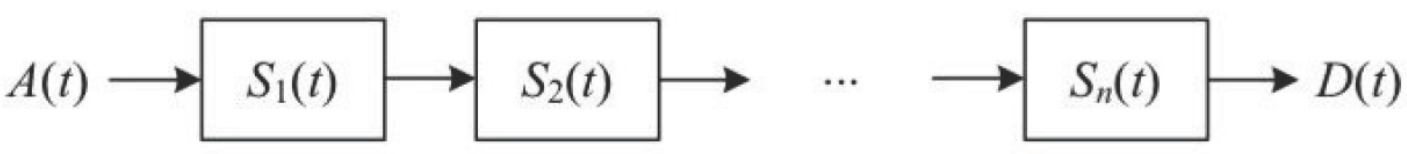

Figura 2.13: Conjunto de sistemas em série que pode ser combinado em um único sistema pela convolução de suas curvas de serviço.

Intimamente relacionada com o Network Calculus baseado em Min-Plus é a formulação baseada na álgebra Max-Plus [BACCELLIO1] onde os tempos de chegada são vistos como uma função de dados, de modo que, por exemplo, $T_{A}(n)$ indica o tempo de chegada do pacote número $n$. A função $T_{A}(n)$ é o pseudo-inverso da função de chegada correspondente $A(t)$, na álgebra MinPlus. Visto que o arcabouço de Max-Plus utiliza a noção de pacotes, ele facilita naturalmente um tratamento de pacotes de tamanho variável, o qual permite avaliar métricas de desempenho diferentes àquelas encontradas com Network Calculus. Muitos dos conceitos referentes à modelagem baseada em curvas de serviços podem ser espelhados na álgebra Max-Plus, criando o conceito de modelagem no domínio do tempo [JIANG08].

\subsubsection{Teoria de sistemas sob a visão da Álgebra de Min- Plus}

Nesta seção é apresentado o modo como o conceito de curva de serviço se relaciona à teoria de sistemas. Diferentes propriedades algébricas importantes da convolução Min-Plus são apresentadas.

\subsubsection{Sistemas Lineares em Min-Plus de Tempo Invariável.}

A teoria básica de sistemas lida com sistemas lineares invariantes no tempo. Considerando pares de sinais de entrada e de saída correspondentes, $(A, D)$ de um sistema, a invariância no tempo significa que uma versão deslocada no tempo de um sinal de entrada de $A(t-\tau)$ resulta em um deslocamento consequente, mas do resto, um sinal idêntico na saída $D(t-\tau)$. Um sistema é linear, se qualquer combinação linear de sinais de entrada $c_{1} A_{1}+c_{2} A_{2}$, resulta em uma combinação linear correspondente de sinais de saída $c_{1} D_{1}+c_{2} D_{2}$ onde $c_{1}, c_{2}$ são constantes. Se, e só se, um sistema é invariante no tempo e linear, o sinal de saída do sistema é dado por:

$$
D(t)=\int_{-\infty}^{\infty} A(t) \cdot S(t-\tau) d \tau=A * S(t)
$$


Onde * é o operador de convolução e $S(t)$ é a resposta do sistema para um impulso unitário de Dirac $\delta(t)$. O impulso de Dirac é definido como infinito em $t=0$, zero nos demais casos, e $\int_{-\infty}^{\infty} \delta(t) d t=1$. Ele é o elemento neutro da convolução.

A semelhança com a definição de curva de serviço torna-se aparente se a Eq.(2.10) for reformulada seguindo a notação da álgebra Min-Plus. Aqui, a soma toma o lugar da multiplicação e o mínimo (inf) toma o lugar da soma, respectivamente, de modo que a definição da curva exata de serviço é derivada:

$$
D(t)=\min _{\tau}\{A(\tau)+S(t-\tau)\}=A \otimes S(t)
$$

A curva de serviço $S(t)$ é a resposta do sistema, se o sinal de entrada é um impulso de variabilidade, o qual é definido como

$$
\delta(t)= \begin{cases}0 & \text { para } t \leq 0 \\ \infty & \text { para } t>0\end{cases}
$$

Por brevidade, utiliza-se a notação $\delta(t)$, para significar o impulso de Dirac, ou o impulso de variabilidade em função da álgebra que seja utilizada. Do mesmo modo que o impulso de Dirac, o impulso de variabilidade é o elemento neutro da convolução Min-Plus ${ }^{13}$, isto é:

$$
\delta \otimes S(t)=S(t)
$$

Do mesmo modo, as curvas inferior e superior de serviço também podem ser utilizadas para limitar o serviço oferecido por um sistema de tempo variável [MARKUS10].

Visto que no modelo de Network Calculus, a descrição comportamental dos recursos é baseada na álgebra de Min-Plus, as expressões matemáticas resultantes correspondem a funções counters $^{14}$, de modo que a curva de serviço, denotada neste contexto como $S(t)$, caracteriza a quantidade de serviço (trabalho) que um recurso pode executar em um determinado intervalo de tempo $t$.

\footnotetext{
${ }^{13}$ Em notação de álgebra de Min-Plus, o valor $\delta(t)=\infty$ seria anotado como $\delta(t)=\varepsilon$, definido como o elemento-zero da álgebra de Min-Plus [RAISCH09].

${ }^{14}$ A função Counter é definida no contexto de Grafos de Eventos Temporizados (seção 2.1.8.1), quando analisados através da álgebra de Min-Plus.
} 
No caso dos modelos baseados em eventos discretos, como os modelos de SDF e SADF, a descrição comportamental dos atores (recursos) é baseada na álgebra de Max-Plus, de modo que as expressões matemáticas resultantes da análise do sistema correspondem a funções daters ${ }^{15}$. Neste caso, uma curva de serviço é denotada como $S(n)$, tal que o serviço caracterizado corresponde à quantidade de tempo que o ator precisa para processar um conjunto de $n$ eventos de entrada. A utilização deste conceito de curva de serviço é apresentada no capítulo 5 da presente tese para propor um novo modelo de curvas de serviço baseadas em cenários para modelos de SADF.

\subsubsection{Análise de Desempenho em Modelos de SDF}

\subsubsection{Análise de Vazão}

A análise de vazão de grafos de SDF tem sido extensivamente estudada na literatura [DASDAN04, DASDAN98, KARP78, REITER68, YOUNG91, GHAMARIAN06a]. A maioria dessas abordagens de análise baseia-se em algoritmos suportados em uma análise da estrutura dos grafos. A desvantagem dessas abordagens é que elas não são diretamente aplicáveis aos grafos de SDF, sendo só aplicáveis a um tipo especial de SDFs, a saber, os SDFs Homogêneos (HSDF). Desta forma, a análise de vazão precisa de uma conversão de um SDF para um HSDF equivalente, o qual é sempre possível na teoria, mas que frequentemente conduz a um aumento proibitivamente grande no tamanho do grafo, fazendo com que os algoritmos deixem de produzir uma estimativa correta da vazão.

\subsubsection{Espaço de Estado de Grafos de SDF}

Em [GHAMARIAN06a], é proposto um método alternativo para medir a vazão nos grafos de SDF, no qual, ao contrário de outros métodos existentes, trabalha diretamente sobre o grafo de SDF, evitando a conversão dispendiosa para um HSDF e o crescimento exponencial do grafo a ser analisado. $O$ método baseia-se na exploração explícita do espaço de estado a fim de encontrar a vazão. No entanto, apesar de o número de estados que precisam ser gerados e armazenados também pode ser grande nas situações do pior-

\footnotetext{
${ }^{15}$ A função Dater é definida no contexto de Grafos de Eventos Temporizados (seção 2.1.8.1), quando analisados através da álgebra de Max-Plus.
} 
caso, as experiências mostram que na prática o método possui um bom desempenho.

\section{Definição - Grafo de SDF:}

Seja $N_{o}=\{0,1, \ldots\}\left(e N=N_{o} \backslash\{0\}\right)$ o conjunto dos números naturais. Um grafo de SDF $G$ é um par $(A, C)$ onde $A$ é um conjunto de atores, e $C \subseteq A^{2} x N^{2}$ é um conjunto de canais. Cada canal $(s, d, p, c) \in C$ denota que o ator $s$ é comunicado com ator $d$, onde $p$ e $c$ são as taxas de produção e consumo, respectivamente. Os canais que conectam o ator $s$ com algum outro ator $d$, são chamados canais de saída de $s$ e canais de entrada de $d$ [GHAMARIANO6a].

\section{Definição - Grafo de SDF Temporizado:}

Para permitir a análise do desempenho, um grafo de SDF é anotado com informações de tempo. Um grafo de $\operatorname{SDF}$ temporizado é uma tripla $(A, C, T)$, com $(A, C)$ um grafo de SDF, e $T: A \rightarrow N_{0}$ um mapeamento do tempo de execução que associa a cada ator $a \in A$, a quantidade de tempo $T(a)$ que precisa para disparar, isto é, o tempo de execução de $a$ [GHAMARIANO6a].

\section{Definição - Estado de Canal:}

Um estado (de canal) $S$ de $G$ é um mapeamento $S: C \rightarrow N_{0}$ que associa a cada canal, o número de tokens disponíveis nesse canal. Cada grafo de SDF tem um estado inicial denotado por $S_{0}$, fornecendo o número de tokens inicialmente disponiveis em cada canal [GHAMARIAN06a].

Dado que, na modelagem em SDF, o interesse está na análise temporal e não, por exemplo, na análise funcional, a modelagem feita é abstraída dos dados reais que estão sendo comunicados [GEILEN11b]. A fim de capturar o comportamento temporal em um SDF, é necessário fazer um rastreamento da 
distribuição de tokens ao longo dos canais, assim como do início e do fim dos disparos dos atores, e do progresso do tempo durante a execução de um grafo de SDF. A execução de um grafo de SDF é definida com base nos disparos dos atores, o qual pode mudar o estado do grafo de SDF e, portanto, determinar o espaço de estado (alcançável) do grafo. Um ator $a \in A$ do grafo de $\operatorname{SDF}(A, C)$ é ativado no estado $S_{i}$, se $S_{i}$ contém pelo menos $c$ tokens para cada canal de entrada $(s, a, p, c)$ de $a$. Um ator pode disparar quando ele estiver habilitado. $\mathrm{O}$ disparo de $a$ muda o estado $S_{i}$ para $S_{i+1}$, consumindo $c$ tokens de cada canal de entrada $(s, a, p, c)$ e produzindo $p$ tokens em cada canal de saída $(a, d, p, c)$ [GEILEN11b].

A Figura 2.14 apresenta um exemplo de um grafo de SDF temporizado composto por quatro atores (os círculos $a$ até o $d$ ) e seis canais (os arcos entre os atores). Associado com as portas de origem e de destino de cada extremo de canal estão as taxas de entrada (ou saída). Os canais podem conter tokens, representados pelos pontos pretos. Estes canais podem conter um número arbitrário de tokens. As limitações de capacidade podem ser modeladas explicitamente. Neste exemplo, os canais da esquerda para a direita podem ser interpretados como conexões de dados, transportando dados entre os atores, e os arcos na direção oposta, com tokens iniciais, modelam o espaço de buffer disponivel.

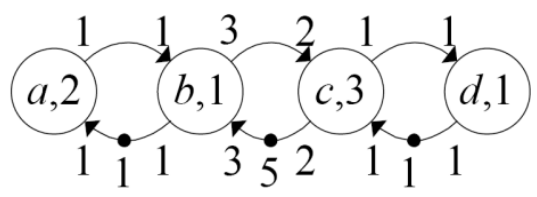

Figura 2.14: Exemplo de um grafo de SDF [GHAMARIAN06a].

Desta forma, a diferença entre o número de disparos de cada ator e o dos seus sucessores pode ser controlado, de modo que isto leva a um número limitado de tokens permitidos nos canais de saida de um ator. Desta forma, o grafo de SDF da Figura 2.14 pode ser interpretado como um modelo de uma aplicação multimídia com quatro tarefas, da $a$ até a $d$, a serem executadas iterativamente de modo pipeline. Os três canais da esquerda para a direita, $a-b, b-c, c-d$, correspondem aos buffers FIFO com tamanhos limitados de 1,5 e 1 , respectivamente, como modelado pelos canais na direção oposta $b-$ $a, c-b, d-c$. Neste grafo os atores $a, b, c$ e $d$ apresentam tempos de execução constantes de 2, 1, 3 e 1, respectivamente; e todas as portas mostram uma 
taxa de escrita e leitura de tokens de 1 , a exceção das portas que comunicam o canal $b-c$, os quais apresentam taxas de escrita e leitura de 3 e 2 respectivamente, assim como no canal $c-b$, o qual apresenta taxas de escrita e leitura de 2 e 3 respectivamente.

\section{Definição - Estado Temporizado:}

Em relação à distribuição de tokens nos canais, define-se o conceito de estado temporizado. Seguindo a definição do estado de canal, o estado temporizado de um grafo de SDF, $G=(A, C, T)$, é um $\operatorname{par}(S, \tau)$, com $S$ um estado de canal, e $\tau$ o tempo acumulado. O estado inicial temporizado de $G$ é $\left(S_{0}, 0\right)$ [GHAMARIANO6a].

\section{Definição - Transição:}

Uma transição do grafo de $\mathrm{SDF}, G=(A, C, T)$, do estado $\left(S_{1}, \tau_{1}\right)$ para o estado $\left(S_{2}, \tau_{2}\right)$, é denotado por $\left(\mathbf{S}_{1}, \boldsymbol{\tau}_{\mathbf{1}}\right) \stackrel{\boldsymbol{\beta}}{\rightarrow}\left(\mathbf{S}_{2}, \boldsymbol{\tau}_{\mathbf{2}}\right)$ onde a etiqueta $\beta \in(A \times\{$ start, end $\}) \cup\{c l k\}$ denota o tipo de transição [GHAMARIAN06a].

\section{Definição - Execução:}

Uma execução $\sigma$ de um SDF é uma sequência infinita de alternância de estados e transições $\mathbf{s}_{\mathbf{0}} \stackrel{\boldsymbol{\beta}_{\mathbf{0}}}{\rightarrow} \mathbf{s}_{\mathbf{1}} \stackrel{\boldsymbol{\beta}_{1}}{\rightarrow}$... começando a partir do estado inicial do grafo, tal que para todos os $n \geq 0, \mathbf{s}_{\mathbf{n}} \stackrel{\boldsymbol{\beta}_{\mathbf{n}}}{\rightarrow} \mathbf{s}_{\mathbf{n}+\mathbf{1}}$. Uma execução temporizada de $G$ é uma sequência (finita ou infinita) de estados temporizados $\left(S_{0}, \tau_{0}\right),\left(S_{1}, \tau_{1}\right), \ldots$ onde $\tau_{i+1} \geq \tau_{i}$. Dois estados temporizados consecutivos correspondem ao disparo de um ator $a$ que iniciou seu disparo em $\tau_{i+1}-T(a)$ e termina o disparo em $\tau_{i+1}$. Uma execução na qual todos os atores disparam logo que estão ativados é chamada de execução autotemporizada [GEILEN10a, GHAMARIANO6a].

A execução autotemporizada é um agendamento no qual cada disparo de ator tem lugar logo que possível, imediatamente quando todos os tokens requeridos estão disponíveis. Deste modo, a execução autotemporizada representa o melhor (mais acurado) limite que pode ser dado sobre o comportamento 
temporal de uma aplicação baseada no modelo de SDF, sendo, por isso, de especial interesse. Como um exemplo, a vazão máxima de um grafo de SDF é obtida a partir da execução autotemporizada [GEILEN10a, GHAMARIAN06a].

\section{Definição - Tempo de Inicio:}

Dado um grafo de $\mathrm{SDF}, G=(A, C)$, e uma execução $\sigma$, define-se $t_{a, k}^{\sigma}$ como o tempo de início do disparo $k$ de qualquer ator $a \in A$ na execução $\sigma$, isto é, o número de transições de relógio até o aparecimento da $k$-ésima transição $\stackrel{(a, \text { start })}{\longrightarrow}$ na execução $\sigma$ [GHAMARIAN06a].

Somente os grafos de SDF que satisfazem a propriedade estrutural de consistência são de interesse para a análise de desempenho. Os grafos inconsistentes, ou apresentam "deadlock" ou precisam de capacidades de canais ilimitadas. A consistência pode ser verificada de modo eficiente como mostrado em [SRIRAM00]. Um grafo de SDF (temporizado), $G=(A, C(, T))$, é consistente se e só se tem um vetor de repetição não-trivial.

\section{Definição - Vetor de Repetição:}

Um vetor de repetição para $G$ é uma função $q: A \rightarrow N_{0}$ tal que, para cada canal $(\boldsymbol{s}, \boldsymbol{d}, \boldsymbol{p}, \boldsymbol{c}) \in C$, a chamada equação de equilíbrio $\boldsymbol{p} \cdot \boldsymbol{q}(\boldsymbol{s})=\boldsymbol{c} \cdot \boldsymbol{q}(\boldsymbol{d})$ é verificada. Um vetor de repetição $q$ é chamado de não-trivial se e somente se $q(a)>0$ para todo $a \in A$. O menor vetor de repetição não-trivial de um grafo de SDF consistente é referido como o Vetor de Repetição. Uma iteração é um conjunto de disparos de atores com tantos disparos como definidos na posição do vetor de repetição, relacionada a cada ator.

\section{Definição - Vazão de um ator:}

A vazão de um ator $a$ para a execução $\sigma$ de um SDF é definida como o número médio de disparos de $a$ por unidade de tempo em $\sigma$ [GHAMARIAN06a]. Dado que as execuções são infinitas, esta média é definida como o limite seguinte: 


$$
\operatorname{Th}(\sigma, a)=\lim _{t \rightarrow \infty} \frac{|\sigma|_{a}^{t}}{t}
$$

onde $|\sigma|_{a}^{t}$ indica o número de ocorrências da transição $\stackrel{(a, \text { start })}{\longrightarrow}$ até a transição de relógio $t$ na execução $\sigma$. Quando a execução inclui um número infinito de transições $\stackrel{(a, \text { start })}{\longrightarrow}$, então o limite é igual a:

$$
\operatorname{Th}(\sigma, a)=\lim _{k \rightarrow \infty} \frac{k}{t_{a, k}^{\sigma}}
$$

Note-se que esta definição expressa a vazão de um SDF para uma execução particular $\sigma$. Com $T h(a)$, denota-se a vazão da execução autotemporizada.

A vazão máxima de um grafo de $\operatorname{SDF}, G=(A, C)$, está associada com a execução autotemporizada de $G$ [GHAMARIAN06a], de modo que nenhum ator $a \in A$ pode iniciar um disparo sem ter tokens suficientes em todos os seus canais de entrada, e qualquer atraso no início do disparo de um ator não tem utilidade nenhuma no aumento do número de disparos de $a$, em si mesmo, ou em qualquer outro ator no grafo.

Junto à propriedade de consistência, está a propriedade de conectividade forte de um grafo. Um grafo de $\mathrm{SDF}, G=(A, C)$ é dito como fortemente conectado se existe uma rota entre qualquer par de atores de $G$. Uma rota é uma sequência de atores $\left\langle a_{0}, a_{1}, \ldots a_{n}\right\rangle$ tal que $\forall i<n,\left(a_{i}, a_{i}+1\right) \in C$.

Lemma 2.1: Para cada grafo de SDF consistente e fortemente conectado, $G=(A, C)$, a vazão de um ator $a \in A$ é igual ao número médio de disparos por unidade de tempo, na parte periódica do espaço de estado autotemporizado [GHAMARIAN06a].

Proposição 2.1: Para um grafo de SDF consistente e fortemente conectado $G=(A, C)$, com vetor de repetição $q$ e atores $a, b \in A, T h(a) \cdot q(b)=\operatorname{Th}(b) \cdot q(a)$ [GHAMARIANO6a]. 


\section{Definição - Vazão de um grafo:}

A vazão de um grafo de $\mathrm{SDF}, G=(A, C, T)$, é definida como $\boldsymbol{T} \boldsymbol{h}(\boldsymbol{G})=\frac{\boldsymbol{T} \boldsymbol{h}(\boldsymbol{a})}{\boldsymbol{q}(\boldsymbol{a})}$, para um ator arbitrário $a \in A$; deste modo a vazão de um grafo de SDF é igual ao número de disparos de ator por unidade de tempo durante um período, normalizado pelo vetor de repetição. Isto, por sua vez, é igual ao número de iterações executadas em um período, dividido pela duração (número de transições de relógio, clk) de um período [GEILEN10a].

Desde modo, a vazão do grafo de SDF pode ser determinada a partir do espaço de estado. Muitas vezes, também é interessante determinar os componentes críticos, isto é, os atores e canais que estão restringindo a vazão. Eles são os candidatos a serem melhorados (em relação à velocidade de um ator ou à capacidade de um canal) caso seja preciso aumentar a vazão. Este tipo de informação também pode ser extraído do espaço de estado [GEILEN10a, GHAMARIAN06a].

\subsubsection{Espaço de Estado na Execução Autotemporizada}

A semântica operacional dos grafos de SDF sob a política de execução autotemporizada leva o espaço de estados a apresentar uma forma particular, tal como a ilustrada na Figura 2.15 para o exemplo da Figura 2.14 onde o vetor de estado $(\gamma, v)$ é codificado através de pares, onde $\gamma$ corresponde aos canais $a-b, b-c, c-d, d-c, c-b, b-a$, e a tupla $v$ define os multiconjuntos temporais para $a, b, c, d$ respectivamente [GHAMARIAN06a]. A execução começa com o estado inicial $((0,0,0,1,5,1),(\{\},\{\},\{\},\{\}))$, onde nenhum ator é disparado e a distribuição de tokens é determinada pelos tokens iniciais representados no grafo. O único ator habilitado neste ponto é $a$. Quando $a$ começa seu disparo, o estado torna-se $((0,0,0,1,5,0),(\{2\},\{\},\{\},\{\}))$, onde o token no canal de entrada de a é consumido e seu tempo de execução é somado a $v(a)$. Nenhum outro ator pode disparar antes que $a$ termine o seu disparo. Visto que o único elemento em qualquer dos $v$ é 2, o tempo avança para 2 unidades de tempo, mudando o estado para $((0,0,0,1,5,0),(\{0\},\{\},\{\},\{\}))$. Depois, o disparo de a finaliza, o qual muda o estado para $((1,0,0,1,5,0),(\{\},\{\},\{\},\{\}))$ habilitando o ator $b$. Similarmente o ator $b$ começa o 
seu disparo e o tempo avança para uma unidade de tempo e, conseqüentemente, o estado muda para $((0,0,0,1,2,0),(\{\},\{0\},\{\},\{\}))$. No fim do disparo do ator $b$ o estado muda para $((0,3,0,1,2,1),(\{\},\{\},\{\},\{\}))$, o qual habilita tanto $a$ e $c$, e eles começam os seus disparos simultaneamente. Isso cria um novo estado $((0,1,0,0,2,0),(\{2\},\{\},\{3\},\{\}))$. Mais uma vez o tempo avança para 2 unidades de tempo, que é o menor valor entre todos os elementos em $v$, o qual conduz ao fim do disparo do ator $a$ e o define o estado $((1,3,1,0,2,0),(\{\},\{\},\{1\},\{\}))$. Este processo continua assim por diante, indefinidamente. Deste modo, o espaço de estados é constituído por uma sequência finita de estados e transições (também chamada de fase transitória), seguida por uma sequência que é periodicamente repetida até o infinito (a fase periódica) (Ver seção 2.2.3.4) [GHAMARIANO6a].

A ordem das transições de início e de fim entre duas transições de relógio é geralmente irrelevante; por este motivo, algumas vezes, as transições de inicio e de fim são convenientemente omitidas na notação de uma execução, e apenas os estados imediatamente após os passos de relógio são apresentados. Note-se que estes estados são sempre os mesmos, independente da ordem de estado e as transições que precede uma transição de relógio. Os passos em tal execução são referidos como macro-passos. Desta forma, a execução de um grafo de SDF temporizado é também indicado como: $\sigma=S_{0}, S_{1}, \ldots$ onde o $S_{i}$ são os estados obtidos dos macro-passos.

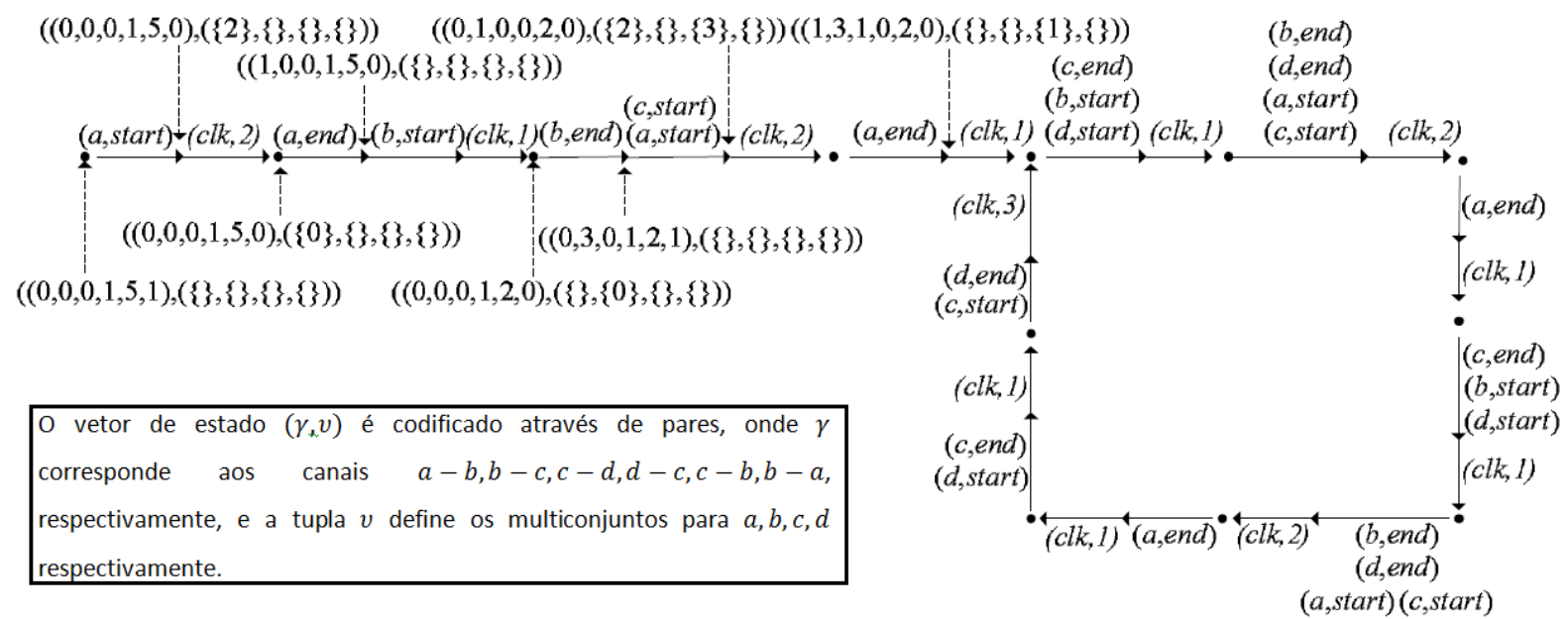

Figura 2.15: Execução autotemporizada do exemplo da Figura 2.14 [GHAMARIANO6a]. 


\subsubsection{Comportamento Temporal Transitório e de Regime Estacionário em SDF [KUMAR09]}

Esta seção foi feita de uma tradução livre da seção 2.4.1 da tese de doutorado de [KUMAR09].

Frequentemente dentro de uma aplicação multimídia, várias iterações são necessárias até que a aplicação comece a apresentar um comportamento periódico. Por exemplo, considere o grafo de aplicação mostrado na Figura 2.16, o qual apresenta três tokens iniciais sobre o arco entre os nós $a_{0}$ e $a_{2}$. Considere-se que cada um dos três atores é mapeado dentro de um sistema multiprocessado com três processadores, $P_{0}, P_{1}$ e $P_{2}$, de modo que o ator $a_{i}$ é mapeado em $P_{i}$, com $i=0,1,2$. Suponha-se que os processadores estão conectados uns aos outros com uma conexão ponto-a-ponto com largura de banda infinita, e com direções semelhantes aos canais no grafo de aplicação [KUMAR09].
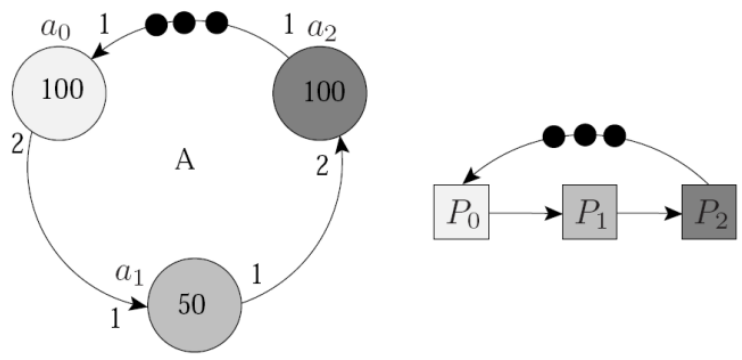

Figura 2.16: Grafo de SDF em estado transitório [KUMAR09].

Neste exemplo, se formos olhar o tempo requerido em uma única iteração, seria obtido um período de 300 ciclos. No entanto, uma vez que cada ator tem seu próprio processador dedicado, em breve seria obtida a distribuição de tokens mostrada na Figura 2.17.

A partir deste ponto, todos os atores podem continuar disparando indefinidamente, uma vez que todos os atores têm tokens suficientes e recursos dedicados. Desta forma, a cada 100 ciclos, uma iteração da aplicação é concluída. (note-se que a primeira iteração ainda leva 300 ciclos para ser concluída). Este estado final é chamado de estado estacionário [KUMAR09]. A execução inicial do grafo, que leva a este estado estacionário, é chamada de fase transitória. 


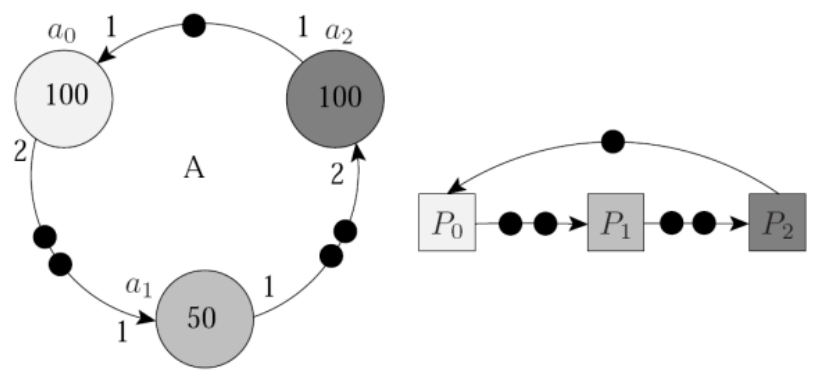

Figura 2.17: Grafo de SDF em estado estacionário [KUMAR09].

Para o grafo mostrado na Figura 2.16, a vazão máxima para processadores de $300 \mathrm{MHz}$ é de 3 milhões de iterações por segundo. Nesta tese, quando formos nos referir à vazão do grafo, geralmente estaremos nos referindo à vazão máxima possivel, salvo alguma indicação contrária. Isto só se refere à vazão em estado estacionário. Quando formos usar o termo de vazão alcançada por um grafo, estaremos nos referindo à vazão média de longo prazo obtida para uma determinada aplicação. Isto também inclui a fase transitória da aplicação. É importante observar que para uma execução infinitamente longa, a vazão média de longo prazo é a mesma que a vazão em estado estacionário [KUMAR09]. 


\section{Capítulo 3}

\section{CARACTERIZAÇÃO DA APLICAÇÃO}

O recente desenvolvimento de sistemas sobre silicio (Systems on Chip, SoC), utilizados para implementar sistemas embarcados distribuídos, está apresentando uma migração da lógica de aplicação específica, para o software dedicado de domínio específico executado nos processadores on-chip, deixando apenas as funções de alto desempenho para serem implementadas no hardware do sistema. Deste modo a implementação em software da funcionalidade das aplicações tem sido descrita em linguagens de alto nivel, a fim de evitar a dependência de qualquer tipo de arquitetura de hardware e aumentar a produtividade dos projetistas.

Como muitos desses sistemas têm restrições de tempo real, os fluxos genéricos de projeto incluem modelos de desempenho que estão suportados por estimativas do Tempo de Execução do Pior-Caso e do Tempo de Execução do Melhor-Caso (Worst Case Execution Time, WCET; e Best Case Execution Time, BCET, respectivamente) das tarefas da aplicação. Por outro lado, reconhece-se que o mais adequado seria incluir modelos que definissem propriedades temporais mais acuradas que considerassem os diferentes eventos que ativam o sistema e impõem uma exigência de execução variável sobre os recursos do sistema [MAXIAGUINE04b]. Basicamente, a definição dessas propriedades temporais consiste em delimitar o tempo de execução de uma tarefa de uma aplicação dada, executada em um processador, com a suposição de que não há interrupções.

Visto que para este trabalho de doutorado foi decidido que a especificação da aplicação é feita através da sua divisão em múltiplas tarefas, de modo que cada tarefa constitui um código de software embarcado a ser implementado em um processador on-chip, no presente capítulo será considerado que cada 
tarefa de uma aplicação multimídia está associada a um código cujo comportamento temporal será analisado através de uma metodologia de caracterização estática explicada no decorrer do capítulo. Conceitos como análise temporal, tempo de execução, modos de operação e rotas de execução estão diretamente relacionados à análise do código-fonte, ou do código executável, que implementa cada tarefa de certa aplicação multimídia em um determinado processador on-chip dentro de um MPSoC.

\subsection{ANÁLISE TEMPORAL}

A análise temporal tenta determinar limites para os tempos de execução de uma tarefa quando executada em um hardware específico. O tempo para uma determinada execução depende da rota, durante o processamento da tarefa, tomada pelo fluxo de controle do seu eventual e respectivo código, e o tempo gasto nas declarações ou instruções sobre essa rota nesse hardware. Desta forma, a determinação dos limites do tempo de execução precisa considerar as rotas potenciais de fluxo de controle e os tempos de execução para este conjunto de rotas. Uma abordagem modular para o problema de análise temporal divide o problema global em uma sequência de subproblemas. Alguns desses subproblemas lidam com as propriedades do fluxo de controle, outros lidam com o tempo de execução das instruções, ou a sequência de instruções, sobre o hardware específico.

\subsection{ANÁLISE DO PIOR-CASO [WILHELM08]}

Esta seção está baseada em uma tradução livre de parágrafos das seções 2, 3 e 4 do artigo de [WILHELM08].

\subsubsection{Problemática}

Assume-se que um sistema de tempo real consiste de uma série de tarefas, que realizam a funcionalidade requerida. A Figura 3.1 mostra várias propriedades relevantes de uma tarefa de software em tempo-real. Uma tarefa tipicamente apresenta certa variação dos tempos de execução, dependendo dos dados de entrada ou comportamento diferente do ambiente. O conjunto de todos os tempos possiveis de execução é apresentado como a curva superior da Figura. O menor tempo real de execução é chamado de tempo de execução 
do melhor-caso, representado na Figura como o BCET ${ }^{16}$, e o maior tempo real é chamado de tempo de execução do pior-caso, representado na Figura como o WCET 17. Na maioria dos casos, o espaço de estado é muito grande para explorar exaustivamente todas as execuções possiveis e, desta forma, determinar os valores exatos dos tempos de execução do pior-caso e do melhor-caso. Por esse motivo atualmente existem duas abordagens diferentes para encontrar e avaliar valores aproximados, próximos destes valores exatos dos tempos extremos de execução. A primeira destas abordagens é baseada em estimação dinâmica (ou simulação), e os valores resultantes desta avaliação são chamados de estimativas. Por outro lado, a segunda abordagem é baseada em análise temporal estática, e os valores resultantes desta avaliação são chamados de limites ou garantias.

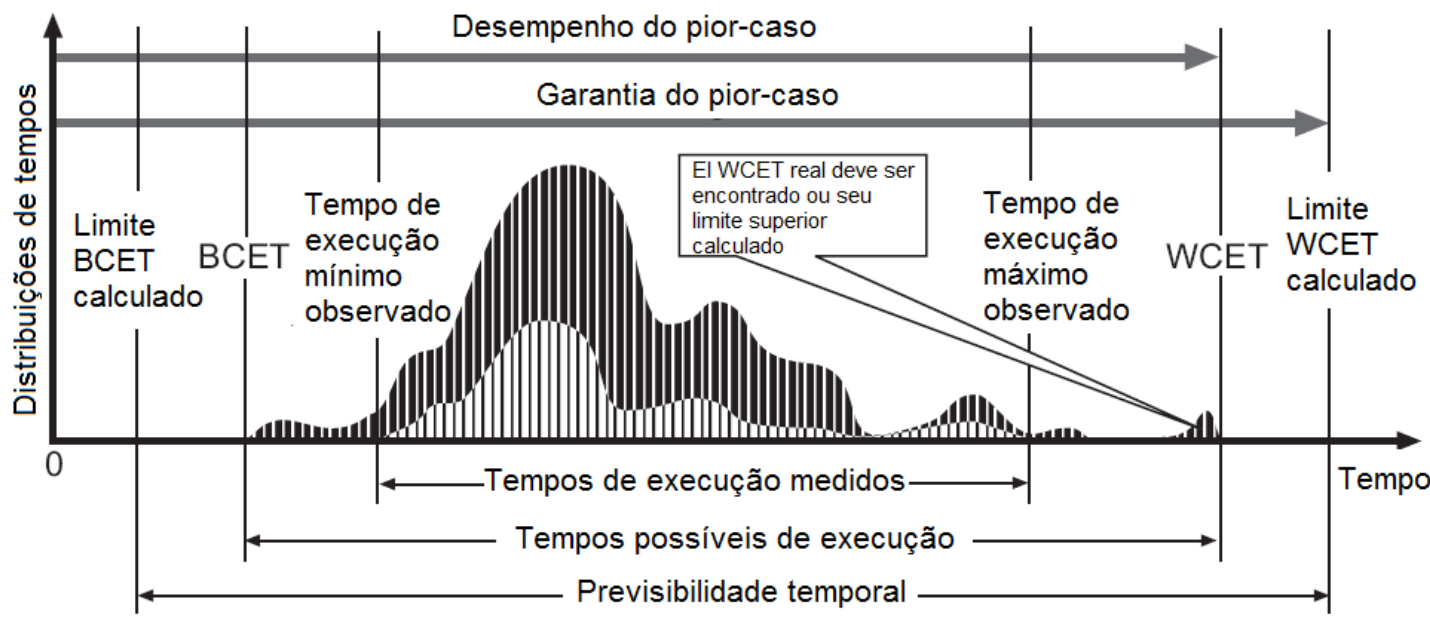

Figura 3.1: Noções básicas concernentes à análise temporal de sistemas [WILHELMO8]

As curvas da Figura 3.1 têm o seguinte significado: a curva menor representa um subconjunto de medidas de tempos de execução. Seus valores, mínimo e máximo, são o tempo de execução mínimo observado e o tempo de execução máximo observado, respectivamente. A curva mais escura, envolvente da curva anterior, representa todos os tempos possiveis de execução. Seus valores, mínimo e máximo, são os tempos de execução do melhor-caso e do pior-caso, abreviados como BCET e WCET, respectivamente.

\footnotetext{
${ }^{16}$ Do Inglês: Best-Case Execution Time

${ }^{17}$ Do inglês: Worst-Case Execution Time.
} 
Hoje, na maioria das casas de projeto e das empresas do setor de Tecnologia da Informação (TI), o método comum para avaliar os tempos de execução é medir o tempo fim-a-fim (end-to-end) de uma tarefa, para um subconjunto das possiveis execuções, via métodos baseados em estimação dinâmica. Esse subconjunto de execuções corresponde aos chamados casos de teste. Isto determina os tempos de execução, mínimo e máximo, observados (indicados respectivamente na Figura), de modo que geralmente superestima-se o BCET, e subestima-se o WCET, o que acaba implicando que tais valores não sejam confiáveis para sistemas rígidos de tempo-real (Hard Real-Time Systems).

Os limites sobre o tempo de execução de uma tarefa podem ser calculados por métodos formais ou semiformais que consideram todos os tempos de execução possiveis, isto é, todas as execuções possiveis da tarefa. Isto é feito através do uso de múltiplas abstrações ${ }^{18}$ da especificação de cada tarefa, definidas para fazer com que a análise temporal da sua funcionalidade seja viável. Estas abstrações têm perda de informação, e o limite WCET calculado geralmente é superestimado em relação ao valor exato do WCET, e vice-versa para o BCET [WILHELM08]. O limite WCET calculado representa a garantia de pior-caso que a aplicação, tarefa, ou sistema, pode oferecer. De quanto é a perda na precisão desta informação temporal depende tanto dos métodos utilizados para a análise temporal, como das propriedades gerais do sistema, tais como a arquitetura de hardware e as características do software. Estas propriedades do sistema podem ser agrupadas sob a noção de previsibilidade temporal, indicado na parte inferior da Figura 3.1.

Os dois principais critérios para avaliar um método ou uma ferramenta para análise temporal são confiabilidade e precisão. $O$ primeiro determina se a ferramenta, ou método, produz estimativas ou limites, enquanto o segundo diz se estas estimativas, ou limites, são próximos dos valores exatos.

A finalidade da análise do tempo de execução do pior-caso no desenvolvimento de sistemas embarcados em tempo real é a de proporcionar informação a priori sobre o pior tempo de execução possivel de um código de software antes dele ser executado dentro de um sistema. Valores confiáveis do WCET são necessários na hora de projetar e verificar sistemas embarcados de tempo real,

\footnotetext{
${ }^{18}$ Definidas posteriormente como modelos analíticos das tarefas
} 
especialmente quando estes sistemas são utilizados para controlar sistemas críticos de segurança tais como veículos e plantas industriais.

Os valores estimados ou calculados do WCET podem ser utilizados para realizar análise de escalonamento, determinar se os objetivos de desempenho são satisfeitos por tarefas periódicas, para verificar que as interrupções possuem tempos de reação suficientemente curtos, para encontrar gargalos de desempenho, assim como para muitos outros propósitos [CASPARSSON98, ENGBLOM01, GANSSLE02].

A previsão de desempenho também é necessária para domínios de aplicação que não possuem características de tempo-real rígido (Hard Real-Time). Neste caso, os sistemas podem ter prazos (deadlines), mas não há obrigatoriedade de se satisfazê-los. Diferentes métodos podem ser aplicados, e critérios diferentes podem ser utilizados, para medir a qualidade dos métodos e das ferramentas.

Para propiciar a análise WCET como parte de uma ferramenta para o desenvolvimento de sistemas embarcados em tempo real, tal análise deve ser inserida dentro do fluxo de projeto, em relação à edição, compilação, prova e depuração dos códigos das tarefas da aplicação. Assim, do mesmo modo como um código de software é checado na busca de bugs, ele também deve ser checado em relação ao seu comportamento de temporização. Para que isto seja alcançado, a análise de WCET deve ser executada no interior do sistema de compilação, o qual exige um método muito eficiente para o seu cálculo. Além disso, o modelo do hardware utilizado na ferramenta de computação do WCET deve ser um módulo separado que seja fácil de se trocar em caso de mudança do processador, ou processadores, alvo(s) da implementação.

\subsubsection{Classificação das Abordagens}

Várias técnicas têm sido desenvolvidas para a obtenção de estimativas valiosas do tempo de execução. Essas técnicas podem ser classificadas em duas famílias: técnicas baseadas em estimação dinâmica e técnicas baseadas em análise estática.

\subsubsection{Estimação Dinâmica}

Os métodos dinâmicos estimam o WCET através de medidas e podem ser divididos em três categorias diferentes: (1) por hardware; (2) por software; e (3) 
métodos híbridos. Os métodos de hardware incluem medidas do tempo de execução utilizando osciloscópios, analisadores lógicos e emuladores. Os métodos de software são baseados em funções temporais fornecidos, por exemplo, pelo sistema operacional. Por outro lado, os métodos híbridos combinam os dois métodos mencionados acima: pequenos trechos de código são inseridos no software que irá ser medido, de modo que quando o software é executado, os pequenos trechos de código inicializam ou param um hardware definido para monitorar o sistema, a fim de medir o tempo de execução do código de software.

Os métodos de estimação dinâmica executam a tarefa de software, ou partes da tarefa, em um hardware específico ou em um simulador, para um conjunto de entradas. Ao longo dessa execução, múltiplos tempos de operação dos diferentes componentes e procedimentos definidos dentro de cada tarefa são avaliados, a fim de calcular os tempos de execução mínimos e máximos observados em toda a tarefa, a distribuição desses tempos, ou também uma combinação entre os tempos de operação de diferentes segmentos de código, tal que seja possível calcular o tempo de execução da tarefa completa.

Por outro lado, os métodos de estimação dinâmica têm a grande desvantagem de não garantir que o maior tempo de execução medido é o verdadeiro tempo de execução do pior-caso [ZHANG05]. O WCET pode ocorrer com pouca frequência e as condições para que ele aconteça são normalmente desconhecidas. Desta forma, todos os métodos dinâmicos só podem medir uma rota de execução de cada vez, e cabe ao usuário encontrar as entradas com alta probabilidade de situações com o maior tempo de execução. Na prática, para uma arquitetura padrão, o WCET é supostamente maior que o maior tempo de execução encontrado, com uma margem de erro significativa tipicamente de 30\% [BEHAMAMOUCH08]. É possivel concluir que esses métodos, apesar de serem amplamente utilizados na indústria, perdem em exaustividade e o maior tempo de execução medido pode não ser o pior.

\subsection{Medição Real baseada em Implementação de Hardware}

A medição real baseada em implementação de hardware consiste em medir o tempo de execução de um código, ou tarefa de software, executado em uma plataforma de hardware, para um conjunto pré-estabelecido de amostras de dados de entrada. A fim de determinar o tempo de execução máximo, é 
necessário definir, para cada código, os dados de entrada mais adequados para efetuar tal medida, ou explorar todos os modos como o software pode ser executado. Muitos métodos diferentes existem para a sua medida [STEWART01], porém não existe uma única técnica que possa ser considerada melhor. Cada técnica apresenta um compromisso entre vários atributos, tais como a resolução, precisão, granularidade e dificuldade da implementação. A adequação de um método determinado dependerá, em primeiro lugar, das características de hardware e da disponibilidade de ferramentas de instrumentação (alguns métodos precisam de características especiais de hardware, outros exigem uma aplicação específica de software ou instrumentos disponíveis de medida). Em segundo lugar, o método desenvolvido também será afetado pelo projeto de software das tarefas da aplicação (por exemplo, o tempo de execução de códigos de software que têm múltiplos e inconsistentes pontos de entrada ou de saída é muito difícil de medir) [STEWART01].

Das múltiplas abordagens para se obter medidas, a abordagem mais simples é por código de instrumentação adicional, a qual coleta um marcador de tempo (timestamp), ou um contador de ciclos de CPU (disponível na maioria dos processadores). As técnicas de instrumentação híbridas de HW/SW precisam de hardware externo para coletar a temporização gerada por código simples de instrumentação.

As ferramentas baseadas em medição podem calcular os limites no tempo de execução para processadores com comportamento temporal simples, porém, no caso de processadores mais complexos só podem gerar estimativas do BCET e do WCET. O problema da medida do comportamento temporal em processadores complexos não é ainda um problema completamente resolvido uma vez que nestes processadores, os recursos de pipeline, cache e predição adaptativa de saltos, complicam a análise temporal da arquitetura completa do sistema. Os resultados da análise baseada em medição podem ser utilizados para fornecer uma imagem da variabilidade real do tempo de execução da aplicação, além de fornecer estimativas do BCET e do WCET. Eles também podem ser utilizados para fornecer validação das abordagens de análise estática. 
Por outro lado, as medidas fim-a-fim (end-to-end) de um subconjunto de possiveis execuções produzem estimativas, não limites, dado que estas execuções correspondem a um conjunto de casos de teste, no qual, mesmo que seja um conjunto amplo, as medidas resultantes só correspondem a superestimações do BCET, e subestimações do WCET. No entanto, tais medidas podem ser úteis para aplicações que não precisam de garantias, tipicamente sistemas de tempo real não-rígidos (Non-hard Real-Time Systems). Tais medidas podem dar ao projetista uma aproximação sobre o tempo de execução em casos comuns, e a probabilidade da ocorrência do pior-caso.

As medições também podem ser realizadas a partir da saída de simuladores de hardware (de processadores, ou mesmo de simuladores VHDL) [WILHELM08].

\subsection{Simulação}

A simulação é uma técnica padrão para estimar o tempo de execução de tarefas em arquiteturas de hardware. Uma das principais vantagens desta abordagem é a possibilidade de derivar estimativas mais precisas do tempo de execução de uma tarefa para um conjunto especifico de dados de entrada, assumindo detalhes suficientes para o modelo temporal do simulador de hardware. No entanto, [DESIKAN01] mostra que nem todos os simuladores operam em precisão por ciclos de relógio para todos os tipos de arquiteturas. No seu trabalho, eles comparam as medidas temporais de execuções realizadas em diferentes simuladores, oferecendo indicações dos erros obtidos para uma arquitetura Alpha. Um dos simuladores utilizados na comparação é o Simplescalar [AUSTIN02], o qual também é utilizado por alguns grupos de pesquisa que investigam o problema do WCET. Os resultados mostram grandes diferenças de tempo quando comparados aos valores medidos.

\subsubsection{Análise Estática}

Devido às limitações inerentes aos métodos de estimação dinâmica, vários métodos formais têm sido desenvolvidos para determinar as propriedades do comportamento dinâmico de uma tarefa dada, sem realmente executá-la [COUSOT77], e encontrar uma estimação mais precisa do WCET. Alguns desses métodos são modificações ou adaptações de métodos importados de diferentes áreas da Ciência da computação, tais como o projeto de 
compiladores, arquitetura de computadores, e estimativas de desempenho e otimização.

Ao executar a análise estática do WCET, presume-se que não existem atividades interferentes de fundo, tais como acesso direto a memória (DMA) ou atualizações de DRAM, e que a execução do código de software é ininterrupta (sem troca de tarefas ou interrupções). Qualquer tempo extra de execução causado por interferências de cache entre tarefas, interrupções, etc, é adiado para uma análise posterior ou outra fase do projeto do sistema.

Como representado na Figura 3.2, o cálculo do WCET é realizado por uma sucessão de análises [FERDINAND99, FERDINAND04]. Primeiro, dado o arquivo executável de um código alvo, a análise estática divide-o em blocos básicos - os quais são sequências de instruções sem saltos dentro do bloco. Tais blocos básicos são depois organizados em um Grafo de Fluxo de Controle (Control Flow Graph, CFG) que replica o fluxo de controle do código de software. Um componente de uma ferramenta de análise temporal que reconstrói o CFG a partir de um código executável é frequentemente chamado de Front-end, como mostrado na Figura 3.2.

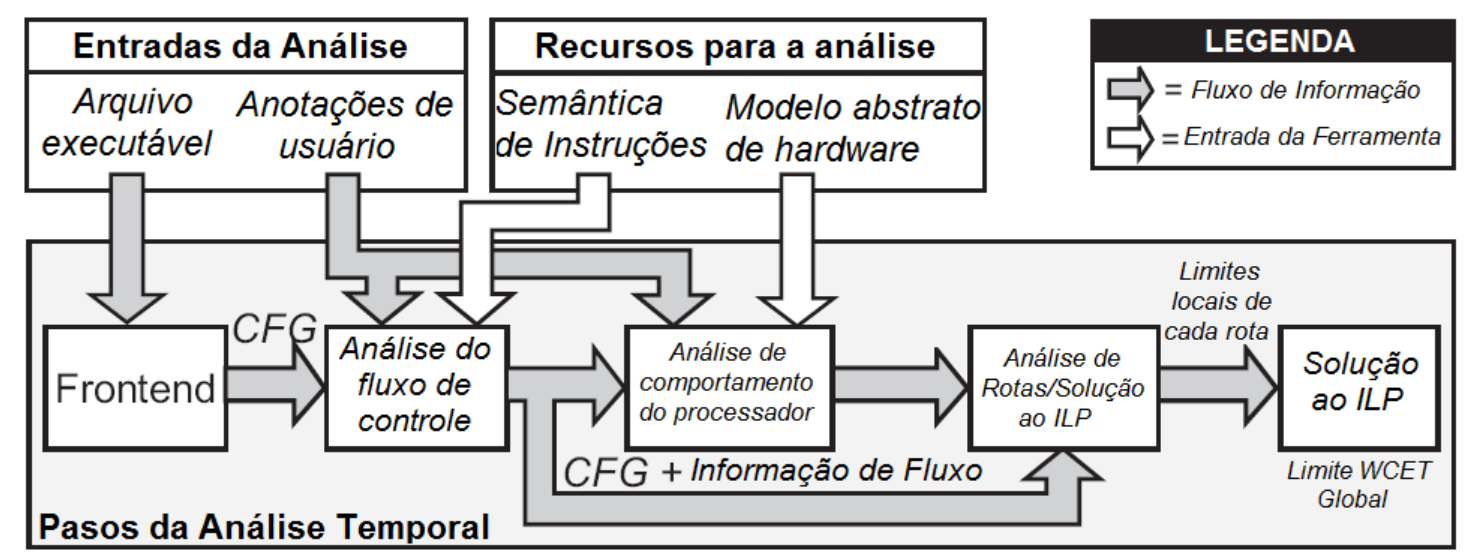

Figura 3.2: Principais componentes da Análise Temporal [WILHELM08]

Um valor do limite superior de WCET calculado é associado com cada laço dentro do código a fim de expressar o maior número possivel de iterações de cada laço. Algumas restrições adicionais sobre a execução dos blocos básicos podem ser adicionadas manualmente pelo programador, ou geradas automaticamente por algumas técnicas de análise. Essas restrições, incluindo os limites de contagem dos laços, costumam ser chamadas de anotações de fluxo (flow facts), das quais são parte as anotações do usuário [WILHELM08]. 
Esta é a análise conhecida como análise do fluxo de controle ou análise de alto nível.

Depois dessa análise, é feita a chamada análise de baixo nível a qual percorre o CFG para determinar as áreas de memória que podem ser atingidas durante a execução do código de software. Nesse percurso, também é calculado o tempo de execução de cada bloco básico, modelando a arquitetura de hardware relacionada ao conjunto de instruções, cache e pipelines. Esta corresponde à etapa de análise de comportamento do processador, a qual também recebe como entrada o modelo abstrato de hardware do processador, como mostrado na Figura 3.2. Nesta etapa da análise, misses e hits potenciais na cache são determinados, e o pipeline é examinado a fim de se calcular, para cada ponto de execução do código analisado, os estados possíveis de execução.

As duas fases da análise estática podem ser desenvolvidas separadamente [THEILING00] ou de forma integrada [METZNER04]. Finalmente, os resultados obtidos das análises de alto nível e de baixo nível são explorados em conjunto com o código-fonte em uma última análise, chamada de análise de rotas, a qual avalia as múltiplas rotas de execução. Uma destas rotas possui o maior tempo de execução, que é então chamada de rota de execução do pior-caso (Worst Case Execution Path, WCEP). Este tempo de execução encontrado corresponde ao limite do WCET calculado.

Encontrar o WCET correspondente ao WCEP pode ser formulado como um problema de otimização. As técnicas de enumeração implícita de rotas (Implicit-Path Enumeration Techniques, IPET) [ENGBLOM00, PUSCHNER97, STEVEN95] codificam a informação estrutural do CFG, as anotações de fluxo e as restrições lineares sobre a contagem de execução dos blocos básicos, em uma formulação suportada por técnicas de programação linear, de modo que o valor do WCET pode ser obtido através da solução de um problema de Programação Linear Inteira (Integer Linear Programming, ILP).

Os métodos formais de análise estática possuem três principais desvantagens: (1) exploram um superconjunto de todas as rotas de execução, de modo que os WCETs das rotas de execução inviáveis também são incluídos; (2) a fim de evitar uma explosão no número de estados, várias rotas de execução costumam ser agregadas, o que pode conduzir a uma aproximação exagerada do tempo de execução; (3) o analisador, ou projetista, deve dar um suporte 
explícito da plataforma alvo do sistema, devendo fornecer abstrações importantes dos componentes de hardware que compõem tal plataforma alvo. Essas abstrações são definidas na modelagem da microarquitetura de hardware.

\subsubsection{Modelagem da Micro-Arquitetura}

A modelagem da microarquitetura descreve estaticamente o hardware do sistema e define a análise temporal de uma sequência conhecida de instruções. É amplamente aceito que tal análise deve ser feita no nivel de código assembly, a fim de capturar todos os efeitos das otimizações do compilador e da implementação da microarquitetura. Para processadores básicos, sem unidades de execução de instruções em pipeline e arquitetura de memória baseada em cache, a modelagem é direta, com o tempo de execução de uma instrução, em boa medida, independente das outras instruções. Podese assumir que o tempo de execução de uma instrução é uma constante e igual ao tempo de execução do pior-caso (WCET) ao longo da execução do código de software.

Nos processadores modernos, recursos de pipeline e cache aceleram o desempenho típico do sistema, porém complicam a análise temporal da arquitetura completa do sistema. O tempo de execução de uma única instrução depende, desta forma, de muitos fatores, e varia muito mais se comparado aos processadores mais simples. A memória cache é particularmente dificil de ser modelada com precisão. Para determinar se a execução de uma instrução resulta em cache hit, várias instruções executadas previamente deverão também ser examinadas. Desta forma, utilizando-se o modelo simples mencionado acima, resultaria em um pessimismo grande na estimação final do tempo de execução de uma instrução e do código inteiro de software. Ainda pior, na medida em que os processadores se tornam mais complexos, o pessimismo devido à modelagem imprecisa aumenta e torna-se um fator dominante nas análises [STEVEN95].

Em geral, os fatores que determinam a complexidade para determinar o tempo de execução de uma única instrução podem ser explicados sob duas óticas diferentes: Dependência de contexto nos tempos de execução e Anomalias de Temporização. 


\subsubsection{Dependência de Contexto nos Tempos de Execução}

As primeiras abordagens para tratar o problema de análise de tempo assumiam a independência de contexto no comportamento temporal; os tempos de execução para instruções individuais eram independentes da história de execução e podiam ser encontradas no manual de instruções (databook) do processador. A partir desta independência de contexto foi derivada a abordagem baseada em estrutura [SHAW89]: se dentro de uma tarefa dada, primeiro executa-se um trecho $A$ de código e depois um trecho $B$, o limite do pior-caso de tempo de execução para $A ; B 19$ era determinado como aquele de $A, \boldsymbol{u} \boldsymbol{b}_{\boldsymbol{A}}{ }^{20}$, mais aquele determinado para $B, \boldsymbol{u} \boldsymbol{b}_{\boldsymbol{B}}$, ou seja $\boldsymbol{u} \boldsymbol{b}_{\boldsymbol{A} ; \boldsymbol{B}}=$ $\boldsymbol{u} \boldsymbol{b}_{A}+\boldsymbol{u} \boldsymbol{b}_{B}$.

Esta independência de contexto, porém, não é mais verdadeira para os processadores mais modernos que possuem caches e pipelines. O tempo de execução de instruções individuais pode mudar em várias ordens de magnitude, dependendo do estado do processador no qual tais instruções são executadas. Desta forma, o tempo de execução de $B$ pode depender fortemente do estado de execução criado pela execução de $A$. Qualquer ferramenta deve explorar a informação de que $A$ é executada antes do que $B$, a fim de determinar um limite superior preciso para $B$ dentro do contexto de $A$. Deste modo, determinar o limite superior $\boldsymbol{u} \boldsymbol{b}_{\boldsymbol{A} ; \boldsymbol{B}}$ para $A ; B$ utilizando-se a expressão $\boldsymbol{u} \boldsymbol{b}_{A ; \boldsymbol{B}}=\boldsymbol{u} \boldsymbol{b}_{\boldsymbol{A}}+\boldsymbol{u} \boldsymbol{b}_{\boldsymbol{B}}$ ignora tal informação e, geralmente, não permitirá obter resultados precisos na estimação do tempo de execução.

\subsubsection{Anomalias de Temporização}

A complexidade da fase de análise do comportamento do processador, e o conjunto de métodos aplicáveis criticamente, dependem da complexidade da arquitetura de processador [HECKMANN08]. Os microprocessadores mais desenvolvidos sofrem de anomalias de temporização [LUNDQVIST99], as quais são influências contra-intuitivas do tempo de execução (local) de uma instrução sobre o tempo de execução (global) de toda a tarefa. Para explicar melhor esse conceito, assuma-se que o sistema sob consideração - ou seja, o

${ }^{19}$ Em teoria de linguagens, $\boldsymbol{A} ; \boldsymbol{B}$ representa duas instruções ou trechos de código executados em sequência em um determinado processador [WILHELM08].

${ }^{20} \boldsymbol{u} \boldsymbol{b}_{\boldsymbol{A}}$ refere-se a uma abreviacao em inglês de Upper Bound, indicando o limite do pior-tempo de execução da instrução $A$ [WILHELM08]. 
hardware executante e o software executado - é muito complexo para permitir uma execução ou simulação exaustiva. Além disso, nem todos os dados de entrada são conhecidos, de modo que os componentes do estado de execução ficam ausentes dentro da análise. No caso de que as decisões dentro da tarefa dependam desses componentes desconhecidos, tal falta de informação pode levar a um comportamento não-determinístico do sistema. Dentro da análise temporal, isto significa que a execução de uma instrução, ou uma sequência de instruções, avaliada em um estado abstrato inicial determinado, pode produzir tempos diferentes baseados em suposições diferentes sobre os componentes de estado ausentes. A informação ausente relacionada com a condição de se a próxima instrução estará na cache pode levar, por exemplo, a que uma execução que começa com uma carga da cache contribua com uma penalização de cache miss dentro do tempo de execução, enquanto que outra execução diferente poderá estar iniciando com uma busca da instrução dentro da cache. A intuição sugeriria que a última dessas execuções sempre estaria conduzindo ao menor tempo de execução de toda a tarefa. No entanto, em processadores com anomalias temporais, isto não necessariamente é verdadeiro. A última dessas execuções pode, de fato, conduzir a um maior tempo de execução dentro da tarefa. Isto foi observado dentro do processador Motorola ColdFire 5307 [HECKMANN08], sendo pela seguinte razão: este processador especula sobre o resultado de saltos condicionais, isto é, esse processador faz uma leitura prévia (prefetch) de instruções em uma das direções do salto condicional. Quando a condição é finalmente avaliada, pode ser descoberto que o processador tenha especulado no sentido errado. Nesse caso, todas as ações realizadas até esse momento precisam ser desfeitas. Além disso, o fato de buscar as instruções erradas leva à corrupção parcial do conteúdo da cache. Com tudo em conjunto, o custo dessa previsão errada vai exceder os custos de uma cache miss. Desta forma, o pior-caso local, a cache miss leva a um tempo de execução globalmente mais curto, uma vez que evita uma predição errada de um salto. Isso exemplifica uma das razões para anomalias temporais: as anomalias causadas por especulação.

Outros tipos de anomalia temporal são instâncias das conhecidas anomalias de escalonamento (ou agendamento), descobertas inicialmente por Graham [GRAHAM66]. Essas ocorrem quando uma sequência de instruções, parcialmente dependentes umas das outras, pode ser agendada de modo 
diferente nos recursos de hardware, tal como a unidade de pipeline. Dependendo do esquema selecionado de agendamento, a execução das instruções ou fases de pipeline pode tomar tempos diferentes.

As anomalias temporais violam uma suposição intuitiva, porém errada, de que escolher a transição local do pior-caso, no caso de uma instrução ou estrutura de decisão, sempre irá produzir o tempo de execução global do pior-caso. Isto significa que a análise não pode se restringir à busca por limites superiores, escolhendo simplesmente os piores casos de cada instrução. Deste modo, a existência de anomalias temporais em um processador tem uma forte influência na aplicabilidade dos métodos para a análise temporal em tal processador [HECKMANN08].

\subsubsection{Análise de Rotas de Execução do Código de Software}

A análise de rotas de execução do código de software permite determinar qual é a sequência de instruções que será executada no cenário do pior-caso. As rotas de execução do código que são inviáveis devem ser removidas do espaço de busca de soluções na medida do possivel. Isto pode ser feito por uma análise de fluxo de dados do código, mas costuma ser mais eficiente se realizado com a ajuda do programador. Esta tarefa exige a presença de um mecanismo de análise de código que ajude a fazer anotações dentro das rotas de execução do software.

A anotação de tarefas com informações dadas pelo projetista ou programador, é uma técnica genérica que permite dar suporte posterior a técnicas aplicadas de validação automática. O projetista, utilizando uma ferramenta para a estimação do WCET, pode precisar fornecer algumas informações para a ferramenta, seja em arquivos separados, ou através de elementos textuais ou numéricos acrescentados no interior de cada tarefa. Esta informação pode descrever:

- O layout de memória e quaisquer características requeridas relacionadas à área de memória,

- Intervalos dos valores de entrada da tarefa, 
- Informações sobre o fluxo de controle da tarefa, caso não seja determinada automaticamente, como por exemplo, limites dos laços, formas de laços aninhados, se iterações de laços internos dependem de variáveis de iteração dos laços exteriores, frequências de saltos ou saltos tomados,

- Desvios na chamada de funções, e

- Diretivas sobre a precisão desejada do resultado, a qual frequentemente depende do esforço investido para diferenciar contextos.

Estas anotações podem ajudar a lidar com o fato de que o número de rotas dentro do código de software é tipicamente exponencial em função do tamanho do código. Desta forma, um método eficiente de análise de rotas, baseado, ou não, em anotações, é necessário a fim de evitar uma busca exaustiva de rotas dentro do código [STEVEN95].

\subsubsection{Cálculo da Estimativa WCET}

Em abordagens dinâmicas, a estimativa do WCET pode subestimar o WCET real, uma vez que apenas um subconjunto de todas as execuções é utilizado para calculá-lo. A combinação de medições feitas sobre trechos de código, para calcular tempos de execução fim-a-fim, pode também superestimar o WCET, no caso em que estimativas pessimistas medidas para os diferentes trechos forem combinadas. Em abordagens estáticas, a fase do cálculo da estimativa avalia um limite superior de todos os tempos de execução de toda a tarefa com base no fluxo do código de software e na informação temporal derivada nas fases anteriores da análise estática.

Existem três classes principais de métodos que combinam tempos medidos, ou determinados analiticamente, com estimativas fim-a-fim propostas na literatura. Essas classes são: baseadas em estrutura, baseadas em rotas, e técnicas que utilizam enumeração implícita de rotas (Implicit Path Enumeration, IPET). A Figura 3.3, extraída de [ERMEDAHL03], apresenta os diferentes métodos, sendo que a Figura 3.3(a) mostra um exemplo de um grafo de fluxo de controle com temporização nos nós, e uma anotação de fluxo referente a um limite no número de laços (maxiter). 


\subsubsection{Métodos de Estimação Baseados em Estrutura}

Em cálculos de limite baseados em estrutura, como aquele utilizado na ferramenta Heptane [COLINOO], um limite superior é calculado em um percurso bottom-up da árvore sintática da tarefa, combinando limites calculados para os componentes das declarações (instruções) seguindo as regras de transformação definidas para esse tipo de declarações [COLINOO, LIM95, COLIN02]. A Figura 3.3(d) ilustra o modo como um método baseado em estrutura poderia proceder de acordo com a árvore sintática da tarefa e as regras de combinação dadas. As coleções de nós são recolhidas em nós únicos, obtendo simultaneamente uma temporização para cada novo nó. Nesse caso, uma boa precisão só pode ser obtida se o mesmo segmento de código é considerado em um número de contextos de fluxo diferentes, visto que os tempos de execução em contextos de fluxo diferentes podem variar significativamente.
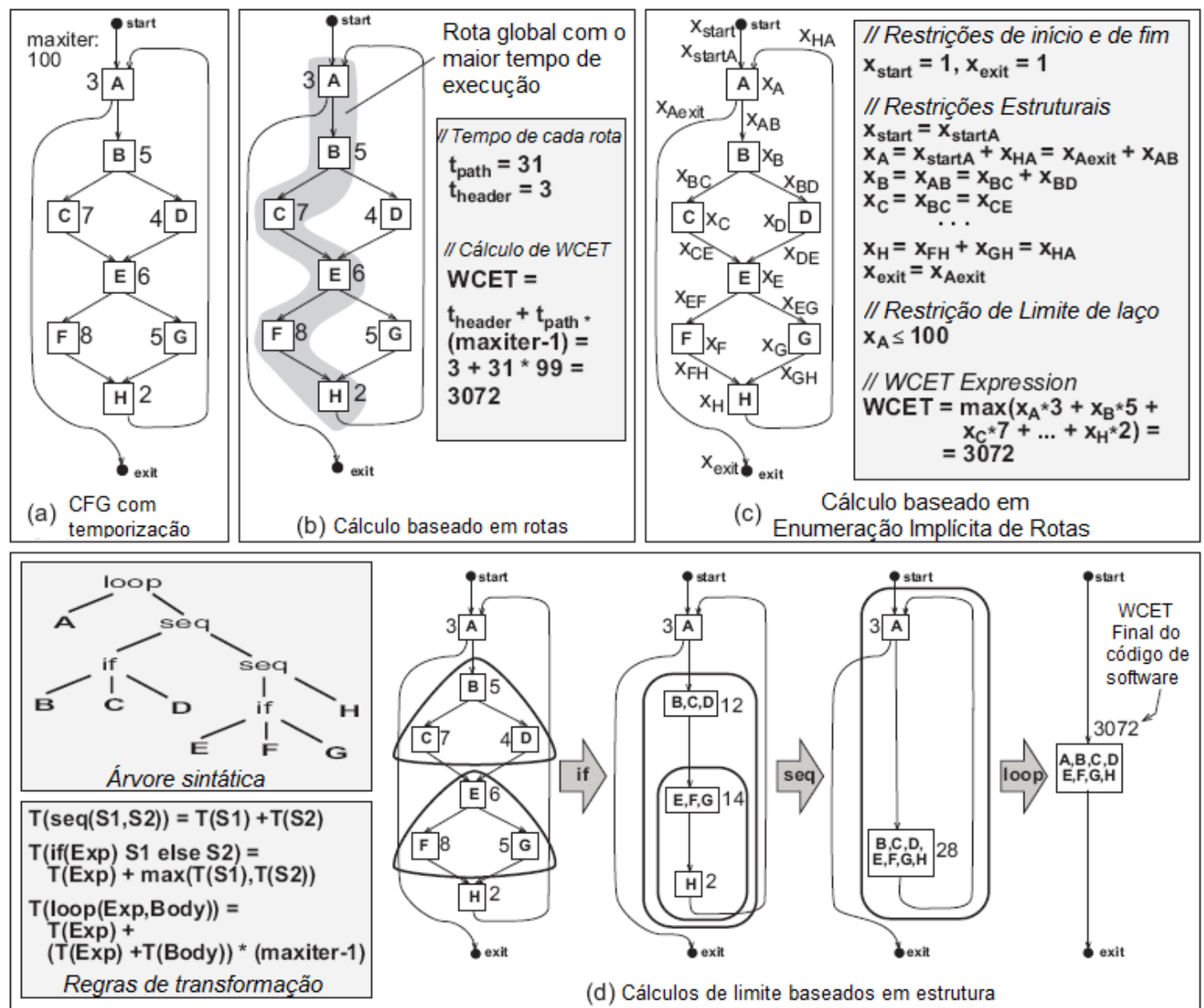

Figura 3.3: Metodologias diferentes para o cálculo do limite do WCET [ERMEDAHL03] 
Levar contextos de fluxo em consideração precisa de transformações da árvore sintática a fim de refletir os diferentes contextos. A maioria das transformações aproveitáveis, tais como o loop unrolling, são facilmente expressadas na árvore sintática [COLIN02].

Alguns problemas da abordagem baseada em estrutura são, por exemplo: (1) Nem todos os fluxos de controle podem ser representados através da árvore sintática; (2) A abordagem assume uma correspondência muito direta entre as estruturas do código-fonte e do código objeto, de modo que as possíveis otimizações feitas no código pelo compilador não são facilmente admissiveis; (3) Em geral, não é possível acrescentar informação adicional de fluxo, tal como pode ser feito no caso IPET [WILHELM08] (ver seção 3.2.5.3).

\subsubsection{Métodos de Estimação Baseados em Rotas}

No cálculo de limite baseado em rotas, o limite superior para uma tarefa é determinado através do cálculo dos limites para as diferentes rotas dentro da tarefa, seguindo uma busca pela rota global com o maior tempo de execução [HEALY99, STAPPERT00, STAPPERT01]. A principal característica que define essa busca é que as rotas de execução possiveis são representadas explicitamente. A abordagem baseada em rotas é natural dentro de uma só iteração de laço, mas tem problemas com a informação de fluxo que se estende ao longo de múltiplos níveis de laços aninhados. O número de rotas é exponencial em relação ao número de pontos de decisão, sendo possivelmente necessário o uso de métodos heurísticos de busca. A Figura 3.3(b) ilustra o modo como o método de cálculo baseado em rota atuaria sobre o grafo da Figura 3.3(a). Primeiro, o laço dentro do grafo é identificado, e a maior rota dentro do ciclo é encontrado. O tempo da maior rota é combinado com informação de fluxo sobre o limite de laço, a fim de se extrair um limite superior para toda a tarefa.

\subsubsection{Enumeração Implícita de Rotas}

$\mathrm{Na}$ metodologia de Enumeração Implícita de Rotas (Implicit Path Enumeration, IPET), o fluxo do código de software e os limites de tempo de execução dos blocos básicos são combinados em conjuntos de restrições aritméticas. A idéia foi originalmente proposta em [STEVEN95] e adaptada para fluxos mais complexos e efeitos temporais de hardware em [PUSCHNER97, ENGBLOM02, 
THEILING02, ERMEDAHL03]. Cada bloco básico e arco de fluxo de código dentro da tarefa possuem um coeficiente temporal $\left(\boldsymbol{t}_{\text {entity }}\right)$, expressando o limite superior da contribuição dessa entidade para o tempo total de execução cada vez que a entidade é executada, e uma variável de contagem ( $\boldsymbol{x}_{\text {entity }}$ ), correspondendo ao número de vezes que a entidade é executada. Um limite superior é determinado maximizando a soma dos produtos das contagens e tempos de execução $\left(\sum_{i \in \text { entities }} x_{i} * t_{i}\right)$, de modo que as variáveis de contagem da execução estão sujeitas a restrições que refletem a estrutura da tarefa e os possíveis fluxos. O resultado de um cálculo IPET é um limite temporal superior e uma contagem do pior-caso, para cada variável de contagem de execução.

A Figura 3.3(c) mostra as restrições e fórmulas geradas por um método de cálculo de limite baseado em IPET para a tarefa ilustrada na Figura 3.3(a). As restrições de início e de fim definem que a tarefa deve ser iniciada e finalizada uma vez. As restrições estruturais refletem o fluxo de código possivel, o que significa que, para um bloco básico ser executado, ele deve ser acessado o mesmo número de vezes que ele é liberado. O limite de laço é especificado como uma restrição no número de vezes que o nó $A$ de encabeçamento pode ser executado.

IPET é capaz de lidar com diferentes tipos de informações de fluxo. Ele tem sido tradicionalmente aplicado de um modo global, tratando de maneira conjunta, como uma unidade, tanto à tarefa completa como toda a informação de fluxo. O cálculo de limite baseado em IPET utiliza técnicas de programação linear inteira (ILP) ou de programação restrita (CP), tendo desta forma uma complexidade potencialmente exponencial em relação ao tamanho da tarefa. Além disso, dado que as anotações de fluxo são traduzidas em restrições, o tamanho do sistema resultante de restrições aumenta com o número de anotações.

\subsubsection{Ferramenta de Análise do WCET: Chronos}

Chronos é uma ferramenta de análise do WCET para software embarcado de tempo-real [LI07]. A ferramenta utiliza como entrada o arquivo binário de um código, desmonta-o (disassembles), e realiza uma análise estática do código assembly. A análise estática envolve a análise do fluxo de código de software, 
bem como a modelagem da microarquitetura. Ao contrário da maioria dos analisadores WCET existentes, Chronos é uma ferramenta de código-aberto. Com isso, o usuário pode alterar as rotinas de análise de microarquitetura, a fim de modelar arquiteturas de processadores, novas e/ou diferentes. Desta forma, o programador ou o projetista pode sempre reutilizar as rotinas desenvolvidas implementando o procedimento padrão: extração do grafo de fluxo de controle, desmontagem do arquivo binário, etc. Adicionalmente, se um novo processador possui, por exemplo, uma estrutura de pipeline completamente diferente, é possivel alterar a análise do núcleo do pipeline com alterações mínimas à análise da estrutura cache e da unidade de predição de saltos.

Chronos é construída sobre o simulador arquitetural Simplescalar [AUSTINO2]. O Simplescalar permite ao usuário modelar flexivelmente diferentes arquiteturas para sua simulação. Ao construir Chronos desta forma, o programador pode rapidamente modelar diferentes plataformas de processadores e executar a estimativa do WCET para uma aplicação determinada. Chronos também suporta uma modelagem precisa de características avançadas da microarquitetura, tais como o pipeline "out-oforder" e a previsão dinâmica de saltos (tanto a local como a global). Para obter um arquivo binário que melhor se assemelhe à estrutura do código-fonte $\mathrm{C}$ original, a opção de otimização do compilador GCC é desligada [LIO7].

$\mathrm{Na}$ configuração que o projetista pode fazer em relação ao processador hospedeiro, Chronos permite ligar ou desligar os módulos de memória cache e de predição de saltos, porém a modelagem do pipeline é necessariamente obrigatória a fim de se fazer a análise do WCET do código sob avaliação [LIO7]. Tal como mencionado na seção 3.2.3.1 sobre a Dependência de Contexto, em Chronos o tempo de execução de um bloco básico depende não só das instruções dentro do bloco, mas também do contexto de pipeline do bloco básico. A Figura 3.4(a) é um exemplo simples de um código $\mathrm{C}$ avaliado pelo Chronos. O corpo principal do exemplo é um laço "while" com a variável $i$ como o contador do laço, e o corpo do laço contém uma estrutura "if-thenelse". O limite do laço é definido como 10. A Figura 3.4(b) é o CFG correspondente gerado por Chronos. Neste exemplo, se BB1 for executado após BBO, ele levará 5 ciclos de execução, porém, se ele é executado após BB6, o tempo de execução é de 4 ciclos. Isto acontece porque BB0 e BB6 
fornecem contextos de pipeline diferentes para BB1. De fato, a modelagem do pipeline leva a uma estimação mais precisa do WCET, sem violar a propriedade de confiabilidade da análise do WCET.

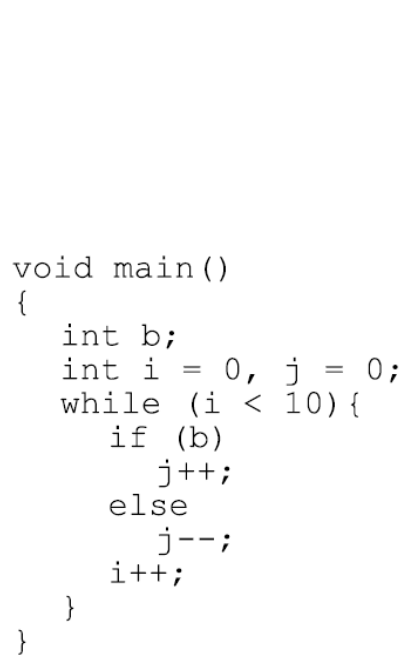

(a) Trecho de código C

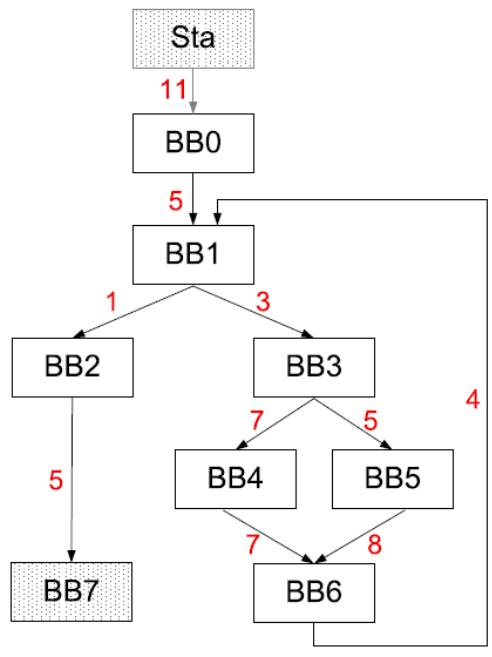

(b) CFG do código

Figura 3.4: Um exemplo de análise estática de código e seu respectivo CFG

\subsection{CARACTERIZAÇÃO DA CARGA DE TRABALHO}

A caracterização da carga de trabalho se dá através de funções e parâmetros quantitativos; o objetivo é obter um modelo capaz de exibir, capturar e reproduzir o comportamento da carga de trabalho e suas características mais importantes. O termo "características da carga de trabalho" refere-se às exigências de execução impostas pelas solicitações enviadas pelos diferentes recursos do sistema. Cada solicitação, isto é, cada componente da carga de trabalho, é descrita por um conjunto de parâmetros que explicam essas exigências [FEITELSON11]. Existem parâmetros estáticos associados ao consumo de hardware e de recursos de software, e parâmetros dinâmicos relacionados com o comportamento das solicitações. As magnitudes desses parâmetros dependem da natureza de uma única solicitação, e podem ser convenientemente utilizadas para quantificar a carga de trabalho.

\subsubsection{Trabalhos Correlatos}

Em [MAXIAGUINE04b] é proposto um método desenvolvido para caracterizar tarefas funcionais com exigências variáveis de execução através de uma 
representação das diferentes correlações entre os múltiplos tempos de execução dentro de cada tarefa. Isto é feito tendo-se em conta a carga do piorcaso (e a de melhor-caso) produzida por uma sequência ou um conjunto de execuções de cada tarefa. O modelo implicitamente inclui informações sobre todas as possiveis sequências de solicitação de diferentes tarefas, de modo tal que o comportamento de cada tarefa (com relação à carga de processamento gerada) é abstraído por curvas de carga de trabalho. Esse projeto foi baseado no conceito de modos de operação, de forma que cada sequência de vários modos é caracterizada com restrições que depois são utilizados no modelo. Tal sequência de modos está relacionada a uma sequência de eventos, tal que eventos de tipos diferentes ativam modos de operação diferentes dentro de cada execução da aplicação. Esse método, comparado com outros métodos que assumem o WCET para cada instanciação ou execução da mesma tarefa, fornece valores reduzidos da carga de processamento gerada pela tarefa.

Em [WANDELER05a], conceitos básicos de Network Calculus são estendidos para o domínio dos sistemas embarcados de tempo real, de modo que os autores propõem um modelo abstrato para representar fluxos que contêm um número finito de diferentes tipos de eventos. Especificam o fluxo de eventos de entrada através de uma máquina de estados finitos que revela uma semântica clara e simples para capturar todos os possiveis rastros (traces) de uma classe completa de fluxos de eventos. Desta forma, o modelo compreende as informações necessárias para avaliar quantitativamente os estreitos limites de carga de processamento impostas em qualquer unidade específica de processamento on-chip.

Em ambos os projetos, as exigências extremas de execução (BCET e WCET), impostas por cada evento, são assumidas como conhecidas ou implicitamente obtidas por uma simulação prévia do sistema. Na seção 6.1 desta tese, (capítulo 6), uma metodologia analitica para caracterizar as exigências extremas de execução impostas por cada evento irá ser apresentada, de modo que tal metodologia é baseada em uma análise estática das rotas do códigofonte da aplicação, e sua posterior análise temporal estática suportada pela modelagem da microarquitetura de um processador hospedeiro. 


\subsubsection{Curvas de Carga de Trabalho}

Considere uma tarefa $\tau$ executada em um processador. $\left[\sigma_{1}, \sigma_{2}, \sigma_{3}, \ldots\right]$ é uma sequência de eventos que ativam a tarefa $\tau$. Cada evento $\sigma_{i}$ nessa sequência é marcado com certo tipo $t \in T$, onde $T$ denota um conjunto finito de todos os possíveis tipos de eventos. A função tipo $\left(\sigma_{i}\right)$ retorna o tipo do evento $\sigma_{i}$ nesta sequência [MAXIAGUINE04b]. É possível caracterizar a exigência de execução imposta por um tipo de evento $t$ através de um intervalo $[\operatorname{bcet}(t), \operatorname{wcet}(t)] \in$ $R>0$, onde $b \operatorname{cet}(t)$ e $\operatorname{wcet}(t)$ denotam o BCET e o WCET do tipo $t$, respectivamente.

As seguintes funções indicam quantos ciclos de processador são consumidos no melhor-caso e no pior-caso para qualquer subsequência de $k$ eventos a partir do evento $j$ dentro da sequência completa de eventos [MAXIAGUINE04b]:

$$
\begin{aligned}
\boldsymbol{\gamma}^{\boldsymbol{b}}(j, k) & =\sum_{i=j}^{j+k-1} \operatorname{bcet}\left(\operatorname{tipo}\left(\boldsymbol{\sigma}_{\boldsymbol{i}}\right)\right) \quad j, k \in \mathbb{Z}>0 \\
\boldsymbol{\gamma}^{\boldsymbol{w}}(j, k) & =\sum_{i=j}^{j+k-1} \operatorname{wcet}\left(\operatorname{tipo}\left(\boldsymbol{\sigma}_{\boldsymbol{i}}\right)\right) \quad j, k \in \mathbb{Z}>0
\end{aligned}
$$

Onde, assume-se que $\gamma^{b}(j, 0)=0 e \gamma^{w}(j, 0)=0 \forall j$.

A partir destas expressões, uma curva de carga de trabalho superior (ou inferior) $\gamma^{u}(k)$ (ou $\gamma^{l}(k)$ ), descrito pelas expressões matemáticas (3.3) e (3.4) abaixo, dá um limite superior (ou inferior) com o número de ciclos que são necessários para processar qualquer conjunto de $k$ ativações consecutivas de uma tarefa $\tau$.

$$
\begin{aligned}
& \boldsymbol{\gamma}^{\boldsymbol{u}}(k)=\max _{\forall j \in \mathbb{Z} \geq 0} \boldsymbol{\gamma}^{\boldsymbol{w}}(j, k) \\
& \boldsymbol{\gamma}^{\boldsymbol{l}}(k)=\min _{\forall j \epsilon \mathbb{Z} \geq 0} \boldsymbol{\gamma}^{\boldsymbol{b}}(j, k)
\end{aligned}
$$

Isto significa que qualquer conjunto de $k$ ativações consecutivas de uma tarefa origina uma exigência de processamento de, no máximo, $\gamma^{u}(k)$ e, de pelo menos, $\gamma^{l}(k)$ ciclos do processador. A partir desta definição de curvas de carga de trabalho, é possivel observar que tais curvas são sequências estritamente crescentes, e, além disso, que os tempos de execução do pior-caso e do 
melhor-caso de uma tarefa são iguais a $\gamma^{\boldsymbol{l}}(1)$ e $\gamma^{\boldsymbol{u}}(1)$, respectivamente [MAXIAGUINE04b]. As curvas de carga de trabalho capturam, de um modo compacto, todas as diferentes sequências possíveis de execução de uma tarefa que podem ocorrer dentro de uma aplicação. Neste sentido, a curva de carga de trabalho não representa uma instância de sequência de execução da tarefa, mas uma classe de sequências de execução.

\subsection{CENÁRIOS DE APLICAÇÃO}

Muitas aplicações de processamento de fluxos são implementadas como um laço principal que lê, processa e escreve fluxos de eventos individuais. Um evento pode ser um bit -pertencente a um bitstream comprimido-, um marcador JPEG, um macrobloco, um quadro de vídeo, uma amostra de áudio ou um pacote de rede. A fim de se refinar a estimativa do WCET, os diferentes modos de operação identificados são agrupados em um conjunto de cenários. Um cenário é definido como o comportamento de uma tarefa para um tipo específico de eventos/dados de entrada. O conjunto de cenários deve cobrir todos os possiveis eventos de entrada.

O conceito de cenários tem sido utilizado há muito tempo em diferentes abordagens de projeto [CARROLL95, ROSSONO2, JACOBSON95], incluindo projeto de hardware e software para sistemas embarcados. Neste trabalho de doutorado, estaremos concentrados nos chamados cenários de aplicação [GHEORGHITA06], de modo que um algoritmo de agrupamento analisa a quantidade de tempo de execução estimado para cada modo de operação identificado pela análise estática de rotas, e em seguida, agrupa os diferentes modos em cenários de aplicação, considerando que a quantidade de tempo de execução estimado para os modos de operação dentro de um cenário sempre deve ser bastante similar.

\subsection{CURVAS DE CARACTERIZAÇÃO DE VARIABILIDADE}

O conceito de Curvas de Caracterização de Variabilidade (Variability Characterization Curves, VCCs) [MAXIAGUINE04a] é definido nesta seção de uma forma genérica, isto é, sem levar em conta qualquer propriedade concreta de sistema, que tais curvas possam caracterizar. Igualmente serão definidas 
algumas propriedades que são comuns a todas as VCCs e que serão úteis no decorrer desta seção e das contribuições apresentadas no capítulo 5 da tese.

\subsubsection{Definições preliminares}

As Curvas de Caracterização de Variabilidade (Variability Characterization Curves, VCCs) podem ser utilizadas para quantificar as características de melhor-caso e de pior-caso de alguns tipos de sequências. Estas sequências podem ser de objetos consecutivos de fluxo pertencentes a uma cadeia, ou sequências de intervalos de tempo consecutivos de algum comprimento específico. Uma VCC $\mathcal{V}$ é definida como uma dupla $\left(\mathcal{V}^{l}(k), \mathcal{V}^{u}(k)\right)$, onde $k$ representa o comprimento da sequência.

Seja uma função $P$ a medida de alguma propriedade dentro de uma sequência, tal que $P(n)$ indica a medida crescente desta propriedade para os primeiros $n$ elementos da sequência. Formalmente, uma função $f$ é crescente se $f\left(x_{1}\right) \leq$ $f\left(x_{2}\right)$ para qualquer $x_{1}<x_{2}$. Em contraste, $f$ é estritamente crescente, se $f\left(x_{1}\right)<f\left(x_{2}\right)$ sempre que $x_{1}<x_{2}$.

Usando esta notação, e dada uma função crescente $P(n)$ para todo $n \geq 0$, as $\operatorname{VCCs} \mathcal{V}^{l}(k)$ e $\mathcal{V}^{u}(k)$ são definidas, para todo $k \geq 0$, como segue:

\section{Definição - VCC Superior:}

Uma VCC superior, para o conjunto de funções crescentes $P$, é uma função crescente $\mathcal{V}^{u}(k)$ que satisfaz a condição:

$$
\mathcal{V}^{u}(k)=\sup _{i \geq 0}\{P(i+k)-P(i)\}
$$

\section{Definição - VCC Inferior:}

Uma VCC inferior para o conjunto de funções crescentes $P$ é uma função crescente $\mathcal{V}^{l}(k)$ que satisfaz a condição:

$$
\mathcal{V}^{l}(k)=\inf _{i \geq 0}\{P(i+k)-P(i)\}
$$

Por conseguinte, $\mathcal{V}^{l}(k)$ e $\mathcal{V}^{u}(k)$ fornecem um limite inferior e superior para a medida $P$, para todas as subsequências de comprimento $k$ dentro de uma sequência maior. 
Antes de apresentar alguns exemplos concretos de VCCs para a modelagem de cargas de trabalho de aplicações multimídia, é conveniente apontar uma propriedade importante de qualquer VCC, independentemente do seu tipo particular: Uma VCC única pode servir como uma abstração compacta de toda uma classe de sequências ou funções com variabilidade semelhante do piorou melhor-caso. Desta forma, as VCCs representam um meio atrativo para capturar vários aspectos do comportamento de um sistema no contexto do projeto de sistemas embarcados heterogêneos, onde tais abstrações são necessárias para dominar a complexidade dos problemas de projeto [MAXIAGUINE04a].

\subsubsection{Definições de tipos de VCC em Aplicações Multimídia [MAXIAGUINE05]}

Esta seção foi feita de uma tradução livre da seção 3.3.2 da tese de doutorado de [MAXIAGUINE05].

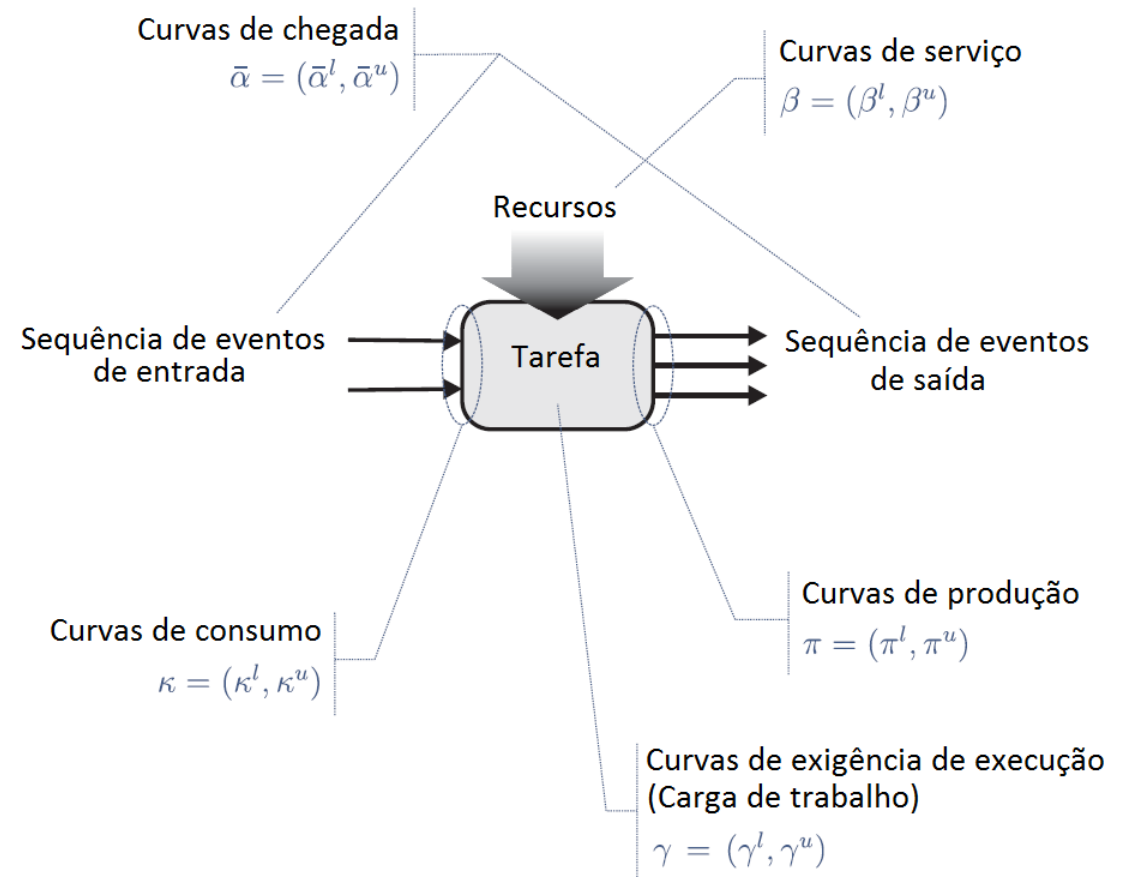

Figura 3.5: Algumas VCCs utilizadas para modelar a carga de trabalho de aplicações multimidia [MAXIAGUINE05].

As características fundamentais de carga de trabalho a serem capturadas em um modelo de carga de trabalho são aquelas características que afetam as propriedades de temporização dos fluxos de solicitação e de recursos, assim como suas respectivas interações. Nesta subseção, estas características fundamentais serão identificadas a fim de definir os diferentes tipos de VCC 
que permitem caracterizá-las. Alguns dos tipos de VCC que serão introduzidos a seguir estão indicados na Figura 3.5, a qual apresenta uma visão abstrata de uma tarefa multimídia.

\subsubsection{Curvas de Chegada Baseadas em Eventos}

O tempo de solicitação de um conjunto de tarefas para utilizar um determinado serviço é influenciado pelo tempo de chegada dos objetos do fluxo que chega aos canais de entrada desta tarefa. Estas chegadas dependem das tarefas que escrevem nestes canais de entrada (ou, do ambiente do sistema, se o fluxo for recebido de fora do sistema). Cada entrada em um canal pode ser modelada como um evento. Desta forma, uma sequência de chegada em um canal dado pode ser representada como um fluxo de eventos. Similar ao modelo de caracterização descrito na seção 2.2.1.1, as propriedades de temporização de tais fluxos de eventos são modeladas com VCCs chamadas curvas de chegada baseadas em eventos [MAXIAGUINE05].

Definição - Curvas de chegada baseadas em eventos $\left(\bar{\alpha}=\left(\overline{\boldsymbol{\alpha}}^{l}, \overline{\boldsymbol{\alpha}}^{u}\right)\right)$ :

Uma curva de chegada inferior baseada em eventos $\bar{\alpha}^{l}$, e uma curva de chegada superior baseada em eventos $\bar{\alpha}^{u}$, são VCCs que caracterizam as propriedades de temporização de um fluxo dado de eventos. $\bar{\alpha}^{l}(\Delta)$ limita por baixo, e $\bar{\alpha}^{u}(\Delta)$ limita por cima, o número de eventos que podem ocorrer no fluxo dentro de qualquer intervalo de tempo de duração $\Delta$.

\subsubsection{As curvas de Consumo}

Outro fator que influencia o tempo de solicitação de tarefas para utilizar um serviço é a quantidade de objetos de fluxo que deve estar disponível em um determinado canal de entrada a fim de ativar a tarefa. Esta quantidade pode variar de ativação para ativação, por exemplo, devido a um comportamento da tarefa dependente de dados. As ativações sucessivas da tarefa resultam em uma sequência de números que representam as quantidades de objetos de fluxo consumidos pela tarefa a partir de um determinado canal de entrada em cada ativação. Como uma abstração de tais sequências usa-se as VCCs chamadas de curvas de consumo [MAXIAGUINE05]. 
Definição - Curvas de Consumo $\left(\kappa=\left(\kappa^{l}, \kappa^{u}\right)\right)$ :

Uma curva inferior de consumo $\kappa^{l}$, e uma curva superior de consumo $\kappa^{u}$, são VCCs que caracterizam a relação entre as ativações das tarefas e o número de objetos de fluxo consumidos pela tarefa a partir de uma determinada entrada de canal. $\kappa^{l}(k)$ limita por baixo, e $\kappa^{u}(k)$ limita por cima, o número de ativações de tarefas requeridas para consumir $k$ objetos de fluxo consecutivos a partir do canal de entrada.

Além da quantidade de objetos de fluxo que devem estar presentes em cada canal individual para ativar a tarefa, as regras de ativação podem impor certas condições ao conjunto de canais de entrada como um todo. As implicações de tais regras também podem ser refletidas nas curvas de consumo. Alternativamente, essas regras podem ser contabilizadas no nível superior de modelagem, ou seja, no modelo de desempenho em si. [JERSAK04] apresenta trabalhos nesta direção.

\subsubsection{Curvas de Exigência de Execução}

A quantidade de recursos de execução requerida por uma tarefa em cada ativação pode variar dependendo, por exemplo, no estado atual da tarefa e os valores dos objetos de fluxo processados, ou em características arquiteturais tais como caches, unidades de predição de saltos e pipelines. Uma sequência de ativações de tarefa resulta em uma sequência de exigências de execução impostas pela tarefa ao elemento de processamento (PE). Para modelar tais sequências usam-se as curvas de exigência de execução [MAXIAGUINE05].

\section{Definição - Curvas de Exigência de Execução $\left(\boldsymbol{\gamma}=\left(\boldsymbol{\gamma}^{l}, \boldsymbol{\gamma}^{\boldsymbol{u}}\right)\right)$ :}

Uma curva inferior de exigência de execução $\gamma^{l}$, e uma curva superior de exigência de execução $\gamma^{u}$, são VCCs que caracterizam a exigência de execução de uma determinada tarefa. $\gamma^{l}(k)$ limita por baixo, e $\gamma^{u}(k)$ limita por cima, a quantidade de unidades de recursos (tais como ciclos de processador) requeridas para completar qualquer número $k$ de execuções consecutivas da tarefa. 


\subsubsection{Curvas de Produção}

As propriedades de temporização dos fluxos de eventos gerados por uma tarefa em suas saídas dependem da quantidade de objetos de fluxo produzidos pela tarefa para os canais de saída em cada ativação. Novamente, esta quantidade pode variar de ativação para ativação. Para caracterizar este aspecto de sequências de ativação da tarefa, utilizam-se as VCCs chamadas curvas de produção [MAXIAGUINE05].

\section{Definição - Curvas de Produção $\left(\pi=\left(\pi^{l}, \pi^{u}\right)\right)$ :}

Uma curva inferior de produção $\pi^{l}$, e uma curva superior de produção $\pi^{u}$, são VCCs que caracterizam a relação entre execuções da tarefa e o número de objetos de fluxo produzidos pela tarefa em um determinado canal de saída. $\pi^{l}(k)$ limita por baixo, e $\pi^{u}(k)$ limita por cima, o número de objetos de fluxo produzidos pela tarefa no canal de saída, como um resultado de $k$ execuções consecutivas desta tarefa.

\subsubsection{Curvas de Serviços Baseadas em Recursos}

Um fator importante que influencia em grande parte às características de desempenho é a disponibilidade de recursos de execução para uma determinada tarefa ao longo do tempo. Várias tarefas mapeadas em um único $\mathrm{PE}$ podem concorrer para o recurso de execução deste PE. A política de escalonamento ou arbitragem determina, então, a ordem em que essas tarefas devem ser executadas no PE. Como consequência, a oferecimento de recursos para as tarefas não é mais uniformemente distribuído no tempo. Esta variabilidade da capacidade de processamento do $\mathrm{PE}$, como vista por uma tarefa individual, é caracterizada usando curvas de serviço baseadas em recursos [MAXIAGUINE05].

\section{Definição - Curvas de Serviço Baseadas em Recursos $\left(\beta=\left(\beta^{l}, \beta^{u}\right)\right)$ :}

Uma curva inferior de serviço baseada em recursos $\beta^{l}$, e uma curva superior de serviço baseada em recursos $\beta^{u}$, são VCCs que caracterizam o serviço oferecido a uma determinada tarefa em um recurso de execução determinado. 
$\beta^{l}(\Delta)$ limita por baixo o número de unidades de recursos (tais como ciclos de processador) que são garantidos para serem fornecidos à tarefa dentro de qualquer intervalo de tempo de tamanho $\Delta$. Igualmente, $\beta^{u}(\Delta)$ limita por cima o número de unidades de recursos que podem ser fornecidos para a tarefa dentro de qualquer intervalo de tempo de tamanho $\Delta$.

\subsubsection{Curvas de Taxa de Tipo}

Em alguns casos, para a análise do desempenho é útil distinguir dentro de um fluxo de eventos (ou qualquer outra sequência) diferentes tipos de eventos. Por exemplo, isso pode ser útil no caso quando diferentes tipos de eventos impõem exigências de execução diferentes em um PE. Os diferentes tipos de eventos podem seguir vários padrões dentro do fluxo. Para a caracterização de tais padrões, utilizam-se as chamadas curvas de taxas de tipo [MAXIAGUINE05, WANDELER05b].

Definição - Curvas tipo de taxa $\left(\boldsymbol{\vartheta}=\left(\boldsymbol{\vartheta}^{l}, \vartheta^{\boldsymbol{u}}\right)\right)$ :

Uma curva inferior de taxa de tipo $\vartheta^{l}$, e uma curva superior de taxa de tipo $\vartheta^{u}$, são VCCs que caracterizam a contenção de um tipo determinado de evento em um fluxo dado de eventos. $\vartheta^{l}(k)$ limita por baixo, e $\vartheta^{u}(k)$ limita por cima, o número de eventos do tipo dado em qualquer subsequência de $k$ eventos consecutivos dentro do fluxo de eventos.

\subsubsection{Curvas de Serviços Baseadas em Eventos e Curvas de Chegada Baseadas em Recursos}

Em contraste com as curvas de serviço baseadas em recursos, as curvas de serviços baseados em eventos expressam a disponibilidade de um PE para uma determinada tarefa em termos de execuções de tarefas em vez de ciclos do processador. Do mesmo modo, em contraste com as curvas de chegada baseadas em eventos, as curvas de chegada baseadas em recursos (por exemplo, ciclos de processador) expressam a quantidade de recursos solicitada por uma tarefa. 
Definição - Curvas de Serviço baseado em eventos $\left(\overline{\boldsymbol{\beta}}=\left(\overline{\boldsymbol{\beta}}^{l}, \overline{\boldsymbol{\beta}}^{u}\right)\right)$ :

Uma curva inferior de serviço baseada em eventos $\bar{\beta}^{l}$, e uma curva superior de serviço baseada em eventos $\bar{\beta}^{u}$, são VCCs que caracterizam o serviço oferecido a uma determinada tarefa em um determinado recurso a execução. $\bar{\beta}^{l}(\Delta)$ limita por baixo o número de execuções de tarefas que são garantidas para terminar dentro de qualquer intervalo de tempo com tamanho $\Delta$. Igualmente $\bar{\beta}^{u}(\Delta)$ limita por cima o número de execuções de tarefa que podem ser concluídas dentro de qualquer intervalo de tempo de tamanho $\Delta$.

\section{Definição - Curvas de Chegada baseada em recursos $\left(\alpha=\left(\alpha^{l}, \alpha^{u}\right)\right)$ :}

Uma curva inferior de chegada baseada em recursos $\alpha^{l}$, e uma curva superior de chegada baseada em recursos $\alpha^{u}$, são VCCs que caracterizam o serviço solicitado por uma determinada tarefa a partir de um recurso de execução dado. $\alpha^{l}(\Delta)$ limita por baixo, e $\alpha^{u}(\Delta)$ limita por cima, o número de unidades de recursos (tais como ciclos de processador), que podem ser solicitados pela tarefa em qualquer intervalo de tempo de tamanho $\Delta$. 


\section{Capítulo 4}

\section{MODELAGEM BASEADA EM ATORES TEMPORAIS}

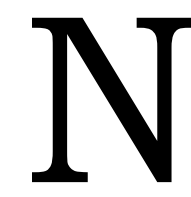

este capítulo serão apresentados conceitos e definições referentes ao tratamento dos atores de um grafo de SDF como atores temporais definidos por interfaces, tal que esses conceitos fazem parte da metodologia conhecida como projeto orientado a atores [LEE04]. Esses conceitos são o fundamento da modelagem do comportamento temporal, baseado em cenários, de uma aplicação multimídia, modelagem que será apresentada posteriormente no capítulo 5 .

Inicialmente será apresentada a metodologia de projeto orientada a atores, da qual vários trabalhos correlatos são identificados a fim de descrever a maneira como cada tarefa, componente ou bloco de um sistema pode ser abstraído utilizando esta metodologia. Posteriormente, é apresentada a descrição de atores temporais definidos por interfaces, para grafos de SDF, de modo que faz-se explícita a descrição dos fluxos de eventos entre os diversos atores, ao longo das iterações que definem a execução do grafo. Esta descrição do fluxo de eventos é suportada pela Álgebra de Max-Plus, brevemente apresentada no final do capítulo.

\subsection{METODOLOGIA DE PROJETO ORIENTADO A ATORES}

Nesta metodologia, os componentes de um sistema são chamados de atores, os quais se executam e comunicam com outros atores, dentro de um modelo. Tais atores têm uma interface de componente bem definida, de modo que essa interface abstrai o estado interno e o comportamento de um ator, e restringe o modo como um ator interage com o seu ambiente. A interface inclui portas que representam pontos de comunicação para o ator, assim como parâmetros que são utilizados para configurar o funcionamento do ator. Frequentemente, os valores dos parâmetros são parte da configuração a priori de um ator e não 
mudam enquanto um modelo é executado. A configuração de um modelo também apresenta os canais de comunicação que passam dados de uma porta para outra. O uso de canais para definir a comunicação implica que os atores interagem apenas com os canais aos quais estão conectados, e não diretamente com outros atores [LEE04].

Essencialmente, o projeto orientado a atores permite aos projetistas considerar a interação entre os componentes separadamente da especificação do comportamento do componente. Igualmente, o projeto orientado a atores permite compor objetos com comportamento simples, a fim de criar comportamentos mais complexos, repetindo tais composições repetidamente e de maneira robusta.

Tal como atores, os quais têm interfaces externas bem definidas, os modelos (que são as composições de atores interconectados) também podem possuir uma interface externa. As interfaces externas permitem abstrações hierárquicas. Esta interface consiste de portas externas e parâmetros externos, os quais são diferentes das portas e dos parâmetros dos atores individuais dentro do modelo. As portas externas de um modelo podem ser conectadas a outras portas externas do modelo através de canais. Por sua vez, os parâmetros externos de um modelo podem ser utilizados para determinar os valores dos parâmetros dos atores dentro do modelo. Colocando todo junto, os conceitos de modelos, atores, portas, parâmetros e canais descrevem a sintaxe abstrata do projeto orientado a atores.

Há muitos exemplos de plataformas, linguagens e técnicas de software orientados a atores, incluindo ferramentas como o Simulink (Mathworks), Labview (National Instruments), System Studio (Synopsys); linguagens como VHDL, Verilog, SystemC; e plataformas como Polis e Metropolis (UC Berkeley) [GÖSSLER02], e Ptolomey (UC Berkeley) [LEE03].

\subsubsection{Projeto Baseado em Interfaces}

Os métodos clássicos de análise de desempenho no nível de sistemas são utilizados para a análise de sistemas embarcados distribuídos de tempo-real, de modo que tal análise é posterior à especificação e ao projeto do sistema. Nestes casos, somente após a conclusão da etapa de projeto, é que a análise de desempenho é aplicada ao projeto do sistema, como uma segunda etapa. É 
neste momento que o resultado da análise irá confirmar se o projeto do sistema desenvolvido na primeira etapa cumpre, ou não, com todos os requisitos de tempo real. Em caso negativo, o projetista deverá voltar para a primeira etapa, realizar modificações necessárias no projeto, e iterar sobre as duas etapas até que um projeto apropriado do sistema seja encontrado. Um exemplo desta abordagem são as metodologias de exploração de espaço de projeto apresentadas no capítulo 1, na seção 1.1 .

Contrária a esta abordagem, existe o projeto baseado em interface [ALFARO01, ALFARO05]. Tal proposta consiste em uma abordagem com uma etapa para o projeto e análise de sistemas, onde os componentes têm interfaces, e o projetista pode decidir se dois componentes podem se conectar para operar em conjunto satisfazendo os requisitos de tempo real, baseado apenas nas informações expostas pelas respectivas interfaces. Tal teoria suporta as propriedades cruciais de refinamento, projeto incremental $\mathrm{e}$ implementabilidade independente [STOIMENOV11].

Uma interface de componente modela o modo como um componente pode ser utilizado, o que está em contraste com a descrição fornecida por um componente abstrato, quando somente aquilo que o componente faz é modelado. Através de premissas na entrada, uma interface de componente modela o que o componente espera dos outros componentes do sistema, e do meio ambiente. Por outro lado, através de garantias na saída, uma interface de componente informa ao resto do sistema, e ao ambiente, o que pode ser esperado do seu respectivo componente. Normalmente tais premissas e garantias especificam intervalos de valores permissiveis de parâmetros específicos do sistema, tais como taxas de entrada de dados, velocidade dos processadores, larguras de banda de comunicação, etc. A composição de componentes em um projeto de sistema é permitida só se as premissas e garantias de interface forem compativeis, de modo que automaticamente elas irão satisfazer todas as restrições na especificação do sistema.

\subsubsection{Trabalhos Correlatos}

\subsubsection{Interfaces de Tempo Real}

Os trabalhos [WANDELER05c, WANDELER06b] apresentam as Interfaces de Tempo-Real (RTI). Unindo os princípios de Real-Time Calculus com o projeto 
baseado em interfaces, as RTIs permitem o projeto de sistemas de tempo-real dentro da plataforma de Análise de Desempenho Modular [WANDELER06a] (ou MPA, seção 2.2.1).

As RTIs são desenvolvidas para lidar com múltiplas premissas e garantias sobre a vazão e o atraso de eventos, assim como a disponibilidade dos recursos. Além destas propriedades, as RTIs também suportam adaptabilidade dinâmica [WANDELER05c, WANDELER06b]. Essas interfaces não expõem apenas informações suficientes para resolver sua capacidade de composição com interfaces de outros componentes, mas também mudam suas premissas e garantias quando componentes novos são adicionados (ou removidos) para (ou de) um sistema parcialmente projetado, seguindo os princípios de propagação de restrições [WANDELER06b].

$\mathrm{Na}$ descrição das RTIs, é feita uma distinção entre componentes abstratos e suas interfaces adaptativas. Os componentes abstratos descrevem os blocos de construção para uma análise ampla de todo o sistema. Eles podem representar diversas entidades combináveis, tais como tarefas, recursos e técnicas de escalonamento. As instâncias das entradas e das saídas de tais componentes representam todas as propriedades relevantes dos componentes concretos de hardware/software, tais como as capacidades dos recursos ou seus fluxos de eventos. Em resumo, um componente abstrato fornece um modelo matemático abstrato de um componente de hardware/software.

De outro lado, as interfaces adaptativas, tal como são usadas no contexto de sistemas de tempo-real [WANDELER05c, WANDELER06b], não só permitem este tipo de análise em sistemas de tempo-real, mas também dão um suporte adicional ao projeto, fornecendo mecanismos para propagar restrições, tais como os atrasos (fim-a-fim), recursos de computação e comunicação, espaços de buffer, e energia. As premissas e garantias deixam de ser estáticas, adaptando-se de acordo com as mudanças nas restrições do sistema. Tais mudanças ocorrem quando o ambiente do sistema muda seus requerimentos ou novos componentes são adicionados aos sistemas, quando os componentes existentes são removidos ou mudam seus parâmetros. Tais mudanças podem ocorrer durante a fase de projeto quando diferentes escolhas do projeto são avaliadas, ou, em fase de execução, se os requisitos dirigidos ao sistema puderem mudar dinamicamente. 
De um ponto de vista formal, um componente abstrato $F$ é a tupla $(X, Y, T, \Psi)$ onde $X$ é um conjunto de variáveis de entrada, $Y$ é um conjunto de variáveis de saída, $T$ é função de transferência, e $\Psi$ é um predicado sobre as variáveis de entrada $X$. Um componente abstrato pode funcionar apropriadamente se e só se $\Psi$ é validado para algum valor das variáveis de entrada $X$.

A função de transferência $T(X)$ representa a transformação dos valores de entrada $X$ para os valores de saída $Y$ na análise, isto é, $Y=T(X)$. O predicado $\Psi(\mathrm{X})$ restringe o escopo no qual o componente analisado pode ser utilizado. $\mathrm{O}$ predicado formaliza a noção de que um componente pode trabalhar apropriadamente, isto é, de que ele satisfaz certos requisitos de tempo-real.

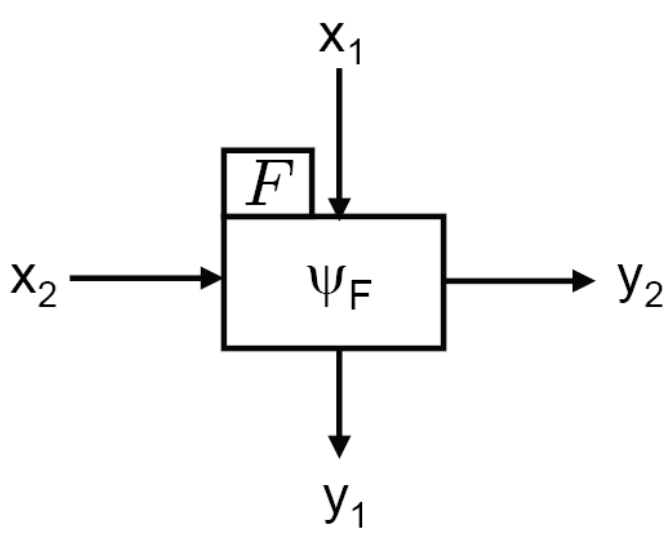

(a)

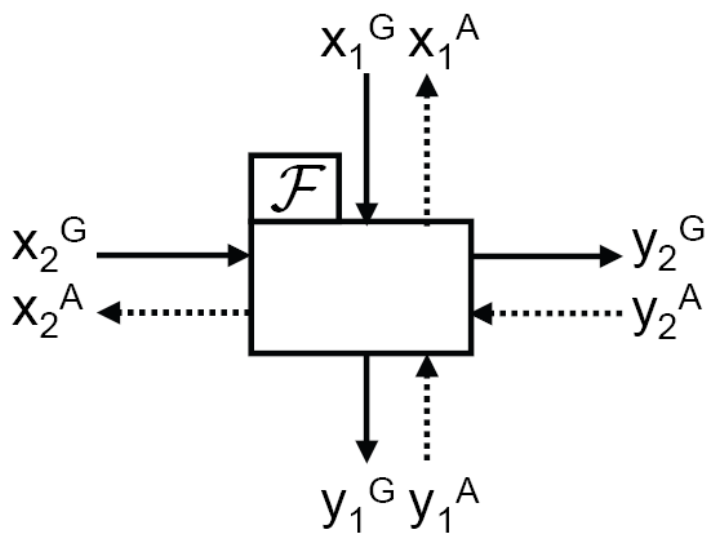

(b)

Figura 4.1: Um componente abstrato simples $F$ e sua representação de interface adaptativa [WANDELER06b].

Como exemplo, Considere-se que uma série de fluxos de pacotes determinado compartilha uma unidade de comunicação. A análise simplesmente adiciona as taxas de dados aos fluxos e exige que a taxa acumulada não exceda a largura de banda disponivel. A Figura 4.1(a) representa um componente abstrato correspondente, $F$, onde $x_{2}$ representa a largura de banda disponivel, e $x_{1}$ à largura de banda utilizada por um único fluxo de pacote. Note-se que o fluxo de pacotes de saída $y_{1}$ pode desencadear uma exigência computacional em uma unidade de computo que esteja conectada à unidade de comunicação. $y_{2}$ representa a largura de banda restante disponivel para outros fluxos. $F$ denota que o componente funciona adequadamente só se a largura de banda disponivel for maior que a solicitada. Neste exemplo, as variáveis de entrada e de saída são números reais não-negativos. Deste modo, as variáveis do 
componente abstrato representam uma abstração do comportamento real do componente, onde $X_{F}=\left(x_{1}, x_{2}\right), Y_{F}=\left(y_{1}, y_{2}\right)$, representam abstrações das suas entradas e saídas, respectivamente. O componente funciona corretamente se $\Psi_{\mathrm{F}}\left(X_{F}\right)$ é satisfeito.

Ao fazer a transição de um componente abstrato $F$ à sua interface de temporeal adaptativa $\mathcal{F}$, (ver Figura 4.1(b)), variáveis de entrada e de saída, e ordens parciais implícitos, são obtidas. As variáveis denotadas com $G$ sobrescrito são chamadas de valores garantidos, $X_{\mathcal{F}}^{G} \geq X_{F}, Y_{\mathcal{F}}^{G} \leq Y_{F}$.

Isto significa que uma rede de componentes abstratos funciona corretamente quando as variáveis dos componentes abstratos são "menores" do que os valores garantidos na rede de interfaces correspondente. O predicado $\Psi_{\mathrm{F}}$ é transformado em novas variáveis de premissa $X_{\mathcal{F}}^{A}$ (denotadas com $A$ sobrescrito). Isto significa que sempre que $X_{\mathcal{F}}^{A} \geq X_{\mathcal{F}}^{G}$, então $\Psi_{\mathrm{F}}$ é satisfeito. Desta forma, a interface adaptativa faz com que o predicado $\Psi_{\mathrm{F}}$ fique explícito na forma de variáveis de suposições de entrada adicionais. Elas também aparecem nas saídas de outras interfaces adaptativas como variáveis de suposições de saída. Portanto, as seguintes interpretações podem ser dadas:

Variáveis de premissas de entrada: As variáveis $X_{\mathcal{F}}^{A}$ descrevem a premissa do componente para o meio ambiente, ou outros componentes. Se $X_{\mathcal{F}}^{A} \geq X_{\mathcal{F}}^{G}$, então, (a) o componente correspondente trabalha corretamente, e (b) os pedidos de todos os componentes conectados (indicado por $Y_{\mathcal{F}}^{A}$ ) são satisfeitos, isto é $Y_{\mathcal{F}}^{A} \geq Y_{\mathcal{F}}^{G}$

Variáveis de premissas de saida: As variáveis $Y_{\mathcal{F}}^{A}$ descrevem a premissa do ambiente, ou outros componentes, para $F$, ou seja, elas solicitam que $Y_{\mathcal{F}}^{A} \geq Y_{\mathcal{F}}^{G}$.

O principal objetivo de uma boa interface de componente é, então, fornecer informações suficientes para decidir se dois ou mais componentes podem 
trabalhar juntos de maneira adequada, tal que, no caso de interfaces de componentes para análise de desempenho de sistemas de tempo-real, a frase "de maneira adequada" refere-se a questões como: o sistema composto satisfaz todas as propriedades de tempo real requeridas, tais como as restrições de atraso e vazão?

Três etapas básicas podem identificar o projeto de sistema de tempo-real baseado em interfaces:

1. A definição de um componente abstrato que descreva as propriedades de tempo-real de um componente concreto do sistema de HW/SW. Isto implica a definição de abstrações adequadas para as entradas e as saídas dos componentes, também como as relações internas dos componentes que significativamente relacionam as entradas abstratas com as saídas abstratas.

2. A obtenção da interface de um componente abstrato, para a qual é necessário definir as variáveis de interface, bem como predicados de entrada e saída sobre essas variáveis de interface.

3. A fim de permitir a adaptabilidade dinâmica, é preciso estabelecer as relações internas de interface que relacionam as garantias e premissas entrantes, com as garantias e premissas que saem da interface.

\subsubsection{Análise de Desempenho Composicional de Sistemas de Tempo Real de Fluxo de Dados Cíclicos}

$\mathrm{Na}$ abordagem de projeto comentado na subseção anterior, um projetista pode decidir se dois componentes podem trabalhar juntos apenas inspecionando suas interfaces, sem considerar os detalhes da implementação interna dos componentes. Uma das principais limitações dessa abordagem é que ela só se aplica a redes de componentes livres de laços direcionados (isto é, arcos direcionados definindo, por exemplo, realimentações entre componentes). O trabalho [STOIMENOV11] apresenta um método de análise de desempenho que pode trabalhar com sistemas cuja rede de componentes contém laços direcionados. Neste caso, os ciclos no fluxo de informação entre os processos individuais de uma aplicação apresentam dependência global em função do estado do sistema completo. Como resultado, o comportamento temporal de um processo (e a utilização dos recursos disponíveis), não só depende dos 
processos anteriores que fornecem os fluxos de dados a serem processados, mas também dos processos sucessores, assim como do próprio processo. Exemplos típicos de tais sistemas são os sistemas embarcados paralelos e distribuídos os quais executam aplicações de controle e de processamento de sinais. Eles são frequentemente especificados como grafo de fluxos de dados com laços de dependência. Exemplos dos modelos de computação correspondentes são os grafos marcados ou grafos de SDF. A Figura 4.2 apresenta um exemplo do problema avaliado pela metodologia de Análise de Desempenho Composicional de Fluxo de dados Cíclicos [STOIMENOV11], onde dois grafos marcados são mapeados a uma plataforma distribuída e os processos individuais compartilham recursos disponiveis usando algum esquema de escalonamento.

Assim, o trabalho [STOIMENOV11] descreve uma abordagem de análise de desempenho composicional de grafos de fluxos de dados cíclicos onde o método proposto lida com laços no fluxo de eventos. O método resulta em limites mais restritivos para parâmetros essenciais, tais como o tamanho do buffer, os atrasos fim-a-fim, e a vazão. Devido à generalidade dessa abordagem, o projetista pode analisar não só sistemas que contém fluxos de eventos cíclicos, mas também implementações que contenham buffers de tamanhos finitos que produzem "contrapressão" em todo o sistema causado pela semântica de bloqueio-na-escrita. A incorporação dessa abordagem na plataforma de Análise de Desempenho Modular [WANDELER06a] (ou MPA, seção 2.2.1) permite a análise de implementações distribuídas que utilizam mecanismos de compartilhamento de recursos, tais como o escalonamento por Prioridade Fixa (FP) e o Acesso Múltiplo por Divisão no Tempo (Time Division Multiple Access, TDMA).

Os grafos marcados da Figura 4.2 compartilham um conjunto de dispositivos de computação e comunicação por meio de politicas de escalonamento FP e TDMA, mostrando uma interação complexa com o meio ambiente. O grafo marcado 1 (MG1) assume a existência de buffers finitos entre os processos $v_{1} \rightarrow v_{2}$ e $v_{2} \rightarrow v_{3}$ limitados ao tamanhos máximo de 1 e 2 , respectivamente. Da mesma forma, o grafo marcado 2 (MG2) também assume a existência de buffers finitos e compartilha a mesma plataforma de execução com MG1. Nesse caso, o interesse da metodologia de Análise de Desempenho Composicional de Fluxo de dados Cíclicos é determinar as características 
essenciais do sistema para os dois grafos, tais como os atrasos fim-a-fim, os tamanhos dos buffers, e a vazão.

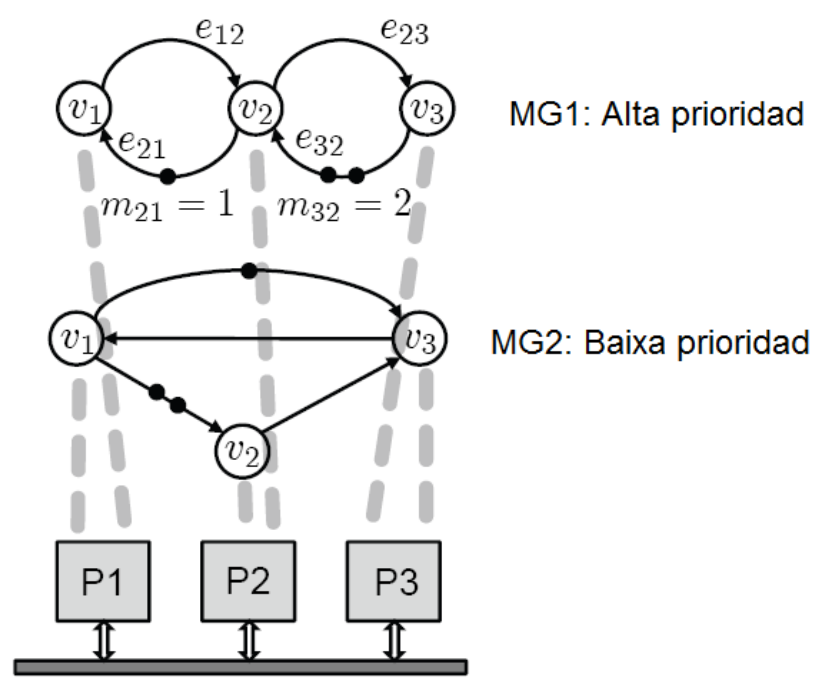

Figura 4.2: Visualização do problema avaliado pela metodologia de Análise de Desempenho Composicional de Fluxo de Dados Cíclicos [STOIMENOV11].

Ao contrário de outros métodos, essa abordagem leva em conta um modelo geral para a interação de recursos baseado no conceito de curvas de serviços, cobrindo modelos de recursos tradicionais tais como o periódico e o atraso limitado [THIELE09], como casos especiais, e um modelo geral de fluxos de dados baseado em curvas de chegada, que cobre modelos tradicionais de fluxo de dados, tais como os modelos periódicos, esporádicos, periódicos com jitter e periódicos com rajadas [THIELE09], como casos especiais. O modelo descreve uma abstração gradual que vai de uma caracterização de um grafo marcado no domínio do tempo a uma representação abstrata no domínio de intervalo temporal, o qual é depois utilizado para determinar os indicadores de desempenho essenciais, e para incorporar a análise em um esquema de composição de sistema baseado em MPA [WANDELER06a].

\subsubsection{Interfaces de Atores Temporais}

O trabalho de [GEILEN11b] também segue as teorias de interface [ALFARO05], as quais também pode ser vistas como teorias focadas em um comportamento dinâmico e concorrente. As interfaces desse trabalho, chamadas de interfaces de ator, são inspiradas nos modelos de computação orientados a atores, tais como as redes de processos [KAHN74] e os fluxos de dados [DENNIS74]. 
Os atores operam consumindo e produzindo tokens em suas portas de entrada e de saída, respectivamente. Visto que o principal objetivo dessa proposta é a análise temporal e de desempenho, a abordagem abstrai-se completamente dos valores dos tokens, e interessa-se apenas com o tempo no qual esses tokens são produzidos. Os atores são então definidos pelas relações entre as sequências de entrada e de saída de eventos discretos que ocorrem em um eixo de tempo determinado.

As principais contribuições do trabalho em [GEILEN11b] são as seguintes:

- Desenvolver uma teoria de interface de atores temporais com uma relação de refinamento que segue o princípio de "enquanto mais cedo, melhor" (The Earlier-is-Better), preservando os limites do pior-caso nas métricas de desempenho (vazão, latência).

- Unificar os modelos existentes (SDF e suas variantes, autômatos finitos, curvas de serviço, etc), tratando os atores semanticamente, através de relações de sequências de eventos, ao invés de sintaticamente, como definido por modelos específicos tais como autômatos ou fluxo de dados.

\subsection{DESCRIÇÃO DE ATORES}

\subsubsection{Introdução}

Nesta tese, a descrição dos atores que compõem os grafos de SDF é baseada no conceito de interfaces de ator, definidos em [GEILEN10b, GEILEN11b], onde cada ator é descrito a partir das relações entre as sequências, finitas ou infinitas, de tokens de entrada, e as sequências de tokens de saída de cada tarefa representada dentro do $\mathrm{SDF}$, tal que o conteúdo de cada token não é considerado na análise do SDF, focando-se apenas nos tempos de chegada ou de produção dos tokens representados como marcas de tempo definidos em um domínio de tempo contínuo e totalmente ordenado, $(\mathcal{T}, \leq)$.

$\mathcal{T}$ contém um elemento mínimo denotado por 0 . A fim de que o domínio de $\mathcal{T}$ também inclua um elemento máximo denotado por $\infty$, de modo que $\mathrm{t}<\infty$ para todos os $t \in \mathcal{T}$, define-se um domínio estendido $\mathcal{T}^{\infty}$ denotado $\mathcal{T} \cup\{\infty\}$. $\mathbb{N}$ denota $o$ 
conjunto dos números naturais e assume-se que $0 \in \mathbb{N}$. $\mathbb{R}$ denota o conjunto de números reais, e $\mathbb{R}^{\geq 0}$ representa o conjunto dos reais não-negativos.

\section{Definição - Sequência de Eventos:}

Uma sequência de eventos é um mapeamento total $\tau: \mathbb{N} \rightarrow \mathcal{T}^{\infty}$, de modo que $\tau$ é fracamente monótono, isto é, para cada $k, m \in \mathbb{N}$ e $k \leq m$, temos $\tau(k) \leq \tau(m)$. Desta forma, $\tau(n)$ captura o tempo de chegada do $n$-ésimo evento ou token.

Para os eventos $i \in \mathbb{N}$ considerados como ausentes dentro da sequência $\tau(n)$, interpreta-se que o seu respectivo tempo é $\tau(i)=\infty$. Assim, todos os eventos $n>i$ também devem estar ausentes [GEILEN10b, GEILEN11a, GEILEN11b].

Devido a esta propriedade, uma sequência de eventos $\tau$ também pode ser vista como uma sequência finita ou infinita de marcas de tempo em $\mathcal{T}$. O comprimento de $\tau$, denotado $|\tau|$, é o menor $n \in \mathbb{N}$ tal que $\tau(n)=\infty$, e abusando um pouco da notação, $|\tau|=\infty$ se $\tau(n)<\infty$, para todos os $n \in \mathbb{N}$. Neste contexto, usa-se $\epsilon$ para denotar a sequência vazia de eventos, tal que para todo $n$, $\epsilon(n)=\infty$.

Dada a sequência de eventos $\tau$ e a marca de tempo $t \in \mathcal{T}$ tal que $t \leq \tau(0)$, t. $\tau$ denota a sequência de eventos que consiste de $t$ seguido por $\tau$. O conjunto de todas as sequências de eventos é denotado por T $\tau$.

As sequências de eventos são comunicadas através de portas. Para um conjunto $P$ de portas, $T \tau(P)$ denota $P \rightarrow T \tau$, como o conjunto de funções totais que mapeiam cada porta de $P$ a uma sequência de eventos. Os elementos de $T \tau(P)$ são chamados de rastros de eventos sobre $P$. Em algumas ocasiões, para um $x \in T \tau(P)$, a notação $(p, n, t) \in x$ é utilizada ao invés de $x(p)(n)=t$. Neste caso $x$ corresponde à informação de uma porta $p \in P$, referente ao rastro de eventos que entra por esta porta, e $x(p)(n)=t$ corresponde ao tempo de chegada do $n$-ésimo token.

\section{Definição - Ator:}

Um ator é uma tupla $A=\left(P, Q, R_{A}\right)$ com um conjunto $P$ de portas de entrada, um conjunto $Q$ de portas de saída, e uma relação de rastro de eventos 
$R_{A} \subseteq T \tau(P) \times T \tau(Q) \quad$ [GEILEN11b]. A notação $x A y$ utiliza-se para denotar $(x, y) \in R_{A}$ quando a tripla de $A$ fica implícita.

Note-se que um rastro de entrada $x$ modela os tempos em que os tokens de entrada são produzidos pelo ambiente do ator, e não os tempos em que esses tokens são consumidos pelo ator. Os tempos de consumo de tokens podem ser modelados adicionando portas de saida especiais para o ator, tal como explicado em [GEILEN11b].

\subsubsection{Refinamento}

O refinamento é uma relação entre dois atores $A$ e $B$, que permite que o ator $B$ seja substituído pelo ator $A$ em um determinado contexto, obtendo, no pior dos casos, "iguais ou melhores" resultados ao longo do tempo. Se $\tau_{A}$ e $\tau_{B}$ são as sequências de eventos produzidas por $A$ e $B$, respectivamente, então " $\tau_{B}$ é igual ou melhor que $\tau_{A}$ " significa que $\tau_{B}$ deve ter pelo menos tantos eventos quanto $\tau_{A}$, e para cada evento que estas sequências tiverem em comum, o evento deverá ser produzido em $\tau_{B}$, não mais tarde do que em $\tau_{A}$.

\section{Definição - Refinamento de uma sequência:}

A sequência de eventos $\tau$ refina a sequência de eventos $\tau^{\prime}$, denotado por $\tau$ 드 $\tau^{\prime}$, se e só se para todo $n \in \mathbb{N}, \tau(n) \leq \tau^{\prime}(n)$.

ᄃ é igualmente aplicado para os rastros $x, x^{\prime} \in T \tau(P): x \sqsubseteq x^{\prime}$ se e só se para todo $p \in P, x(p) \sqsubseteq x^{\prime}(p)[$ GEILEN10b].

A Figura 4.3 apresenta três sequências de eventos, $\tau_{1}, \tau_{2}$ e $\tau_{3}$ visualizadas como pontos pretos sobre uma linha de tempo horizontal: $\tau_{1}=3 \cdot 5 \cdot 6 \cdot \varepsilon ; \tau_{2}=3 \cdot 5$. $7 \cdot 8 \cdot 9 \cdot \varepsilon$ e $\tau_{3}=0 \cdot 3 \cdot 5 \cdot 7 \cdot 9 \cdot \varepsilon$.

Neste caso, $\tau_{3} \sqsubseteq \tau_{2}, \tau_{2} \sqsubseteq \tau_{1}$, mas $\tau_{1} \nsubseteq \tau_{2}$. As relações de refinamento sobre as sequências de eventos, e rastros de eventos, são ordens parciais, ou seja, cumprem as propriedades reflexiva, transitiva e antissimétrica. 


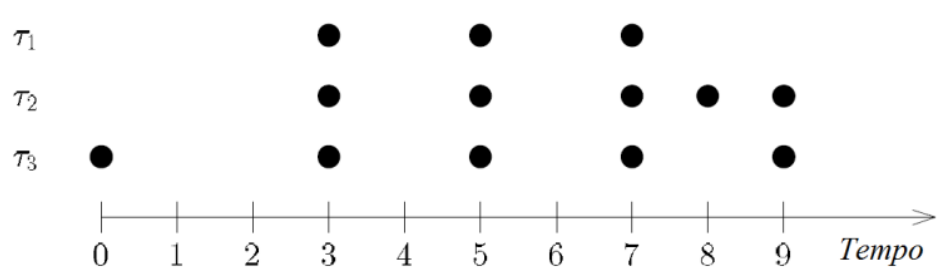

Figura 4.3: Três sequências de eventos [GEILEN10b].

\subsection{REPRESENTAÇÃO DE FLUXO DE DADOS}

O modelo de SDF é um modelo de fluxo de dados onde as computações dos atores são acionadas pela disponibilidade dos dados de entrada. As conexões entre os atores representam o fluxo de dados desde um ator produtor, até um ator consumidor, geralmente armazenado através de buffers.

Informalmente o conceito de atores de SDF temporizados já foi utilizado em seções anteriores. Nesta seção, esse conceito será definido formalmente. Tipicamente, nos modelos de SDF temporizados o dominio do tempo é composto pelos reais não-negativos ou inteiros. Portanto, no restante desta subseção, será assumido que $\mathcal{T}=\mathbb{R}^{\geq 0}$ ou $\mathcal{T}=\mathbb{N}$.

\section{Definição - Atores SDF:}

Um ator $A=\left(P, Q, R_{A}\right)$ é um ator de um SDF homogêneo com duração de disparo $d \in \mathcal{T}$, se e só se,

$$
R_{A}=\left\{(x, y)|\forall q \in Q:| y(q)\left|=\min _{p \in P}\right| x(p)|\wedge \forall n<| y(q) \mid: y(q)(n)=\max _{p \in P} x(p)(n)+d\right\}
$$

Onde $|y(q)| e|x(p)|$ refere-se ao tamanho do rastro na saida $q \in Q$, e na entrada $p \in P$, respectivamente. Igualmente $|y(q)|=\min _{p \in P}|x(p)|$ indica a condição de que o tamanho do rastro de saída é igual ao tamanho do menor rastro de entrada no ator $A$ [GEILEN11b].

Ou seja, o $n$-ésimo disparo de $A$ começa logo que o $n$-ésimo token chegar a cada entrada. O disparo leva $d$ unidades de tempo, após o qual, um único token é produzido em cada saída.

Exemplo 4.1: Considere o ator de SDF $A$ mostrado na Figura 4.4. 


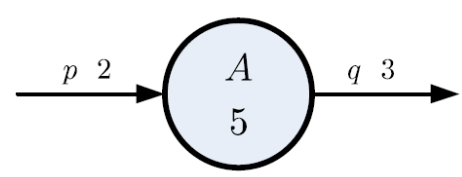

Figura 4.4: Ator de SDF [GEILEN10b].

$A$ tem uma porta de entrada $p$ (com taxa 2) e uma porta de saída $q$ (com taxa 3). A duração do seu disparo é 5. Um exemplo de um rastro de eventos de entrada-saída de $A$, é mostrado na Figura 4.5. O eixo horizontal representa o tempo discreto $\mathcal{T}=\mathbb{N}$. Cada bolinha representa um evento, e múltiplos eventos acontecendo ao mesmo tempo são empilhados uns sobre outros. Os disparos de $A$ iniciam nos tempos 2, 4 e 5 e se sobrepõem no tempo. Note-se que o token de entrada número $\mathbf{7}$ não conduz a saída nenhuma.

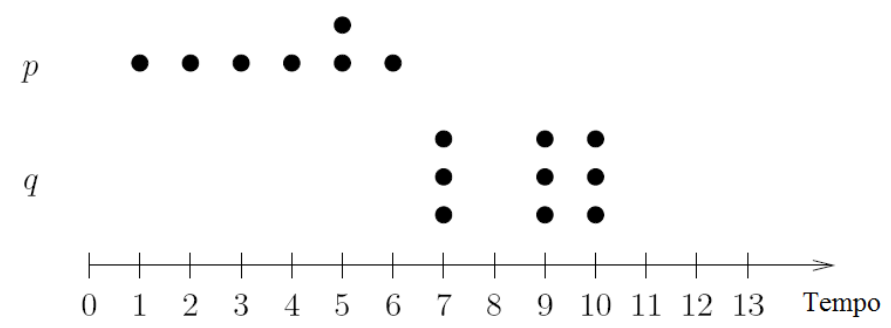

Figura 4.5: Rastro de eventos para o ator SDF da Figura 4.4 [GEILEN1Ob].

Um grafo de SDF representa a composição de múltiplos atores de SDF, tal como o exemplo mostrado na Figura 2.14.

\subsubsection{Semântica de Max-Plus para Representação de SDFs}

Existem duas diferentes semânticas ou abordagens para tratar os grafos de SDF. Uma abordagem concentra-se no comportamento funcional dos atores e dos grafos, e a outra está focada no comportamento temporal e de desempenho dos grafos de SDF. Essa tese está centrada no segundo tipo, considerando a análise de grafos de SDF temporizados [GEILEN10a, GEILEN10b, GEILEN11a].

Os grafos de SDF podem ser traduzidos em grafos de eventos equivalentes (seção 2.1.8.1), mesmo que isso possa implicar um aumento considerável no tamanho do grafo. A partir disso, o comportamento temporal dos grafos de SDF segue padrões semelhantes aos grafos de eventos. Em particular, o seu comportamento é determinístico e eventualmente torna-se periódico. Este 
comportamento pode ser capturado de forma eficiente por meio da álgebra Max-Plus [BACCELLI01], a qual é uma álgebra linear baseada nas operações de máximo e soma.

$\mathrm{Na}$ análise do comportamento dos grafos de SDF, o tempo é codificado como funções Dater ${ }^{21}$, as quais atribuem um determinado estado temporal aos diferentes tokens dentro do grafo, colocando uma marca de tempo referente ao momento quando o respectivo token acontece dentro do grafo.

Dentro da execução autotemporizada indicada para definir a dinâmica dos grafos de SDF, duas operações essenciais caracterizam seu comportamento temporal: A sincronização e o atraso. A sincronização é observada cada vez que acontece uma espera pelos tokens de entrada suficientes para disparar um determinado ator, enquanto o atraso é observado cada vez que um ator começa um disparo e leva uma quantidade fixa de tempo antes de concluir e produzir seus respectivos tokens de saída. Esta quantidade fixa de tempo é definida como o tempo de execução do ator. Estas duas características correspondem às operações de Max-Plus de máximo e de soma.

Se $T$ é o conjunto de tokens exigidos por um ator para iniciar o disparo, e para cada $\tau \in T, t_{\tau}$ é o tempo quando o token se torna disponivel, então o tempo de início do disparo do ator é dado por:

$$
\max _{\tau \in T} t_{\tau} \quad(4.1 a)
$$

Seja $e$ o tempo de execução desse ator, então os tokens de saída produzidos pelo ator tornam-se disponíveis para seu consumo por outros atores em:

$$
\max _{\tau \in T} t_{\tau}+e
$$

que é uma expressão de Max-Plus.

O comportamento de um grafo de fluxo de dados pode ser caracterizado de dois modos diferentes, ou pelos tempos nos quais os atores iniciam os seus disparos, ou pelos tempos em que os tokens nos canais são produzidos. Cada opção pode ser derivada uma a partir da outra.

\footnotetext{
${ }^{21}$ Assim como a função Dater está relacionada à álgebra de Max-Plus, também existe a função Counter, a qual representa o número de tokens encontrados até um determinado tempo $t$. Esta função está relacionada à álgebra de Min-Plus [BACCELLI01, RAISCH09].
} 
Como ilustração do comportamento de um grafo de SDF, a Figura 4.7 descreve um grafo que apresenta uma iteração composta de três disparos, dois do ator da esquerda, e um do ator da direita [GEILEN09]. No estado inicial (a) as marcas de tempo dos tokens iniciais no grafo são indicadas de modo simples por $t_{1}, t_{2}, t_{3}$ e $t_{4}$. Em um primeiro instante, o ator da esquerda consome os tokens marcados com $t_{1}$ e $t_{2}$. Consequentemente, os disparos acontecem em um tempo $\max \left(t_{1}, t_{2}\right)$ e finalizam no tempo $\max \left(t_{1}+3, t_{2}+3\right)$, considerando o tempo de execução de 3 unidades do próprio ator. Este tempo de finalização é a marca de tempo simbólico dos novos tokens produzidos no estado (b). Uma vez no estado (b), o ator da esquerda dispara de novo, consumindo os tokens marcados com $t_{3}$ e $\max \left(t_{1}+3, t_{2}+3\right)$, de modo que o disparo começa em $\max \left(t_{1}+3, t_{2}+3, t_{3}\right)$ e finaliza em $\max \left(t_{1}+6, t_{2}+6, t_{3}+3\right)$, criando dois novos tokens no estado (c). Dado que o ator da direita precisa de dois tokens para disparar, no estado (c) ele consegue disparar, consumindo todos os tokens disponíveis nas suas entradas, tal que no estado (d) o disparo do ator da direita trouxe o grafo de volta ao estado original, porém com os tokens simbólicos representando o impacto temporal de uma única iteração.

(a)

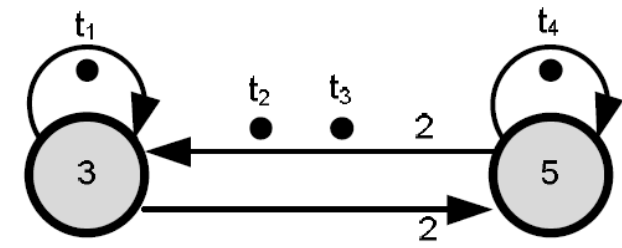

(c)

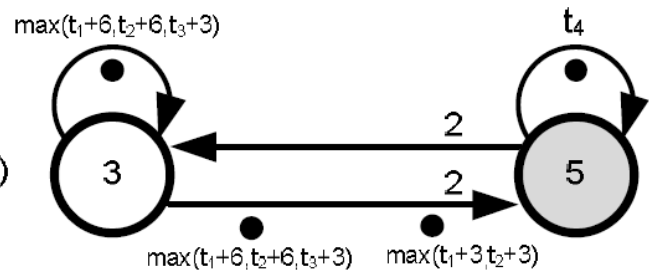

b)

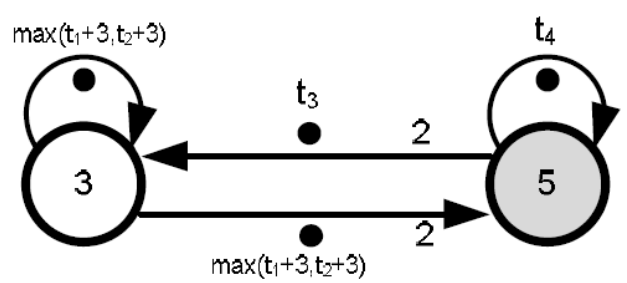

(d)

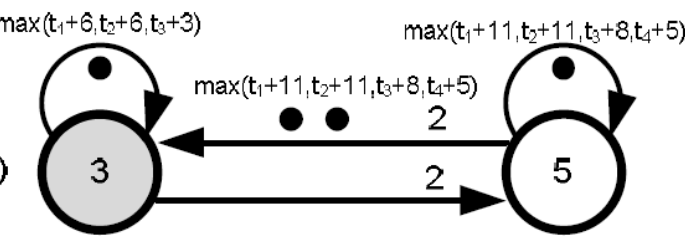

Figura 4.7: Exemplo de uma execução autotemporizada de um grafo de SDF [GEILEN09].

\subsection{1. Álgebra Max-Plus}

\section{Definição - Álgebra de Max-Plus:}

A álgebra Max-Plus [BACCELLI01, RAISCH09] consiste do conjunto $R:=\mathbb{R} U$ $\{-\infty\}$ e duas operações binárias sobre $R: \oplus$ e $\otimes$.

$\bigoplus$ é chamada a adição, ou soma, da álgebra Max-Plus e é definida por 
$a \oplus b=\max (a, b) \quad \forall a, b \in R$.

$\otimes$ é chamada a multiplicação da álgebra Max-Plus e é definida por $a \otimes b=a+b \quad \forall a, b \in R$.

A álgebra Max-Plus obedece às seguintes propriedades:

$\checkmark \oplus$ e $\otimes$ são comutativas, isto é,

$$
\begin{array}{ll}
a \bigoplus b=b \bigoplus a & \forall a, b \in R \\
a \otimes b=b \otimes a & \forall a, b \in R .
\end{array}
$$

$\checkmark \oplus$ e $\otimes$ são associativas, isto é,

$$
\begin{array}{ll}
(a \oplus b) \oplus c=a \oplus(b \oplus c) & \forall a, b, c \in R \\
(a \otimes b) \otimes c=a \otimes(b \otimes c) & \forall a, b, c \in R .
\end{array}
$$

$\checkmark \otimes$ é distributiva sobre $\oplus$, isto é,

$$
c \otimes(a \oplus b)=(a \oplus b) \otimes c=(a \otimes c) \oplus(b \otimes c) \quad \forall a, b, c \in R
$$

Esta propriedade corresponde também à evidência da linearidade na álgebra de Max-Plus, visto que em notação aritmética convencional, esta propriedade equivale a:

$$
c+\max (a, b)=\max (a+c, b+c) \quad \forall a, b, c \in R
$$

$\varepsilon:=-\infty$ é o e elemento neutro com relação a $\bigoplus$, isto é,

$$
a \oplus \varepsilon=a \quad \forall a \in R
$$

Em notação convencional, Isto é:

$$
\max (a,-\infty)=a \quad \forall a \in R
$$

$\varepsilon$ também é chamado o elemento-zero da álgebra Max-Plus.

$\checkmark \quad e:=0$ é o elemento neutro com relação a $\otimes$, isto é,

$$
a \otimes e=a \quad \forall a \in R
$$


Em notação convencional, Isto é:

$$
a+0=a \quad \forall a \in R .
$$

$e$ também é chamado o elemento-um da álgebra Max-Plus.

$\checkmark \varepsilon$ é absorvente para $\otimes$, isto é,

$$
a \otimes \varepsilon=\varepsilon \quad \forall a \in R .
$$

$\checkmark \oplus$ é idempotente, isto é,

$$
a \bigoplus a=a \quad \forall a \in R
$$

Isso faz com que a álgebra Max-Plus seja um semianel idempotente

\begin{tabular}{|c|c|}
\hline $\begin{array}{c}\text { Operação } \oplus: \text { "soma" } \\
\text { (Max) }\end{array}$ & $\begin{array}{c}\text { Operação } \otimes: \text { "Multiplicação" } \\
\text { (Soma) }\end{array}$ \\
\hline$a \oplus b=\max (a, b)$ & $a \otimes b=a+b$ \\
\hline$a \oplus b=b \oplus a$ & $a \otimes b=b \otimes a$ \\
\hline$a \oplus(b \oplus c)=(a \oplus b) \oplus c$ & $a \otimes(b \otimes c)=(a \otimes b) \otimes c$ \\
\hline \multicolumn{2}{|c|}{$a \otimes(b \oplus c)=a \otimes b \oplus a \otimes c$} \\
\hline \multirow[t]{4}{*}{$a \oplus \varepsilon=a=\varepsilon \oplus a$} & $a \otimes e=a=e \otimes a$ \\
\hline & $a \otimes \varepsilon=\varepsilon=\varepsilon \otimes a$ \\
\hline & $a^{n}=n \cdot a \quad(\forall a \in \mathbb{R})$ e $(\forall n \in \mathbb{R})$ \\
\hline & $(\forall a \in \mathbb{R})\left(\exists a^{-1}\right) \quad a \otimes a^{-1}=e$ \\
\hline
\end{tabular}
[BACCELLI01]. A Tabela 4.1 apresenta um resumo destas propriedades da álgebra de Max-Plus.

Tabela 4.1: Propriedades básicas da álgebra de Max-Plus

Usando a definição de $\oplus \mathrm{e} \otimes, \forall a, b, c \in R$, as seguintes propriedades para as desigualdades na álgebra de Max-Plus podem facilmente ser deduzidas [BACCELLIO1]:

$$
\begin{aligned}
& a \leq b \Rightarrow a \oplus c \leq b \oplus c, \\
& a \leq b \Leftrightarrow a \otimes c \leq b \otimes c, \\
& a \leq b \Leftrightarrow a \oplus b=b .
\end{aligned}
$$


Módulo ou Magnitude de um vetor: seja $\boldsymbol{a} \in R^{1 \times n}$, ou $\boldsymbol{a} \in R^{m \times 1}$, com elementos $a_{i}$. Então,

$$
\|\boldsymbol{a}\|=\max _{i}\left(a_{i}\right)
$$

Denota o módulo, ou magnitude, do vetor $\boldsymbol{a}$. Isto quer dizer que o módulo de um vetor corresponde ao seu elemento máximo [BACCELLIO1].

Dentro da álgebra de Max-Plus, o módulo de um vetor apresenta as seguintes propriedades:

i. $\quad\|\boldsymbol{a}\|=-\infty$ se, e somente se, $a_{i}=-\infty$ para todo $i$;

ii. Dado um escalar $c$, então $\|c+\boldsymbol{a}\|=c+\|\boldsymbol{a}\|$;

iii. $\quad\|\max (\boldsymbol{a}, \boldsymbol{b})\| \leq \max (\|\boldsymbol{a}\|,\|\boldsymbol{b}\|)$;

iv. Para um vetor $\boldsymbol{a}$ com $\|\boldsymbol{a}\|>-\infty$, define-se $\boldsymbol{a}^{\text {norm }}$ para denotar $\boldsymbol{a}-\|\boldsymbol{a}\|$, o vetor normalizado de $\boldsymbol{a}$, tal que $\left\|\boldsymbol{a}^{\text {norm }}\right\|=0$.

Também é possivel estender $\oplus \mathrm{e} \otimes$ para matrizes com elementos em $R$ :

Matriz Soma: seja $A, B \in R^{m \times n}$ com elementos $a_{i j}, b_{i j}$. Então,

$$
\begin{aligned}
(A \oplus B)_{i j} & :=a_{i j} \oplus b_{i j} \\
& =\max \left(a_{i j}, b_{i j}\right)
\end{aligned}
$$

Matriz Multiplicação: Seja $A \in R^{m \times n}, B \in R^{n \times q}$, Então,

$$
\begin{array}{r}
(A \otimes B)_{i j}:=\bigoplus_{k=1}^{n}\left(a_{i k} \otimes b_{k j}\right) \\
=\max _{k=1, \ldots, n}\left(a_{i k}+b_{k j}\right)
\end{array}
$$

Multiplicação com um escalar: Seja $A \in R^{m \times n}, \alpha \in R$. Então,

$$
\begin{aligned}
(\alpha \otimes A)_{i j} & :=\alpha \otimes a_{i j} \\
& =\alpha+a_{i j}
\end{aligned}
$$




\section{Matriz Nula e Identidade:}

$N:=\left[\begin{array}{ccc}\varepsilon & \cdots & \varepsilon \\ \vdots & \ddots & \vdots \\ \varepsilon & \cdots & \varepsilon\end{array}\right]$ é a matriz nula, e

$E:=\left[\begin{array}{cccc}e & \varepsilon & \cdots & \varepsilon \\ \varepsilon & e & \cdots & \vdots \\ \vdots & \vdots & \ddots & \varepsilon \\ \varepsilon & \cdots & \varepsilon & e\end{array}\right]$ é a matriz de identidade.

Desta forma, a matriz identidade é uma matriz diagonal como todos os valores da diagonal iguais a zero $(e)$.

\section{Exemplo 4.2:}

$$
\left(\begin{array}{cc}
2 & 4 \\
-1 & 5
\end{array}\right) \oplus\left(\begin{array}{cc}
-1 & 7 \\
e & 4
\end{array}\right)=\left(\begin{array}{ll}
2 & 7 \\
e & 5
\end{array}\right)
$$

\section{Exemplo 4.3:}

$$
\left(\begin{array}{cc}
2 & 3 \\
-1 & 4
\end{array}\right) \otimes\left(\begin{array}{l}
5 \\
2
\end{array}\right)=\left(\begin{array}{c}
(2 \otimes 5) \oplus(3 \otimes 2) \\
(-1 \otimes 5) \oplus(4 \otimes 2)
\end{array}\right)=\left(\begin{array}{l}
7 \\
6
\end{array}\right)
$$

Exemplo 4.4:

$$
3 \otimes\left(\begin{array}{cc}
7 & -3 \\
2 & 1
\end{array}\right)=\left(\begin{array}{cc}
10 & e \\
5 & 4
\end{array}\right)
$$

\section{Exemplo 4.5:}

$$
\left(\begin{array}{ll}
3 & 7 \\
2 & 4
\end{array}\right) \otimes\left(\begin{array}{ll}
1 & e \\
3 & 2
\end{array}\right)=\left(\begin{array}{ll}
(3 \otimes 1) \oplus(7 \otimes 3) & (3 \otimes e) \oplus(7 \otimes 2) \\
(2 \otimes 1) \oplus(4 \otimes 3) & (2 \otimes e) \oplus(4 \otimes 2)
\end{array}\right)=\left(\begin{array}{ll}
10 & 9 \\
7 & 6
\end{array}\right)
$$

A partir da definição das operações entre matrizes, é imediato considerar que para toda matriz $A, B, C$, vetores $x, y$ de tamanhos compativeis, e $\alpha, \beta \in R$, as seguintes propriedades são satisfeitas,

$$
A \otimes(\alpha \otimes B)=\alpha \otimes(A \otimes B),
$$




$$
\begin{gathered}
\alpha \otimes(A \oplus B)=\alpha \otimes A \oplus \alpha \otimes B \\
x^{T} \otimes \alpha \otimes y=\alpha \otimes\left(x^{T} \otimes y\right) \\
(\alpha \oplus \beta) \otimes A=\alpha \otimes A \oplus \beta \otimes A \\
A \leq B \Rightarrow A \oplus C \leq B \oplus C, \\
A \leq B \Rightarrow A \otimes C \leq B \otimes C, \\
x \leq y \Rightarrow A \otimes x \leq A \otimes y, \\
A \leq B \Leftrightarrow A \oplus B=B .
\end{gathered}
$$

Também se $A$ é uma matriz quadrada, então o produto iterativo:

$$
A \otimes A \otimes \cdots \otimes A
$$

No qual a matriz é multiplicada $k$ vezes, será denotada como $A^{k}$.

Tal como na álgebra tradicional, nesta tese será frequentemente omitido o símbolo de multiplicação, ou seja, $A B$ irá significar $A \otimes B$. De igual maneira é importante indicar que qualquer multiplicação vetorial ou matricial apresentada nesta tese estará se referindo a uma multiplicação vetorial ou matricial em notação de Max-Plus, e não a uma multiplicação vetorial ou matricial tradicional.

\subsubsection{1 Álgebra de Max-Plus e Grafos de Precedência}

A cada matriz quadrada com elementos em $R$, é possivel associar exclusivamente um grafo de precedência [BACCELLI01, RAISCH09].

\section{Definição - Grafo de Precedência:}

Seja $A \in R^{m \times n}$. Seu grafo de precedência $\mathcal{G}(A)$ é um grafo direcionado e ponderado, com $n$ nós, etiquetados como $1, \ldots, n$, com um arco do nó $j$ até o nó $i$, se $\mathrm{a}_{\mathrm{ij}} \neq \varepsilon ; i, j=1, \ldots, n$. Se um arco do nó $j$ até o nó $i$ existe, seu peso é $a_{i j}$.

Exemplo 4.6: Considere a matriz $5 \times 5$ : 


$$
A=\left[\begin{array}{lllll}
\varepsilon & 5 & \varepsilon & 2 & \varepsilon \\
\varepsilon & \varepsilon & 8 & \varepsilon & 2 \\
\varepsilon & \varepsilon & \varepsilon & \varepsilon & \varepsilon \\
\varepsilon & 3 & 7 & \varepsilon & 4 \\
\varepsilon & \varepsilon & 4 & \varepsilon & \varepsilon
\end{array}\right]
$$

O grafo de precedência tem 5 nós, com a coluna $j$ de A representando os arcos que saem do nó $j$, enquanto a fila $i$ representa os arcos que acabam no nó $i$; veja a Figura 4.8 para entendê-lo.

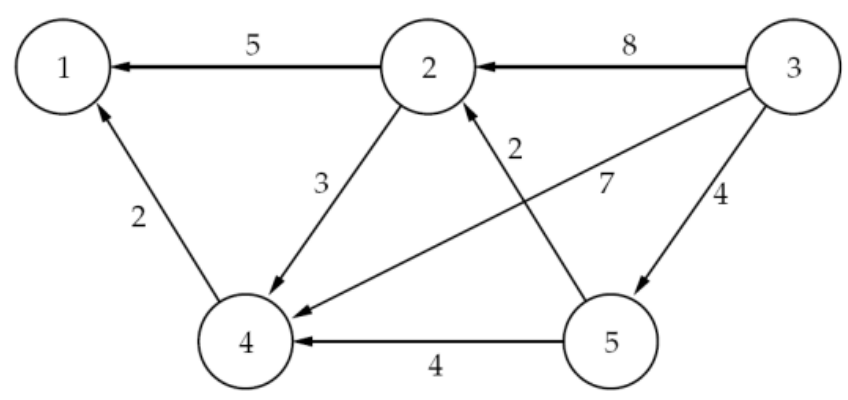

Figura 4.8: Grafo de precedência para a Matriz A [RAISCH09].

\subsubsection{Representação de grafos de SDF através de matrizes Max-Plus}

A Figura 4.9 descreve a representação de um grafo de SDF como um sistema com rastros de eventos de entrada $x$, e rastros de eventos de saída $y$, de modo que $M$ é a matriz de Max-Plus que descreve o comportamento temporal do grafo [GEILEN10b].

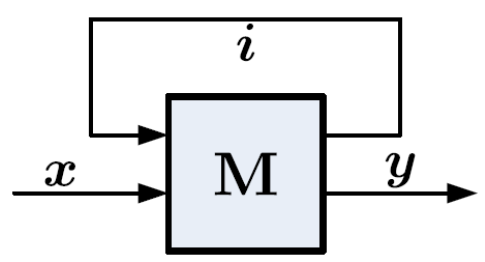

Figura 4.9: Representação em Max-Plus de um grafo de SDF [GEILEN1Ob].

Em geral, para um grafo de $\operatorname{SDF} A$ com portas de entrada e saída $P$ e $Q$, $r_{A}: P \cup Q \rightarrow \mathbb{N}$ denota o vetor de taxas relativas de escrita e de leitura das portas de entrada e saída do grafo, o qual atribui a cada porta externa as taxas em que os tokens são consumidos e produzidos, e especifica o padrão em que as dependências de tokens são repetidas [GEILEN10b]. Dado o rastro de eventos de entrada $x \in T \tau(P)$ (possivelmente contendo sequências finitas de eventos), é feita uma transformação sobre ele a fim de se obter uma sequência infinita 
$v_{0}, v_{1}, \ldots$, de vetores Max-Plus. São vetores ordinários utilizados dentro da álgebra de matrizes Max-Plus, ao invés da álgebra linear tradicional. Na indexação desses vetores será usada uma dupla indexação indicando a porta $p$ em $P$ e o índice de evento $n$, com $0 \leq n<r(p)$, dentro de uma iteração, indexação utilizada a fim de simplificar a notação vetorial.

$$
v_{k}(p, n)=x(p)(k \cdot r(p)+n)
$$

$\operatorname{com} p \in P, k \in \mathbb{N}$ e $0 \leq n<r(p)$

Isto é, $v_{k}(p)$ representa as marcas de tempo da $k$-ésima repetição de $r(p)$ eventos acontecendo na porta $p$. O tamanho do vetor $v_{k}$ é igual à soma dos componentes do vetor de taxas relativas $r$ referentes a cada porta de entrada.

Por outro lado, é possivel transformar uma sequência infinita de vetores de saida Max-Plus, $w_{k}(q, n)$, novamente em um rastro de eventos de saida, $y(q)(n)$ :

$$
y(q)(n)=w_{n \div r(q)}(q, n \bmod r(q))
$$

Onde mod é o resto da divisão inteira.

Com esta codificação de vetores para os rastros de eventos, a relação de entrada-saida de qualquer grafo de SDF, tal como o mostrado na Figura 4.9, pode ser caracterizada por uma equação linear recursiva de Max-Plus, definida da seguinte forma:

$$
\left[\begin{array}{c}
i_{k+1} \\
w_{k}
\end{array}\right]=M_{A}\left[\begin{array}{c}
i_{k} \\
v_{k}
\end{array}\right]
$$

Onde, os vetores $i_{k}$ capturam o estado interno do grafo de SDF. O tamanho do vetor $i_{k}$ é igual ao número de tokens iniciais no grafo de SDF. Geralmente $i_{0}=0$. Os vetores $v_{k}$ e $w_{k}$ capturam as entradas e as saídas, respectivamente [GEILEN10b].

É conveniente dividir a matriz $M$ em quatro quadrantes que representam as dependências mútuas entre as entradas, as saídas e o estado interno.

$$
\left[\begin{array}{l}
i_{k+1} \\
w_{k}
\end{array}\right]=\left[\begin{array}{ll}
M^{A} & M^{B} \\
M^{C} & M^{D}
\end{array}\right]\left[\begin{array}{l}
i_{k} \\
v_{k}
\end{array}\right]
$$




\section{Definição - Ator de tokens iniciais:}

$\mathrm{O}$ ator de tokens iniciais, com $n$ tokens, $I_{n}$, é representado por uma matriz $(n+1) \times(n+1)$. Ele consome e produz um token por iteração. Visto que o primeiro token consumido é o token $(n+1)$-ésimo a ser liberado na saída, $I_{n}$ tem uma memória de $n$ tokens, representados por um vetor interno $i_{k}$ de tamanho $n$, e um vetor inicial de tamanho $n, i_{0}=0$ [GEILEN10b].

O vetor se desloca para cima em cada iteração e a marca de tempo do último token consumido é adicionada à base, isto é, a memória é formada pelo vetor $i_{k}$ de tamanho $n$, para os quais $i_{k+1}(m)=i_{k}(m+1)$ para $0 \leq m<n-1$,

$$
\mathbf{I}_{n}=\left[\begin{array}{ccccc|c}
-\infty & 0 & -\infty & -\infty & \cdots & -\infty \\
-\infty & -\infty & 0 & -\infty & \cdots & -\infty \\
-\infty & -\infty & -\infty & 0 & \cdots & -\infty \\
\vdots & \vdots & \vdots & \vdots & \ddots & \vdots \\
-\infty & -\infty & -\infty & -\infty & \cdots & 0 \\
\hline 0 & -\infty & -\infty & -\infty & \cdots & -\infty
\end{array}\right]
$$

Sob esta definição, qualquer grafo de SDF com uma entrada e uma saída, tal como aquele da Figura 4.9, pode ser visto como um ator de tokens iniciais de maneira que o deslocamento no vetor interno $i_{k}$ refere-se à realimentação definida pela dependência entre as interações $k$ e $k+1$ das marcas de tempo dos tokens gerados. Como exemplo, para um grafo de SDF com um número de tokens iniciais $n=1$, temos

$$
\mathbf{I}_{1}=\left[\begin{array}{c|c}
-\infty & 0 \\
\hline 0 & -\infty
\end{array}\right]
$$

O qual corresponde ao seguinte sistema de equações Max-Plus:

$$
\begin{aligned}
i_{k+1} & =v_{k} \\
w_{k} & =i_{k}=v_{k-1}
\end{aligned}
$$

Um ator de SDF homogêneo com duração de disparo $d$ é representado por uma matriz de $1 \times 1, A=[d]$, e um vetor inicial vazio, dado que ele é sem 
memória e o evento de saída é determinado diretamente a partir do evento de entrada [GEILEN10b].

Exemplo 4.7: Considere os grafos de SDF da Figura 4.10.
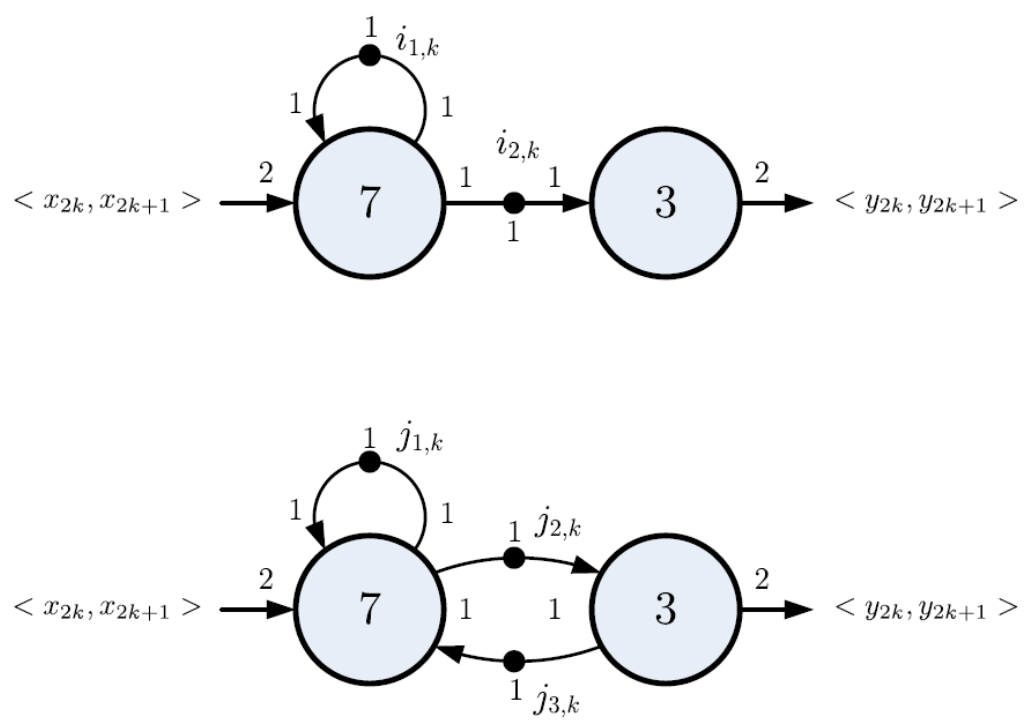

Figura 4.10: Dois grafos de SDF diferentes [GEILEN10b].

O comportamento do primeiro grafo da Figura 4.10 é capturado pela seguinte equação Max-Plus:

$$
\left[\begin{array}{c}
i_{1, k+1} \\
i_{2, k+1} \\
y_{2 k} \\
y_{2 k+1}
\end{array}\right]=\left[\begin{array}{cc|cc}
7 & -\infty & 7 & 7 \\
7 & -\infty & 7 & 7 \\
\hline-\infty & 3 & -\infty & -\infty \\
-\infty & 3 & -\infty & -\infty
\end{array}\right]\left[\begin{array}{c}
i_{1, k} \\
i_{2, k} \\
x_{2 k} \\
x_{2 k+1}
\end{array}\right]
$$

correspondente ao seguinte sistema de equações Max-Plus:

$$
\begin{aligned}
i_{1, k+1} & =i_{2, k+1}=\max \left\{i_{1, k}, x_{2 k}, x_{2 k+1}\right\}+7 \\
y_{2 k} & =y_{2 k+1}=i_{2, k}+3
\end{aligned}
$$

Ou, em notação de Max-Plus:

$$
\begin{aligned}
i_{1, k+1} & =i_{2, k+1}=7 \otimes\left(i_{1, k} \oplus x_{2 k} \oplus x_{2 k+1}\right) \\
y_{2 k} & =y_{2 k+1}=3 \otimes i_{2, k}
\end{aligned}
$$

Desta forma, a representação da matriz desse primeiro grafo é: 


$$
\left[\begin{array}{cc|cc}
7 & -\infty & 7 & 7 \\
7 & -\infty & 7 & 7 \\
\hline-\infty & 3 & -\infty & -\infty \\
-\infty & 3 & -\infty & -\infty
\end{array}\right]
$$

O segundo grafo de SDF da Figura 4.10, que possui um arco adicional capaz de modelar um buffer de capacidade finita, é representado pela matriz:

$$
\left[\begin{array}{ccc|cc}
7 & -\infty & 7 & 7 & 7 \\
7 & -\infty & 7 & 7 & 7 \\
-\infty & 3 & -\infty & -\infty & -\infty \\
\hline-\infty & 3 & -\infty & -\infty & -\infty \\
-\infty & 3 & -\infty & -\infty & -\infty
\end{array}\right]
$$

\subsubsection{Execução Autotemporizada representada na Álgebra de Max-Plus}

Em uma execução autotemporizada de um grafo de SDF homogêneo, cada ator começa um disparo quando existe pelo menos um token em todos os seus canais de entrada. A existência destes tokens nos canais de entrada depende, por sua vez, do final dos disparos dos atores, os quais fornecem tokens para os canais. Deste modo, os tempos de início de cada disparo de ator podem ser representados em termos dos tempos de início dos disparos de outros atores.

Como exemplo, nesta seção será assumido um grafo de $\operatorname{SDF}(A, C)$ homogêneo, com distribuição inicial de tokens $\gamma \cdot t_{a, k}$ denota o tempo de início do $k$-ésimo disparo de um ator $a \in A$, sob uma execução autotemporizada, e $\tau(a)$ denota o tempo de execução do ator $a$. Quando o ator termina o $k$-ésimo disparo, ele produz o $(k+\gamma(c))$-ésimo tokens em cada canal $c \in C$ ligado a uma das suas respectivas portas de saida. Dentro do conjunto de canais $C$, os conjuntos $\operatorname{InC}(a)$ e OutC(a) denotam o conjunto de canais de entrada e de saída, respectivamente, do ator $a$. Adicionalmente define-se $t_{c, k}$ como o tempo no qual o $k$-ésimo token é produzido no canal $c \in C$ (onde $t_{c, k}=0$ para todos os $0 \leq k<\gamma(c)$, dado que os tokens iniciais encontram-se no canal no momento do inicio da execução) [GHAMARIAN06a].

$t_{a, k}$ depende da disponibilidade de tokens em todas as suas entradas e começa logo após o último dos tokens requeridos ter chegado. Os tokens são 
produzidos quando o ator que escreve para tal canal termina seu disparo. A partir disto, é possivel obter as seguintes equações para os tempos de disparo dos atores. Para cada ator $a \in A$ :

$$
t_{a, k}=\max _{c \in \operatorname{InC}(a)} t_{c, k}, \quad \text { para todo } k \geq 0
$$

Igualmente, para cada ator $a \in A$ e cada canal $c \in$ OutC(a), derivam-se as seguintes equações:

$$
t_{c, k}=t_{a, k-\gamma(c)}+\tau(a), \quad \text { para todo } k \geq \gamma(c)
$$

A combinação destas equações resulta em um conjunto de equações no qual o $k$-ésimo tempo de disparo de cada ator está relacionado com o $k$-ésimo, ou anterior, tempo de disparo de outros atores. Através da substituição e a introdução de variáveis auxiliares (veja [GHAMARIAN06a] para mais detalhes), este conjunto de equações é convertido a um conjunto de equações diferenciais da forma:

$$
t_{i, n}=\max _{j} t_{j, n-1}+\tau_{i, j}
$$

Onde o conjunto de variáveis de $t_{i, n}$ inclui os tempos de disparo dos atores, $t_{a, n}$.

É conveniente formular essas equações usando a notação da álgebra MaxPlus. Dela, uma descrição de álgebra linear é obtida e a equação (4.9) pode ser representada usando a formulação Max-Plus como se segue:

$$
t_{i, n}=\bigoplus_{j} t_{j, n-1} \otimes \tau_{i, j}
$$

Este conjunto de equações de soma-de-produtos pode ser codificado como uma equação matriz.

$$
\boldsymbol{t}_{n}=\mathbf{M} \boldsymbol{t}_{\boldsymbol{n - 1}}
$$

Onde o vetor $\boldsymbol{t}_{n}$ consiste de todos os $t_{i, n}$. M é uma matriz com os coeficientes $\tau_{i, j}$. Se $\boldsymbol{t}_{0}$ codifica o estado inicial e a distribuição inicial de tokens, então a sequência $\left\{\boldsymbol{t}_{k} \mid k \geq 0\right\}$, onde $\boldsymbol{t}_{k}=\mathbf{M}^{\mathrm{k}} \boldsymbol{t}_{\mathbf{0}}$ descreve a evolução do grafo ao longo do tempo. 
Note-se que através da conexão entre os tempos de disparo nos grafos de SDF, e seus correspondentes tempos de disparo no grafo de SDF homogêneo equivalente, este modelo também aplica-se à execução dos grafos de SDF, sempre que todos os tempos de disparo de uma interação sejam representados em um único vetor.

\subsubsection{Análise Espectral}

Na teoria tradicional de sistemas lineares, o estudo da evolução de $\boldsymbol{t}_{k}=\mathbf{M}^{\mathrm{k}} \boldsymbol{t}_{\mathbf{0}}$ para uma execução longa está relacionado com a análise espectral da matriz M. Em particular, a análise espectral lida com o estudo da equação de autovalores, a qual, em termos de Max-Plus, é definida como:

$$
\mathbf{M t}=\lambda \otimes \boldsymbol{t}
$$

Para qualquer combinação de $\lambda$ e $\|\boldsymbol{t}\|>-\infty$ que satisfaz a equação acima, $\lambda$ é chamado de autovalor, e $\boldsymbol{t}$ é chamado de vetor próprio. Em [BACCELLIO1, GHAMARIAN06a] foi demonstrado que qualquer grafo de SDF, conectado e restrito, possui uma matriz correspondente como um único autovalor. Se $t$ é um vetor próprio, então $\boldsymbol{c} \otimes \boldsymbol{t}$ também é para qualquer valor inteiro de $\boldsymbol{c}$.

Quando um grafo é executado durante um tempo prolongado de maneira autotemporizada, o comportamento converge a um comportamento em regime estacionário, de modo que a solução dessa equação caracteriza o grafo na sua fase periódica. Para o vetor $\boldsymbol{t}$, todos os tempos de execução da próxima iteração (Mt) são iguais aos tempos de execução correspondentes à iteração atual, deslocados por $\lambda$ unidades de tempo. Com $\boldsymbol{t}$ sendo um vetor próprio, o mesmo deslocamento acontece na próxima iteração, e assim por diante. [BACCELLI01, GEILEN10a] descreve que este comportamento periódico pode abranger múltiplas iterações, mas o tamanho do período é exatamente igual a uma iteração quando o vetor $\boldsymbol{t}$ é um vetor próprio da matriz $\mathbf{M}$ (neste caso, a duração do período é o autovalor da matriz).

Proposição 4.1: Seja M uma matriz Max-Plus de um grafo de SDF com autovalor $\lambda$. Seja $\left\{\boldsymbol{t}_{\boldsymbol{k}} \mid 1 \leq k \leq n\right\}$ a fase periódica na execução autotemporizada do grafo, isto é, $\boldsymbol{t}_{\boldsymbol{k}+\mathbf{1}}=\mathbf{M} \boldsymbol{t}_{\boldsymbol{k}}$ e $\mathbf{M} \boldsymbol{t}_{\boldsymbol{n}}=\boldsymbol{n} \boldsymbol{\lambda} \otimes \boldsymbol{t}_{1}$, então $\boldsymbol{t}^{S}$ é um vetor próprio de $\mathbf{M}$ [GEILEN10a], onde, 


$$
\boldsymbol{t}^{\boldsymbol{S}}=\max _{1 \leq k \leq n} \boldsymbol{t}_{\boldsymbol{k}}-k \lambda
$$

Como será apresentado no capítulo 5, esta descrição do comportamento temporal periódico de um grafo de SDF através da análise espectral da sua respectiva matriz $\mathbf{M}$, será fundamental para descrever o comportamento de cada cenário que compõe uma aplicação definida por múltiplos modos de operação. 


\section{Capítulo 5}

\section{MODELO ANALÍTICO DE EVENTOS BASEADO EM SADF E CURVAS DE CENÁRIOS}

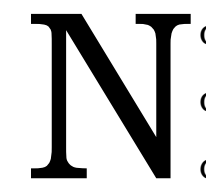

o capítulo 4 foi apresentada uma descrição dos atores que compõem os grafos de SDF temporizados. Tal descrição foi baseada no conceito de interfaces de ator, definido em [GEILEN10b], onde cada ator é descrito a partir das relações entre as sequências de tokens de entrada e de saída de cada tarefa representada dentro do SDF, tal que o conteúdo de cada token não é considerado na análise do SDF, focando-se apenas nos tempos de chegada dos tokens em um domínio de tempo contínuo e totalmente ordenado. Seguindo esta descrição, o comportamento temporal dos grafos de SDF segue um padrão determinístico, eventualmente periódico, de modo que tal comportamento pode ser capturado de forma eficiente por meio da álgebra de Max-Plus. Tendo isto como base, o presente capítulo apresenta uma metodologia analítica e matemática que é utilizada para caracterizar os fluxos de eventos de saída de cada tarefa, dado o respectivo fluxo de eventos de entrada, dentro de um modelo de grafo de SDF definido para representar cada cenário de uma aplicação, considerando uma modelagem orientada a atores temporais.

Considerando as características de linearidade da álgebra de Max-Plus, esta modelagem é apresentada seguindo um paralelo de semelhança com os sistemas clássicos lineares, tanto invariantes no tempo como variantes no tempo, a fim de exemplificar os diferentes alcances da modelagem baseada em Max-Plus e da metodologia analítica descrita neste capítulo.

Como a maior contribuição desta tese, um modelo analitico de geração de eventos de saída para aplicações multimídia, baseado em um grafo de SADF, é apresentado no final do capítulo, de modo que a solução de um conjunto de 
equações de Max-Plus constitui uma solução do modelo de espaço de estado de um grafo de SADF utilizado para representar a aplicação sob análise. Tal solução é definida como a soma das respostas homogênea e da resposta forçada da aplicação multimídia, de modo que esta última resposta define a função de transferência da aplicação no espaço de Max-Plus. Na análise proposta, os grafos de SADF são descritos como modelos lineares em MaxPlus, variantes no tempo, em função da dinâmica temporal originada pela inclusão dos diversos cenários de execução. Ao final do capítulo, um conjunto de expressões matemáticas é obtido para conhecer os vetores de Max-Plus relacionados aos rastros de saída e de estado interno do grafo de SADF utilizado para modelar certa aplicação.

\subsection{MODELO DE ESPAÇO DE ESTADO PARA GRAFOS DE SDF}

Nesta seção, o modelo de espaço de estado dos grafos de SDF é introduzido, de modo que o tratamento matemático segue a mesma análise utilizada nos sistemas clássicos discretos lineares, conforme apresentado por [GEILEN11a]. A relação de entrada e saída de tais sistemas é definida como a soma de uma resposta em regime transitório, ou de estado homogêneo, e uma resposta forçada ou de regime estacionário. No caso dos grafos de SDF, essa análise é baseada nas características de linearidade da álgebra de Max-Plus, tal que a descrição matemática resultante corresponde a um modelo linear em MaxPlus invariável no tempo.

Na seção 4.3.2 foi conceituado que, dada a codificação de vetores de rastros de eventos como na Eq.(4.2), a relação de entrada-saída de qualquer grafo de SDF pode ser caracterizada por uma equação linear recursiva de Max-Plus, definida pela Eq.(4.4), a qual, seguindo a divisão matricial apresentada na Eq.(4.5), pode ser reescrita como:

$$
\begin{aligned}
i_{k+1} & =M^{A} i_{k} \oplus M^{B} v_{k} \\
w_{k} & =M^{C} i_{k} \oplus M^{D} v_{k}
\end{aligned}
$$

Mudando a notação matricial utilizada neste conjunto de equações a fim de facilitar seu entendimento e tratamento matemático, a nova notação será a seguinte: 


$$
\begin{aligned}
& A:=M^{A} \\
& B:=M^{B} \\
& C:=M^{C} \\
& D:=M^{D}
\end{aligned}
$$

denotando as quatro matrizes que representam as dependências mútuas entre as entradas, as saídas e o estado interno do grafo de SDF. Desta forma, a Eq.(5.1) pode ser reescrita como:

$$
\begin{aligned}
i_{k+1} & =A i_{k} \oplus B v_{k} \\
w_{k} & =C i_{k} \oplus D v_{k}
\end{aligned}
$$

Dadas as propriedades de linearidade da álgebra de Max-Plus, este conjunto de equações é semelhante às equações de estado de um sistema clássico linear discreto no tempo como o apresentado na Figura I.1 do Anexo I, onde $u(k)$, $y(k)$ e $h(k)$ correspondem à entrada, à saída e à resposta ao impulso, respectivamente, do sistema linear discreto no tempo [WILLIAM83]. Desta forma, o tratamento matemático dado às equações lineares recursivas de MaxPlus é semelhante ao encontrado na análise de sistemas clássicos lineares, baseado nas semelhanças encontradas entre as operações $\oplus$ e $\otimes$ de Max-Plus e as operações soma e multiplicação de álgebra convencional. Esta semelhança é aproveitada na apresentação dos modelos e das análises feitas neste capítulo para descrever explicitamente o comportamento temporal dos grafos de SDF, assim como uma extensão feita para grafos de SADF, apresentada como uma das contribuições originais deste capítulo.

Caso o leitor não esteja familiarizado com a análise de variáveis de estado de um sistema clássico linear discreto no tempo, o Anexo I apresenta uma breve descrição desta análise.

\subsubsection{Espaço de Estado dos grafos de SDF}

Esta seção descreve uma análise do grafo de SDF temporizado descrito por atores, apresentado na seção 4.3.2, replicado na Figura 5.1. Ela mostra a representação de um grafo de SDF como um sistema com rastros de eventos de entrada $x$, e rastros de eventos de saída $y$, de modo que $M$ é a matriz de Max-Plus que define o comportamento temporal do grafo. 


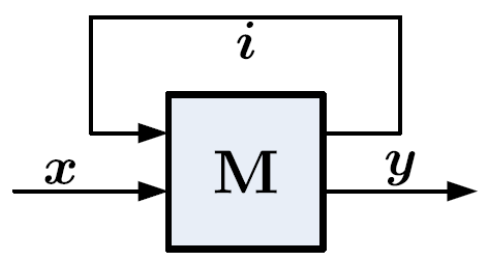

Figura 5.1: Representação em Max-Plus de um grafo de SDF [GEILEN10b].

Relembrando a Eq.(4.2), a sequência de eventos $v_{k}(p, n)$ corresponde a uma transformação feita sobre a entrada $x \in T \tau(P)$, a fim de se obter uma sequência infinita $v_{0}, v_{1}, \ldots$, de vetores Max-Plus.

$$
v_{k}(p, n)=x(p)(k \cdot r(p)+n)
$$

com $p \in P, k \in \mathbb{N}$ e $0 \leq n<r(p)$, sendo $P$ o conjunto de portas de entrada do grafo,e $r(p)$ o componente do vetor de taxas relativas de escrita referente à cada porta de entrada $p \in P$ do grafo de SDF.

Com esta codificação de vetores para os rastros de eventos, foi definida a relação de entrada-saída de um grafo de SDF como o da Figura 5.1, de modo que o grafo fica caracterizado pelas Eq.(5.1) e Eq.(5.2) mencionadas no começo deste capítulo, onde, os vetores $i_{k}$ capturam o estado interno do grafo de SDF, isto é, $i_{k}$ correspondem às variáveis de estado do grafo visto como um sistema linear em Max-Plus.

\subsubsection{Solução ao Modelo de Espaço de Estado em grafos de SDF}

A fim de ser coerente com o tratamento matemático apresentado nos sistemas clássicos lineares discretos no tempo, assim como com a análise de espaço de estado na álgebra de Max-Plus (resumida no Anexo III), a notação apresentada nas Eq.(5.1) e Eq.(5.2) pode ser modificada de modo que o subindice $k$, que representa a $k$-ésima iteração do grafo de SDF, represente a evolução da sequência discreta das equações de estado do grafo, isto é:

$$
\begin{aligned}
i(k+1) & =A i(k) \oplus B v(k) \\
w(k) & =C i(k) \oplus D v(k)
\end{aligned}
$$

Tal que, aplicando a transformada- $\gamma$ (resumida no Anexo II) nas diferentes variáveis, é possivel obter: 


$$
\begin{aligned}
\gamma^{-1} I(\gamma)-\gamma^{-1} i(0) & =A I(\gamma) \oplus B V(\gamma) \\
I(\gamma) & =\gamma A I(\gamma) \oplus \gamma B V(\gamma) \oplus i(0) \\
I(\gamma) & =\gamma A I(\gamma) \oplus[\gamma B V(\gamma) \oplus i(0)]
\end{aligned}
$$

Desta forma, a transformada- $\gamma$ da variável de estado $i(k)$ corresponde a:

$$
I(\gamma)=\gamma A I(\gamma) \oplus[\gamma B V(\gamma) \oplus \gamma i(0)]
$$

E dado que na álgebra de Max-Plus, a solução de uma equação do tipo $\boldsymbol{X}=A \boldsymbol{X} \oplus B$ corresponde com $\boldsymbol{X}=A^{*} \otimes B$ [BACCELLIO1], sendo $A^{*}$ a operação Star Kleene $e^{22}$, então a solução para $I(\gamma)$ é:

$$
\begin{aligned}
& I(\gamma)=(\gamma A)^{*} \otimes[\gamma B V(\gamma) \oplus i(0)] \\
& =(\gamma A)^{*} i(0) \oplus(\gamma A)^{*} \gamma B V(\gamma) \\
& I(\gamma)=(\gamma A)^{*} i(0) \oplus(\gamma A)^{*} \gamma B V(\gamma)
\end{aligned}
$$

A Eq.(5.5) corresponde à solução das equações de estado do grafo de SDF no domínio da transformada- $\gamma$, indicando a evolução das variáveis internas do grafo, isto é, dos tempos de produção dos tokens iniciais do grafo em cada iteração $k$.

\subsubsection{Resposta Homogênea e Resposta Forçada ou de Regime Estacionário.}

Aplicando a transformada- $\gamma$ sobre a expressão de $w(k)$ que descreve a saída do grafo de SDF na Eq.(5.4), obtém-se a transformada $W(\gamma)$ :

$$
\begin{gathered}
W(\gamma)=C I(\gamma) \oplus D V(\gamma) \\
W(\gamma)=C\left[(\gamma A)^{*} i(0) \oplus(\gamma A)^{*} \gamma B V(\gamma)\right] \oplus D V(\gamma) \\
W(\gamma)=C(\gamma A)^{*} i(0) \oplus C(\gamma A)^{*} \gamma B V(\gamma) \oplus D V(\gamma) \\
W(\gamma)=C(\gamma A)^{*} i(0) \oplus\left[C(\gamma A)^{*} \gamma B \oplus D\right] V(\gamma)
\end{gathered}
$$

a qual, tal como nos sistemas clássicos lineares, pode ser decomposta em uma componente homogênea ou em estado transitório (et), devida ao tempo inicial de produção dos tokens iniciais dentro do grafo, $i(0)$; e uma componente de resposta forçada $(r f)$, devida ao conjunto de entradas do grafo, $v(k)$, Desta forma,

\footnotetext{
${ }^{22}$ A operação Star Kleene [BACCELLI01] é definida como a soma infinita: $A^{*}=\bigoplus_{n \in N} A^{n}$.
} 


$$
W(\gamma)=W(\gamma)_{e t} \oplus W(\gamma)_{r f}
$$

\subsection{Resposta Homogênea}

Identificando cada componente da Eq.(5.8) dentro da Eq.(5.7), identifica-se que a resposta homogênea corresponde a:

$$
W(\gamma)_{e t}=C(\gamma A)^{*} i(0)
$$

E aplicando uma transformação inversa de $\gamma$,

$$
w(k)_{e t}=C A^{k} i(0)
$$

A qual corresponde à resposta em estado transitório do grafo de SDF da Figura 5.1.

\subsection{Resposta Forçada}

Igualmente, é possivel identificar que a resposta forçada corresponde a:

$$
W(\gamma)_{r f}=D V(\gamma) \oplus C(\gamma A)^{*} \gamma B V(\gamma)
$$

Tal que aplicando a definição da operação Star Kleene sobre $(\gamma \mathrm{A})^{*}$, a equação Eq.(5.11) é reescrita como:

$$
\begin{aligned}
W(\gamma)_{r f} & =D V(\gamma) \oplus \sum_{n=0}^{\infty} C(\gamma A)^{n} \gamma B V(\gamma) \\
& =D V(\gamma) \oplus \sum_{n=0}^{\infty} C \gamma^{n+1} A^{n} B V(\gamma)
\end{aligned}
$$

De modo que expandindo a somatória infinita, a expressão para $W(\gamma)_{r f}$ é:

$$
W(\gamma)_{r f}=D V(\gamma) \oplus \gamma C B V(\gamma) \oplus \gamma^{2} C A B V(\gamma) \oplus \gamma^{3} C A^{2} B V(\gamma) \oplus \cdots
$$

E aplicando a transformada inversa- $\gamma$ :

$$
\begin{aligned}
w(k)_{r f} & =D v(k) \oplus C B v(k-1) \oplus C A B v(k-2) \oplus C A^{2} B v(k-3) \oplus \cdots \oplus C A^{k-1} B v(0) \\
& =D v(k) \oplus \bigoplus_{n=1}^{k} C A^{n-1} B v(k-n) \\
& =D v(k) \oplus \bigoplus_{n=1}^{k} C A^{k-n} B v(n)
\end{aligned}
$$


Deste modo, a solução completa para a saída do grafo de SDF da Figura 5.1, corresponde à soma em Max-Plus das componentes em estado transitório e da resposta forçada das Eq.(5.10) e Eq.(5.13a).

$$
\begin{gathered}
w(k)=w(k)_{e t} \oplus w(k)_{r f} \\
w(k)=C A^{k} i(0) \oplus D v(k) \oplus \bigoplus_{n=1}^{k} C A^{n-1} B v(k-n)
\end{gathered}
$$

\subsubsection{Função de Transferência}

De modo semelhante ao observado nos sistemas clássicos de tempo discreto, a relação entre as saídas e as entradas de um grafo de SDF em regime forçado, ou estacionário, define a função de transferência do grafo, tal que a partir da Eq.(5.11), anotada de novo como:

$$
W(\gamma)_{r f}=D V(\gamma) \oplus C(\gamma A)^{*} \gamma B V(\gamma)
$$

Identifica-se que a função de transferência de um grafo de SDF é definida como:

$$
H(\gamma)=D \oplus C(\gamma A)^{*} \gamma B
$$

\subsubsection{Resposta ao Impulso}

A partir da Eq.(5.15) é possível fazer uma manipulação nos índices da somatória a fim de incluir dentro da soma o componente da resposta associado à matriz $D$. Deste modo, define-se a função de Resposta ao Impulso como:

$$
h(k)= \begin{cases}D & k=0 \\ C A^{k-1} B & k \geq 1\end{cases}
$$

E a componente forçada $w(k)_{r f}$ da função de saída representada pela Eq.(5.13a), pode ser reescrita como:

$$
w(k)_{r f}=\bigoplus_{n=0}^{k} h(n) v(k-n)
$$

Consequentemente, a função total de saída do grafo de SDF pode ser reescrita como: 


$$
w(k)=C A^{k} i(0) \oplus \bigoplus_{n=0}^{k} h(n) v(k-n)
$$

\section{Definição - Função de Convolução:}

Seja $\tau_{1}(k)$ e $\tau_{2}(k)$ duas sequências de eventos.

A sequência $\max \left(\tau_{1}, \tau_{2}\right)(k)$ (também escrita como $\tau_{1}(k) \oplus \tau_{2}(k)$ ) é a sequência de eventos tal que:

$$
\max \left(\tau_{1}, \tau_{2}\right)(k)=\max \left(\tau_{1}(k), \tau_{2}(k)\right) .
$$

Igualmente, a convolução de Max-Plus $\tau_{1} \otimes \tau_{2}(k)$ [GEILEN10b] é a sequência de eventos tal que:

$$
\tau_{1} \otimes \tau_{2}(k)=\max _{0 \leq n \leq k}\left(\tau_{1}(n)+\tau_{2}(k-n)\right) .
$$

Ou, em notação de Max-Plus:

$$
\tau_{1} \otimes \tau_{2}(k)=\bigoplus_{n=0}^{k} \tau_{1}(n) \tau_{2}(k-n)
$$

Usando este operador de convolução, é possivel reescrever a Eq.(5.19) como:

$$
w(k)=C A^{k} i(0) \oplus(h \otimes v(k))
$$

A qual representa os vetores de Max-Plus de rastros de saída de um grafo de SDF para cada $k$-ésima iteração.

\subsubsection{Avaliação de desempenho baseada em Grafos de SDF}

Frequentemente o interesse no desempenho dos sistemas de multimídia resume-se na avaliação da vazão e da latência dos modelos de fluxo de dados utilizados para representar tais sistemas [GEILEN10a].

\subsubsection{Vazão}

Inicialmente define-se a vazão de uma sequência infinita de eventos $\tau$. Uma primeira tentativa para esta definição é considerar a vazão como o 
comportamento limite infinito do número médio de tokens que aparecem na sequência de eventos por unidade de tempo [GEILEN11b]: $T(\tau)=\lim _{n \rightarrow \infty} \frac{n}{\tau(n)}$. Desta forma, pela definição usual do limite, ele existe e é igual a $T$, se

$$
\forall \varepsilon>0: \exists K>0: \forall n>K: T-\varepsilon<\frac{n}{\tau(n)}<T+\varepsilon
$$

Porém, visto que este limite pode não sempre existir para uma sequência dada $\tau$, e devido a que entre todos os comportamentos possiveis de um ator pode haver alguns para os quais este limite não existe, então, no lugar de considerar o limite infinito, é preferivel utilizar os limites inferior e superior da vazão, os quais resultam ser mais robustos tendo-se em conta tais restrições de existência [GEILEN10b].

\section{Definição - Limites da vazão de uma sequência de eventos:}

Dada uma sequência infinita de eventos $\tau$, o limite inferior da vazão é:

$$
T^{l b}(\tau)=\sup \left\{T \in R^{\geq 0} \mid \exists K>0: \forall n>K: n>\tau(n) \cdot T\right\}
$$

e o limite superior é

$$
T^{u b}(\tau)=\inf \left\{T \in R^{\geq 0} \mid \exists K>0: \forall n>K: n<\tau(n) \cdot T\right\}
$$

Onde, por convenção, considera-se $\sup \mathbb{R}^{\geq 0}=\inf \emptyset=\infty$, isto é, o valor superior do conjunto dos $\mathbb{R}^{\geq 0}$ é o $\infty$, o qual também é o valor inferior do conjunto vazio $\emptyset$.

$T^{l b}(\tau)$ é o maior limite inferior da vazão média assintótico de $\tau$, e similarmente, $T^{u b}(\tau)$ define o menor limite superior. Multiplicando-se ambos os lados das desigualdades da Eq.(5.22) por $\tau(n)$ evitam-se problemas de divisão por zero, resultando nas expressões Eq.(5.23a) e Eq.(5.23b).

A seguir, define-se o limite da vazão para um ator $A$. Um ator pode ter múltiplas portas de saída com vazões geralmente diferentes. Para uma porta determinada, a vazão geralmente depende do rastro de entrada, bem como as escolhas não-determinísticas do ator. Considera-se, portanto, o cenário do pior caso. 


\section{Definição - Limite inferior da vazão de um ator:}

Para um ator $A$, com portas de entrada $P$ e portas de saida $Q$, e dadas algumas portas específicas de saída $q \in \mathrm{Q}$, e rastro de entrada $x \in \operatorname{Tr}(P)$, define-se $\mathrm{o}$ seguinte limite inferior da vazão de $A$ :

$$
T^{l b}(A, x, q)=\inf \left\{T^{l b}(\tau) \in R^{\geq 0} \mid \exists y: x A y \wedge: \tau=y(q)\right\}
$$

Desta forma, pode-se definir, então, a vazão em todas as portas de saída simultaneamente como um vetor indexado pelas portas de saída:

$$
T^{l b}(A, x)=\left(T^{l b}(A, x, q)\right)_{\mathrm{q} \in \mathrm{Q}}
$$

Igualmente a vazão superior pode ser definida para $T^{u b}(A, x, q)$ e $T^{u b}(A, x)$.

\subsection{Cálculo dos Limites da Vazão em Grafos de SDF}

Existem métodos bem conhecidos para calcular a vazão de um grafo de SDF [GHAMARIAN06a]. Nesta seção é mostrado que tais métodos também podem ser utilizados para definir a noção de limites de vazão. A vazão do modelo de SDF é tipicamente calculada para grafos fechados sem algum tipo de entrada, visto que as fontes nestes grafos são usualmente modeladas como parte do grafo. As técnicas mais comuns para calcular a vazão são baseadas na análise da Taxa do Ciclo Máximo ${ }^{23}$ (incorretamente chamado, na literatura de SDFs, de análise da Média de Ciclo Máximo ${ }^{24}$ ) de um grafo de SDF homogêneo equivalente [GHAMARIAN06a], sob uma exploração explícita do espaço de estado considerando uma execução autotemporizada.

$\mathrm{Na}$ Eq.(5.10) foi observado que a resposta homogênea de um grafo de SDF, correspondente também à resposta de um grafo sem entradas explícitas, apresenta a seguinte expressão para calcular o rastro de saída.

$$
w(k)=C A^{k} i(0)
$$

Sabe-se [GEILEN10a] que a sequência de vetores $w(k)$ torna-se eventualmente periódica e que a taxa média na qual todas as entradas no vetor crescem, são

\footnotetext{
${ }^{23}$ Maximum Cycle Ratio

${ }^{24}$ Maximum Cycle Mean
} 
determinados pelo vetor próprio da matriz $A$. Se os eventos na porta de saída $q$ são regidos pelo autovalor $\lambda$, então a vazão nessa porta é igual a $r(q) / \lambda$.

\section{Teorema 5.1: Vazão de um rastro de eventos}

Seja $P$ um conjunto de portas de entrada ou de saída de um determinado ator, de modo que uma porta $p \in P$. A taxa de tokens consumidos ou produzidos na porta $p$ é denotada por $r(p)$. Seja $x \in T \tau(P)$ um rastro de eventos sobre $P$, tal que $x(p)(n)=t$ corresponde ao tempo de chegada do $n$-ésimo token através da porta $p \in P$.

Se dado $p \in P, k \in \mathbb{N}$ e $0 \leq m<r(p), v(k)=v_{k}(p, m)=x(p)(k \cdot r(p)+m)$ é uma sequência infinita de vetores de Max-Plus que representam as marcas de tempo dos eventos acontecendo na porta $p$, então, a relação entre a vazão da sequência de marcas de tempo $v_{k}(p, m)$ e a vazão do rastro de eventos $x(p)$ é dado por:

$$
T(v(k))=\frac{T(x(p))}{r(p)}
$$

\section{Demonstração:}

Pela definição original da vazão dada na seção 5.1.3.1, vista como o limite infinito $T(\tau)=\lim _{n \rightarrow \infty} \frac{n}{\tau(n)}$, a vazão da sequência $v(k)$ é dada pelo limite:

$$
T(v(k))=\lim _{k \rightarrow \infty} \frac{k}{v(k)}
$$

Visto que $v(k)=v_{k}(p, m)=x(p)(k \cdot r(p)+m)$, o limite pode ser reescrito como:

$$
T(v(k))=\lim _{k \rightarrow \infty} \frac{k}{x(p)(k \cdot r(p)+m)}
$$

Então, fazendo uma troca de variável $n=k \cdot r(p)$

$$
\begin{aligned}
T(v(k)) & =\lim _{n \rightarrow \infty} \frac{n / r(p)}{x(p)(n+m)} \\
& =\frac{1}{r(p)} \lim _{n \rightarrow \infty} \frac{n}{x(p)(n+m)}
\end{aligned}
$$

tal que, quando $n \rightarrow \infty \Rightarrow n+m \rightarrow n$. Deste modo, 


$$
\begin{aligned}
T(v(k)) & =\frac{1}{r(p)} \lim _{n \rightarrow \infty} \frac{n}{x(p)(n)} \\
& =\frac{1}{r(p)} T(x(p))
\end{aligned}
$$

onde,

$$
\begin{gathered}
T(x(p))=\lim _{n \rightarrow \infty} \frac{n}{x(p)(n)} \\
T(v(k))=\frac{T(x(p))}{r(p)}
\end{gathered}
$$

A seguir, será analisado o caso dos grafos de SDF que possuem entradas explícitas, como no caso da Figura 5.1 e analisado na seção 5.1.2. Claramente, neste caso, a vazão nas sequências de saída depende da vazão com a qual as entradas são oferecidas nas portas de entrada. No entanto, as dependências internas dentro do grafo de SDF podem resultar em que a vazão de saída não seja proporcional à vazão nas entradas, mas sendo restrita pela limitação da vazão interna do grafo de SDF. Lembrando a Eq.(5.15) que apresenta a expressão geral da sequência de vetores de saída:

$$
w(k)=C A^{k} i(0) \oplus D v(k) \oplus \bigoplus_{n=1}^{k} C A^{n-1} B v(k-n)
$$

A qual foi reescrita na Eq.(5.21) como:

$$
\begin{aligned}
& w(k)=C A^{k} i(0) \oplus(h \otimes v(k)) \\
& w(k)=w_{i}(k) \oplus(h \otimes v(k))
\end{aligned}
$$

com, $w_{i}(k)=C A^{k} i(0)$.

determina-se que a vazão da sequência de saída $w(k)$ é definida pela combinação das operações $\max (\oplus)$ e da convolução $(\otimes)$ de Max-Plus das sequências internas $w_{i}(k)$, a sequência da resposta ao impulso $h$, e a sequências de entrada de $v(k)$. A seguir será conferido como a definição de vazão comporta-se para essas duas operações [GEILEN10b]. 


$$
\begin{array}{ll}
T^{l b}\left(\max \left(\tau_{1}, \tau_{2}\right)\right) & =\min \left(T^{l b}\left(\tau_{1}\right), T^{l b}\left(\tau_{2}\right)\right) \\
T^{l b}\left(\tau_{1} \otimes \tau_{2}\right) & =\min \left(T^{l b}\left(\tau_{1}\right), T^{l b}\left(\tau_{2}\right)\right)
\end{array}
$$

Observa-se que a vazão das sequências $w_{i}(k)$ e $h$, é determinada pelos autovalores da matriz $A$, e as vazões são iguais a $1 / \lambda$ se $\lambda$ é o único autovalor de $A$ [GEILEN10b]. Em um grafo de SDF fortemente conectado, $A$ tem um único autovalor e a vazão de cada um destas sequências é a mesma. Considerando estas propriedades do cálculo da vazão de acordo às operações Max e convolução, deriva-se a seguinte proposição, a qual determina o limite inferior da vazão para um grafo $\boldsymbol{G}$ de SDF [GEILEN10b].

Proposição 5.1: Seja $\boldsymbol{G}$ um grafo de SDF fortemente conectado, com um conjunto $P$ de portas de entrada e um conjunto $Q$ de portas de saída, representado pelas matrizes de Max-Plus $\boldsymbol{A}, \boldsymbol{B}, \boldsymbol{C} \boldsymbol{e} \boldsymbol{D}$.

Seja $r: P \cup Q \rightarrow \mathbb{N}$ a quantidade de tokens que interagem nas portas de $\boldsymbol{G}$. Seja $x$ um rastro de entrada de $\boldsymbol{G}$. Então $\boldsymbol{A}$ tem um único autovalor $\lambda$, e

$$
T^{l b}(\boldsymbol{G}, x, q)=r(q) \cdot \min \left(\frac{1}{\lambda}, \min _{p \in P} \frac{T^{l b}(x(p))}{r(p)}\right)
$$

\subsection{ESPECIFICAÇÃO DE UM MODELO DE ESPAÇO DE ESTADO PARA SADF}

Nesta seção, a análise apresentada na seção anterior para os grafos de SDF é estendida para os grafos de SADF de modo que a descrição matemática resultante corresponde a um modelo linear em Max-Plus variável no tempo, do qual derivam-se as componentes da resposta homogênea e de resposta forçada. Inicialmente, nas duas primeiras sub-seções, são apresentados, respectivamente, o modelo de SADF [GEILEN10a] e os autômatos de Max-Plus para SADF [FALK11]. Nas sub-seções seguintes, tais conceitos são utilizados conjuntamente e o tratamento matemático baseado nos sistemas clássicos discretos lineares já utilizados para SDF são estendidos para os grafos SADF como uma das contribuições originais desta tese. 


\subsubsection{Modelo de SADF}

Em aplicações embarcadas de multimídia, algumas das dificuldades na modelagem residem no fato de que diferentes cenários são simultaneamente ativos em diferentes estágios de uma implementação em pipeline. As técnicas introduzidas em [GEILEN10a, THEELEN06, STUIJK08] e também nesta tese, permitem que esses cenários sejam tratados individualmente, de um modo modular.

Os grafos de SADF [GEILEN10a], apresentados brevemente na seção 2.1.6, são uma variante de MoCs de fluxo de dados, a qual tenta ocupar um lugar na modelagem de sistemas e aplicações em relação à troca entre analisabilidade e expressividade, em particular sobre a capacidade de expressar um comportamento mais dinâmico das aplicações, indicando uma preferência pelo aspecto da expressividade explicado na seção 2.1.7 e representado na Figura 2.8 .

O modelo de SADF caracteriza cada cenário, ou modo de operação, individualmente através de um grafo de SDF específico, de modo que cada grafo de SDF modela as tarefas com tempos constantes de execução do piorcaso. Um modelo de SADF é também caracterizado pela especificação explícita da possivel ordem em que determinados cenários podem ser executados. O SADF especifica uma sequência de cenários por meio de uma máquina de estados finitos (modelo FSM-SADF, apresentado na seção 2.1.6.2), ou estocasticamente por meio de uma cadeia de Markov (seção 2.1.6.1). Em ambos os casos, cada estado é marcado com um cenário e estados diferentes podem ser marcados com o mesmo cenário.

O exemplo da Figura 5.2a descreve um modelo de FSM-SADF composto por um grafo direcionado, representando a conexão entre as tarefas $A, B$ e $C$ da aplicação, e os tempos de execução de cada tarefa em relação aos dois possíveis cenários $a$ e $b$, tal que, por exemplo, a tarefa $B$ terá um tempo de execução de 2 ciclos de relógio quando executada no cenário $a$, e um tempo de execução de 3 ciclos de relógio quando executada no cenário $b$. A FSM mostrada na Figura 5.2b representa a possivel sequência de execução dos cenários $a$ e $b$ dentro da execução global da aplicação representada. 


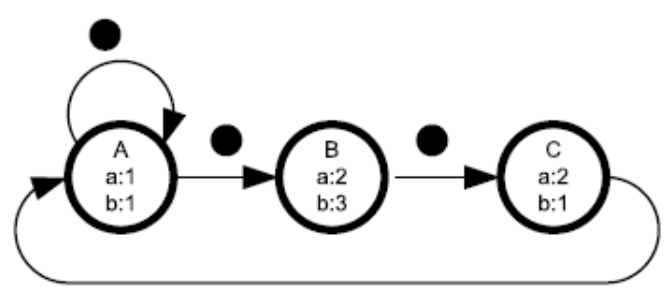

(i) Grafo de SADF com dois cenários possiveis $\{a, b\}$

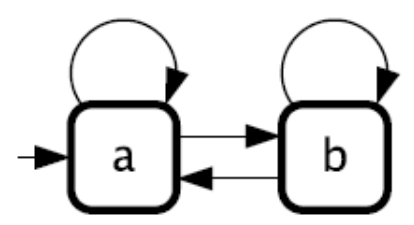

(ii) FSM do grafo de SADF de (i) indicando a possivel ordem entre cenários.

Figura 5.2: Exemplo de um grafo de SADF [GEILEN 10a].

Visto que este trabalho foi focado para aplicações de multimídia, assume-se uma execução infinita de uma FSM a fim de caracterizar as sequências de cenários que podem ocorrer.

Inicialmente, o grafo de SADF tem uma distribuição especifica dos seus tokens iniciais ao longo do grafo. Essa distribuição permanece invariável com as iterações individuais realizadas pelo grafo, independente do cenário que esteja sendo executado. Os tempos de produção desta coleção de tokens iniciais, ao final de uma iteração, capturam exatamente o ponto de partida para a iteração seguinte, seja no mesmo ou em outro cenário. A situação é ilustrada na Figura 5.3 com o grafo da Figura 5.2 em uma execução inicial de uma sequência de quatro cenários, aaab. O primeiro disparo do ator $A$, por exemplo, começa no tempo 2, visto que ele precisa um token de saída de $C$, o qual necessita completar seu primeiro disparo. As iterações são alternadamente representadas em fundos cinza clara e escura. Observe-se que as iterações se sobrepõem indicando algum grau de pipelining na execução.

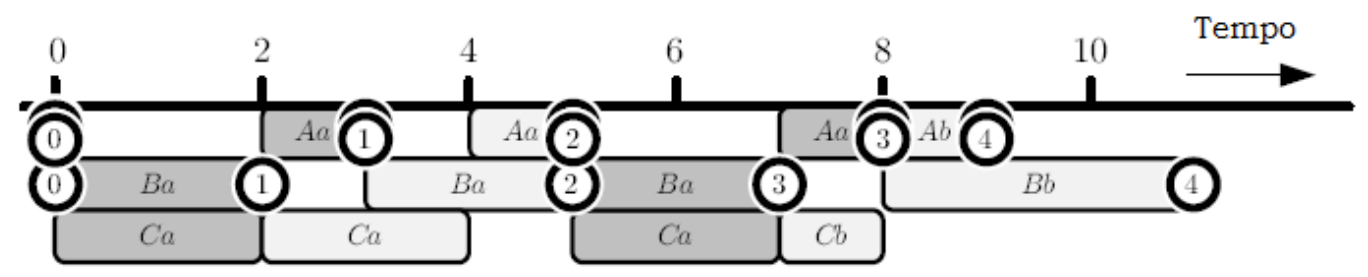

Figura 5.3: Exemplo do grafo da Figura 5.2 para a sequência de cenários aaab [GEILEN 10a].

Um grafo de SDF, sem atores de entrada e saída explícitos é caracterizado simplesmente pela sua matriz $\mathbf{M}$, de modo que o comportamento temporal é regido pela seguinte equação $i_{k+1}=\mathbf{M} i_{k}$. Em um grafo de SADF, cada cenário individual é modelado por um grafo de $\mathrm{SDF}$, de modo que uma matriz $\mathbf{M}_{\boldsymbol{s}}$ 
caracteriza cada cenário $s \in \Sigma$, sendo $\Sigma$ o conjunto de todos os possíveis cenários dentro do SADF. Se a iteração $k$ é executada no cenário $s$, então,

$$
i_{k+1}=\mathbf{M}_{s} i_{k}
$$

Para a Figura 5.2, por exemplo, as matrizes associada a cada cenário são as seguintes:

$$
M_{a}=\left[\begin{array}{ccc}
1 & -\infty & 3 \\
1 & -\infty & 3 \\
-\infty & 2 & -\infty
\end{array}\right] \quad M_{b}=\left[\begin{array}{ccc}
1 & -\infty & 2 \\
1 & -\infty & 2 \\
-\infty & 3 & -\infty
\end{array}\right]
$$

Um valor $t$ na coluna $k$ e fila $m$ na matriz especifica que existe uma distância mínima de $t$ entre as marcas de tempo do token $k$ da iteração prévia, ao token $m$ da nova iteração, seguindo as dependências no grafo. Uma entrada $-\infty$ significa que não existe relação de dependência.

Neste caso, se a última iteração executada gerou seus tokens de acordo ao vetor de produção $[3 ; 3 ; 2]^{T}$, como mostrado nos tokens indicados com o círculo de marca ' 1 ' na Figura 5.3, e uma nova iteração é executada no cenário $a$, então os novos tokens são gerados de acordo ao seguinte vetor:

$$
i=\left[\begin{array}{ccc}
1 & -\infty & 3 \\
1 & -\infty & 3 \\
-\infty & 2 & -\infty
\end{array}\right]\left[\begin{array}{l}
3 \\
3 \\
2
\end{array}\right]=\left[\begin{array}{c}
\max \{(1+3),(-\infty+3),(3+2)\} \\
\max \{(1+3),(-\infty+3),(3+2)\} \\
\max \{(-\infty+3),(2+3),(-\infty+2)\}
\end{array}\right]=\left[\begin{array}{l}
5 \\
5 \\
5
\end{array}\right]
$$

Ou, equivalentemente em notação de Max-Plus:

$$
i=\left[\begin{array}{lll}
1 & \varepsilon & 3 \\
1 & \varepsilon & 3 \\
\varepsilon & 2 & \varepsilon
\end{array}\right]\left[\begin{array}{l}
3 \\
3 \\
2
\end{array}\right]=\left[\begin{array}{l}
(1 \otimes 3) \oplus(\varepsilon \otimes 3) \oplus(3 \otimes 2) \\
(1 \otimes 3) \oplus(\varepsilon \otimes 3) \oplus(3 \otimes 2) \\
(\varepsilon \otimes 3) \oplus(2 \otimes 3) \oplus(\varepsilon \otimes 2)
\end{array}\right]=\left[\begin{array}{l}
5 \\
5 \\
5
\end{array}\right]
$$

O novo vetor de produção de tokens é representado na Figura 5.3 pelos três tokens indicados nos círculos com marca ' 2 '. Os tokens iniciais de um grafo são desenhados no arco de saída do ator que os produz e são numerados com as iterações. Observe-se que o conjunto de tokens iniciais, produzidos no final de uma iteração contém informação suficiente para determinar a temporização da iteração seguinte. 
Um ponto importante do modelo de SDF temporizado é o seu determinismo. Com isso, um objetivo importante de um modelo FSM-SADF é misturar uma quantidade limitada de comportamento não-determinístico através de transições de cenários expressadas pela FSM, sem sacrificar os benefícios do comportamento determinístico dentro dos cenários para uma análise eficiente.

De maneira formal, um grafo de SADF é modelado como o conjunto de todos os cenários e seus grafos de SDF correspondentes modelados por matrizes $\mathbf{M}_{\boldsymbol{s}}$. A combinação das máquinas de estado e da multiplicação das matrizes de Max-Plus é chamada de autômato de Max-Plus, rapidamente introduzida na próxima subseção.

\subsubsection{Autômato de Max-Plus para SADF}

Os autômatos de Max-Plus [BACCELLI01] representam sistemas com mudanças dinâmicas lineares ao longo do tempo com diferentes modos de ativação, dependendo do estado do autômato. Este modelo é utilizado nesta tese uma vez que a dinâmica linear de Max-Plus captura muito bem o comportamento do modelo de SDF, enquanto que os diferentes modos de ativação do autômato podem capturar os diferentes cenários da aplicação.

Um autômato de Max-Plus é uma tupla $\mathcal{A}=(\Sigma, \mathbf{M}, \mathcal{M})$ que consiste de um conjunto finito $\Sigma$ de cenários, um mapeamento $\mathbf{M}$, o qual atribui para cada cenário, $\sigma \in \Sigma$, uma matriz de Max-Plus $\mathbf{M}(\sigma)$ e um morfismo $\mathcal{M}$ sobre sequências finitas de cenários, que mapeia tais sequências a uma matriz de Max-Plus tal que:

$$
\mathcal{M}\left(\sigma_{1}, \cdots \sigma_{k}\right)=\mathbf{M}\left(\sigma_{k}\right) \cdots \mathbf{M}\left(\sigma_{1}\right)
$$

A Eq.(5.31) representa o produto matricial, em notação de Max-Plus, entre as diversas matrizes associadas com cada cenário dentro da sequência $\bar{\sigma}=$ $\sigma_{1}, \cdots \sigma_{k}$.

Para uma sequência de cenários dada, o autômato define o tempo de finalização da operação do grafo da seguinte forma:

$$
\mathcal{A}\left(\sigma_{1}, \cdots \sigma_{k}\right)=\left\|\mathcal{M}\left(\sigma_{1}, \cdots \sigma_{k}\right) \boldsymbol{i}_{\mathbf{0}}\right\|=\left\|\mathbf{M}\left(\boldsymbol{\sigma}_{\boldsymbol{k}}\right) \cdots \mathbf{M}\left(\boldsymbol{\sigma}_{\mathbf{1}}\right) \boldsymbol{i}_{\mathbf{0}}\right\|
$$


Então, $\mathcal{M}(\bar{\sigma}) \boldsymbol{i}_{\mathbf{0}}$ captura os tempos de produção de tokens do SADF depois da sequência de cenários $\bar{\sigma}$. Desta forma o morfismo $\mathcal{M}$ corresponde a uma matriz de Max-Plus variável em função da sequência de cenários $\bar{\sigma}=\sigma_{1}, \cdots \sigma_{k}$ definida, possivelmente, por uma máquina de estados.

\subsubsection{Modelo de SADF como um Modelo Linear em Max-Plus}

Seguindo a visão sistêmica apresentada até agora para tratar os grafos de SDF, nesta seção estendemos esta visão também para os grafos de SADF, de modo que eles podem ser definidos como um modelo linear em Max-Plus parecido com aquele apresentado na seção 5.1.1 e na Figura 5.1 para os grafos de SDF com entradas e saídas explícitas. No caso dos grafos de SADF o tratamento analítico difere um pouco devido ao morfismo $\mathcal{M}$ definido dentro do autômato de Max-Plus (seção anterior), dada uma sequência de cenários $\bar{\sigma}$. Neste caso, o modelo linear de Max-Plus corresponde ao mostrado na Figura 5.4, onde agora a matriz do sistema já não é constante, e varia em função da sequência de cenários executadas na aplicação até a $k$-ésima iteração. Desta forma, dada uma execução do grafo de SADF modelada com um autômato de Max-Plus $\mathcal{A}=(\Sigma, \mathbf{M}, \mathcal{M})$, a matriz do novo modelo linear em Max-Plus corresponderá ao respectivo morfismo $\mathcal{M}$ da Eq.(5.31), aplicado sobre a sequência de cenários $\bar{\sigma}=\sigma_{1}, \cdots \sigma_{k}$.

O conjunto de afirmações feitas nesta seção é próprio deste trabalho de doutorado, e corresponde a uma parte das contribuições da tese, as quais serão provadas nas seguintes seções e nos casos de uso apresentados no capítulo 6 da tese.

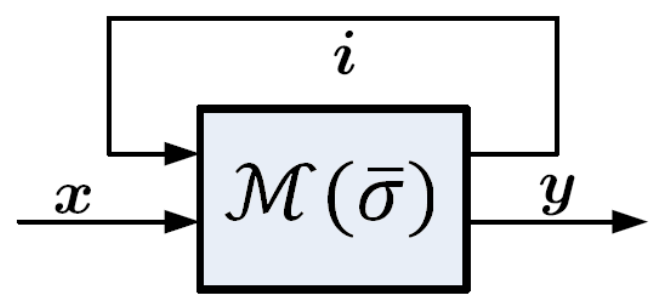

Figura 5.4: Representação em Max-Plus de um grafo de SADF.

Em vista deste tratamento linear proposto para os grafos de SADF, onde a matriz do grafo varia com cada iteração em função do produto de matrizes definido pelo morfismo $\mathcal{M}$, o modelo linear em Max-Plus possui características 
de um modelo variável no tempo, no qual o novo sistema de equações de estado é definido como:

$$
\begin{aligned}
i(k+1) & =\mathbf{M}\left(\sigma_{k+1}\right) i(k) \oplus B\left(\sigma_{k+1}\right) v(k) \\
w(k) & =C i(k) \oplus D v(k)
\end{aligned}
$$

de modo que em cada iteração da execução do grafo de SADF, a matriz considerada deve ser aquela do cenário sendo executado nesse instante pelo grafo, de forma semelhante à indicada na Eq.(5.30), e considerando que a condição inicial para cada novo cenário corresponde aos vetores de estado da última execução do cenário prévio.

Dada esta descrição matemática para o espaço de estado do grafo de SADF, o qual corresponde com um modelo linear em Max-Plus variante no tempo discreto, o tratamento analítico que pode ser dado é semelhante àquele encontrado nos sistemas clássicos lineares discretos e variantes no tempo. $\mathrm{O}$ Anexo II faz um breve resumo da análise deste tipo de sistemas.

\subsubsection{Espaço de Estados em SADF}

Como foi brevemente anotado na seção 5.2.3, o tratamento analítico dado para o espaço de estados do grafo de SADF, o qual corresponde a um modelo linear em Max-Plus variante no tempo, pode ser semelhante ao apresentado no anexo II para sistemas clássicos lineares discretos e variantes no tempo. A partir das equações de estado, Eq.(5.33), do grafo de SADF da Figura 5.4, a próxima subseção apresenta a derivação da sua solução. Com isto define-se o modelo analítico de geração de eventos para uma aplicação multimídia descrita através de um grafo de $\mathrm{SADF}$, dado um conjunto de cenários $\Sigma$ e de um autômato de Max-Plus $\mathcal{A}=(\Sigma, \mathbf{M}, \mathcal{M})$, o que, por sua vez, define a dinâmica de transição entre os diferentes cenários da aplicação.

\subsubsection{Solução ao Espaço de Estados em SADF}

Nas equações de estado dadas na Eq.(5.33), em cada iteração do grafo de SADF, a matriz considerada deve ser aquela do cenário sendo executado naquele instante pelo grafo. Considerando-se também que a condição inicial para cada novo cenário corresponde ao vetor de estado da última execução do cenário prévio, segue-se que para as primeiras duas iterações, as variáveis internas do grafo de SADF têm a seguinte forma: 


$$
\begin{aligned}
i(1) & =\mathbf{M}\left(\boldsymbol{\sigma}_{\mathbf{1}}\right) i(0) \oplus B\left(\boldsymbol{\sigma}_{\mathbf{1}}\right) v(0) \\
i(2)=\mathbf{M}\left(\boldsymbol{\sigma}_{2}\right) i(1) \oplus B\left(\boldsymbol{\sigma}_{2}\right) v(1) & \mathbf{M}\left(\boldsymbol{\sigma}_{\mathbf{2}}\right) \mathbf{M}\left(\boldsymbol{\sigma}_{\mathbf{1}}\right) i(0) \oplus \mathbf{M}\left(\boldsymbol{\sigma}_{\mathbf{2}}\right) B\left(\boldsymbol{\sigma}_{\mathbf{1}}\right) v(0) \oplus B\left(\boldsymbol{\sigma}_{2}\right) v(1)
\end{aligned}
$$

sendo $\sigma_{1} e \sigma_{2}$ dois cenários diferentes, cada um com um grafo de SDF, representados pelas matrizes $\mathbf{M}\left(\sigma_{1}\right)$ e $\mathbf{M}\left(\boldsymbol{\sigma}_{2}\right)$, respectivamente. Seguindo progressivamente em cada nova iteração, o valor das variáveis internas do grafo na $k$-ésima iteração, corresponde a

$$
\begin{aligned}
i(k)= & \left(\mathbf{M}\left(\boldsymbol{\sigma}_{\boldsymbol{k}}\right) \cdots \mathbf{M}\left(\boldsymbol{\sigma}_{\mathbf{1}}\right)\right) i(0) \oplus\left(\mathbf{M}\left(\boldsymbol{\sigma}_{\boldsymbol{k}}\right) \cdots \mathbf{M}\left(\boldsymbol{\sigma}_{\mathbf{2}}\right)\right) B\left(\boldsymbol{\sigma}_{\mathbf{1}}\right) v(0) \oplus \cdots \\
& \cdots \oplus \mathbf{M}\left(\boldsymbol{\sigma}_{\boldsymbol{k}}\right) B\left(\boldsymbol{\sigma}_{\boldsymbol{k}-\mathbf{1}}\right) v(k-2) \oplus B\left(\boldsymbol{\sigma}_{\boldsymbol{k}}\right) v(k-1) . \\
= & \mathcal{M}\left(\boldsymbol{\sigma}_{\mathbf{1}}, \cdots \boldsymbol{\sigma}_{\boldsymbol{k}}\right) i(0) \oplus \mathcal{M}\left(\boldsymbol{\sigma}_{2}, \cdots \boldsymbol{\sigma}_{\boldsymbol{k}}\right) B\left(\boldsymbol{\sigma}_{\mathbf{1}}\right) v(0) \cdots \\
& \cdots \oplus \mathcal{M}\left(\boldsymbol{\sigma}_{\boldsymbol{k}}\right) B\left(\boldsymbol{\sigma}_{\boldsymbol{k}-\mathbf{1}}\right) v(k-2) \oplus B\left(\boldsymbol{\sigma}_{\boldsymbol{k}}\right) v(k-1)
\end{aligned}
$$

de modo que ao representar as multiplicações de Max-Plus por uma multiplicação em série, o valor das variáveis internas do grafo na iteração $k$, corresponde a

$$
i(k)=\bigotimes_{s=1}^{k} \mathbf{M}\left(\boldsymbol{\sigma}_{\boldsymbol{s}}\right) i(0) \oplus \bigoplus_{n=0}^{k-1}\left[\bigotimes_{s=n+2}^{k} \mathbf{M}\left(\boldsymbol{\sigma}_{\boldsymbol{s}}\right)\right] B\left(\sigma_{\boldsymbol{n}+\mathbf{1}}\right) v(n)
$$

Ou também:

$$
i(k)=\bigotimes_{s=1}^{k} \mathbf{M}\left(\boldsymbol{\sigma}_{\boldsymbol{s}}\right) i(0) \oplus \bigoplus_{n=1}^{k}\left[\bigotimes_{s=k}^{k-n+2} \mathbf{M}\left(\boldsymbol{\sigma}_{\boldsymbol{s}}\right)\right] B\left(\sigma_{k-n+1}\right) v(k-n)
$$

Ao substituir a Eq.(5.35b) na variável de saída do grafo de SADF da Eq.(5.33), a expressão resultante para o conjunto de saídas é

$$
w(k)=c \bigotimes_{s=1}^{k} \mathbf{M}\left(\boldsymbol{\sigma}_{s}\right) i(0) \oplus D v(k) \oplus c \bigoplus_{n=1}^{k}\left[\bigotimes_{s=k}^{k-n+2} \mathbf{M}\left(\boldsymbol{\sigma}_{s}\right)\right] B\left(\sigma_{k-n+1}\right) v(k-n)
$$

Como no caso dos sistemas clássicos lineares variáveis no tempo (anexo II), é possível definir uma de matriz de transição de estados $\Phi(\boldsymbol{k}, \boldsymbol{p})$, descrita por:

$$
\boldsymbol{\Phi}(\boldsymbol{k}, \boldsymbol{p})=\left\{\begin{array}{cl}
\mathbf{M}\left(\boldsymbol{\sigma}_{\boldsymbol{k}}\right) \mathbf{M}\left(\boldsymbol{\sigma}_{\boldsymbol{k}-\mathbf{1}}\right) \cdots \mathbf{M}\left(\boldsymbol{\sigma}_{\boldsymbol{p}}\right), & k \geq p \geq 0 \\
E, & p>k
\end{array}\right.
$$

ou também, 


$$
\boldsymbol{\Phi}(\boldsymbol{k}, \boldsymbol{p})=\left\{\begin{array}{cc}
\bigotimes_{s=p}^{k} \mathbf{M}\left(\boldsymbol{\sigma}_{s}\right), & k \geq p \geq 0 \\
E, & p>k
\end{array}\right.
$$

onde $E$ é a matriz identidade em Max-Plus definida na seção 4.3.1.1. Desta forma, substituindo a Eq.(5.38) na Eq.(5.36), a nova expressão para descrever as saídas do grafo é:

$$
w(k)=C \boldsymbol{\Phi}(\boldsymbol{k}, \mathbf{1}) i(0) \oplus D v(k) \oplus C \bigoplus_{n=1}^{k} \boldsymbol{\Phi}(k, k-n+2) B\left(\boldsymbol{\sigma}_{\boldsymbol{k}-\boldsymbol{n}+\mathbf{1}}\right) v(k-n)
$$

A partir da Eq.(5.39) é possível fazer uma manipulação nos índices da somatória a fim de incluir dentro da soma o componente da resposta associado à matriz $D$. Deste modo, define-se a função $\mathbf{h}(k, n)$ como:

$$
\mathbf{h}(k, n)= \begin{cases}D & n=0 \\ C \boldsymbol{\Phi}(k, k-n+2) B\left(\boldsymbol{\sigma}_{\boldsymbol{k}-\boldsymbol{n}+\mathbf{1}}\right) & n>0\end{cases}
$$

E a saída do grafo de SADF pode ser reescrita como:

$$
w(k)=C \boldsymbol{\Phi}(\boldsymbol{k}, \mathbf{1}) i(0) \oplus \bigoplus_{n=0}^{k} \mathbf{h}(k, n) v(k-n)
$$

Esta equação representa os vetores de Max-Plus de rastros de saída de um grafo de SADF para cada $k$-ésima iteração, considerando uma sequência de cenários $\bar{\sigma}=\sigma_{1}, \cdots \sigma_{k}$ definida, possivelmente, por uma máquina de estados.

\subsubsection{Resposta Homogênea e Resposta Forçada}

Do mesmo modo como foi apresentado para o espaço de estado de um grafo de SDF, a solução das equações de estado para um grafo de SADF também apresenta os componentes próprios de uma resposta homogênea ou em estado transitório (et), associada só ao impacto do vetor inicial, i(0), de tempos de produção dos tokens iniciais do grafo. Da mesma forma ocorre para uma resposta forçada ( $r f$ ) devido ao impacto do vetor de entradas $v(k)$ do grafo, e da matriz de transição de estados do grafo de SADF.

$$
w(k)=w(k)_{e t} \oplus w(k)_{r f}
$$




\subsection{Resposta Homogênea}

Identificando cada elemento da Eq.(5.42) na Eq.(5.41), observa-se que a resposta homogênea corresponde a:

$$
w(k)_{e t}=C \boldsymbol{\Phi}(\boldsymbol{k}, \mathbf{1}) i(0)
$$

\subsection{Resposta Forçada}

Do mesmo modo, na Eq.(5.41) identifica-se o componente referente à resposta forçada do grafo de SADF:

$$
w(k)_{r f}=\bigoplus_{n=0}^{k} \mathbf{h}(k, n) v(k-n)
$$

a qual representa os vetores de Max-Plus de rastros de saída, em regime forçado, de um grafo de SADF para cada $k$-ésima iteração, considerando uma sequência de cenários $\bar{\sigma}=\sigma_{1}, \cdots \sigma_{k}$.

\subsection{CURVAS DE CARACTERIZAÇÃO DE VARIABILIDADE PARA GRAFOS DE SADF}

Nesta seção, um modelo de curvas de carga de trabalho baseada em cenários de aplicação, e um modelo de curvas de serviços para grafos de SADF, são apresentados a partir da análise realizada e das expressões matemáticas obtidas na seção 5.2, a fim de simplificar o modelo de geração de eventos baseados nestes grafos e desenvolver um modelo analítico de desempenho que permita estimar a vazão de uma aplicação ou de um sistema modelado através de um grafo de SADF.

No capitulo 3 foi apresentado o conceito de Curvas de Caracterização de Variabilidade ou VCCs, as quais podem ser utilizadas para quantificar as características de melhor- e do pior-caso de qualquer tipo de sequências caracterizadas por certa propriedade medida por uma função $P$. Dado que $P(n)$ indica a medida desta propriedade para os primeiros $n$ elementos da sequência, então duas curvas $\mathcal{V}^{l}(k)$ e $\mathcal{V}^{u}(k)$, definidas pelas Eqs.(3.5), fornecem um limite inferior e superior para a medida $P$, para todas as subsequências de comprimento $k$ dentro de uma sequência maior. Estes conceitos são utilizados nas próximas seções para apresentar as curvas de 
carga de trabalho e as curvas de serviços, baseadas em cenários, cujas definições são também contribuição deste trabalho de doutorado.

\subsubsection{Curvas de Carga de Trabalho baseadas em} Cenários

Dada uma aplicação multimídia representada através de um grafo de SADF, o qual é caracterizado por um conjunto possivel de cenários $\Sigma$, cada execução da aplicação corresponde à execução de uma sequência de cenários, $\bar{\sigma}=\sigma_{1}, \cdots \sigma_{k}$, referente à execução de $k$ iterações dentro do grafo. Cada cenário nesta sequência tem associado uma matriz de Max-Plus especificada em função dos tempos de execução das múltiplas tarefas que compõem a aplicação, os quais se assumem como variáveis em relação com cada cenário executado (seção 2.1.6).

Seja $m_{i, j}$ o tempo de execução da tarefa relacionada ao nó $i, j$ do grafo de SADF quando referido ao cenário $\sigma_{s}$. Desta forma, dada qualquer subsequência de $\alpha$ cenários percorrida de modo decrescente a partir do cenário $\sigma_{\beta}$, definido como o último da sequência, a seguinte expressão define o componente $i, j$ da matriz que resulta da multiplicação das matrizes referentes a esta subsequência de $\alpha$ cenários dentro do grafo de SADF:

$$
\psi_{i, j}(\alpha, \beta)=\bigotimes_{s=\beta}^{\beta-\alpha+1} m_{i, j}\left(\boldsymbol{\sigma}_{s}\right) \quad 0 \leq i, j \leq n ; \quad n, \alpha, \beta \in Z_{>0}
$$

Deste modo, uma matriz de $n \times n$, denotada como $\Psi(\alpha, \beta)$, abrange estes componentes reais. Em notação matricial de Max-Plus, a matriz $\Psi(\alpha, \beta)$ é definida como:

$$
\boldsymbol{\Psi}(\alpha, \beta)=\bigotimes_{s=\beta}^{\beta-\alpha+1} \mathbf{M}\left(\boldsymbol{\sigma}_{s}\right) \quad \alpha, \beta \in Z_{>0}
$$

Dada uma sequência de cenários $\bar{\sigma}=\sigma_{a}, \cdots \sigma_{k}$, a matriz $\boldsymbol{\Psi}(\alpha, \beta)$ é uma multiplicação com sub-índices decrescentes em relação à sequência dada, contendo um número $\alpha$ de matrizes. Deste modo $\sigma_{\beta}$ é o cenário associado à primeira matriz avaliada dentro de cada subsequência de cenários. Como um exemplo, considere-se uma sequência de cenários $\bar{\sigma}=\sigma_{2}, \cdots \sigma_{5}$, tal que a matriz $\boldsymbol{\Psi}(\alpha, \beta)$ corresponde à multiplicação de matrizes de Max-Plus $\mathbf{M}\left(\boldsymbol{\sigma}_{\boldsymbol{s}}\right)$. Neste 
caso o número de matrizes da sequência é $\alpha=4$, e o último cenário da sequência corresponde a $\boldsymbol{\sigma}_{\boldsymbol{\beta}}=\boldsymbol{\sigma}_{5}$, de modo que a matriz $\boldsymbol{\Psi}(\alpha, \beta)$ é avaliada como:

$$
\boldsymbol{\Psi}(4,5)=\mathbf{M}\left(\sigma_{5}\right) \mathbf{M}\left(\sigma_{4}\right) \mathbf{M}\left(\sigma_{3}\right) \mathbf{M}\left(\sigma_{2}\right)
$$

A fim de encontrar o máximo e o mínimo da multiplicação dos tempos de execução de todas as sequências de cenários possiveis, definem-se as curvas de carga de trabalho baseada em cenários, as quais consideram o máximo e minimo de cada componente $\psi_{i, j}(\alpha, \beta)$ para todos os possiveis cenários $\boldsymbol{\sigma}_{\boldsymbol{\beta}}$ considerados como o último cenário em cada possível subsequência.

$$
\psi_{i, j}^{u}(\alpha)=\max _{\forall \beta}\left(\psi_{i, j}(\alpha, \beta)\right) \quad 0 \leq i, j \leq n ; \quad n, \alpha, \beta \in Z_{>0}
$$

Nesta expressão, $\psi_{i, j}^{u}(\alpha)$ define-se então como a curva superior de carga de trabalho baseada em cenários de aplicação para a tarefa $i, j$, considerando uma sequência de cenários de tamanho $\alpha$. Este conjunto $(i, j)$ de curvas superiores de carga de trabalho baseadas em cenários, refere-se à matriz $\boldsymbol{\Psi}^{\mathbf{u}}(\alpha)$, descrita pela Eq.(5.48):

$$
\boldsymbol{\Psi}^{\mathbf{u}}(\alpha)=\max _{\forall \beta}(\boldsymbol{\Psi}(\alpha, \beta)) \quad \alpha, \beta \in Z_{>0}
$$

De modo mais simples, a matriz $\Psi^{\mathbf{u}}(\alpha)$ é aquela contendo os maiores elementos que resultam da multiplicação dos tempos de execução entre tarefas, dada cada subsequência de tamanho $\alpha$, terminada pelo cenário $\sigma_{\beta}$. Sob esta consideração, a matriz $\Psi^{\mathbf{u}}(\alpha)$ pode ser definida como uma curva matricial superior de cenários.

Igualmente é possivel definir o conjunto de curvas inferiores baseada em cenários de aplicação para a tarefa $i, j$ :

$$
\psi_{i, j}^{l}(\alpha)=\min _{\forall \beta}\left(\psi_{i, j}(\alpha, \beta)\right) \quad 0 \leq i, j \leq n ; \quad n, \alpha, \beta \in Z_{>0}
$$

tal que define-se também a respectiva curva matricial inferior de cenários $\Psi^{\mathbf{l}}(\alpha)$, constituída pelas diferentes curvas inferiores $\psi_{i, j}^{l}(\alpha)$.

$$
\boldsymbol{\Psi}^{\mathbf{l}}(\alpha)=\min _{\forall \beta}(\Psi(\alpha, \beta)) \quad \alpha, \beta \in Z_{>0}
$$


Os conceitos apresentados aqui de curvas de carga de trabalho baseadas em cenários de aplicação, e curvas matriciais de cenários, estão intimamente relacionado ao conceito de curva de carga de trabalho definido em [MAXIAGUINE04b], o qual foi apresentado na seção 3.3.2, de modo que as expressões matemáticas das Eq.(5.45) até a Eq.(5.50) são uma extensão da especificação matemática utilizada para definir as curvas de trabalho em [MAXIAGUINE04b].

Os conceitos de curvas matriciais de cenários serão utilizados na próxima seção para ajudar a definir as curvas de serviços baseadas em cenários, conceito apresentado como contribuição desta tese.

\subsubsection{Curva de Serviço baseada em Cenários}

Uma das características dos sistemas clássicos lineares variantes no tempo é que eles não possuem uma resposta ao impulso no sentido habitual da sua definição [BOOM06]. Nestes casos, uma eventual resposta ao impulso só poderia ser conhecida para cada instante de tempo, devido à mesma restrição de variabilidade temporal deste tipo de sistemas.

Esta situação foi observada na análise dos grafos de SADF, onde na expressão da resposta forçada do grafo, derivada na procura da função da saída, e representada pela Eq.(5.44), não é possivel definir a função de saída $w(k)_{r f}$ como uma convolução entre $\mathbf{h}(k, n)$ e $v(k)$, justamente devido à dependência de h em função de $k$, apresentando a variabilidade própria de um modelo linear variante no tempo. No caso do grafo de $\mathrm{SDF}$, tal variância no tempo não existe, e a função $h$ pôde ser definida como a resposta ao impulso do sistema modelado pelo grafo de SDF, a qual é descrita pela Eq.(5.17).

Do mesmo modo como nos sistemas clássicos lineares, esta resposta ao impulso permite caracterizar completamente a aplicação ou o sistema modelado pelo grafo SDF, tal que várias características e estimativas de desempenho podem ser avaliadas conhecendo a representação explícita da resposta ao impulso. Uma destas características é o serviço que é fornecido pelo sistema modelado como um grafo de fluxo de dados. 
Na seção 2.2.2 foi apresentado o modelo de curva de serviços definido dentro do arcabouço teórico de Network Calculus, onde um sistema diz-se oferecer uma curva de serviço $S(t)$ se para todo $t \geq 0$, ela satisfaz:

$$
D(t) \geq \min _{\tau \in[0, t]}\{A(\tau)+S(t-\tau)\}=: A \otimes S(t)
$$

onde $A(t)$ é a função acumulativa de chegada de pacotes em uma rede, $D(t)$ é a função acumulativa de saída de pacotes na rede, e o operador $\otimes$ é referido, neste caso, como a convolução Min-Plus.

As curvas de serviços podem ser vistas como a resposta ao impulso de um sistema linear, tal que no caso do modelo de Network Calculus, a descrição das curvas de serviços é baseada na Álgebra Min-Plus. Se um sistema implementa $S(t)$ tanto como uma curva inferior e uma curva superior de serviço, a Eq.(5.51) considera só a componente de igualdade, e $S(t)$ é referida como uma Curva Exata de Serviço.

No caso dos grafos de SDF, os quais têm sido analisados no domínio da álgebra Max-Plus, onde a convolução é definida como na Eq.(5.20), a resposta forçada da função de saída dos grafos de SDF foi derivada na Eq.(5.18). Neste caso, seguindo a definição de curva de serviço referente à convolução que relaciona as funções de entrada e de saída, a resposta ao impulso do grafo de SDF corresponderia à curva de serviço do grafo, tal que:

$$
S(k)=h(k)= \begin{cases}D & k=0 \\ C A^{k-1} B & k \geq 1\end{cases}
$$

Onde o serviço medido corresponde à quantidade de tempo que o grafo precisaria para processar um conjunto de $k$ de eventos de entrada.

No caso dos grafos de SADF é necessário definir uma aproximação sobre a função $\mathbf{h}(k, n)$ da Eq.(5.40), de modo que seja possivel conhecer uma aproximação à uma possível resposta ao impulso, o que poderá levar a uma definição de limites do serviço oferecido pela aplicação ou pelo sistema modelado pelo grafo de SADF.

Considerando a expressão que descreve a função $\mathbf{h}(k, n)$, a seguinte expressão é uma expansão da Eq.(5.40): 


$$
\mathbf{h}(k, n)= \begin{cases}D & n=0 \\ C B\left(\boldsymbol{\sigma}_{\boldsymbol{k}-\boldsymbol{n}+\mathbf{1}}\right) & n=1 \\ C\left[\bigotimes_{s=k}^{k-n+2} \mathbf{M}\left(\boldsymbol{\sigma}_{\boldsymbol{s}}\right)\right] B\left(\boldsymbol{\sigma}_{\boldsymbol{k}-\boldsymbol{n}+\mathbf{1}}\right) & n>1\end{cases}
$$

Tal que o produto matricial referente à sequência de cenários $\bar{\sigma}=\sigma_{k}, \cdots \sigma_{k-n+2}$, para $n>1$, pode ser reescrito considerando a definição do produto matricial dado na Eq.(5.46), para $\beta=k$ e $\alpha=n-1$. Deste modo, $\mathbf{h}(k, n)$ pode ser reescrito como:

$$
\mathbf{h}(k, n)= \begin{cases}D & n=0 \\ C B\left(\boldsymbol{\sigma}_{\boldsymbol{k}-\boldsymbol{n}+\mathbf{1}}\right) & n=1 \\ C \boldsymbol{\Psi}(n-1, k) B\left(\boldsymbol{\sigma}_{\boldsymbol{k}-\boldsymbol{n}+\mathbf{1}}\right) & n>1\end{cases}
$$

A fim de encontrar os limites máximos e mínimos de $\mathbf{h}(k, n)$ para todas as possíveis opções do cenário de inicio $\boldsymbol{\sigma}_{\boldsymbol{k}}$ definem-se duas funções $\mathbf{h}^{\mathbf{u}}(n)$ e $\mathbf{h}^{\mathbf{l}}(n)$ para representar o limite máximo e mínimo, respectivamente da função $\mathbf{h}(k, n)$ para todo $k$. Isto é,

$$
\mathbf{h}^{\mathbf{l}}(n) \leq \mathbf{h}(k, n) \leq \mathbf{h}^{\mathbf{u}}(n)
$$

Deste modo $\mathbf{h}^{u}(n)$ é definido como:

$$
\mathbf{h}^{\boldsymbol{u}}(n)=\max _{\forall k} \begin{cases}D & n=0 \\ C B\left(\boldsymbol{\sigma}_{\boldsymbol{k}-\boldsymbol{n}+\mathbf{1}}\right) & n=1 \\ C \boldsymbol{\Psi}(n-1, k) B\left(\boldsymbol{\sigma}_{\boldsymbol{k}-\boldsymbol{n}+\mathbf{1}}\right) & n>1\end{cases}
$$

e $\mathbf{h}^{l}(n)$ é definido como:

$$
\mathbf{h}^{\boldsymbol{u}}(n)=\min _{\forall k} \begin{cases}D & n=0 \\ C B\left(\boldsymbol{\sigma}_{\boldsymbol{k}-\boldsymbol{n}+\mathbf{1}}\right) & n=1 \\ C \boldsymbol{\Psi}(n-1, k) B\left(\boldsymbol{\sigma}_{\boldsymbol{k}-\boldsymbol{n}+\mathbf{1}}\right) & n>1\end{cases}
$$

Avaliando a operação max na Eq.(5.55), deriva-se:

$$
\mathbf{h}^{\boldsymbol{u}}(n)= \begin{cases}D & n=0 \\ \max _{\forall k}\left(C B\left(\boldsymbol{\sigma}_{\boldsymbol{k}-\boldsymbol{n}+\mathbf{1}}\right)\right) & n=1 \\ \max _{\forall k}\left(C \boldsymbol{\Psi}(n-1, k) B\left(\boldsymbol{\sigma}_{\boldsymbol{k}-\boldsymbol{n}+\mathbf{1}}\right)\right) & n>1\end{cases}
$$


De modo que o $\max _{\forall k}\left(C B\left(\boldsymbol{\sigma}_{\boldsymbol{k}-\boldsymbol{n}+\mathbf{1}}\right)\right)=C B_{\max }$, sendo $B_{\max }$ a maior matriz $B$ entre dos possiveis cenários dentro do grafo de SADF sob análise. Por outro lado,

$$
\max _{\forall k}\left(C \boldsymbol{\Psi}(n-1, k) B\left(\boldsymbol{\sigma}_{\boldsymbol{k}-\boldsymbol{n}+\mathbf{1}}\right)\right)=C \max _{\forall k}(\boldsymbol{\Psi}(n-1, k)) B_{\max }
$$

Onde $\max _{\forall k}(\Psi(n-1, k))$ corresponde à curva matricial superior de cenários $\boldsymbol{\Psi}^{\mathbf{u}}(\alpha)$ definida na seção 5.3.1, com $\alpha=n-1$. Agrupando estas análises e aproximações, o limite superior de $\mathbf{h}(k, n)$ é descrito por:

$$
\mathbf{h}^{\boldsymbol{u}}(n)= \begin{cases}D & n=0 \\ C B_{\max } & n=1 \\ C \boldsymbol{\Psi}^{\boldsymbol{u}}(n-1) B_{\max } & n>1\end{cases}
$$

Esta expressão resume todas as possiveis sequências de cenários de tamanho $n-1$, de modo que os elementos da matriz $\boldsymbol{\Psi}^{\boldsymbol{u}}(n-1)$ correspondem aos maiores produtos de tempos de execução de cada tarefa, dada cada sequência de cenários avaliada, de tamanho $n-1$.

Do mesmo modo é possivel derivar o limite inferior de $\mathbf{h}(k, n)$, sendo definido como:

$$
\mathbf{h}^{l}(n)= \begin{cases}D & n=0 \\ C B_{\min } & n=1 \\ C \Psi^{l}(n-1) B_{\min } & n>1\end{cases}
$$

Considerando esta análise e aproximação, é possivel eliminar a dependência de $\mathbf{h}(k, n)$ em relação a $k$, tal que a resposta forçada da função de saída, e sua relação com a função de entrada do grafo de SADF agora também fica descrita através de dois limites possíveis:

$$
w(k)_{r f}^{l} \leq w(k)_{r f} \leq w(k)_{r f}^{u}
$$

onde,

$$
\begin{aligned}
& w(k)_{r f}^{u}=\bigoplus_{n=0}^{k} \mathbf{h}^{\boldsymbol{u}}(n) v(k-n) \quad \mathrm{e}, \\
& w(k)_{r f}^{l}=\bigoplus_{n=0}^{k} \mathbf{h}^{\boldsymbol{l}}(n) v(k-n)
\end{aligned}
$$


Expressões que seguem a forma da convolução em Max-Plus apresentada na Eq.(5.20). Com isto, os limites da resposta forçada do grafo de SADF podem ser reescritos como:

$$
\begin{aligned}
& w(k)_{r f}^{u}=\mathbf{h}^{u} \otimes v(k) \\
& w(k)_{r f}^{l}=\mathbf{h}^{l} \otimes v(k)
\end{aligned}
$$

Com esta aproximação, os limites $\mathbf{h}(n)$ para o grafo de SADF têm o papel de $\mathbf{h}(n)=C A^{n-1} B$ para o grafo de SDF apresentado na Eq.(5.17), de modo que a ordem $n$ refere-se ao tamanho da sequência de cenários avaliada e, portanto ao número de matrizes multiplicadas.

Observando que agora a resposta forçada do grafo de SADF corresponde à convolução entre uma função $\mathbf{h}(n)$, superior e inferior, e a função de entrada do grafo de SADF, é possível dizer que os limites $\mathbf{h}(n)$ correspondem a limites da resposta ao impulso da aplicação ou do sistema modelado pelo grafo de SADF, tal que estas funções também representam as curvas, superior e inferior, do serviço oferecido pela entidade modelada. Desta forma, para uma aplicação modelada com um grafo de SADF, o serviço $S(k)$ oferecido tem limites:

$$
S^{l}(k) \leq S(k) \leq S^{u}(k)
$$

Onde, de acordo à Eq.(5.57) e a Eq.(5.58),

$$
\begin{aligned}
& S^{l}(k)=\mathbf{h}^{l}(n) \quad \mathrm{e}, \\
& S^{u}(k)=\mathbf{h}^{u}(n)
\end{aligned}
$$

\subsection{AVALIAÇÃO DE DESEMPENHO BASEADO EM GRAFOS DE SADF}

\subsubsection{Modelo de Vazão}

A vazão é, talvez, a métrica de desempenho mais dominante utilizada na realização de aplicações. Dependendo do tipo de aplicação, é possível estar interessado na vazão de pior-caso (isto é, um limite inferior garantido da vazão da aplicação), ou na vazão média esperada ou de longo prazo. 
Para determinar a vazão de pior-caso de uma aplicação modelada com um grafo de fluxo de dados, é necessário assumir que é possivel encontrar os tempos de execução de pior-caso dos atores do grafo. Nesta premissa, deve se observar que estes tempos de execução sejam precisos para os sistemas de tempo-real considerados, quando os atores são executados sob um esquema conduzido por dados, ou sob uma execução autotemporizada [GHAMARIANO6a].

\subsubsection{Vazão em Grafos de SADF sem Atores de Entrada e de Saída}

Uma das utilidades das curvas de carga de trabalho e das curvas de serviços baseadas em cenários, apresentadas na seção 5.3, é o cálculo de limites inferiores e superiores de diversas métricas de desempenho, de modo que o cálculo da vazão de pior-caso foi definido como de maior destaque para ser analisada no presente trabalho.

Em relação à modelagem através de grafos de $\mathrm{SADF}$, vários métodos são conhecidos para avaliar limites acurados da vazão, tanto nos atores do grafo, nas sequências de entrada e saída, e no grafo completo [GEILEN10a, THEELEN06, GEILEN11b, FALK11, SIYOUM12]. Estes métodos estão focados a grafos de SADF fechados, onde o sistema ou a aplicação modelada não apresentam sequências de entrada externas. A fim de apresentar na próxima seção (5.4.3) um modelo de cálculo da vazão proposto na presente tese para grafos de SADF com entradas externas, esta seção apresenta o formalismo desenvolvido até agora no estado da arte para modelar o desempenho (em particular a vazão) de grafos de SADF fechados, os quais não possuem atores de entrada e de saída.

Para isto, é preciso especificar o grafo, e o que significa sua vazão. Um grafo de SADF é definido formalmente pela tupla $\left(\boldsymbol{\Sigma}, \boldsymbol{G}, \rho, N_{i}, N_{f}, \pi, \boldsymbol{A}\right)$ [FALK11]. Ele tem um conjunto finito $\Sigma$ de cenários e cada cenário $\boldsymbol{\sigma} \in \boldsymbol{\Sigma}$ tem associado um grafo de SDF $\boldsymbol{G}(\boldsymbol{\sigma})$, e um vetor parcial de repetição $\rho(\boldsymbol{\sigma})$, o qual mapeia cada ator de $\boldsymbol{G}(\boldsymbol{\sigma})$ a um número não-negativo que especifica quantas vezes o ator dispara no cenário $\boldsymbol{\sigma}$. O grafo $\boldsymbol{G}(\boldsymbol{\sigma})$ tem uma coleção de tokens iniciais $N_{i}(\boldsymbol{\sigma}) \in \mathbb{N}$, os quais são indexados como $0 \leq n<N_{i}(\boldsymbol{\sigma})$. Depois da execução do vetor parcial de repetição, o grafo $\boldsymbol{G}(\boldsymbol{\sigma})$ tem uma coleção de tokens "finais" $N_{f}(\boldsymbol{\sigma}) \in \mathbb{N}$, os 
quais são indexados de acordo a $0 \leq n<N_{f}(\sigma)$. ( $N_{f}$ pode ser determinado a partir de $N_{i}, G$ e $\rho$, porém é conveniente torná-lo explícito) [FALK11].

Além destas especificações, usa-se a semântica de Max-Plus dos grafos de SDF para associar com cada grafo $\boldsymbol{G}(\boldsymbol{\sigma})$ uma matriz de Max-Plus $\mathbf{M}(\boldsymbol{G}(\boldsymbol{\sigma})) \in$ $\left(\mathbb{R}^{-\infty}\right)^{N_{f}(\sigma) \times N_{i}(\sigma)}$, ou simplesmente $\mathbf{M}(\boldsymbol{\sigma})$, que caracteriza precisamente a relação entre as marcas de tempo dos tokens iniciais e finais no grafo nesse cenário, como ilustrado na Seção 5.2.1. Além disto, o grafo considera uma FSM $\mathcal{A}$, a qual é definida como uma tupla $\left(Q, q_{0}, \delta\right)$ com um conjunto $Q$ de estados, um estado inicial $q_{0}$ e uma relação de transição marcada $\delta \subseteq Q \times \Sigma \times Q$. Os rótulos dos cenários nos arcos devem ser consistentes no sentido que para qualquer estado $q \in Q$, qualquer arco de entrada marcado com cenário $\sigma_{1}$ e arco de saída marcado com cenário $\sigma_{2}, N_{f}\left(\sigma_{1}\right)=N_{i}\left(\sigma_{2}\right)$, ou seja, o número de tokens finais e iniciais de cenários consecutivos na execução do grafo deve coincidir.

Denota-se $n(q)$ como o número de tokens para um estado $q$. $\mathcal{A}$ aceita a sequência $\overline{\boldsymbol{\sigma}}(\boldsymbol{n})$ de cenários se, e somente se, existir uma sequência $q$ de estados tal que $\bar{q}(0)=q_{0}$ e para cada $n \geq 0$, existe um $\operatorname{arco}(\bar{q}(n), \bar{\sigma}(n), \bar{q}(n+$ 1)) $\in \delta[$ FALK11].

Com a sequência $\overline{\boldsymbol{\sigma}}(\boldsymbol{n})=\boldsymbol{\sigma}_{1}, \cdots \boldsymbol{\sigma}_{\boldsymbol{n}}$, associa-se o comportamento temporal, o qual é definido através de uma sequência de vetores de Max-Plus $\boldsymbol{i}_{\boldsymbol{n}}$, tal que $\boldsymbol{i}_{\mathbf{0}}=0$, e para todo $n>0, \boldsymbol{i}_{\boldsymbol{n}+\mathbf{1}}=\mathbf{M}(\boldsymbol{\sigma}(\boldsymbol{n})) \boldsymbol{i}_{\boldsymbol{n}}$. Na definição acima, pode-se reconhecer claramente a estrutura de um autômato de Max-Plus como foi explicado na seção 5.2.2.

De modo geral, na análise do fluxo síncrono de dados, é comum quantificar a vazão pela medida do número de iterações por unidade de tempo. Em outros casos a quantificação da vazão depende do modelo e de uma medida do "progresso" feito por cenário. Em geral, define-se uma função de bonificação ${ }^{25}$ $\boldsymbol{\pi}: \Sigma \rightarrow \mathbb{R}^{\geq 0}$, a qual quantifica a quantidade de progresso por cenário $\boldsymbol{\sigma}$, como $\boldsymbol{\pi}(\boldsymbol{\sigma})$. A vazão obtida a partir de uma sequência de cenários $\overline{\boldsymbol{\sigma}}$ pode, então, ser definida como se segue [FALK11]:

$$
\tau(\overline{\boldsymbol{\sigma}})=\lim _{k \rightarrow \infty} \sup \frac{\sum_{n=0}^{k-1} \pi(\overline{\boldsymbol{\sigma}}(\boldsymbol{n}))}{\left\|i_{k}\right\|}
$$

\footnotetext{
${ }^{25}$ Do inglês Reward Function
} 
Ou seja, a vazão é definida como o valor médio do progresso realizado por unidade de tempo [FALK11]. (O lim sup é utilizado em vez de um limite comum devido a que este último limite pode não ser definido para certas sequências irregulares de cenários.). Na literatura [GHAMARIANO6a, GEILEN10a, GEILEN10b], este valor médio também costuma ser denotado como a taxa de crescimento do progresso. Também, a seguinte expressão permite conhecer a vazão do pior caso de um grafo de SADF [FALK11]:

$$
\tau=\inf _{\bar{\sigma} \in \mathcal{L}(\mathcal{A})} \tau(\bar{\sigma})
$$

Onde $\mathcal{L}(\mathcal{A})$ é o conjunto possivel de sequências de cenários, definido também como a linguagem do autômato $\mathcal{A}$.

A fim de se determinar o ínfimo dos valores da vazão para todas as possiveis sequências de cenários no grafo, é necessário encontrar a sequência de cenários do pior-caso. Em qualquer sequência de cenários, tanto o tempo, como a bonificação total (seção 5.4.2), aumentam com os cenários sendo executados. O progresso do tempo é medido como a norma de Max-Plus do vetor de estado $\boldsymbol{i}_{\boldsymbol{k}}$, isto é, o elemento máximo deste vetor. Visto que $\boldsymbol{i}_{\boldsymbol{k}+\mathbf{1}}=$ $\mathbf{M}(\boldsymbol{\sigma}(\boldsymbol{k})) \boldsymbol{i}_{\boldsymbol{k}}$, cada elemento de $\boldsymbol{i}_{\boldsymbol{k}+\mathbf{1}}$ é determinado por algum elemento de $\boldsymbol{i}_{\boldsymbol{k}} \mathrm{e}$ deslocado pela dependência numérica associada com cada elemento da matriz de Max-Plus. Este elemento de $\boldsymbol{i}_{\boldsymbol{k}}$ pode, por sua vez, ser rastreada até um único elemento em $\boldsymbol{i}_{\boldsymbol{k}-\mathbf{1}}$, e assim por diante até chegar em $\boldsymbol{i}_{\mathbf{0}}$. Deste modo, $\boldsymbol{i}_{\boldsymbol{k}+\mathbf{1}}=\mathcal{M}(\bar{\sigma}) \boldsymbol{i}_{\mathbf{0}}$, dada a sequência de cenários $\overline{\boldsymbol{\sigma}}=\boldsymbol{\sigma}_{\mathbf{1}}, \cdots \boldsymbol{\sigma}_{\boldsymbol{k}}$ e o morfismo $\mathcal{M}$, tal como indicado na seção 5.2.2.

Desta forma, considerando esta observação, no momento de avaliar a relação entre o progresso do tempo e as sequências de cenários, não é preciso olhar para vetores completos, mas sim se focar em elementos individuais (tokens iniciais/finais) e suas dependências individuais tal como estão expressas pelos componentes das diferentes matrizes [GEILEN10a]. Desta maneira, o efeito acumulado de uma sequência $\bar{\sigma}=\sigma_{1}, \cdots \sigma_{\boldsymbol{k}}$ é capturado pela multiplicação das matrizes de cenários $\mathbf{M}_{\sigma_{\boldsymbol{k}}} \cdots \mathbf{M}_{\sigma_{2}} \mathbf{M}_{\sigma_{1}}$. Neste caso, o problema de análise da vazão é mapeado em um problema de Taxa de Ciclo Máximo (Maximum Cycle Ratio, MCR) em um multigrafo direcionado, derivado de um autômato de MaxPlus. Uma generalização da análise de taxa de ciclo, ou média de ciclo, é fornecida pela análise espectral de sistemas lineares em Max-Plus 
[GEILEN10a]. A análise espectral oferece não apenas a média do ciclo, (isto é, o autovalor $\lambda$ referente à matriz que representa o grafo de SDF de cada cenário, seção 5.1.3.1.1), mas também um vetor próprio, o qual fornece a informação sobre os tempos relativos de disparo dos atores, ou latência.

Em [GAUBERT95], Gaubert mostra como a taxa máxima de crescimento definida pela Eq.(5.64), pode ser eficientemente calculada como o inverso da média do ciclo máximo do grafo equivalente de eventos temporizados (Timed Event Graph, TEG, seção 2.1.8.1) [FALK11] da matriz $\mathbf{M}=\max _{\sigma \in \Sigma} \mathbf{M}(\sigma) \operatorname{sempre}$ que as matrizes sejam todas quadradas e do mesmo tamanho. Gaubert também descreve como, dado uma sub-linguagem regular infinita de $\Sigma^{*}$, isto é, o conjunto de todas as sequências finitas de cenários, a taxa máxima de crescimento pode ser determinada usando a construção de um autômato clássico [FALK11]. Seu comportamento de pior caso pode, então, ser analisado pela análise espectral de uma matriz correspondente, ou, caso esteja-se apenas interessado na vazão, pela análise média do ciclo máximo diretamente no grafo do autômato [GEILEN10a]. A seguinte proposição resume esta análise para encontrar a vazão de um grafo de SADF [GEILEN10a].

Proposição 5.2: A vazão de um grafo de SADF, com uma FSM completamente conectada, é igual ao inverso da média de ciclo máxima do grafo de eventos temporais correspondente à matriz $G=\max _{q \in Q} G_{\Sigma(q)}$.

Deste modo, o maior autovalor corresponde ao periodo médio de pior-caso com o qual a execução do grafo de SDF irá terminar. Este é o inverso da vazão máxima garantida a ser alcançada.

É importante anotar que a vazão, medida em iterações por unidade de tempo, pode também ser expressa como uma vazão medida em disparos de ator por unidade de tempo, uma vez que o número de disparos de um ator por iteração é fixo [GEILEN10a, FALK11]. 


\subsubsection{Vazão em Grafos de SADF com Atores de Entrada e de Saída}

Considerando cada análise apresentada até agora, assim como os diferentes modelos desenvolvidos neste capítulo como parte fundamental deste trabalho de doutorado, esta seção apresenta uma nova proposta para estimar analiticamente a vazão de uma aplicação ou de um sistema modelado através de um grafo de SADF.

As análises resultantes sobre a carga de trabalho baseada em cenários, e as curvas de serviço definidas como a resposta ao impulso do grafo de SADF, junto à análise espectral do TEG resultante da maior matriz de cenários, são aproveitados nesta seção para propor um modelo analítico de cálculo da vazão em grafos de SADF que apresentam entradas externas e saídas específicas. O ponto de partida desta proposta é a Eq.(5.41), a qual representa a função de sequência de vetores de saída de um grafo de SADF:

$$
w(k)=C \boldsymbol{\Phi}(\boldsymbol{k}, \mathbf{1}) i(0) \oplus \bigoplus_{n=0}^{k} \mathbf{h}(k, n) v(k-n)
$$

Dada esta expressão, a resposta forçada do grafo de SADF foi reescrita na Eq.(5.59) definida a partir de dois limites que dependem das curvas inferior e superior de serviços, propostas na seção 5.3.2. Como consequência disto, a função completa da sequência de vetores de saída $w(k)$ pode ser definida agora por dois limites $w^{l}(k)$ e $w^{u}(k)$.

$$
w^{l}(k) \leq w(k) \leq w^{u}(k)
$$

Tal que, considerando a Eq.(5.61a) e a Eq.(5.61b):

$$
\begin{aligned}
& w^{l}(k)=w_{0}(k) \oplus\left(\mathbf{h}^{l} \otimes v(k)\right) \\
& w^{u}(k)=w_{0}(k) \oplus\left(\mathbf{h}^{u} \otimes v(k)\right)
\end{aligned}
$$

onde, $w_{0}(k)=C \boldsymbol{\Phi}(\boldsymbol{k}, \mathbf{1}) i(0)$.

\section{Proposição 5.3:}


Visto que em [Gaubert95], Gaubert mostrou que a taxa máxima de crescimento de uma sequência de eventos pode ser eficientemente calculada como o inverso da média do ciclo máximo do TEG equivalente da matriz $\mathbf{M}=\max _{\sigma \in \Sigma} \mathbf{M}(\sigma)$, isto é, o inverso do maior autovalor do conjunto de matrizes de Max-Plus associado ao conjunto de cenários $\boldsymbol{\Sigma}$ definidos dentro do grafo de $\mathrm{SADF}$, a vazão da sequência $w_{o}(k)$, e dos limites da resposta ao impulso $\mathbf{h}^{l} \mathrm{e}$ $\mathbf{h}^{\boldsymbol{u}}$, para todo $k$, é igual a $\frac{1}{M C M\left(\max _{\sigma \in \Sigma} \boldsymbol{M}(\sigma)\right.}=\frac{1}{\lambda_{\max }}$, sendo $\lambda_{\max }$ o autovalor da matriz $\mathbf{M}=\max _{\boldsymbol{\sigma} \in \boldsymbol{\Sigma}} \mathbf{M}(\boldsymbol{\sigma})$.

Consequentemente, tendo em conta as propriedades do cálculo da vazão para as operações $\max (\oplus)$ e na convolução $(\otimes)$ de Max-Plus (Eq.(5.28a) e Eq.(5.28b)), assim como o valor da vazão da sequência referente à resposta homogênea $w_{o}(k)$ e dos limites da resposta ao impulso $\mathbf{h}^{\boldsymbol{l}}$ e $\mathbf{h}^{\boldsymbol{u}}$, deriva-se a seguinte proposição, a qual determina o limite inferior da vazão para um grafo $\mathbb{S}_{\mathrm{A}}$ de $\mathrm{SADF}$ com atores de entradas e de saída.

\section{Proposição 5.4:}

Seja $\mathbb{S}_{\mathbb{A}}=(\boldsymbol{\Sigma}, \boldsymbol{G}, \mathbf{M}, \boldsymbol{B}, \boldsymbol{C}, \boldsymbol{D}, \boldsymbol{r}, \boldsymbol{\Lambda}, \boldsymbol{P}, \boldsymbol{Q})$ um grafo de SADF fortemente conectado, conformado por um conjunto finito $\boldsymbol{\Sigma}$ de cenários, onde cada cenário $\boldsymbol{\sigma} \in \boldsymbol{\Sigma}$ tem associado um grafo de SDF $\boldsymbol{G}(\boldsymbol{\sigma})$, e apresenta uma matriz de Max-Plus $\mathbf{M}(\boldsymbol{\sigma})$ que depende dos tempos variáveis de execução de cada tarefa ao interior de cada cenário $\sigma$.

O grafo $\mathbb{S}_{\mathbb{A}}$ apresenta também o conjunto $\Lambda$ de autovalores $\lambda$ de cada matriz $\mathbf{M}(\boldsymbol{\sigma})$, assim como o conjunto $\boldsymbol{P}$ de portas de entrada e o conjunto $\boldsymbol{Q}$ de portas de saída, cuja relação é representada em cada cenário pelo conjunto de matrizes de Max-Plus $\mathbf{M}(\boldsymbol{\sigma}), \mathbf{B}(\boldsymbol{\sigma}), \boldsymbol{C} \boldsymbol{e} \boldsymbol{D}$. As taxas de escrita e de leitura das portas de entrada e saída, respectivamente, são representados pela função $\boldsymbol{r}: \boldsymbol{P} \cup \boldsymbol{Q} \rightarrow \mathbb{N}$.

Seja $x$ um rastro de entrada de $\mathbb{S}_{\mathbb{A}}$. Então seguindo a proposição 5.3 , o espaço de estado indicado pelo autômato, apresenta um período médio de pior-caso dado pelo maior autovalor $\lambda_{\max }$ do conjunto de autovalores $\Lambda$, e 


$$
T^{l b}\left(\mathbb{S}_{\mathbb{A}}, x, q\right)=r(q) \cdot \min \left(\frac{1}{\lambda_{\max }}, \min _{p \in P} \frac{T^{l b}(x(p))}{r(p)}\right)
$$

A qual representa a vazão de cada rastro de eventos de saída do grafo, obtidos nas portas $q \in \boldsymbol{Q}$, em função dos diversos rastros de eventos de entrada que chegam pelas portas $p \in \boldsymbol{P}$.

\section{Demonstração:}

Considerando que a vazão de um rastro de eventos pode ser descrita pela vazão da sua respectiva sequência infinita de vetores de Max-Plus (Teorema 5.1, seção 5.1.3.1.1), a seguinte demonstração é iniciada encontrando primeiro uma expressão para a vazão da sequência de tempos de produção de tokens de saída do grafo de SADF.

A Eq.(5.67) definiu esta sequência em função das sequências de tempos de produção de entrada, e das curvas de serviço baseadas em cenários da aplicação. Considerando um número de entradas $1 \leq j \leq L$ e um número de saídas $1 \leq i \leq N$, a sequência de tempos de produção para cada saída individual corresponde ao j-ésimo componente do vetor $\boldsymbol{w}(\boldsymbol{k})$. Ou seja, da Eq.(5.61a) e Eq.(5.42)

$$
\boldsymbol{w}^{\boldsymbol{u}}(k)=\boldsymbol{w}_{\mathbf{0}}(k) \oplus\left(\mathbf{h}^{\boldsymbol{u}} \otimes \boldsymbol{v}(k)\right)
$$

$\operatorname{Com} \boldsymbol{w}_{\mathbf{0}}(k)=C \otimes_{s=1}^{k} \mathbf{M}\left(\boldsymbol{\sigma}_{\boldsymbol{s}}\right) i(0)$

Então, usando a definição da convolução:

$$
\boldsymbol{w}^{\boldsymbol{u}}(k)=\boldsymbol{w}_{\mathbf{0}}(k) \oplus \bigoplus_{n=0}^{k} \boldsymbol{h}^{\boldsymbol{u}}(k) \boldsymbol{v}(k-n)
$$

De modo que ao considerar cada elemento vetorial individualmente, a sequência de tempos de produção de saída corresponde a,

$$
w_{i}^{u}(k)=w_{0_{i}}(k) \oplus \bigoplus_{n=0}^{k} \bigoplus_{j=1}^{L} h_{i, j}^{u}(k) v_{j}(k-n) \quad \text { para } 1 \leq i \leq N \quad \text { e } 1 \leq j \leq L
$$

Trocando a ordem das somatórias em Max-Plus: 


$$
w_{i}^{u}(k)=w_{0 i}(k) \oplus \bigoplus_{j=1}^{L} \bigoplus_{n=0}^{k} h^{u}{ }_{i, j}(k) v_{j}(k-n)
$$

Tal que ao aplicar de novo a definição da convolução, a sequência de tempos de produção para a $i$-ésima saída corresponde a,

$$
w_{i}^{u}(k)=w_{0_{i}}(k) \oplus \bigoplus_{j=1}^{L} h_{i, j}^{u} \otimes v_{j}(k)
$$

Desta forma, a vazão desta sequência é equivalente a,

$$
T^{l b}\left(w_{i}^{u}(k)\right)=T^{l b}\left(w_{0_{i}}(k) \oplus \bigoplus_{j=1}^{L} h_{i, j}^{u} \otimes v_{j}(k)\right)
$$

E aplicando recursivamente as propriedades da vazão para os operações max e convolução como foi indicado na Eq.(5.28a) e na Eq.(5.28b),

$$
\begin{aligned}
T^{l b}\left(w_{i}^{u}(k)\right) & =\min \left(T^{l b}\left(w_{0_{i}}(k)\right), T^{l b}\left(\bigoplus_{j=1}^{L} h^{u}{ }_{i, j} \otimes v_{j}(k)\right)\right) \\
& =\min \left(T^{l b}\left(w_{0_{i}}(k)\right), \min _{1 \leq j \leq L} T^{l b}\left(h^{u}{ }_{i, j} \otimes v_{j}(k)\right)\right) \\
& =\min \left(T^{l b}\left(w_{0_{i}}(k)\right), \min _{1 \leq j \leq L} \min \left(T^{l b}\left(h^{u}{ }_{i, j}\right), T^{l b}\left(v_{j}(k)\right)\right)\right) \\
= & \left.\min \left(T^{l b}\left(w_{0_{i}}(k)\right), \min _{1 \leq j \leq L}\left(\min ^{l b}\left(h^{u}{ }_{i, j}\right), T^{l b}\left(v_{j}(k)\right)\right)\right)\right) \\
= & \min \left(T^{l b}\left(w_{0_{i}}(k)\right), \min _{1 \leq j \leq L}\left(T^{l b}\left(h^{u}{ }_{i, j}\right), T^{l b}\left(v_{j}(k)\right)\right)\right)
\end{aligned}
$$

Nesta última expressão a vazão $T^{l b}\left(w_{0_{i}}(k)\right)$, da $i$-ésima componente do vetor da resposta transitória (Eq.(5.43)), e a vazão do componente $(i, j)$ da sequência da resposta ao impulso, $T^{l b}\left(h_{i, j}^{u}\right)$, dependem dos autovalores das matrizes associadas a cada cenário, de modo que a vazão é $1 / \operatorname{MCM}\left(\max _{\sigma \in \Sigma} \boldsymbol{M}(\sigma)\right)$ de acordo à proposição 5.3. Desta forma, 


$$
T^{l b}\left(w_{i}^{u}(k)\right)=\min \left(\frac{1}{\lambda_{\max }}, \min _{1 \leq j \leq L}\left(\frac{1}{\lambda_{\max }}, T^{l b}\left(v_{j}(k)\right)\right)\right)
$$

Eliminando a redundância na avaliação da operação min em cima da constante $\frac{1}{\lambda_{\max }}$, a vazão da componente $i$-ésima da sequência de tempos dos tokens de saída, corresponde a,

$$
T^{l b}\left(w_{i}^{u}(k)\right)=\min \left(\frac{1}{\lambda_{\max }}, \min _{1 \leq j \leq L}\left(T^{l b}\left(v_{j}(k)\right)\right)\right)
$$

onde lembra-se que $L$ corresponde ao número de portas de saída do grafo de SADF.

A partir da análise desta equação, fica evidente que a vazão das sequência de saída depende da vazão com que as sequência de entrada são oferecidas às portas de entrada do grafo. No entanto, as dependências internas dentro do grafo de SADF, representadas pela resposta ao impulso, e o maior autovalor das matrizes de cada cenário, pode resultar em que a vazão na saída não seja proporcional à vazão nas entradas, mas sendo restritas pela limitação da vazão interna do grafo de SADF.

Finalmente, considerando o teorema 5.1 na seção 5.1.3.1.1, a vazão das sequências de eventos nas diferentes portas de saída $q \in Q$, depende da vazão das sequências de eventos de entrada nas diversas portas de entrada $p \in P$.

$$
\begin{gathered}
\frac{T^{l b}(y(q))}{r(q)}=\min \left(\frac{1}{\lambda_{\max }}, \min _{p \in P}\left(\frac{T^{l b}(x(p))}{r(p)}\right)\right) \\
T^{l b}(y(q))=r(q) \cdot \min \left(\frac{1}{\lambda_{\max }}, \min _{p \in P}\left(\frac{T^{l b}(x(p))}{r(p)}\right)\right)
\end{gathered}
$$

Ou de modo geral, para o grafo de $\mathrm{SADF}, \mathbb{S}_{\mathbb{A}}$, com rastro de eventos de entrada $x$ e a porta de saída $q$ :

$$
T^{l b}(y(q))=r(q) \cdot \min \left(\frac{1}{\lambda_{\max }}, \min _{p \in P}\left(\frac{T^{l b}(x(p))}{r(p)}\right)\right)
$$




\section{Capítulo 6}

\section{IMPLEMENTAÇõES E CASOS DE USO}

H ste capítulo descreve a especificação de uma metodologia analítica de caracterização das tarefas de uma aplicação multimídia que terá exigências variáveis de execução ao ser implementada em uma determinada plataforma MPSoC. Na plataforma, os recursos de hardware para computação referem-se somente a processadores do tipo MIPS, representados neste capitulo por um conjunto de processadores Simplescalar, sendo que para cada um deles, uma tarefa da aplicação é mapeada.

A metodologia apresentada é desenvolvida considerando a análise estática das múltiplas rotas de execução do código executável de cada tarefa da aplicação; objetiva encontrar seus múltiplos modos de operação e, posteriormente, estimar o WCET e o BCET de cada modo encontrado, sendo que esta estimação é baseada na modelagem da microarquitetura do processador Simplescalar. A análise estática de rotas foi baseada em uma plataforma de desenvolvimento de compiladores conhecida como Rose [ROSE12], e as estimativas do WCET e do BCET foram baseadas na ferramenta Chronos [LIO7].

A modelagem da microarquitetura implementada pela ferramenta Chronos lida com a análise temporal de uma sequência conhecida de instruções no nível de linguagem assembly, o que é essencial para se capturar todos os efeitos das otimizações do compilador e da implementação da microarquitetura do processador. Além disso, os modos de operação encontrados na análise estática, que são semelhantes do ponto de vista das exigências dos recursos de processamento, são agrupados a fim de se construir uma curva de carga de trabalho para cada tarefa, considerando seus respectivos fluxos de eventos de entrada.

Logo após caracterizar as tarefas da aplicação através da identificação analítica das suas exigências variáveis de execução, duas metodologias 
diferentes foram desenvolvidas e implementadas para caracterizar a operação global da aplicação, considerando a caracterização da sua carga de trabalho e diferentes métricas de desempenho. A primeira destas metodologias apresenta-se como um exemplo da utilidade da caracterização analítica das tarefas, e consiste em um procedimento de avaliação analítica de desempenho, baseada em Real-Time Calculus, desenvolvido com o intuito de analisar o desempenho da aplicação multimídia sendo projetada. Este procedimento foi baseado no Toolbox de Real-Time Calculus de Matlab [WANDELER12].

A segunda metodologia utilizada corresponde a um fluxo de análise planejado e desenvolvido neste trabalho de doutorado, de modo que a aplicação sob análise é representada através de um grafo de SADF, e seguindo diferentes análises matemáticas no domínio de Max-Plus, é possível descrever o serviço oferecido pela aplicação, definido como o tempo que ela precisa para processar uma sequência de eventos. Os limites, inferior e superior, deste serviço são descritos através de um modelo de curvas de serviços baseadas em cenários.

\subsection{FLUXO DE CARACTERIZAÇÃO DA CARGA DE TRABALHO}

A Figura 6.1 ilustra um fluxo de análise das tarefas de uma aplicação multimídia a fim de caracterizar a carga de trabalho de cada uma delas. $\mathrm{Na}$ Seção 6.2 será apresentada uma forma de uso desta caracterização com a avaliação do desempenho da aplicação analiticamente. Este fluxo engloba basicamente a teoria e os métodos descritos nos capítulos 2 e 3 desta tese.

O elemento-chave do fluxo da Figura 6.1 é a ferramenta Chronos que captura o arquivo binário de um programa, desmonta-o e realiza uma análise estática do código assembly em conjunção com a modelagem da microarquitetura. A ferramenta suporta uma modelagem precisa de características avançadas da microarquitetura, tais como o pipeline "out-of-order" e a previsão dinâmica de saltos (tanto a local como a global). Na configuração que o projetista pode fazer em relação ao processador hospedeiro, Chronos permite ligar ou desligar os módulos de memória cache e de predição de saltos. 


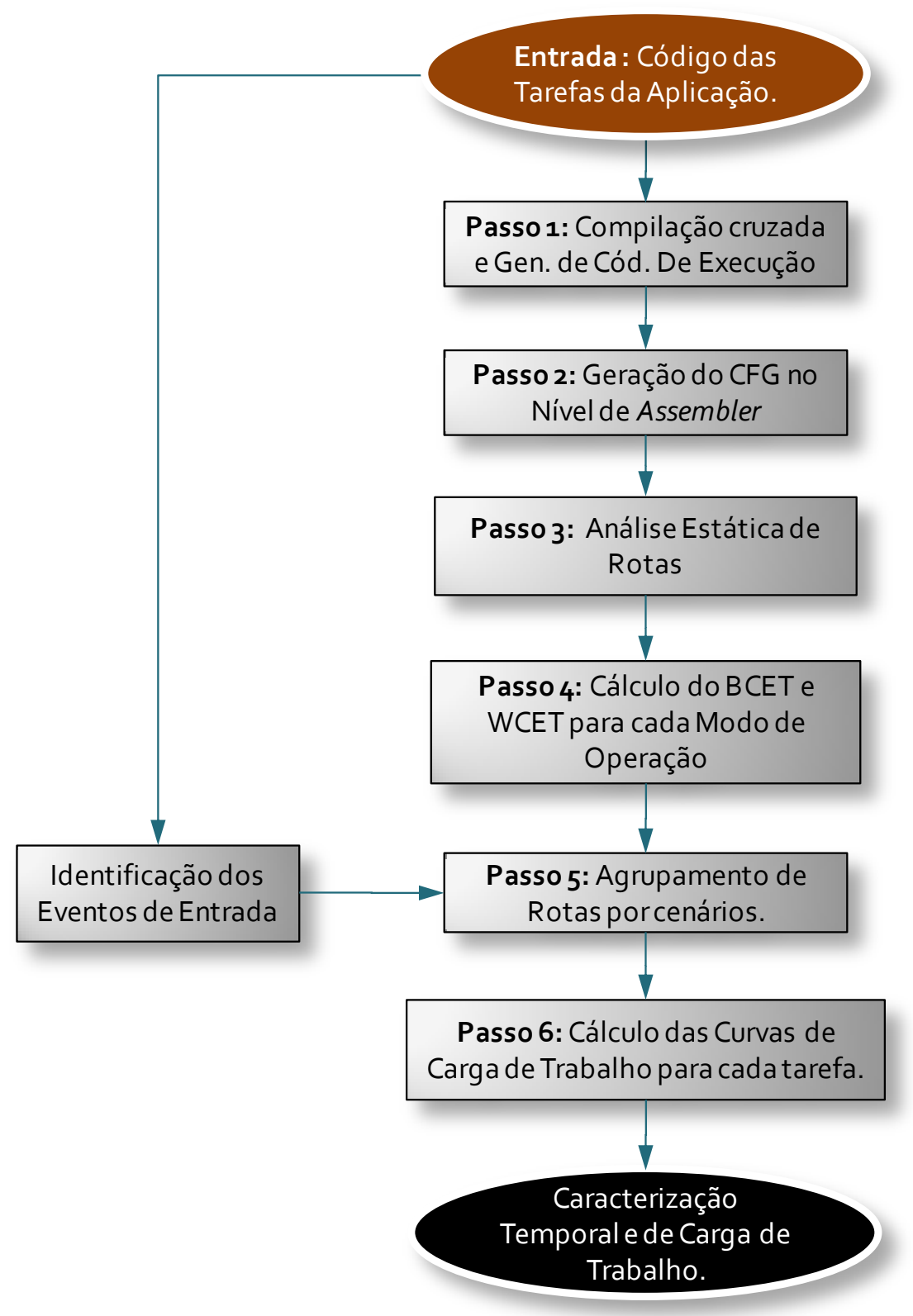

Figura 6.1: Fluxo de análise desenvolvido neste projeto

Grande precisão é obtida também pelo fato de o tempo de execução de um bloco básico depender não só das instruções dentro do bloco, mas também do contexto de pipeline do bloco básico. Ademais, Chronos é uma ferramenta de código-aberto, permitindo ao usuário modificar as rotinas de análise de microarquitetura, a fim de modelar arquiteturas de processadores novas e/ou diferentes. Caso um novo processador possuir, por exemplo, uma estrutura de pipeline completamente diferente, é possivel modificar a análise do núcleo do pipeline com alterações mínimas à análise da estrutura da memória cache e da unidade de predição de saltos. 
A entrada do fluxo de caracterização de carga de trabalho é o conjunto de códigos-fonte associado com o conjunto de tarefas de uma determinada aplicação, e o resultado é a caracterização em termos de carga de trabalho (recursos utilizados com os eventos).

O procedimento contém sete passos:

Passo 1: Consiste na compilação cruzada dos códigos-fonte da aplicação para o processador Simplescalar, uma vez que sua arquitetura já foi modelada pela ferramenta Chronos. Esta compilação cruzada gera um arquivo binário que é analisado no passo 2 .

Passo 2: Gera um CFG baseado em blocos básicos para cada procedimento dentro do arquivo binário da aplicação no nível de linguagem assembly. Esta geração do CFG é implementada em Chronos de forma tal que cada bloco básico possui anotações temporais dos respectivos tempos de execução extremos, considerando a análise da microarquitetura do processador Simplescalar, com as características de precisão já mencionadas.

Passo 3: Como o número de modos de operação resulta frequentemente em uma explosão exponencial dependente do número de instruções de controle e do tamanho dos códigos fonte da aplicação, foi necessário desenvolver uma ferramenta eficiente de análise de rotas. Esta foi baseada na análise do CFG de cada procedimento (função) no nível assembly, a fim de se identificar todas os rotas de execução possiveis para cada nó nos CFGs obtidos a partir de cada tarefa. Esta ferramenta foi suportada em uma infraestrutura de compilação com código aberto, conhecida como Rose [ROSE12], que opera sobre a leitura do código-fonte e/ou binário, gerando posteriormente uma árvore sintática abstrata (AST), que define um grafo que representa a estrutura do arquivo de entrada. Esta AST é mantida em memória a fim de se fornecer meios rápidos de operar sobre o grafo. Vários mecanismos são fornecidos por Rose para percorrer e manipular tal AST. A Figura 6.2 mostra um exemplo de um CFG baseado em blocos básicos, obtido a partir de um trecho de código $\mathrm{C}$ usando Rose.

A Figura 6.3 descreve o algoritmo baseado em rotas, desenvolvido para esta tese, utilizado para encontrar as rotas de execução dos diversos códigos-fonte da aplicação analisada. 


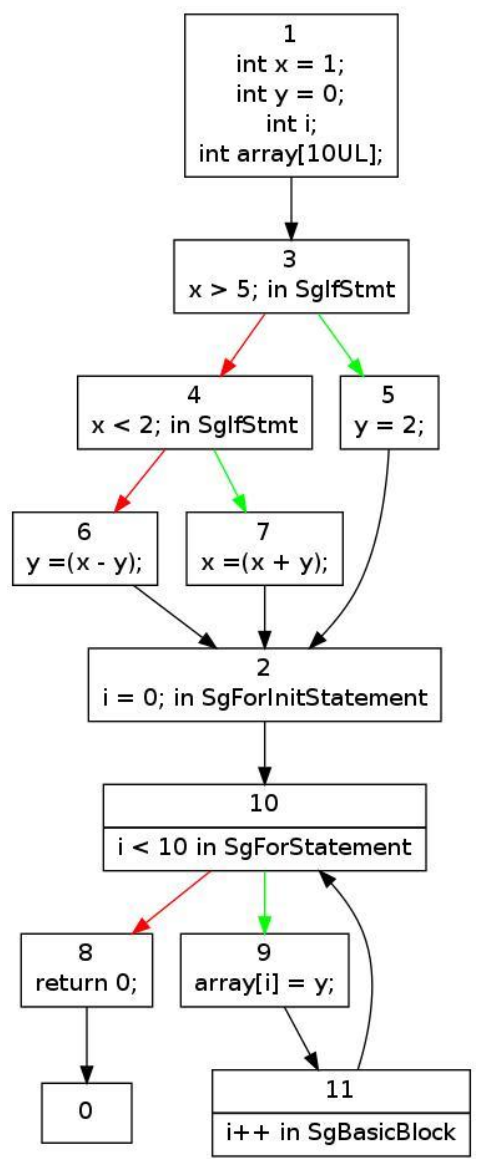

Figura 6.2: Exemplo de um código $\mathrm{C}$ e seu respectivo CFG obtido usando Rose [ROSE12]

Basicamente, este algoritmo encontra os CFGs dos intraprocedimentos relacionados a cada código de tarefa, e logo após, identifica os marcadores condicionais relacionados às declarações de fluxo de controle, tais como if, for, e switch. Para cada marcador condicional, o algoritmo encontra suas respectivas sub-rotas, de modo que as rotas completas de execução são construídas, posteriormente, através de um percurso exaustivo de todos os marcadores condicionais e suas sub-rotas relacionadas.

Passo 4: Uma vez que os múltiplos modos de operação relacionados com cada tarefa da aplicação tiverem sido identificados, é necessário calcular os tempos extremos de execução de cada modo, considerando-se as estimativas de bcet e wcet $^{26}$ dos blocos básicos incluídos em cada rota de execução. Desta forma, o cálculo do BCET e WCET da j-ésima rota corresponde às seguintes expressões:

\footnotetext{
${ }^{26}$ Nesta nomenclatura, é feita uma diferenciação entre maiúsculos e minúsculos, indicando que bcet e wcet refere-se ao pior melhor e pior tempo de execução, respectivamente, dos blocos básicos de cada modo ou rota de operação; enquanto que $\boldsymbol{B C E T}$ e $\boldsymbol{W C E T}$ refere-se aos tempos extremos de execução
} 


$$
\text { BCET }_{\mathrm{j}}=\sum_{i=1}^{N_{j}} \text { bcet }_{i} ; \quad \text { WCET }_{\mathrm{j}}=\sum_{i=1}^{N_{j}} \text { wcet }_{i}
$$

Onde $N_{j}$ é o número de blocos básicos dentro da rota $j$.

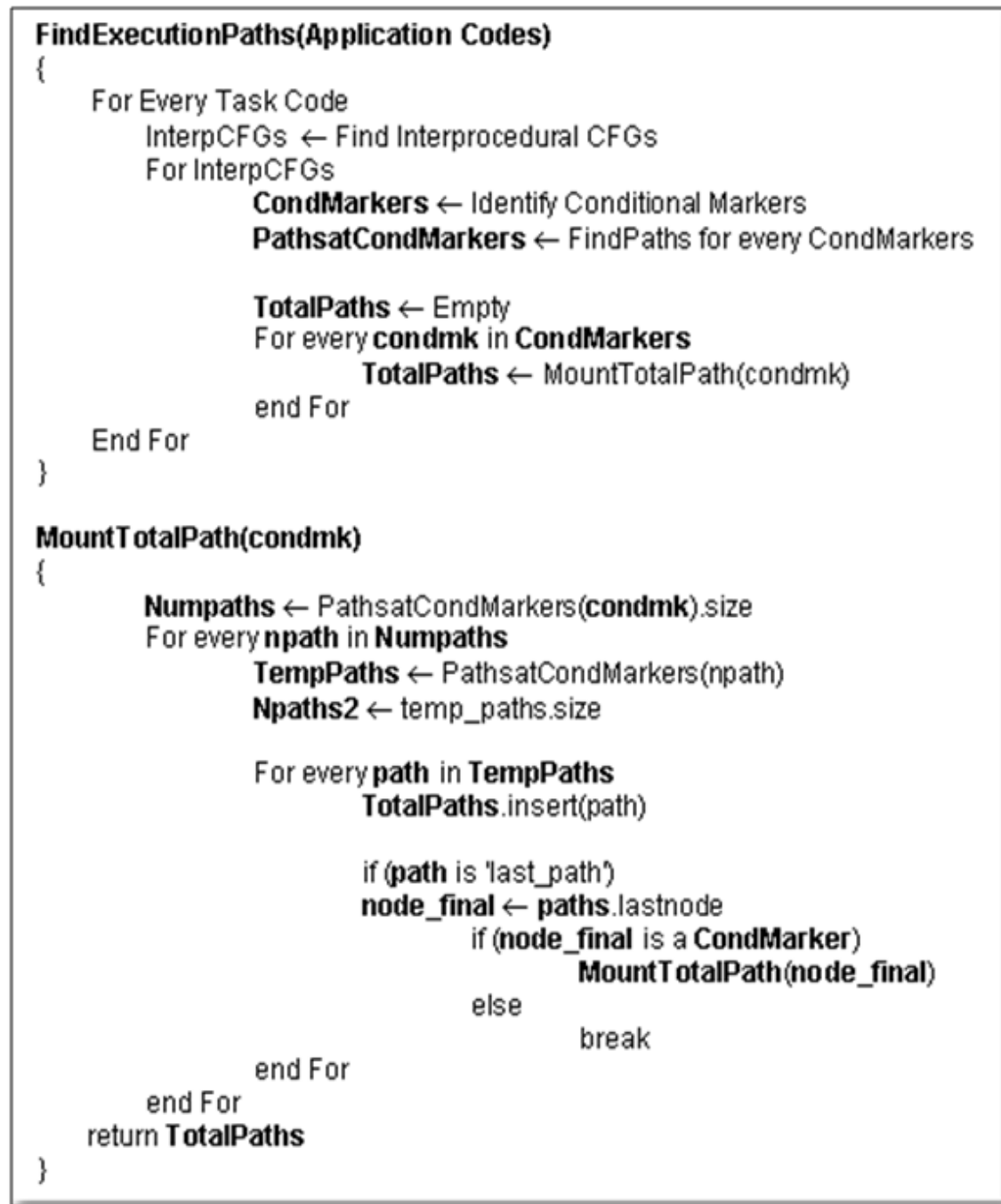

Figura 6.3: Algoritmo baseado em análise estática de rotas para encontrar as rotas de execução dos códigos-fonte das tarefas de uma aplicação.

Passo 5: Seguindo um autômato dos eventos de entrada (seção 2.2.1.1.1), tal como aquele descrito na Figura 6.10 para um decodificador JPEG (explicado mais adiante na seção 6.4.1), define-se um conjunto de cenários que correspondem cada um a um tipo de evento associado. Estes cenários agrupam em diferentes clusters os múltiplos modos de operação, a partir de uma perspectiva de exigência de recursos representada pelo BCET e WCET

de cada rota completa. 
calculados no passo anterior, de modo que cada cluster corresponde a um tipo de evento associado a cada cenário.

Dentro de cada cluster identifica-se o Modo de Operação do Pior-Caso (MOPC) que representa ao respectivo cenário, tal que apenas um número de modos de operação, igual ao número de cenários, é selecionado para ser associado com o conjunto de eventos de entrada da aplicação dada.

Passo 6: Estas etapas consistem na implementação das funções matemáticas (3.1) (3.2) (3.3) (3.4) mostradas na seção 3.3.2, a fim de se obter as curvas de carga de trabalho para cada tarefa da aplicação, utilizando os tempos extremos de execução do MOPC identificados para cada cluster associado a um evento/cenário.

\subsection{ANÁLISE DE DESEMPENHO BASEADO EM REAL-TIME CALCULUS}

Antes de apresentar a metodologia completa de caracterização da carga de trabalho baseada em grafos de SADF, proposta na presente tese, a qual segue a modelagem e análise descrita no capítulo 5, esta seção apresenta um fluxoexemplo para o uso da caracterização analítica da carga de trabalho descrito na seção anterior (seção 6.1), seguindo um procedimento de avaliação analitica de desempenho baseado em Real-Time Calculus e implementado no respectivo Toolbox de Matlab [WANDELER12]. O fluxo é apresentado na Figura 6.4, de modo que as entradas do fluxo são o conjunto de códigos-fonte associado com o conjunto de tarefas de uma determinada aplicação para a identificação dos eventos (como utilizado no fluxo da seção anterior), as curvas de serviço dos recursos utilizados, e as cargas de trabalho correspondentes a cada tarefa. O resultado deste procedimento é o atraso e as estimativas de tamanho de buffer para cada tarefa da aplicação.

O pequeno fluxo é composto de quatro passos:

Passo A: Corresponde à execução do fluxo de caracterização de cada tarefa apresentado na seção 6.1 e descrito no fluxo da Figura 6.1. Os valores encontrados dos tempos extremos de execução de cada tarefa são utilizados no próximo passo B2 para calcular as exigências médias de execução de cada 
tarefa, as quais são necessárias para a especificação dos parâmetros de operação temporal do Grafo Marcado especificado no passo C.

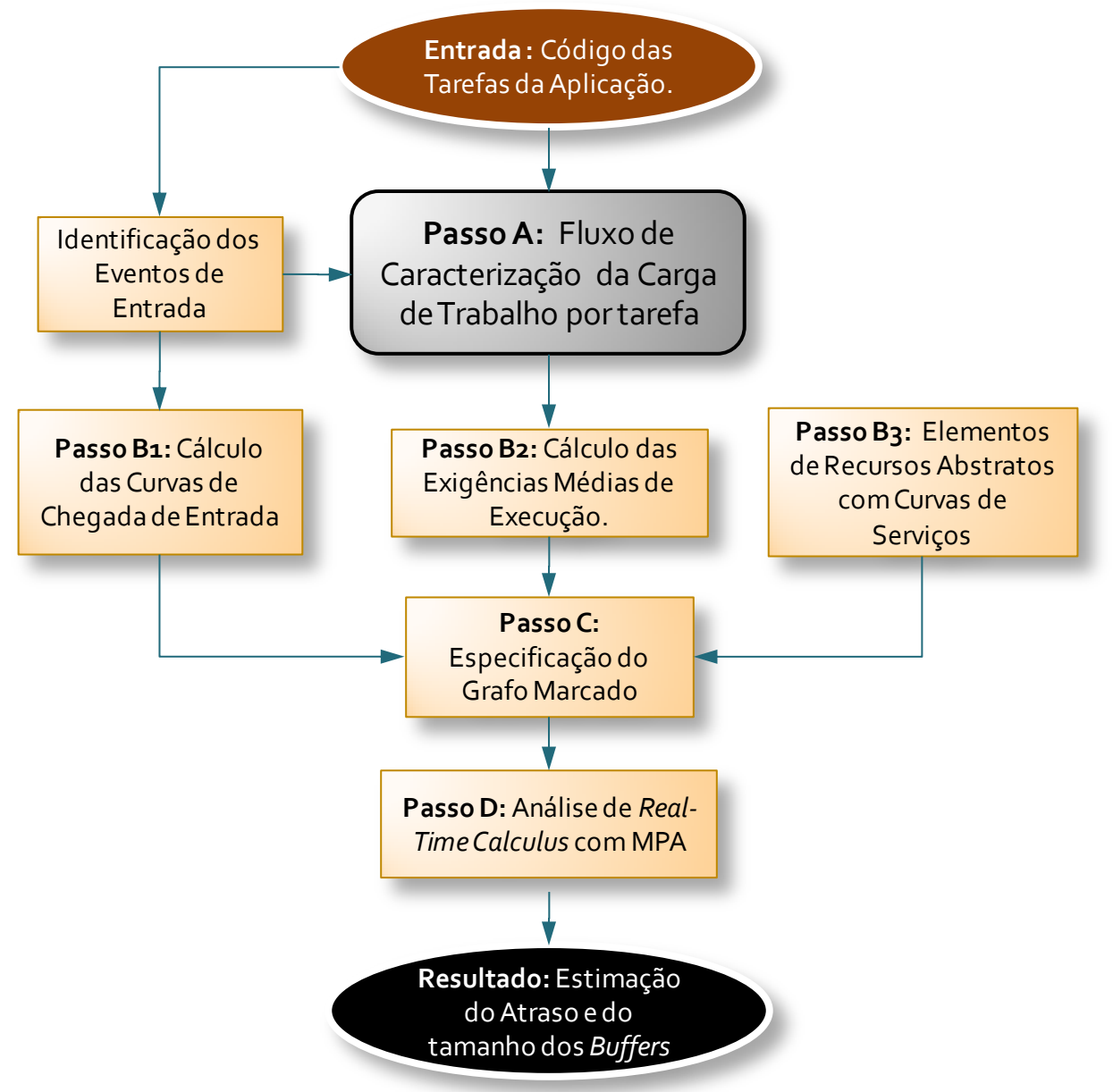

Figura 6.4: Fluxo de análise de desempenho baseado em Real-Time Calculus.

Passo B1: Dado um fluxo de entrada com um número definido de tipos de eventos, neste passo derivam-se as diferentes curvas de chegada para cada evento, considerando um padrão de chegada de eventos definido pelos parâmetros $(p, j, d)$, onde $p$ denota o período, $j$ o jitter e $d$ a distância mínima entre-chegadas de eventos no fluxo modelado [WANDELER05a]. Desta forma, os fluxos de eventos especificados com esses parâmetros são modelados pelas seguintes curvas de entrada:

$$
\bar{\alpha}^{l}(\Delta)=\left\lfloor\frac{\Delta-j}{p}\right\rfloor ; \quad \bar{\alpha}^{u}(\Delta)=\min \left\{\left\lceil\frac{\Delta+j}{p}\right\rceil,\left\lceil\frac{\Delta}{d}\right\rceil\right\}
$$

Passo C: Este passo define os elementos necessários para uma análise do desempenho da aplicação, dadas as exigências de execução identificadas na caracterização prévia das diversas tarefas (seção 6.1), a qual é aplicada no 
passo A sobre os códigos de software da aplicação sob análise. Utilizando esta informação do comportamento temporal de cada tarefa, a aplicação analisada é modelada no passo C como um Grafo Marcado (seção 2.1.2), isto é, como um conjunto de processos que se comunicam através de buffers FIFO com capacidade ilimitada, e que no momento do disparo consumem e produzem um token em qualquer entrada e saída, respectivamente [THIELE09]. Neste modelo de fluxo de dados, as capacidades finitas dos buffers são modeladas adicionando um novo arco entre dois processos que se comunicam com um buffer de tamanho finito, tal que o novo arco é desenhado na direção oposta para representar a capacidade disponivel deste buffer.

Passo D: Neste último passo, os limites de atraso e de Backlog são calculados para cada nó no Grafo Marcado da aplicação. Isto é feito utilizando o Toolbox de RTC [WANDELER12], o qual é uma ferramenta livre baseada em Matlab para análise de desempenho no nivel de sistemas que descreve as múltiplas curvas definidas dentro da teoria de Real-Time Calculus, e implementa a maioria dos operadores de álgebra Min-Plus e Max-Plus para essas curvas. O Toolbox de RTC fornece uma biblioteca de funções para a abordagem MPA (explicada na seção 2.2.1) e análise de Grafos Marcados com técnicas de RealTime Calculus [THIELE09].

\subsection{CARACTERIZAÇÃO ANALÍTICA DE CARGA DE TRABALHO BASEADA EM GRAFOS DE SADF}

Nesta seção apresenta-se o fluxo de análise que reúne os diferentes elementos de caracterização de cada tarefa de software, e do comportamento temporal da aplicação completa, seguindo os diversos modelos descritos na presente tese, de modo que o fluxo apresentado conforma o arcabouço completo de contribuições especificadas e implementadas neste projeto de doutorado.

A figura 6.5 apresenta o fluxo de análise, o qual consiste em 9 passos fundamentais: 


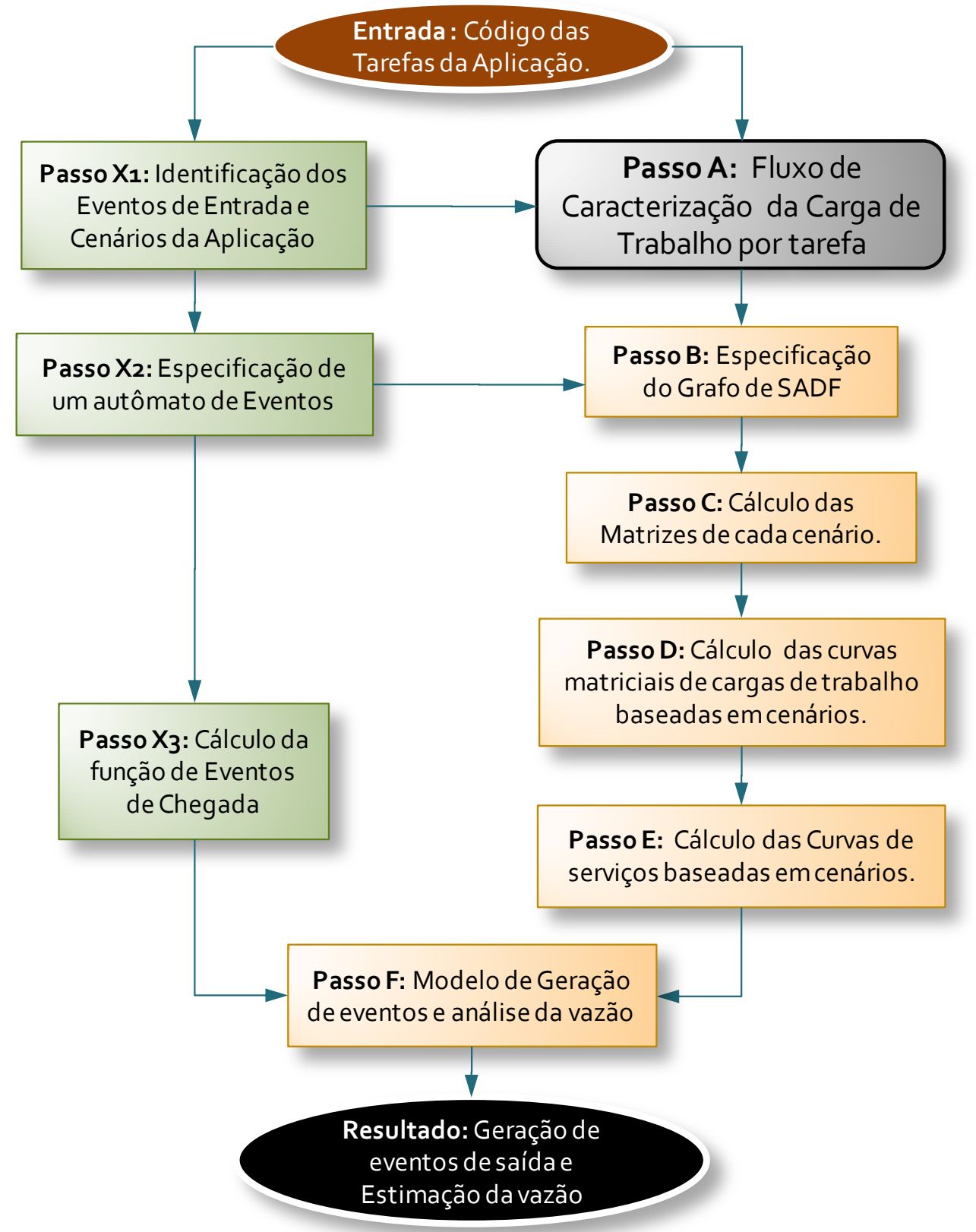

Figura 6.5: Fluxo da caracterização analítica da carga de trabalho baseada em grafos de SADF, proposto na presente tese.

Passo A: Igual que no fluxo-exemplo apresentado na seção anterior (seção 6.2), o passo A corresponde à execução do fluxo de caracterização dos tempos variáveis de execução cada tarefa de software da aplicação analisada (seção 6.1).

Passo B: Considerando a especificação original da aplicação através de um modelo de KPN (seção 2.1.7), ou de um grafo de aplicação genérico (Application Graph, APG) indicando um conjunto de tarefas que se comunicam através de canais FIFO ou diversos tipos de arcos, no passo B tal informação é utilizada 
para modelar a aplicação como um grafo de SADF, de modo que os atores deste grafo representam cada uma das tarefas especificadas, e o conjunto de cenários de operação são indicados pela variabilidade temporal de cada tarefa previamente caracterizada. O modelo SADF considerado é aquele no qual a ordem de cenários é definida por uma FSM, especificada neste caso por um autômato de eventos que indica a ordem em que os diversos eventos chegam na aplicação.

Passo C: A partir da informação dos tempos de execução de pior-caso e melhor-caso encontrados na caracterização desenvolvida no passo A, junto à topologia do grafo de SADF especificado no passo $\mathrm{B}$, o passo $\mathrm{C}$ consiste basicamente em construir as diferentes matrizes associadas a cada cenário de aplicação, considerando que o conjunto de cenários foi previamente identificado no passo X1 a partir da especificação original da aplicação e do conjunto especificado de eventos de entrada que podem chegar na aplicação. $\mathrm{O}$ conjunto de matrizes de cenários refere-se à matriz $\mathbf{M}$ do autômato de MaxPlus para o grafo de SADF (seção 5.2.2). Tal conjunto de matrizes será necessário posteriormente para especificar as curvas de carga de trabalho e de serviços baseadas em cenários propostas na presente tese e implementadas no próximo passo D.

Passo D: Dado o grafo de SADF e o conjunto de matrizes associadas a cada cenário, o passo D consiste em implementar as curvas matriciais de carga de trabalho definidas pela Eq.(5.48) e a Eq.(5.50) na seção 5.3.1 da presente tese.

Passo E: Utilizando as curvas matriciais de carga de trabalho implementadas no passo $\mathrm{D}$, o passo $\mathrm{E}$ consiste em implementar as curvas de serviços baseadas em cenários definidas nas equações Eq.(5.63), Eq.(5.57) e Eq.(5.58), as quais dão um limite superior e inferior do tempo que a aplicação pode demorar para processar $k$ eventos consecutivos (seção 5.3.2).

Passo F: Finalmente no passo F, os modelos de curvas de serviço e uma função de eventos de chegada são utilizados para estimar os limites na geração dos eventos de saída da aplicação e nos limites no cálculo da vazão. Neste caso, as equações implementadas correspondem à Eq.(5.59), Eq.(5.61a) e Eq.(5.61b). Finalmente o resultado deste fluxo de análise é a estimativa numérica destes limites. 


\subsection{CASO DE USO}

\subsubsection{Decodificador JPEG}

O decodificador JPEG corresponde a um processo capaz de reconstituir os dados de uma imagem a partir de um fluxo de dados de uma imagem comprimida, codificados sob a norma JPEG [STUIJK01]. Isto requer que algumas transformações sejam aplicadas aos dados da imagem comprimida.

O codificador JPEG divide uma imagem em blocos de 8 por 8 pixels, e depois aplica um certo número de operações sobre cada um destes blocos. As operações incluem uma transformada discreta de cosseno, ordenamento ziguezague, quantização e codificação de comprimento variável. O resultado destas operações, e do codificador, é uma imagem comprimida.

O decodificador, por sua vez, precisa inverter as transformações aplicadas pelo codificador aos dados da imagem. O decodificador, portanto, recebe como entrada os dados da imagem comprimida. A partir daí, é aplicada uma decodificação de comprimento variável (variable length decoding, VLD), um reordenamento ziguezague, uma quantificação inversa (Inverse Quantization, IQZZ), Transformada Discreta Inversa de Cosseno (Inverse Discrete Cosine Transform, IDCT), uma conversão de cores (CC) e um último processo (Raster), para se colocar os valores dos pixels em uma unidade minima codificada (Minimum Coded Unit, MCU) no lugar da imagem. A imagem é então gravada em memória quando a conversão for concluída. A Figura 6.5 mostra o decodificador JPEG descrito em um modelo de KPN, anotado com tamanhos dos buffers entre as tarefas.

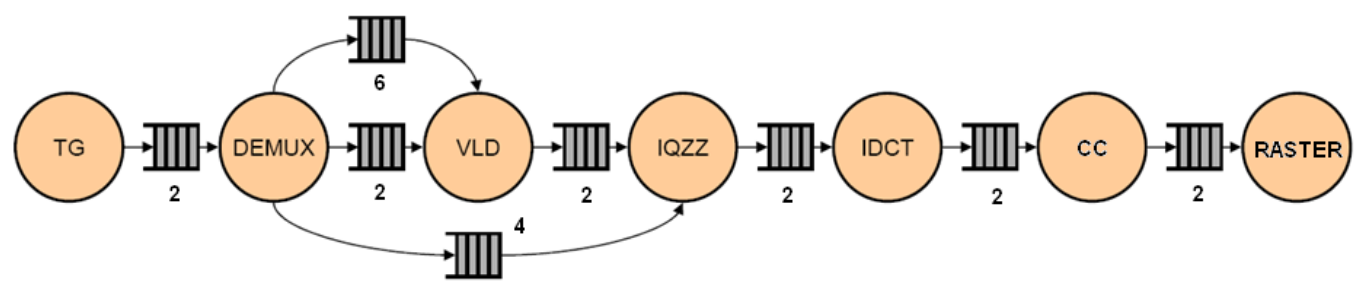

Figura 6.5: KPN de um decodificador JPEG.

Os dados da imagem comprimida formam um fluxo de bytes de entrada para o decodificador. Este fluxo de bytes contém elementos chamados de marcadores. Um marcador é uma combinação de dois bytes, os quais identificam uma parte estrutural dos dados da imagem comprimida. A Tabela 6.1 resume os marcadores mais comuns utilizados na norma JPEG. 
No decodificador JPEG, a sequência de marcadores pode ser considerada como a sequência de eventos de entrada que ativam o decodificador. A Figura 6.9 apresenta um fluxo de eventos de entrada para o decodificador JPEG, de modo que a máquina de estados finitos mostrada na Figura 6.10 representa a ordem como os marcadores acontecem e ativam cada cenário dentro da tarefa Demux.

O fluxo de análise descrito na seção 6.1 foi utilizado para caracterizar a carga de trabalho do decodificador JPEG, de modo que uma compilação cruzada é executada sobre os códigos fontes das seis tarefas que compõem o decodificador e, logo após, seguindo o fluxo de análise proposto, todos os possíveis modos de operação para cada tarefa são identificados, a fim de calcular o BCET e o WCET para cada modo de operação previamente identificado.

\begin{tabular}{|c|c|}
\hline Marcador & Atividade \\
\hline SOI & Inicia a decodificação da Imagem \\
\hline EOI & Para a decodificação da imagem \\
\hline APP & Lê um segmento do fluxo de entrada \\
\hline COM & Lê um segmento do fluxo de entrada \\
\hline DRI & Define um intervalo de reinicialização \\
\hline DQT & Acessa a tabela de dequantização \\
\hline DHT & Acessa a tabela de Huffman \\
\hline SOF & Processa o encabezamento do quadro (frame ) \\
\hline SOS & $\begin{array}{c}\text { Processa o inicio da barredura do encabezamento } \\
\text { Processa todas as unidades MCU em dados de imagem } \\
\text { comprimida } \\
\text { Envia um EOI nos canais de comunicação }\end{array}$ \\
\hline
\end{tabular}

Tabela 6.1: Marcadores suportados pelo decodificador JPEG

Para exemplificar um dos diferentes passos aplicados na análise dos códigos fonte das tarefas da aplicação, as Figuras 6.6, 6.7 e 6.8 apresentam os grafos de fluxo de controle das tarefas CC, IQZZ e RASTER, respectivamente. Tais CFGs apresentam múltiplas rotas de execução que foram identificadas automaticamente seguindo uma implementação em $\mathrm{C}++$ do algoritmo descrito na Figura 6.3. Os CFGs das tarefas DEMUX e VLD não são mostrados neste texto devido ao tamanho grande dos seus respectivos grafos, o qual não permitiu que os grafos ficassem legiveis na versão impressa desta tese. 


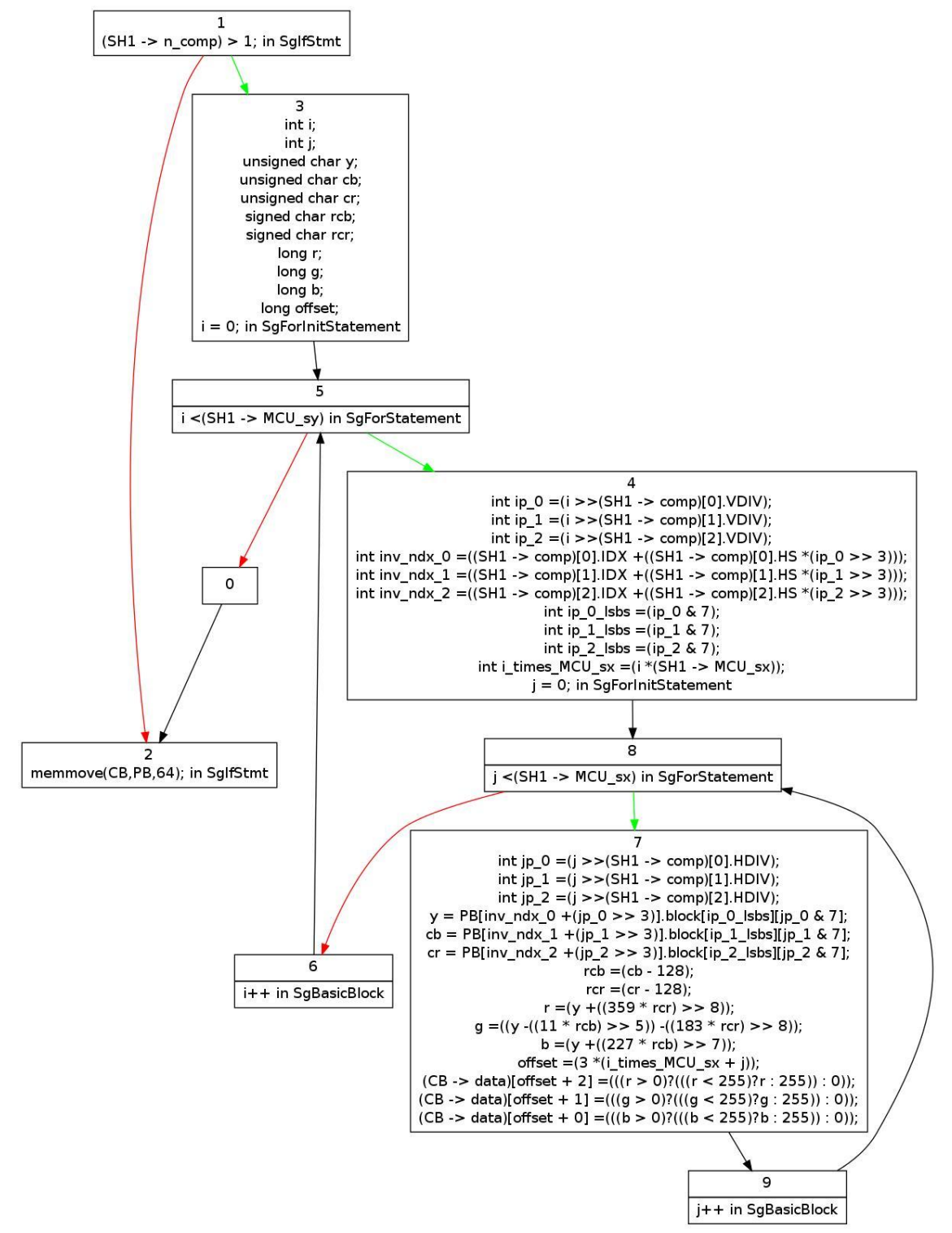

Figura 6.6: CFG do código-fonte da tarefa CC do JPEG da Figura 6.5

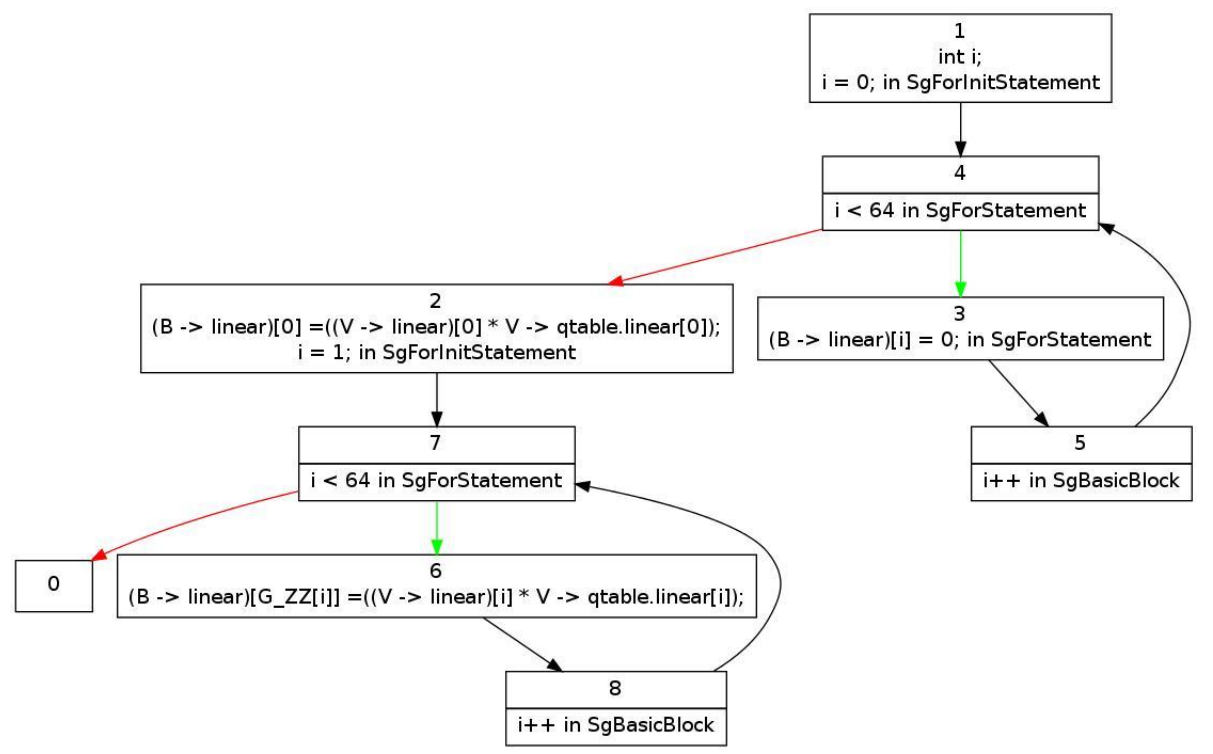

Figura 6.7: CFG do código-fonte da tarefa IQZZ do JPEG da Figura 6.5 


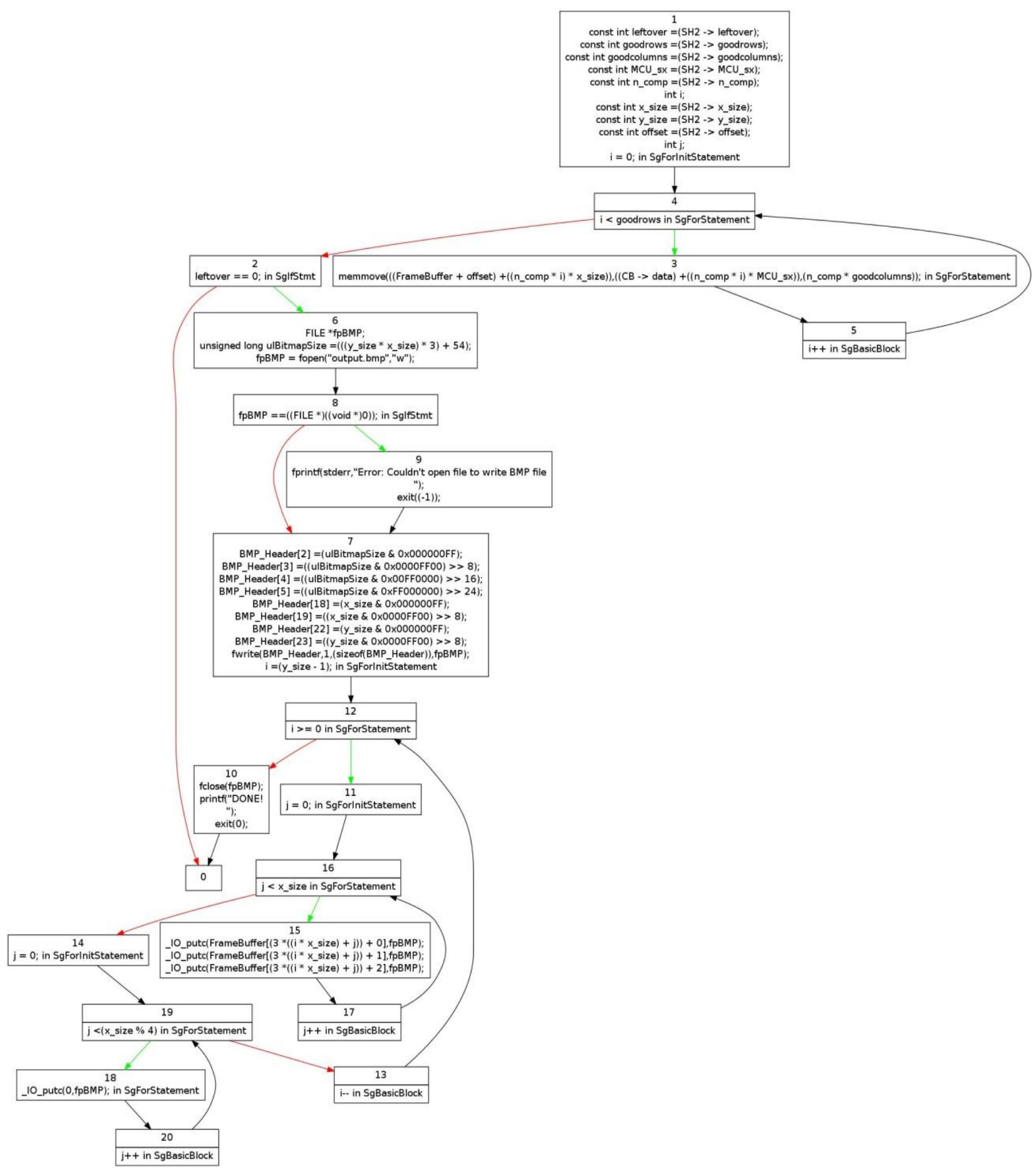

Figura 6.8: CFG do código-fonte da tarefa RASTER do JPEG da Figura 6.5

A fim de aplicar a modelagem baseada em cenários indicada no capítulo 5, o autômato de eventos de entrada mostrado na Figura 6.10 (composto de treze tipos diferentes de eventos) foi utilizado para definir um conjunto de cenários requeridos inicialmente para agrupar em diversos clusters (cada um representando um cenário) os diferentes modos de operação encontrados na 
análise estática de rotas de cada tarefa. O agrupamento foi feito em função do BCET e do WCET calculados na etapa da análise temporal de cada código. Dentro de cada conjunto de modos, o MOPC foi identificado, de maneira que só treze modos de operação foram escolhidos para representar os cenários de cada tarefa do decodificador. Cada um destes modos é associado com um respectivo marcador de entrada, daqueles definidos dentro do decodificador JPEG.

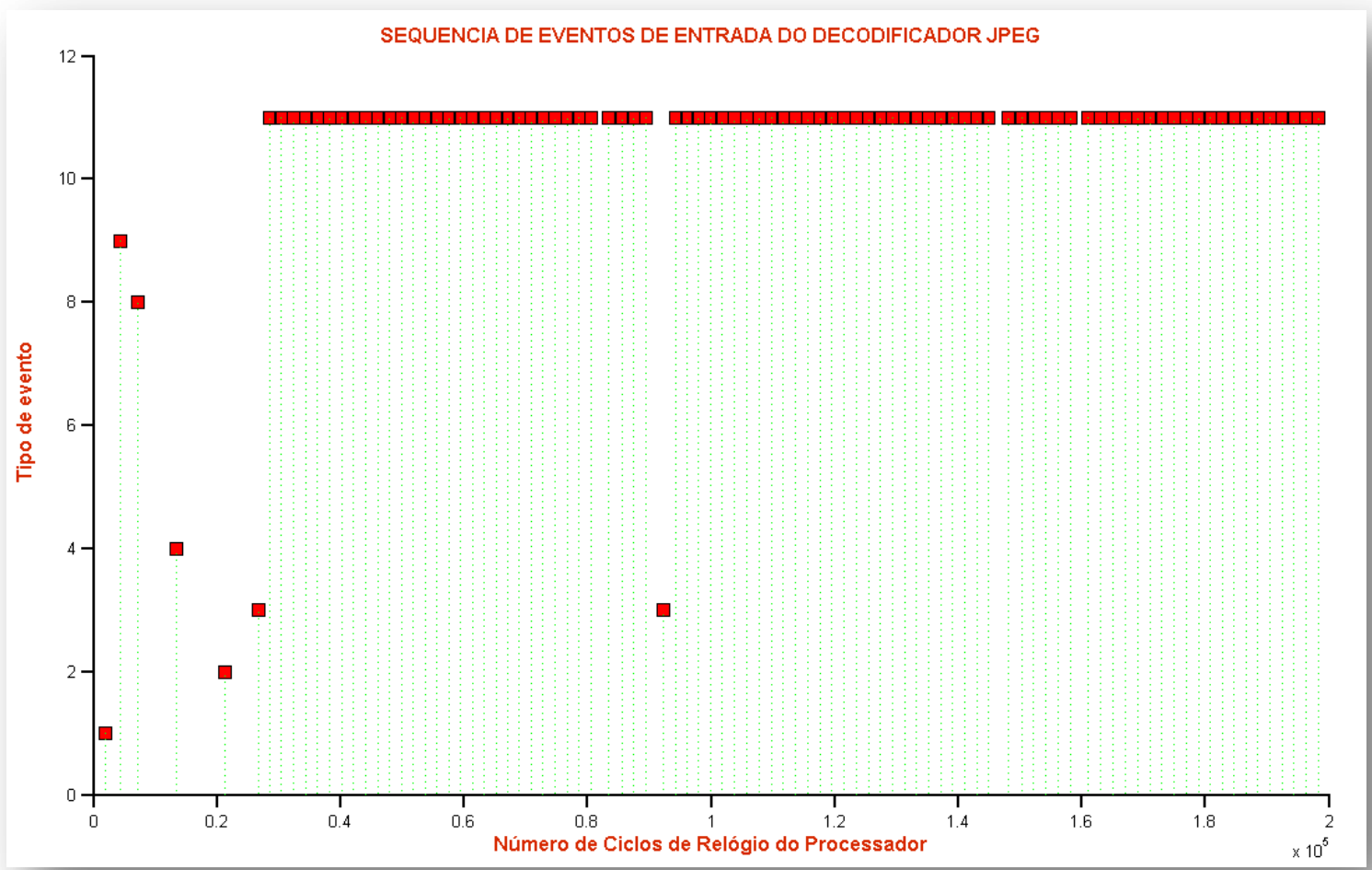

Figura 6.9: Sequência de eventos (ou marcadores) de entrada para o decodificador JPEG.

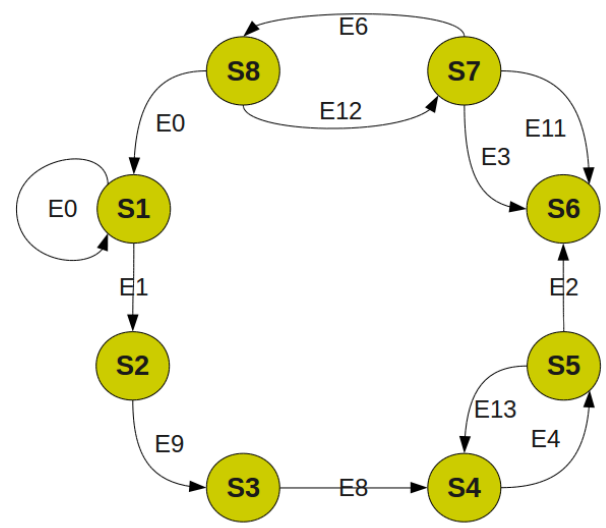

Figura 6.10: Autômato de eventos para o fluxo de eventos de entrada, como aquele da Figura 6.9, de um decodificador JPEG. 
Com o intuito se trabalhar somente com números inteiros pequenos, a unidade de tempo utilizada foi de um décimo de um milésimo de segundo. A Tabela 6.2 mostra as exigências extremas de execução dos treze modos de operação obtidos pela análise temporal estática do código da tarefa Demux, e o respectivo evento/marcador associado a cada modo de operação.

Finalmente, as curvas de carga de trabalho são obtidas usando estas exigências extremas de execução de cada tarefa. A Figura 6.11 mostra as curvas de carga de trabalho obtidas para a tarefa Demux a partir dos dados da tabela 6.2 e usando as equações Eq.(3.3) e Eq.(3.4).

\begin{tabular}{|c|c|c||}
\hline Event/Marker & bcet & wcet \\
\hline E1 & 5.3 & 12.4 \\
\hline E2 & 2.5 & 12.4 \\
\hline E3 & 6.3 & 8.5 \\
\hline E4 & 8.3 & 16.3 \\
\hline E5 & 8.1 & 14.8 \\
\hline E6 & 8.2 & 10.4 \\
\hline E7 & 4.7 & 9.3 \\
\hline E8 & 9.2 & 12 \\
\hline E9 & 3.5 & 8.9 \\
\hline E10 & 5.3 & 7.2 \\
\hline E11 & 5.1 & 11.2 \\
\hline E12 & 7.4 & 15.6 \\
\hline E13 & 4.8 & 9.6 \\
\hline
\end{tabular}

Tabela 6.2: Exigências extremas de execução da tarefa Demux, relacionadas com os marcadores (eventos) de entrada do decodificador JPEG

\subsubsection{Análise de Desempenho baseado em Real-Time Calculus}

A fim de obter uma avaliação analítica de desempenho do decodificador JPEG, o fluxo proposto na seção 6.2 foi seguido. O decodificador foi representado como um Grafo Marcado (ver seção 2.1.2) o qual corresponde a um grafo de HSDF, como representado na Figura 6.12, onde os tokens mostrados indicam o tamanho do buffer definido para os canais entre as tarefas.

Dada uma imagem comprimida de entrada para o decodificador, um conjunto de curvas de chegada de entrada foi definido para os diferentes eventos de entrada que representam a ocorrência de um novo marcador entre os diversos dados na imagem comprimida. 


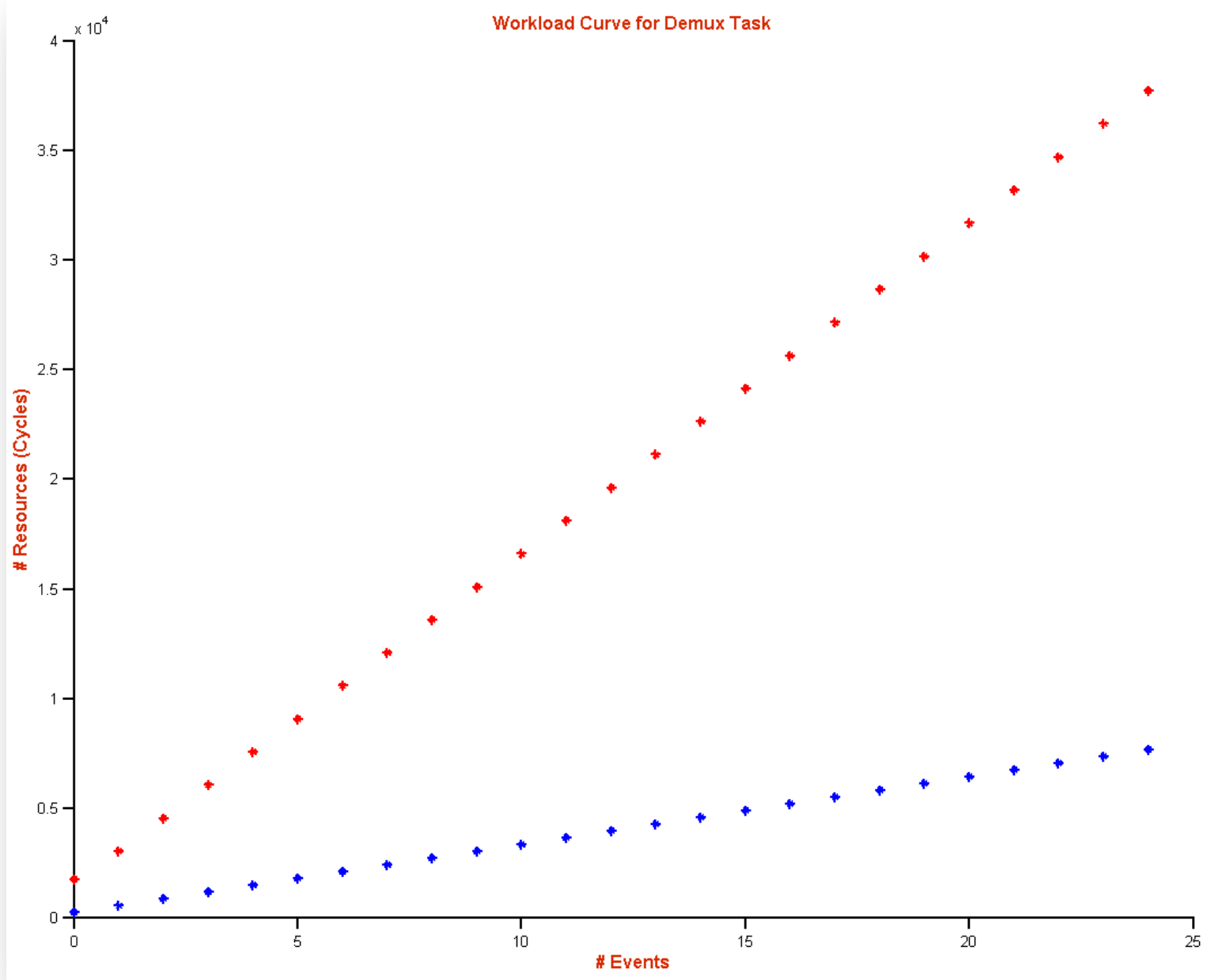

Figura 6.11: Curvas de carga de trabalho para a tarefa Demux do decodificador JPEG.

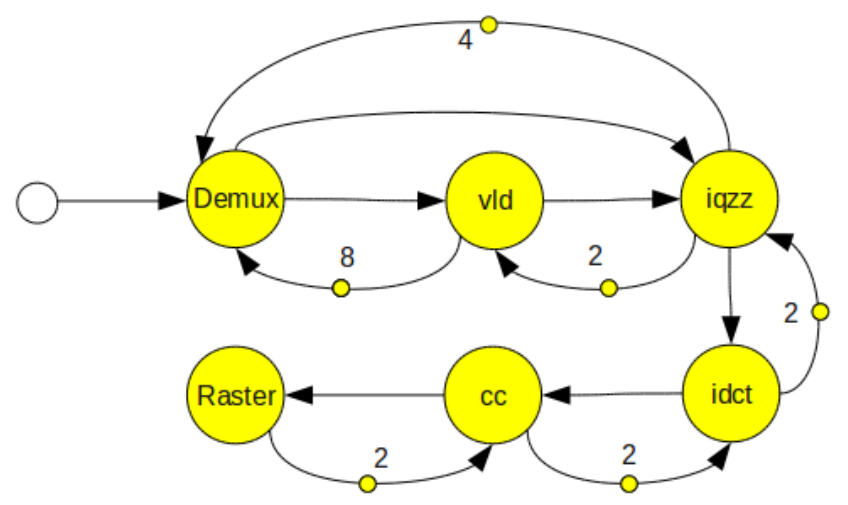

Figura 6.12: Grafo Marcado do decodificador JPEG

Depois, considerando um processador Simplescalar, para a implementação de cada tarefa, um conjunto de curvas de serviços foi definido. As curvas superior e inferior foram representadas através de linhas retas do tipo $\beta^{u}(\Delta)=\beta^{l}(\Delta)=$ 
$f \Delta$, onde $f$ corresponde à frequência de operação do processador, definida como de $100 \mathrm{MHz}$ nos diferentes testes e casos de uso.

Deste modo, o grafo do decodificador foi implementado usando o Toolbox de RTC do Matlab, a fim de se avaliar o desempenho do decodificador seguindo a abordagem MPA apresentado na seção 2.2.1. A Tabela 6.3 resume a exigência média de execução de cada tarefa do decodificador JPEG; cada exigência de execução é requerida pelo Toolbox de RTC para calcular o atraso e os limites de Backlog para cada nó (tarefa) no grafo marcado.

\begin{tabular}{||c|c|c||}
\hline Task/Exec. Dem. & Best & Worst \\
\hline Demux & 0.7 & 1.3 \\
\hline VId & 1.9 & 3 \\
\hline Iqzz & 2.7 & 11.4 \\
\hline Idct & 0.9 & 2.2 \\
\hline Libu & 0.9 & 3.1 \\
\hline Ramdac & 0.7 & 2.4 \\
\hline
\end{tabular}

Tabela 6.3: Exigência média de execução para as tarefas do decodificador JPEG

\subsubsection{Resultados}

A Figura 6.13b mostra os limites para o fluxo de eventos de saída, dado o fluxo de eventos de entrada limitado pela curva de chegada de entrada mostrada na Figura 6.13a, a qual segue o autômato de eventos da Figura 6.10 .

Além destes resultados, a tabela 6.4 resume os atrasos calculados para cada tarefa e os requisitos mínimos de buffer, necessários para armazenar o fluxo de entrada de cada nó no grafo marcado. Estes resultados mostram a precisão da análise e a viabilidade da metodologia proposta, baseada na caracterização temporal estática de tarefas com exigência variável de execução, para avaliar o desempenho de uma aplicação multimídia.

\begin{tabular}{||c|c|c|c|c|c|c||}
\hline & \multicolumn{6}{|c|}{ Performance Results for JPEG Decoder } \\
\hline & Demux & Vld & Iqzz & Idct & Libu & Ramdac \\
\hline Delay & 1.5571 & 2.0835 & 2.4538 & 3.5649 & 4.6761 & 6.1046 \\
\hline Buffer & 2 & 2 & 2 & 3 & 3 & 4 \\
\hline
\end{tabular}

Tabela 6.4: Atrasos e requisitos minimos de buffer para o decodificador JPEG 

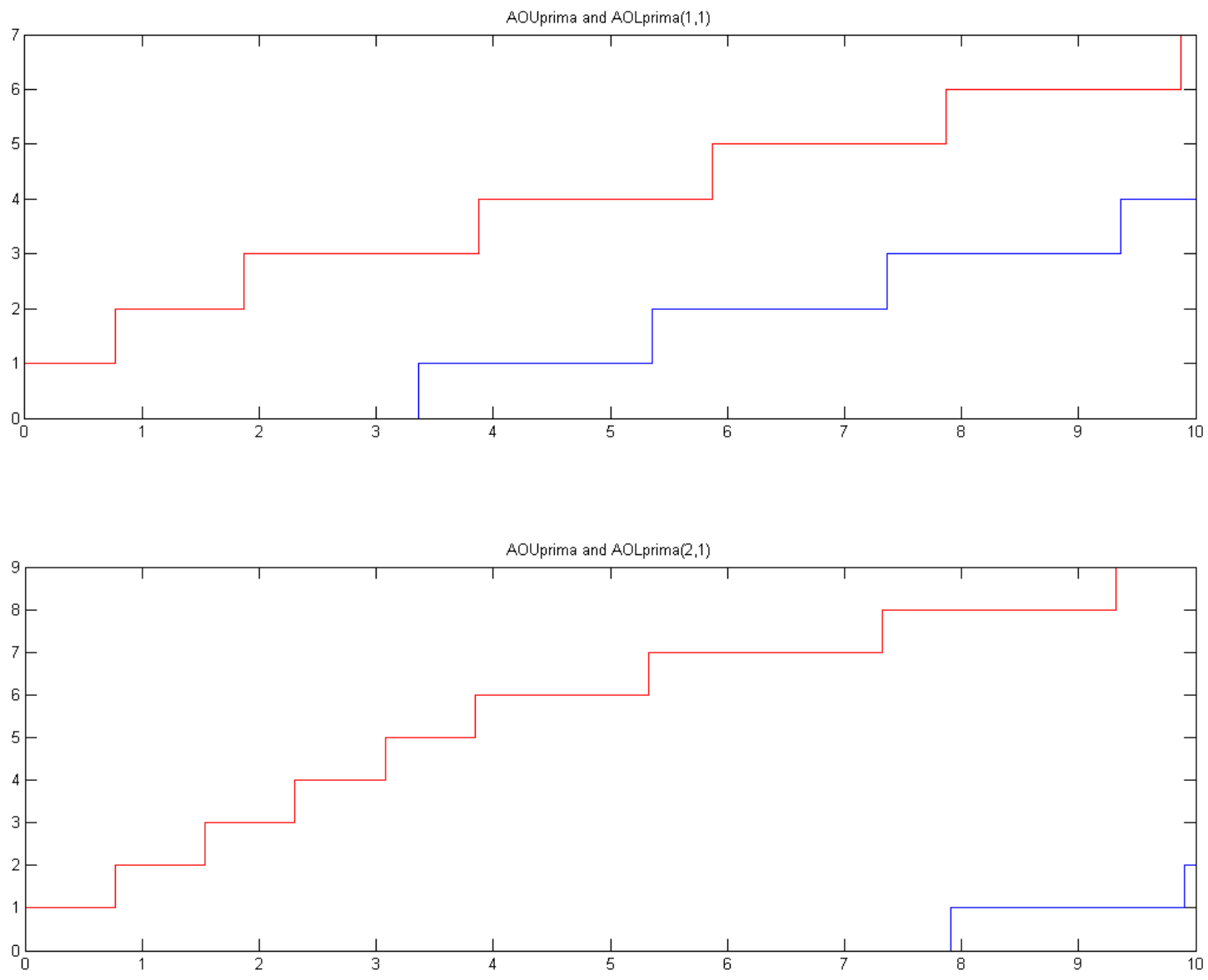

Figura 6.13: Curvas de chegada de entrada e de saida, do grafo marcado mostrado na Figura 6.12.

\subsubsection{Análise de Desempenho baseado em SADF}

Nas próximas seções, o decodificador JPEG é analisado através do MoC de SADF apresentado no capítulo 5, de maneira que os modelos desenvolvidos naquele capítulo para a geração dos eventos de saída, derivação de curvas de serviços baseadas em cenários e análise da vazão são utilizados nesta seção para analisar o decodificador JPEG modelado por um grafo de SADF.

\subsubsection{Modelo de SADF do Decodificador JPEG}

A Figura 6.14 apresenta o grafo de SDF do decodificador JPEG, considerando cinco tarefas principiais: O conversor VLD, o quantificador IQZZ, a conversão IDCT, o conversor de cores CC e a tarefa RASTER para a preparação final da imagem de saída. Visto que a sequência de cenários dentro do SADF pode ser definida através de uma cadeia de Markov (seção 2.1.6.1) ou uma máquina de 
estados finitos (seção 2.1.6.2), neste trabalho a sequência de cenários foi definida a partir da sequência de eventos que ativam cada cenário, de modo que tal sequência é definida pela cadeia de eventos de entrada apresentada na Figura 6.9 e pelo autômato de eventos da Figura 6.10.

Na Figura $6.14, \tau_{v l d}, \tau_{i q z z}, \tau_{i d c t}, \tau_{c c}, \tau_{\text {raster }}$ são definidos como os piores tempos de execução de cada tarefa dentro de cada cenário. Neste caso, este pior tempo de execução corresponde à característica da aplicação JPEG que determina o comportamento temporal dinâmico do grafo de SADF, mostrando explicitamente os diferentes modos de operação associados a cada cenário de execução, e com isto, também os diferentes tempos de resposta da aplicação diante cada tipo de evento de entrada.

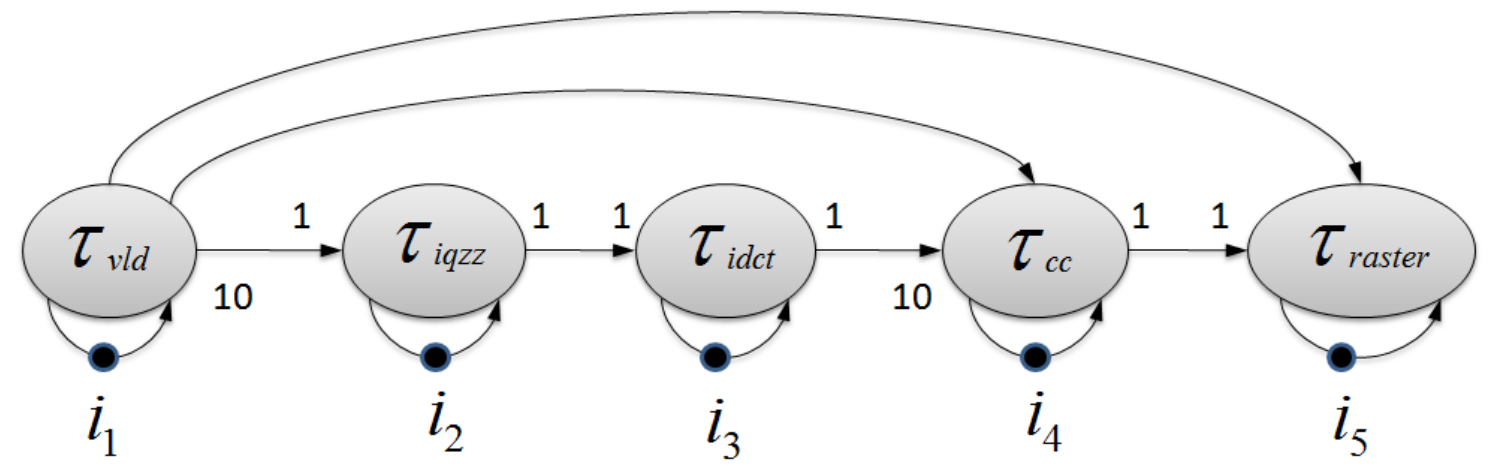

Figura 6.14: Modelo de SADF do Decodificador JPEG sem entradas nem saidas

As tabelas de 6.5 a 6.9 apresentam os tempos de execução extremos dentro de cada tarefa, obtidos na caracterização da carga de trabalho das diferentes tarefas a partir do seu respectivo código-fonte em $\mathrm{C}$, seguindo a metodologia apresentada na seção 6.1, e no algoritmo de análise de código apresentado na figura 6.3.

\begin{tabular}{|c|c|c|}
\hline Cenário & bcet & wcet \\
\hline & 223 & 708 \\
\hline & 274 & 1346 \\
\hline & 776 & 1965 \\
\hline
\end{tabular}

Tabela 6.5: Tempos extremos de execução para a tarefa RASTER.

\begin{tabular}{|c|c|c|}
\hline Cenário & bcet & wcet \\
\hline & 88 & 365 \\
\hline
\end{tabular}

Tabela 6.6: Tempos extremos de execução para a tarefa IQZZ 


\begin{tabular}{|c|c|c|}
\hline Cenário & bcet & wcet \\
\hline & 458 & 1108 \\
\hline
\end{tabular}

Tabela 6.7: Tempos extremos de execução para a tarefa IDCT

\begin{tabular}{|c|c|c|}
\hline Cenário & bcet & wcet \\
\hline & 65 & 166 \\
\hline & 187 & 259 \\
\hline & 195 & 332 \\
\hline & 226 & 397 \\
\hline & 227 & 431 \\
\hline & 260 & 467 \\
\hline & 390 & 563 \\
\hline & 421 & 628 \\
\hline & 448 & 667 \\
\hline & 512 & 734 \\
\hline & 547 & 797 \\
\hline & 554 & 860 \\
\hline
\end{tabular}

Tabela 6.8: Tempos extremos de execução para a tarefa VLD.

\begin{tabular}{|c|c|c|}
\hline Cenário & bcet & wcet \\
\hline & 251 & 498 \\
\hline & 404 & 1665 \\
\hline
\end{tabular}

Tabela 6.9: Tempos extremos de execução para a tarefa CC.

A fim de se apresentar explicitamente a configuração do grafo SADF da Figura 6.14 para cada cenário, a tabela 6.10 apresenta os tempos de cada tarefa em relação aos diferentes cenários avaliados dentro do código, os quais foram determinados a partir da operação de leitura e escrita de marcadores no protocolo JPEG, segundo foi explicado na seção 6.4.1.

\subsubsection{Espaço de Estados do grafo SADF sem entradas externas}

A partir do grafo de SADF apresentado na Figura 6.14, é necessário identificar as equações de estado a fim de conhecer explicitamente o comportamento temporal dinâmico da aplicação, considerando que as variáveis de estado do grafo correspondem aos tempos de produção dos tokens iniciais indicados na Figura, de modo que estes tempos são associados às variáveis $\boldsymbol{i}_{\mathbf{1}}, \boldsymbol{i}_{\mathbf{2}}, \boldsymbol{i}_{\mathbf{3}}, \boldsymbol{i}_{\mathbf{4}}, \boldsymbol{i}_{\mathbf{5}}$. 
Antes de derivar as equações de estado, é importante conhecer o vetor de repetição do grafo, a fim de identificar a quantidade de ativações que são necessárias de parte de cada ator para definir uma iteração completa do grafo.

\begin{tabular}{|c|c|c|c|c|c||}
\hline \multicolumn{5}{|c|}{ Pior Tempo de Execução por tarefa para cada cénario } \\
\hline Cenario & vld & iqzz & idct & cc & Raster \\
\hline 1 & 166 & 365 & 1108 & 498 & 708 \\
\hline 2 & 259 & 365 & 1108 & 1665 & 1346 \\
\hline 3 & 332 & 365 & 1108 & 498 & 1965 \\
\hline 4 & 397 & 365 & 1108 & 1665 & 708 \\
\hline 5 & 431 & 365 & 1108 & 498 & 1346 \\
\hline 6 & 467 & 365 & 1108 & 1665 & 1965 \\
\hline 7 & 563 & 365 & 1108 & 498 & 708 \\
\hline 8 & 628 & 365 & 1108 & 1665 & 1346 \\
\hline 9 & 667 & 365 & 1108 & 498 & 1965 \\
\hline 10 & 734 & 365 & 1108 & 1665 & 708 \\
\hline 11 & 797 & 365 & 1108 & 498 & 1346 \\
\hline 12 & 860 & 365 & 1108 & 1665 & 1965 \\
\hline \hline
\end{tabular}

Tabela 6.10: Tempos extremos de execução de cada tarefa em relação aos diferentes cenários da aplicação JPEG.

\subsection{Vetor de Repetição}

Seja $q=\left[q_{v l d}, q_{i q z z}, q_{i d c t} q_{c c}, q_{\text {raster }}\right]^{T}$ o vetor de repetição do grafo da Figura 6.14. Cada elemento deste vetor deve cumprir a equação de equilíbrio que relaciona a taxa de consumo/produção entre cada par de atores interconectados, e os seus respectivos valores no vetor de repetição (ver seção 2.2.3.1). Neste caso, as equações de equilíbrio do grafo são:
Entre os atores VLD e IQZZ
$10 \cdot q_{v l d}=1 \cdot q_{i q z z}$
Entre os atores IQZZ e IDCT
$1 \cdot q_{i q z z}=1 \cdot q_{i d c t}$
Entre os atores IDCT e CC
$1 \cdot q_{i d c t}=10 \cdot q_{c c}$
Entre os atores CC e RASTER
$1 \cdot q_{c c}=1 \cdot q_{\text {raster }}$

Resolvendo estas equações de equilíbrio com os menores valores inteiros para cada variável, o vetor de repetição resultante é: 


$$
q=\left[\begin{array}{c}
q_{v l d} \\
q_{i d c t} \\
q_{i q z z} \\
q_{c c} \\
q_{\text {raster }}
\end{array}\right]=\left[\begin{array}{c}
1 \\
10 \\
10 \\
1 \\
1
\end{array}\right]
$$

\subsection{Equações de Estado}

Considerando-se os tempos de execução de cada tarefa como os parâmetros variáveis do grafo, as equações de estado são apresentadas a seguir.

Da análise de Max-Plus da tarefa VLD dentro do grafo da Figura 6.14, seguese que a equação de estado para $\boldsymbol{i}_{\mathbf{1}}$ é:

$$
\boldsymbol{i}_{1}(k+1)=\tau_{v l d} \otimes \boldsymbol{i}_{1}(k)
$$

de modo que o tempo de finalização da ativação da tarefa VLD, corresponde ao tempo de produção dos seus respectivos tokens:

$$
\boldsymbol{t}_{\boldsymbol{v l d}}(k+1)=\boldsymbol{i}_{1}(k+1)
$$

Igualmente, analisando-se a tarefa IQZZ, cujo tempo de finalização corresponde ao tempo de produção de token $\boldsymbol{i}_{2}$, a equação de estado para este tempo é:

$\boldsymbol{i}_{\mathbf{2}}(k+1)=\tau_{i q z Z} \otimes\left(\boldsymbol{i}_{\mathbf{2}}(k) \oplus \boldsymbol{t}_{\boldsymbol{v l d}}(k+1)\right)$

Neste caso, dado o vetor de repetição do grafo, uma iteração completa do modelo corresponde a 10 ativações do ator IQZZ, ou seja,

$$
\begin{aligned}
& \boldsymbol{i}_{\mathbf{2}}(k+2)=\tau_{i q z z} \otimes\left[\tau_{i q z z} \otimes\left(\boldsymbol{i}_{\mathbf{2}}(k) \oplus \boldsymbol{t}_{\boldsymbol{v} \boldsymbol{l} \boldsymbol{d}}(k+1)\right) \oplus \boldsymbol{t}_{\boldsymbol{v l d}}(k+1)\right] \\
& \boldsymbol{i}_{\mathbf{2}}(k+3)=\tau_{i q z z} \otimes\left[\tau_{i q z z} \otimes\left[\tau_{i q z z} \otimes\left(\boldsymbol{i}_{\mathbf{2}}(k) \oplus \boldsymbol{t}_{\boldsymbol{v l d}}(k+1)\right) \oplus \boldsymbol{t}_{\boldsymbol{v l d}}(k+1)\right] \oplus \boldsymbol{t}_{\boldsymbol{v l d}}(k+1)\right]
\end{aligned}
$$

e o tempo de ativação do ator para cada nova iteração corresponde a,

$$
\boldsymbol{i}_{\mathbf{2}}(k+10)=\left(\tau_{i q z z}{ }^{10} \otimes \tau_{v l d} \otimes \boldsymbol{i}_{\mathbf{1}}(k)\right) \oplus\left(\tau_{i q z z}{ }^{10} \otimes \boldsymbol{i}_{\mathbf{2}}(k)\right)
$$

Onde o valor de $\boldsymbol{i}_{\mathbf{2}}$ também corresponde ao tempo de finalização do ator IQZZ. Então, 


$$
\boldsymbol{t}_{\boldsymbol{i q z z}}(k+1)=\boldsymbol{i}_{\mathbf{2}}(k+1)
$$

Do mesmo modo, considerando-se o vetor de repetição do grafo, cada nova iteração precisa de 10 ativações do ator IDCT, ou seja,

$$
\begin{aligned}
& \boldsymbol{i}_{\mathbf{3}}(k+1)=\tau_{i d c t} \otimes\left(\boldsymbol{i}_{\mathbf{3}}(k) \oplus \boldsymbol{t}_{\boldsymbol{i q z z}}(k+1)\right) \\
& \boldsymbol{i}_{\mathbf{3}}(k+1)=\left[\left(\tau_{i d c t} \otimes \tau_{i q z z} \otimes \tau_{v l d}\right) \otimes \boldsymbol{i}_{\mathbf{1}}(k)\right] \oplus\left[\left(\tau_{i d c t} \otimes \tau_{i q z z}\right) \otimes \boldsymbol{i}_{\mathbf{2}}(k)\right] \oplus\left[\tau_{i d c t} \otimes \boldsymbol{i}_{\mathbf{3}}(k)\right] \\
& \boldsymbol{i}_{\mathbf{3}}(k+2)=\tau_{i d c t} \otimes\left(\boldsymbol{i}_{\mathbf{3}}(k+1) \oplus \boldsymbol{t}_{\boldsymbol{i q z z}}(k+2)\right) \\
& \boldsymbol{i}_{\mathbf{3}}(k+2)=\left[\left(\tau_{i d c t}^{2} \otimes \tau_{i q z z} \otimes \tau_{v l d} \oplus \tau_{i d c t} \otimes \tau_{i q z z}^{2} \otimes \tau_{v l d}\right) \otimes \boldsymbol{i}_{\mathbf{1}}(k)\right] \oplus \\
& {\left[\left(\tau_{i d c t}^{2} \otimes \tau_{i q z z} \oplus \tau_{i d c t} \otimes \tau_{i q z z}^{2}\right) \otimes \boldsymbol{i}_{\mathbf{2}}(k)\right] \oplus\left[\tau_{i d c t}^{2} \otimes \boldsymbol{i}_{\mathbf{3}}(k)\right]} \\
& \boldsymbol{i}_{\mathbf{3}}(k+10)=\left[\left(\bigoplus_{n=1}^{10}\left(\tau_{i d c t}{ }^{n} \otimes \tau_{i q z z}{ }^{11-n}\right) \otimes \tau_{v l d}\right) \otimes \boldsymbol{i}_{\mathbf{1}}(k)\right] \oplus \\
& {\left[\bigoplus_{n=1}^{10}\left(\tau_{i d c t}{ }^{n} \otimes \tau_{i q z z}{ }^{11-n}\right) \otimes \boldsymbol{i}_{\mathbf{2}}(k)\right] \oplus\left[\tau_{i d c t}{ }^{10} \otimes \boldsymbol{i}_{\mathbf{3}}(k)\right]}
\end{aligned}
$$

E o tempo de finalização da tarefa IDCT, correspondente também ao tempo de produção $\boldsymbol{i}_{3}$, é calculado da Eq.(6.5):

$$
\boldsymbol{i}_{\mathbf{3}}(k+10)=\left[\left(A \otimes \tau_{v l d}\right) \otimes \boldsymbol{i}_{\mathbf{1}}(k)\right] \oplus\left[A \otimes \boldsymbol{i}_{\mathbf{2}}(k)\right] \oplus\left[\tau_{i d c t}{ }^{10} \otimes \boldsymbol{i}_{\mathbf{3}}(k)\right]
$$

onde $A$ é definido como:

$$
A=\bigoplus_{n=1}^{10}\left(\tau_{i d c t}{ }^{n} \otimes \tau_{i q z z}{ }^{11-n}\right)
$$

Por outro lado, o tempo de produção de tokens da tarefa $\mathrm{CC}$, corresponde à variável $\boldsymbol{i}_{\mathbf{4}}$, cuja equação em Max-Plus é definida como:

$$
\begin{aligned}
& \boldsymbol{i}_{\mathbf{4}}(k+1)=\tau_{c c} \otimes\left(\boldsymbol{i}_{\mathbf{1}}(k+1) \oplus \boldsymbol{i}_{\mathbf{3}}(k+10) \oplus \boldsymbol{i}_{\mathbf{4}}(k)\right) \\
& \boldsymbol{i}_{\mathbf{4}}(k+1)=\left[A \otimes \tau_{c c} \otimes \tau_{v l d} \otimes \boldsymbol{i}_{\mathbf{1}}(k)\right] \oplus\left[A \otimes \tau_{c c} \otimes \boldsymbol{i}_{\mathbf{2}}(k)\right] \oplus\left[\tau_{i d c t}{ }^{10} \otimes \tau_{c c} \otimes \boldsymbol{i}_{\mathbf{3}}(k)\right] \oplus \\
& {\left[\tau_{c c} \otimes \boldsymbol{i}_{\mathbf{4}}(k)\right]}
\end{aligned}
$$

Finalmente, relacionado à tarefa RASTER há o tempo de produção $\boldsymbol{i}_{5}$, cuja equação de estado é: 


$$
\boldsymbol{i}_{\mathbf{5}}(k+1)=\tau_{\text {raster }} \otimes\left(\boldsymbol{i}_{\mathbf{1}}(k+1) \oplus \boldsymbol{i}_{\mathbf{4}}(k+1) \oplus \boldsymbol{i}_{\mathbf{5}}(k)\right)
$$

$$
\begin{gathered}
\boldsymbol{i}_{\mathbf{5}}(k+1)=\left[A \otimes \tau_{c c} \otimes \tau_{v l d} \otimes \tau_{\text {raster }} \otimes \boldsymbol{i}_{\mathbf{1}}(k)\right] \oplus\left[A \otimes \tau_{c c} \otimes \tau_{\text {raster }} \otimes \boldsymbol{i}_{\mathbf{2}}(k)\right] \oplus \\
{\left[\tau_{\text {idct }}{ }^{10} \otimes \tau_{c c} \otimes \tau_{\text {raster }} \otimes \boldsymbol{i}_{\mathbf{3}}(k)\right] \oplus\left[\tau_{c c} \otimes \tau_{\text {raster }} \otimes \boldsymbol{i}_{\mathbf{4}}(k)\right] \oplus} \\
{\left[\tau_{\text {raster }} \otimes \boldsymbol{i}_{\mathbf{5}}(k)\right]}
\end{gathered}
$$

Consequentemente, reunindo-se os coeficientes das equações Eq.(6.1), Eq.(6.3), Eq.(6.5), Eq.(6.6) e Eq.(6.7), a matriz de estado do grafo de SADF, sem variáveis de entrada nem de saída, fica definida parametricamente pela matriz abaixo, cujos elementos possuem diferentes valores a partir dos tempos de execução de cada tarefa dentro de cada cenário da aplicação.

$$
\mathbf{M}\left(\boldsymbol{\sigma}_{\boldsymbol{k}}\right)=\left[\begin{array}{ccccc}
\tau_{v l d} & \varepsilon & \varepsilon & \varepsilon & \varepsilon \\
\tau_{i q z z}{ }^{10} \tau_{v l d} & \tau_{\text {iqzz }}{ }^{10} & \varepsilon & \varepsilon & \varepsilon \\
A \tau_{v l d} & A & \tau_{i d c t}{ }^{10} & \varepsilon & \varepsilon \\
A \tau_{c c} \tau_{v l d} & A \tau_{c c} & \tau_{i d c t}{ }^{10} \tau_{c c} & \tau_{c c} & \varepsilon \\
A \tau_{c c} \tau_{v l d} \tau_{\text {raster }} & A \tau_{c c} \tau_{\text {raster }} & \tau_{\text {idct }}{ }^{10} \tau_{c c} \tau_{\text {raster }} & \tau_{c c} \tau_{\text {raster }} & \tau_{\text {raster }}
\end{array}\right]
$$

Considerando-se esta matriz, a evolução temporal do grafo de SADF segue a equação Eq.(5.30), definida na seção 5.2.1, indicada novamente como:

$$
\overrightarrow{\boldsymbol{i}}(k+1)=\boldsymbol{M}\left(\boldsymbol{\sigma}_{\boldsymbol{k}}\right) \overrightarrow{\boldsymbol{l}}(k)
$$

Onde o vetor de estado $\overrightarrow{\boldsymbol{\imath}}$ é um vetor coluna composto pelas cinco variáveis de estado $\boldsymbol{i}_{1}, \boldsymbol{i}_{2}, \boldsymbol{i}_{3}, \boldsymbol{i}_{4}$, e $\boldsymbol{i}_{5}$.

\subsubsection{Espaço de Estados do grafo SADF com entrada externa}

O grafo da Figura 6.15 apresenta uma mudança em relação ao grafo da Figura 6.14, devida à presença das variáveis de entrada e de saída, $x(k)$ e $y(k)$, respectivamente, dentro do grafo de SADF. Visto que a dependência do grafo em relação a estas variáveis só fica definida pela conexão da entrada ao ator VLD, e da saída ao ator RASTER, as equações de estado apresentam poucas mudanças, de modo que a derivação de cada equação segue o mesmo procedimento indicado na seção anterior. 


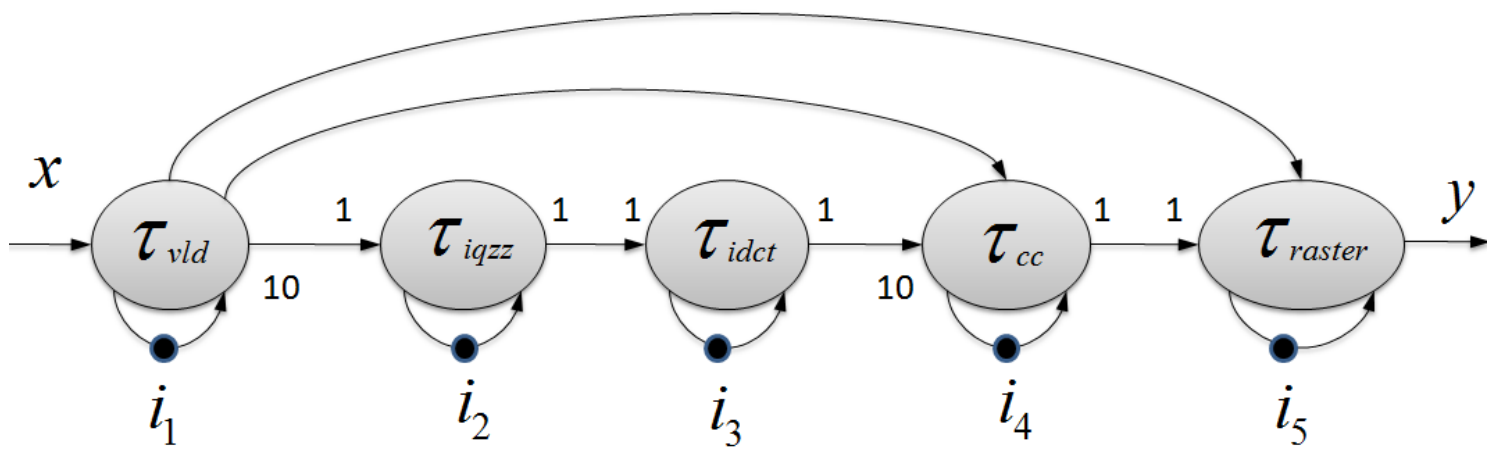

Figura 6.15: Modelo de SADF do Decodificador JPEG com entrada $x$ e saida $y$.

Em primeiro lugar, para o tempo de produção $\boldsymbol{i}_{\mathbf{1}}$, a equação de estado corresponde a

$$
\begin{aligned}
\boldsymbol{i}_{\mathbf{1}}(k+1)= & \tau_{\text {vld }} \otimes\left(\boldsymbol{i}_{\mathbf{1}}(k) \oplus \boldsymbol{x}(k)\right) \\
& \boldsymbol{i}_{\mathbf{1}}(k+1)=\left(\tau_{\text {vld }} \otimes \boldsymbol{i}_{\mathbf{1}}(k)\right) \oplus\left(\tau_{\text {vld }} \otimes \boldsymbol{x}(k)\right)
\end{aligned}
$$

tal que o tempo de finalização da tarefa VLD corresponde ao tempo de produção $\boldsymbol{i}_{1}$ :

$\boldsymbol{t}_{\boldsymbol{v l d}}(k+1)=\boldsymbol{i}_{\mathbf{1}}(k+1)$

De maneira semelhante, a equação de estado referente ao tempo de produção $\boldsymbol{i}_{2}$, corresponde à expressão Eq.(6.11), considerando-se novamente que uma iteração do grafo precisa de dez ativações do ator IQZZ.

$$
\begin{aligned}
& \boldsymbol{i}_{\mathbf{2}}(k+1)=\tau_{i q z z} \otimes\left(\boldsymbol{i}_{\mathbf{2}}(k) \oplus \boldsymbol{t}_{\text {vld }}(k+1)\right) \\
& \boldsymbol{i}_{\mathbf{2}}(k+10)=\left(\tau_{i q z z}{ }^{10} \otimes \tau_{v l d} \otimes\left(\boldsymbol{i}_{\mathbf{1}}(k) \oplus \boldsymbol{x}(k)\right)\right) \oplus\left(\tau_{i q z z}{ }^{10} \otimes \boldsymbol{i}_{\mathbf{2}}(k)\right) \\
& \boldsymbol{i}_{\mathbf{2}}(k+10)=\left(\tau_{\text {iqzz }}{ }^{10} \otimes \tau_{v l d} \otimes \boldsymbol{i}_{\mathbf{1}}(k)\right) \oplus\left(\tau_{i q z z}{ }^{10} \otimes \boldsymbol{i}_{\mathbf{2}}(k)\right) \oplus\left(\tau_{i q z z}{ }^{10} \otimes \tau_{v l d} \otimes \boldsymbol{x}(k)\right)
\end{aligned}
$$

Igual procedimento aplica-se ao tempo de produção $\boldsymbol{i}_{3}$ :

$$
\begin{gathered}
\boldsymbol{i}_{\mathbf{3}}(k+10)=\left[\left(A \otimes \tau_{v l d}\right) \otimes \boldsymbol{i}_{\mathbf{1}}(k)\right] \oplus\left[A \otimes \boldsymbol{i}_{\mathbf{2}}(k)\right] \oplus\left[\tau_{\text {idct }}{ }^{10} \otimes \boldsymbol{i}_{\mathbf{3}}(k)\right] \oplus \\
{\left[\left(A \otimes \tau_{v l d}\right) \otimes \boldsymbol{x}(k)\right]}
\end{gathered}
$$

onde,

$$
A=\bigoplus_{n=1}^{10}\left(\tau_{i d c t}{ }^{n} \otimes \tau_{i q z z}{ }^{11-n}\right)
$$


De modo semelhante, o procedimento também aplica-se ao tempo de produção $\boldsymbol{i}_{4}$ :

$$
\begin{gathered}
\boldsymbol{i}_{\mathbf{4}}(k+1)=\tau_{c c} \otimes\left[\left(\boldsymbol{i}_{\mathbf{1}}(k+1) \oplus \boldsymbol{x}(k+1)\right) \oplus \boldsymbol{i}_{\mathbf{3}}(k+10) \oplus \boldsymbol{i}_{\mathbf{4}}(k)\right] \\
\boldsymbol{i}_{\mathbf{4}}(k+1)=\left[A \otimes \tau_{c c} \otimes \tau_{v l d} \otimes \boldsymbol{i}_{\mathbf{1}}(k)\right] \oplus\left[A \otimes \tau_{c c} \otimes \boldsymbol{i}_{\mathbf{2}}(k)\right] \oplus\left[\tau_{i d c t}{ }^{10} \otimes \tau_{c c} \otimes \boldsymbol{i}_{\mathbf{3}}(k)\right] \oplus \\
{\left[\tau_{c c} \otimes \boldsymbol{i}_{\mathbf{4}}(k)\right] \oplus\left[A \otimes \tau_{c c} \otimes \tau_{v l d} \otimes \boldsymbol{x}(k)\right]}
\end{gathered}
$$

E também, para o tempo de produção $\boldsymbol{i}_{5}$ :

$$
\begin{aligned}
\boldsymbol{i}_{\mathbf{5}}(k+1)=\tau_{\text {raster }} \otimes\left[\left(\boldsymbol{i}_{\mathbf{1}}(k+1) \oplus \boldsymbol{x}(k+1)\right) \oplus \boldsymbol{i}_{\mathbf{4}}(k+1) \oplus \boldsymbol{i}_{\mathbf{5}}(k)\right] \\
\boldsymbol{i}_{\mathbf{5}}(k+1)=\left[A \otimes \tau_{c c} \otimes \tau_{\text {vld }} \otimes \tau_{\text {raster }} \otimes \boldsymbol{i}_{\mathbf{1}}(k)\right] \oplus\left[A \otimes \tau_{c c} \otimes \tau_{\text {raster }} \otimes \boldsymbol{i}_{\mathbf{2}}(k)\right] \oplus \\
{\left[\tau_{\text {idct }}{ }^{10} \otimes \tau_{c c} \otimes \tau_{\text {raster }} \otimes \boldsymbol{i}_{\mathbf{3}}(k)\right] \oplus\left[\tau_{c c} \otimes \tau_{\text {raster }} \otimes \boldsymbol{i}_{\mathbf{4}}(k)\right] \oplus } \\
{\left[\tau_{\text {raster }} \otimes \boldsymbol{i}_{\mathbf{5}}(k)\right] \oplus\left[A \otimes \tau_{c c} \otimes \tau_{\text {vld }} \otimes \tau_{\text {raster }} \otimes \boldsymbol{x}(k)\right] }
\end{aligned}
$$

de modo que a saída do grafo de SADF é equivalente ao tempo de produção $\boldsymbol{i}_{\mathbf{5}}$. Consequentemente,

$$
\boldsymbol{y}(k+1)=\boldsymbol{i}_{\mathbf{5}}(k+1)
$$

Dado que neste caso o grafo de SADF possui uma variável de entrada $x(k)$ e uma variável de saída $y(k)$, o sistema de equações que define o comportamento temporal do decodificador JPEG é:

$$
\begin{aligned}
\overrightarrow{\boldsymbol{\imath}}(k+1) & =\boldsymbol{M}\left(\boldsymbol{\sigma}_{\boldsymbol{k}}\right) \overrightarrow{\boldsymbol{\imath}}(k) \oplus \boldsymbol{B}\left(\boldsymbol{\sigma}_{\boldsymbol{k}}\right) \boldsymbol{x}(k) \\
\boldsymbol{y}(k) & =\boldsymbol{C} \overrightarrow{\boldsymbol{i}}(k)
\end{aligned}
$$

onde a matriz de estado $\boldsymbol{M}\left(\boldsymbol{\sigma}_{\boldsymbol{k}}\right)$ continua sendo descrita pela Eq.(6.8), e as matrizes de Max-Plus $\boldsymbol{B}\left(\boldsymbol{\sigma}_{\boldsymbol{k}}\right)$ e $\boldsymbol{C}$ são descritas do seguinte modo:

$$
\boldsymbol{B}\left(\boldsymbol{\sigma}_{\boldsymbol{k}}\right)=\left[\begin{array}{c}
\tau_{v l d} \\
\tau_{i q z z}{ }^{10} \tau_{v l d} \\
A \tau_{v l d} \\
A \tau_{c c} \tau_{v l d} \\
A \tau_{c c} \tau_{v l d} \tau_{\text {raster }}
\end{array}\right] \quad \boldsymbol{C}=\left[\begin{array}{lllll}
\varepsilon & \varepsilon & \varepsilon & \varepsilon & e
\end{array}\right]
$$

\subsubsection{Autômato de Max-Plus para SADF}

O autômato de Max-Plus para o grafo SADF do decodificador JPEG segue a máquina de estados da Figura 6.10, a qual indica a possivel ordem de eventos 
que chegam à aplicação e que, por conseguinte, define a ordem de execução de cada cenário de aplicação relacionado aos diferentes eventos. Neste caso, o autômato de Max-Plus definido pela tupla $\mathcal{A}=(\Sigma, \mathbf{M}, \mathcal{M})$ consiste então do conjunto $\Sigma$ composto pelos doze cenários associados aos doze possíveis eventos de entrada, definidos no protocolo JPEG (seção 6.4.1). O mapeamento M, o qual atribui para cada cenário, $\sigma \in \Sigma$, uma matriz de Max-Plus $\mathbf{M}(\sigma)$, está relacionado aos valores dos tempos de execução de cada tarefa dentro dos diferentes cenários, os quais por sua vez, vão definir diferentes matrizes $\mathbf{M}(\sigma)$ de acordo com o valor de cada tempo de execução na matriz da Eq.(6.8). Considerando-se os valores destes tempos de execução para cada tarefa, dados na tabela 6.10, as matrizes associadas com cada cenário são definidas nas tabelas de 6.11 a 6.22 .

$\begin{array}{|ccccc|}166 & -\infty & -\infty & -\infty & -\infty \\ 3816 & 3650 & -\infty & -\infty & -\infty \\ 11611 & 11445 & 11080 & -\infty & -\infty \\ 12109 & 11943 & 11578 & 498 & -\infty \\ 12817 & 12651 & 12286 & 1206 & 708\end{array}$

Tabela 6.11: Cenário 1 do grafo de SADF da Figura 6.15

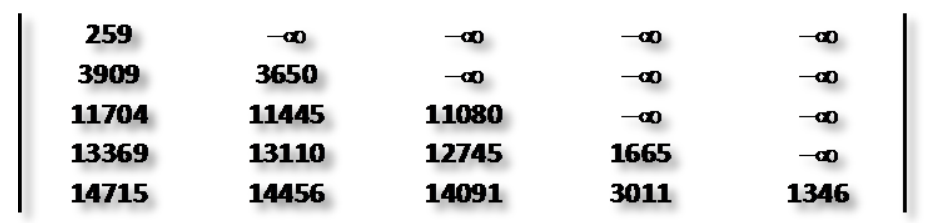

Tabela 6.12: Cenário 2 do grafo de SADF da Figura 6.15

\begin{tabular}{ccccc|}
332 & $-\infty$ & $-\infty$ & $-\infty$ & $-\infty$ \\
3982 & 3650 & $-\infty$ & $-\infty$ & $-\infty$ \\
11777 & 11445 & 11080 & $-\infty$ & $-\infty$ \\
12275 & 11943 & 11578 & 498 & $-\infty$ \\
14240 & 13908 & 13543 & 2463 & 1965
\end{tabular}

Tabela 6.13: Cenário 3 do grafo de SADF da Figura 6.15

$\begin{array}{|ccccc|}397 & -\infty & -\infty & -\infty & -\infty \\ 4047 & 3650 & -\infty & -\infty & -\infty \\ 11842 & 11445 & 11080 & -\infty & -\infty \\ 13507 & 13110 & 12745 & 1665 & -\infty \\ 14215 & 13818 & 13453 & 2373 & 708\end{array}$

Tabela 6.14: Cenário 4 do grafo de SADF da Figura 6.15

$\begin{array}{|ccccc|}431 & -\infty & -\infty & -\infty & -\infty \\ 4081 & 3650 & -\infty & -\infty & -\infty \\ 11876 & 11445 & 11080 & -\infty & -\infty \\ 12374 & 11943 & 11578 & 498 & -\infty \\ 13720 & 13289 & 12924 & 1844 & 1346\end{array}$


Tabela 6.15: Cenário 5 do grafo de SADF da Figura 6.15

$\begin{array}{|ccccc|}467 & -\infty & -\infty & -\infty & -\infty \\ 4117 & 3650 & -\infty & -\infty & -\infty \\ 11912 & 11445 & 11080 & -\infty & -\infty \\ 13577 & 13110 & 12745 & 1665 & -\infty \\ 15542 & 15075 & 14710 & 3630 & 1965\end{array}$

Tabela 6.16: Cenário 6 do grafo de SADF da Figura 6.15

$\begin{array}{|ccccc|}563 & -\infty & -\infty & -\infty & -\infty \\ 4213 & 3650 & -\infty & -\infty & -\infty \\ 12008 & 11445 & 11080 & -\infty & -\infty \\ 12506 & 11943 & 11578 & 498 & -\infty \\ 13214 & 12651 & 12286 & 1206 & 708\end{array}$

Tabela 6.17: Cenário 7 do grafo de SADF da Figura 6.15

$$
\begin{array}{|ccccc|}
628 & -\infty & -\infty & -\infty & -\infty \\
4278 & 3650 & -\infty & -\infty & -\infty \\
12073 & 11445 & 11080 & -\infty & -\infty \\
13738 & 13110 & 12745 & 1665 & -\infty \\
15084 & 14456 & 14091 & 3011 & 1346
\end{array}
$$

Tabela 6.18: Cenário 8 do grafo de SADF da Figura 6.15

$$
\begin{array}{|ccccc|}
667 & -\infty & -\infty & -\infty & -\infty \\
4317 & 3650 & -\infty & -\infty & -\infty \\
12112 & 11445 & 11080 & -\infty & -\infty \\
12610 & 11943 & 11578 & 498 & -\infty \\
14575 & 13908 & 13543 & 2463 & 1965
\end{array}
$$

Tabela 6.19: Cenário 9 do grafo de SADF da Figura 6.15

$$
\begin{array}{|ccccc|}
734 & -\infty & -\infty & -\infty & -\infty \\
4384 & 3650 & -\infty & -\infty & -\infty \\
12179 & 11445 & 11080 & -\infty & -\infty \\
13844 & 13110 & 12745 & 1665 & -\infty \\
14552 & 13818 & 13453 & 2373 & 708
\end{array}
$$

Tabela 6.20: Cenário 10 do grafo de SADF da Figura 6.15

$$
\begin{array}{|ccccc|}
797 & -\infty & -\infty & -\infty & -\infty \\
4447 & 3650 & -\infty & -\infty & -\infty \\
12242 & 11445 & 11080 & -\infty & -\infty \\
12740 & 11943 & 11578 & 498 & -\infty \\
14086 & 13289 & 12924 & 1844 & 1346
\end{array}
$$

Tabela 6.21: Cenário 11 do grafo de SADF da Figura 6.15

$$
\begin{array}{|ccccc|}
860 & -\infty & -\infty & -\infty & -\infty \\
4510 & 3650 & -\infty & -\infty & -\infty \\
12305 & 11445 & 11080 & -\infty & -\infty \\
13970 & 13110 & 12745 & 1665 & -\infty \\
15935 & 15075 & 14710 & 3630 & 1965
\end{array}
$$

Tabela 6.22: Cenário 12 do grafo de SADF da Figura 6.15 


\subsubsection{Curvas de Carga de Trabalho baseada em Cenários}

A partir das matrizes dos diferentes cenários, indicadas nas tabelas de $6.11 \mathrm{a}$ 6.22, e considerando-se uma sequência de eventos de entrada tal como aquela apresentada na Figura 6.9, a qual segue uma ordem de eventos dada pelo autômato da Figura 6.10, as expressões Eq.(5.47) e Eq.(5.49) foram implementadas em ScicosLab [SCICOSLAB12]. Objetivou-se conhecer as Curvas, inferior e superior, de Carga de Trabalho baseada em Cenários, de modo que seja possivel aplicar as curvas matriciais de cenários definidas na seção 5.3.1. Com isto, auxilia-se o cálculo das curvas de serviços baseadas em cenários, que foram, por sua vez, definidas na seção 5.3.2, e a especificação dos limites dos tempos de produção dos eventos de saída do grafo de SADF, dada pela expressão Eq.(5.59). Nas tabelas de 6.23 a 6.25 são apresentados três exemplos das curvas matriciais, $\boldsymbol{\Psi}^{\mathbf{u}}(\alpha)$ e $\boldsymbol{\Psi}^{\mathbf{l}}(\alpha)$ de cenários para $k=1, k=$ 10 e $k=50$.

\begin{tabular}{ccccc|}
860 & $-\infty$ & $-\infty$ & $-\infty$ & $-\infty$ \\
4510 & 3650 & $-\infty$ & $-\infty$ & $-\infty$ \\
12305 & 11445 & 11080 & $-\infty$ & $-\infty$ \\
13970 & 13110 & 12745 & 1665 & $-\infty$ \\
15935 & 15075 & 14710 & 3630 & 1965
\end{tabular}

Tabela 6.23: Valor da curva matricial superior $\Psi^{\mathrm{u}}(k)$ para $k=1$

$\begin{array}{|ccccc|}5938 & -\infty & -\infty & -\infty & -\infty \\ 37360 & 36500 & -\infty & -\infty & -\infty \\ 112025 & 111165 & 110800 & -\infty & -\infty \\ 113690 & 112830 & 112465 & 13149 & -\infty \\ 115592 & 114795 & 114430 & 16982 & 15898\end{array}$

Tabela 6.24: Valor da curva matricial superior $\Psi^{\mathrm{u}}(k)$ para $k=10$

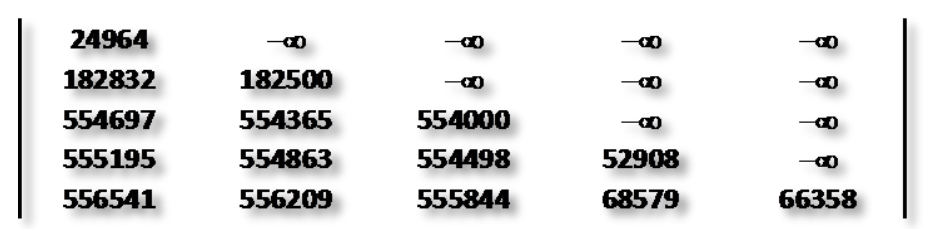

Tabela 6.25: Valor da curva matricial superior $\Psi^{\mathrm{u}}(k)$ para $k=50$

\subsubsection{Curva de Serviço baseada em Cenários}

Considerando-se as curvas matriciais de cenários encontradas na seção anterior, foi possivel calcular as sequências das curvas de serviço, inferior e superior, para o decodificador JPEG indicado no grafo da Figura 6.15. O cálculo foi feito implementando-se em Scicoslab as expressões propostas para 
cada curva $\boldsymbol{S}^{\boldsymbol{l}}(\boldsymbol{k})$ e $\boldsymbol{S}^{\boldsymbol{u}}(\boldsymbol{k})$, indicadas na seção 5.3.2 pela Eq.(5.63), Eq.(5.57) e a Eq.(5.58). A Figura 6.16 e a Figura 6.17 descrevem as curvas calculadas, considerando um máximo de iterações de $k=10$ e de $k=50$, respectivamente.

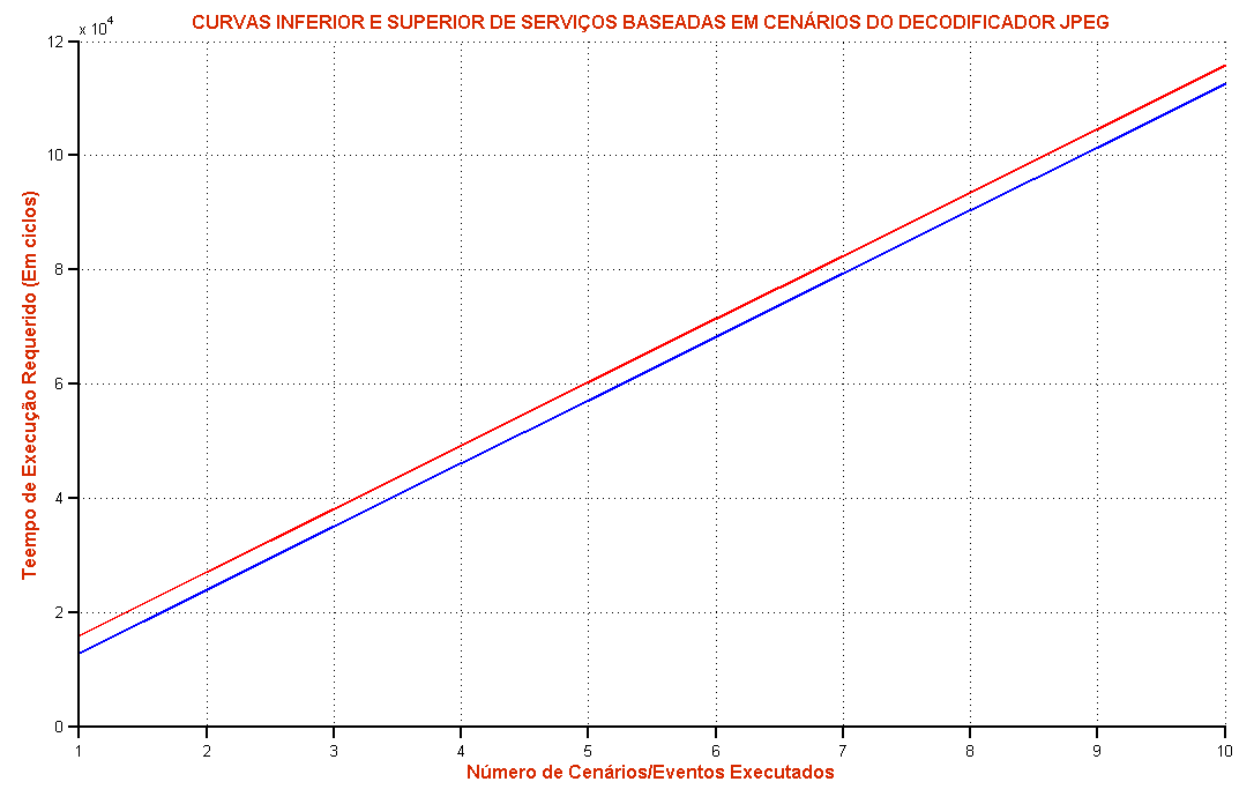

Figura 6.16: Curvas de serviço baseadas em cenários para o decodificador JPEG $(k=1 \ldots 10)$.

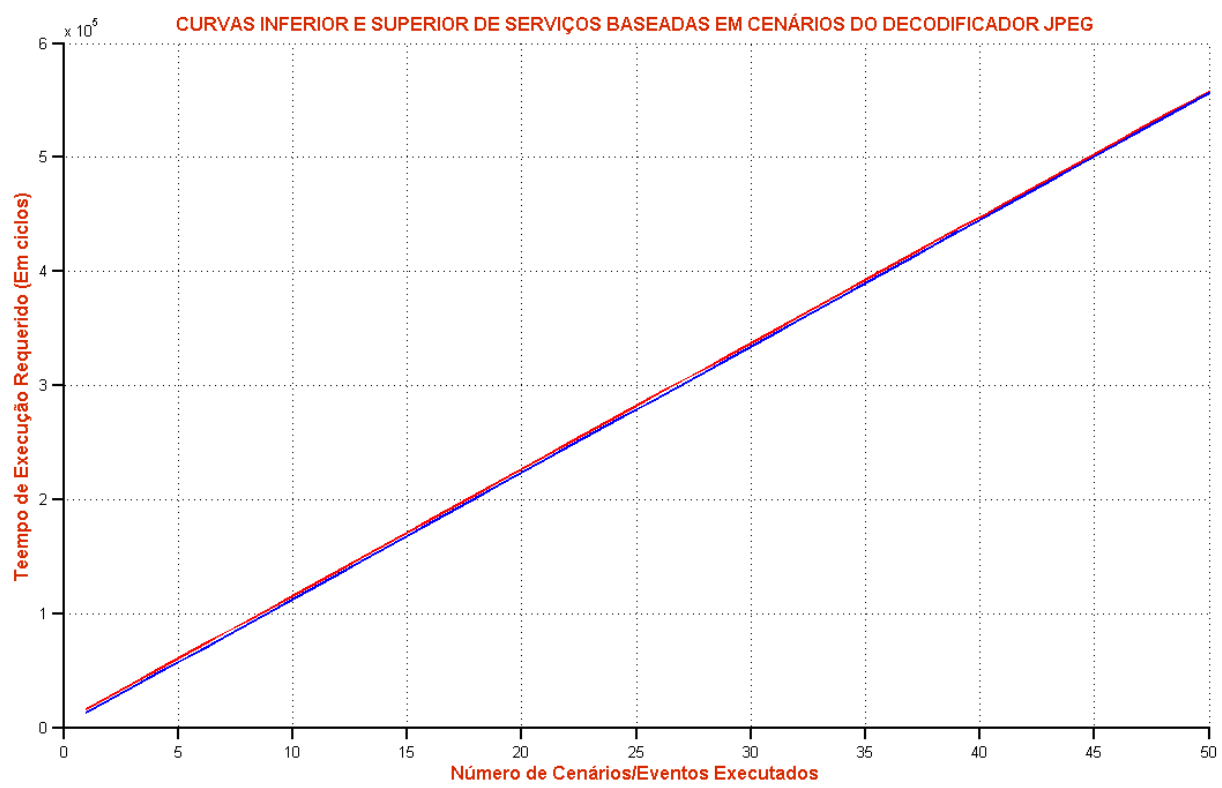

Figura 6.17: Curvas de serviço baseadas em cenários para o decodificador JPEG $(k=1 . .50)$. 


\section{CONCLUSÕES}

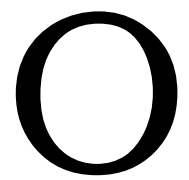

projeto de doutorado apresentado nesta tese colocou as bases para uma metodologia analítica de caracterização de aplicações, orientada a identificar a dinâmica temporal que tanto a aplicação como as tarefas que a compõem apresentam sob a condição de múltiplos tipos de eventos de entrada que provocam diferentes exigências de processamento nos recursos de arquitetura da plataforma alvo de um projeto MPSoC.

Desta forma as contribuições da presente tese estão relacionadas a dois grandes problemas tratados ao longo do texto, como são: a caracterização das tarefas de software de uma aplicação, baseada na análise estática dos modos de operação; e a especificação de um modelo de eventos temporais que caracteriza a carga de trabalho de uma aplicação multimídia, suportado na caracterização estática das suas tarefas e dos múltiplos cenários de aplicação.

Em relação à caracterização das tarefas da aplicação, uma metodologia de análise estática do código-fonte e executável de cada tarefa foi implementada, a fim de estimar o BCET e o WCET de cada modo de operação encontrado através de uma análise temporal baseada na modelagem da microarquitetura de um processador on-chip, de modo que esta metodologia permite conhecer a carga de trabalho de processamento colocada por cada tarefa sobre $\mathrm{o}$ processador.

A caracterização da operação global da aplicação foi realizada através da sua modelagem baseada em um modelo de computação de SADF, de modo que os atores do grafo especificado apresentam interfaces temporais que permitem conhecer analiticamente a transferência de eventos entre as diferentes tarefas (atores) que compõem a aplicação. Ao considerar os diferentes cenários de 
operação que fazem explícita a dinâmica comportamental da aplicação, o grafo de SADF resultante apresenta um comportamento temporal que foi analisado como um modelo linear em um espaço de estados baseado na Álgebra de MaxPlus, de modo que a presença das diferentes sequências de cenários ao longo do tempo acrescenta uma característica de variação temporal ao modelo linear identificado. A partir do tratamento matemático realizado foi possivel derivar expressões analiticas formais que descrevem a geração das sequências de eventos em função de cada iteração do grafo de SADF originalmente utilizado para modelar a aplicação. Considerando o conjunto completo de possíveis cenários de aplicação, junto às exigências variáveis de execução encontradas na caracterização de cada tarefa da aplicação, é possivel caracterizar todas as possíveis sequências de cenários utilizando os conceitos de "curvas de carga de trabalho baseadas em cenários", "curvas matriciais de cenários" e "curvas de serviço baseadas em cenários", definidos neste trabalho, os quais possuem direta relação à carga de trabalho gerada pela execução da aplicação.

Tanto a caracterização das tarefas da aplicação como a caracterização da operação global da aplicação foram implementadas como ferramentas descritas em linguagens de alto nível para testar as diferentes metodologias propostas ao longo da tese. Como um caso de uso foi utilizado um decodificador JPEG, definido como uma aplicação dividida em diferentes tarefas de software descritas em Ansi C, de modo que a caracterização do tempo de execução variável de cada tarefa implicou desenvolver ferramentas de análises de árvores sintáticas no nível de código-fonte e no nível assembly procurando identificar as diferentes rotas de execução e seus respectivos tempos extremos de execução, quando mapeadas em um processador on-chip, utilizando nesta tese a processador Simplescalar. Logo após identificar as diferentes rotas de execução agrupadas dentro de um conjunto de cenários de aplicação, duas metodologias diferentes foram utilizadas para caracterizar a operação global da aplicação, considerando a caracterização da sua carga de trabalho e diferentes métricas de desempenho. A primeira destas metodologias é baseada no modelo de Real-Time Calculus, de modo que a aplicação JPEG foi representada através de um grafo marcado, e posteriormente analisado para encontrar os valores de Backlog e de atraso utilizando a proposta de Análise Modular de Desempenho. Esta metodologia foi implementada em Matlab utilizando o Toolbox de Real-Time Calculus (RTC Toolbox). 
A segunda metodologia utilizada foi completamente proposta e desenvolvida neste trabalho, de modo que a aplicação é representada através de um grafo de SADF, e seguindo diferentes análises matemáticas no domínio de Max-Plus, foi possivel descrever o serviço oferecido pela aplicação, definido como o tempo que ela precisa para processar uma sequência de eventos, e descrito através de um modelo de curvas de serviços baseadas em cenários. Este modelo junto a diversas características da álgebra de Max-Plus permitiu também caracterizar a vazão de pior caso da aplicação. Esta metodologia foi implementada em Scicoslab utilizando o Toolbox de Max-Plus.

Tanto os resultados obtidos com a metodologia baseada em Real-Time Calculus, como aqueles obtidos na metodologia proposta baseada em grafos de $\mathrm{SADF}$, resultaram coerentes quando comparados aos resultados de desempenho obtidos por metodologias convencionais de simulação.

O trabalho futuro que pode ser derivado da presente tese de doutorado é resumido em quatro itens:

- Incluir o mapeamento da comunicação na caracterização da carga de trabalho de aplicação.

- Utilizar casos de uso que apresentem maior variabilidade na execução temporal e dinamismo comportamental.

- Comparar os resultados analíticos obtidos com simulações realizadas de aplicações com características semelhantes.

- Incluir a modelagem de mais métricas de desempenho, como a latência, jitter e consumo de potência, entre outros. 


\section{REFERÊNCIAS BIBLIOGRÁFICAS}

AUSTIN, Todd, LARSON, Eric, ERNST, Dan. Simplescalar. An Infrastructure for Computer System Modeling. IEEE Computer v. 35, n. 2. p. 59-67, 2002.

BALARIN, Felice, WATANABE, Yosinori, HSIEH, Harry, LAVAGNO, Luciano, PASSERONE, Claudio, SANGIOVANNI-VINCENTELLI, Alberto. Metropolis: An integrated electronic system design environment. Computer, v. 36, n. 4, p. 45-52, 2003.

BACCELLI, Francois, COHEN, Guy, OLSDER, Geert Jan, Quadrat, Jean-Pierre. Synchronization and Linearity. www.rocq.inria.fr/metalau/cohen/SED/book-online.html. Wiley, 2001.

BEHAMAMOUCH, Bilel, MONSUEZ, Bruno, VÉDRINE, Franck. 2008. Computing WCET using symbolic execution. Proc of the Second international conference on Verification and Evaluation of Computer and Communication Systems (VECoS'08), Rahma Ben Ayed and Karim Djemame (Eds.). British Computer Society, Swinton, UK, p. 128-139, 2008.

BILSEN, G. ENGELS, M, LAUWEREINS, Rudy, PEPERSTRAETE, Jan., "Cyclo-Static Dataflow," Signal Processing, IEEE Transactions on, v. 44, n. 2, p. 397-408, 1996.

BOOM, Ton van den. "Discrete-time systems analysis". Lecture Notes for the course SC4090. Delft University of Technology. Delft Center for Systems and Control. October, 2006.

BUCK, Joseph Tobin. Scheduling dynamic dataflow graphs with bounded memory using the token flow model. PhD thesis, UC Berkeley, 1993.

CARROLL, John, (Editor). Scenario-based design: envisioning work and technology in system development. John Wiley \& Sons Inc, NY, USA, 1995.

CASPARSSON, Lennart, RAJNAK, Antal, TINDELL, Ken, MALMBERG, Peter. Volcano. A revolution in on-board communications. Volvo Technology Report, v. 1 p. 9-19, 1998.

CHAKRABORTY, Samarjit, KUNZLI, Simon, THIELE, Lothar. A general framework for analysing system properties in platform-based embedded system designs, in: Proc. 6th Design, Automation and Test in Europe, v. 1, p. 190-195, 2003.

COHEN, G.; Moller, P.; Quadrat, J.; and Viot, M. "Algebraic tools for the performance evaluation of discrete event systems," Proceedings of the IEEE, vol. 77, no. 1, pp. 39-58, Jan. 1989.

COLIN, Antoine, PUAUT, Isabelle. Worst Case Execution Time Analysis for a Processor with Branch Prediction. The Journal of Real-Time Systems v. 18, n. 2/3, p. 249-274, 2000.

COLIN, Antoine, BERNAT, Guillem. Scope-tree: a Program Representation for Symbolic WorstCase Execution Time Analysis. Proc. 14th Euromicro Conference of Real-Time Systems, (ECRTS'02). p. 50-59, 2002. 
COMMONER, F, HOLT, A.W, EVEN, Shimon, and PNEULI, Amir. Marked directed graphs. Journal of Computer and System Sciences, v. 5, n. 5, p. 511-523, 1971.

CORRÉÏA, Aurélien; Abbas-Turki, Abdeljalil; Bouyekhf, Rachid; and El Moudni, Abdellah. 2009. A dioid model for invariant resource sharing problems. Trans. Sys. Man Cyber. Part A 39, 4 (July 2009), 770-781.

COUSOT, Patrick, COUSOT, Radhia. Abstract Interpretation: A Unified Lattice Model for Static Analysis of Programs by Construction or Approximation of Fixpoints. Proc of the $4^{\text {th }}$ ACM Symposium on Principles of Programming Languages. Los Angeles, California, p. 238-252. 1977.

CRUZ, Rene. A calculus for network delay, IEEE Trans. Inform. Theory v. 37, n. 1, p. 114-141, 1991.

DALLY, William, TOWLES, Brian. Route packets, not wires: on-chip inteconnection networks. Procs of the 38th Conf on Design Automation (DAC), p. 684-689, New York, NY, USA, 2001.

DASDAN, Ali, GUPTA, Rajesh. Faster maximum and minimum mean cycle algorithms for systemperformance analysis. Trans. on Computer-Aided Design of Integrated Circuits and Systems, v. 17, n. 10, p. 889-899, 1998.

DASDAN, Ali. Experimental analysis of the fastest optimum cycle ratio and mean algorithms. Trans. on Design Automation of Electronic Systems, v. 9, n. 4, p. 385-418, 2004.

DE ALFARO, Luca, HENZINGER, Thomas. Interface-based design. Engineering Theories of Software-intensive Systems, volume 195, p. 83-104, 2005.

DE ALFARO, Luca, HENZINGER, Thomas. Interface theories for component-based design. In Proceedings of the First International Workshop on Embedded Software, EMSOFT '01, p. 148$165,2001$.

DENNIS, Jack. First version of a data flow procedure language. In Programming Symposium, v. 19, p. 362-376, 1974.

DESIKAN, Rajagopalan, BURGER, Doug, and KECKLER, Stephen. Measuring Experimental Error in Microprocessor Simulation. In Proc. 28th International Symposium on Computer Architecture, 2001.

DUTTA, Santanu, JESEN, Rune, RIECKMANN, Alf. Viper: A multiprocessor SOC for advanced set-top box and digital TV systems. IEEE Design \& Test of Computers, v. 18, n. 5, p. 21-31, 2001. ENGBLOM, Jakob, ERMEDAHL, Andreas. Modeling complex flows for worst-case execution time analysis. Proc of 21th IEEE Real-Time Systems Symposium, Los Alamitos, p. 163-174, 2000.

ENGBLOM, Jakob, ERMEDAHL, Andreas, SJÖDIN, Mikael, GUSTAFSSON, Jan, HANSSON, Hans. Worst-case execution-time analysis for embeded real-time systems. International Journal On Software Tools for Technology Transfer, v. 4, n. 4, p. 437-455, 2001. 
ENGBLOM, Jakob. Processor Pipelines and Static Worst-Case Execution Time Analysis. Ph.D. thesis, Uppsala University, Dept. of Information Technology, Box 337, Uppsala, Sweden, 2002.

ERMEDAHL, Andreas. A Modular Tool Architecture for Worst-Case Execution Time Analysis. Ph.D. thesis, Uppsala University, Dept. of Information Technology, Box 325, Uppsala, Sweden, 2003.

FALK, Joachim; Marc Geilen; Christian Haubelt; Twan Basten; Bart Theelen and Sander Stuijk. Performance Analysis of Weakly-Consistent Scenario-Aware Dataflow Graphs. Technical Report ESR-2011-03, Eindhoven University of Technology, Department of Electrical Engineering, Eindhoven, The Netherlands, December 2011.

FEITELSON, Dror G. Workload Modeling for Computer Systems Performance Evaluation. V. 2459, p. 114-141, 2011.

FERDINAND, Christian, HECKMANN, Reinhold. Worst Case Execution Time prediction by static program analysis. Parallel and Distributed Processing Symposium. Proc. 18th International Volume, pages 125-134, 2004.

FERDINAND, Christian, KASTNER, Daniel, LANGENBACH, Marc, MARTIN, Florian, SCHMIDT, Michael, SCHNEIDER, Jorn, THEILING, Henrik, THESING, Stephan, WILHELM, Reinhard. Runtime guarantees for real-time systems - the USES approach. In GI Jahrestagung, pages 410-419, 1999.

FRAKES, William, KANG, Kyo. Software reuse research: status and future. IEEE Transactions on Software Engineering, v. 31, n. 7, p. 529-536, 2005.

GAJSKI, Daniel, VAHID, Frank, NARAYAN, Sanjiv, GONG, Jie. "Specification and Design of Embedded Systems", Prentice-Hall, Englewood Cliffs, N.J., 1994.

GANSSLE, Jack. Really Real-Time Systems. Proc of the Embedded Systems Conference Chicago, 2002.

GAUBERT, S. Performance evaluation of (max, +) automata. IEEE Trans. Automatic Control, 40(12):2014-2025, 1995.

GEILEN, Marc. Reduction techniques for synchronous dataflow graphs. In Proceedings of the 46th Annual Design Automation Conference (DAC '09). ACM, New York, NY, USA, 2009. 911-916.

GEILEN, Marc, STUIJK, Sander. Worst-case performance analysis of synchronous dataflow scenarios. Proc of the eighth IEEE/ACM/IFIP international conference on Hardware/software codesign and system synthesis. ACM, New York, NY, USA, P. 125-134, 2010.

GEILEN, Marc; Tripakis, Stavros; and Wiggers, Maarten. The Earlier the Better: A Theory of Timed Actor Interfaces; EECS Department; University of California, Berkeley. Technical Report No. UCB/EECS-2010-130 October 7, 2010 (Extended Version). 
GEILEN, Marc. Synchronous dataflow scenarios. ACM Trans. Embed. Comput. Syst. v. 10, n. 2, p. 31, 2011.

GEILEN, Marc, TRIPAKIS, Stavros, WIGGERS, Maarten. 2011. The Earlier the Better: A Theory of Timed Actor Interfaces. Proc of the 14th international conference on Hybrid systems: computation and control. ACM, New York, NY, USA, p. 23-32, 2011.

GHAMARIAN, Amir Hossein, GEILEN, Marc, BASTEN, Twan, THEELEN, Bart, MOUSAVI, Mohamma Reza, MOONEN, Arno, BEKOOIJ, Marco. 2006. Throughput Analysis of Synchronous Data Flow Graphs. Proc of the Sixth International Conference on Application of Concurrency to System Design (ACSD '06). IEEE Computer Society, Washington, DC, USA, p. 25-36, 2006.

GHAMARIAN, Amir Hossein, GEILEN, Marc, BASTEN, Twan, THEELEN, Bart, MOUSAVI, Mohamma Reza, STUIJK, sander. Liveness and boundedness of synchronous data flow graphs. Proc Formal Methods in Computer Aided Design, p. 68-75, 2006.

GHAMARIAN, Amir Hossein, STUIJK, Sander, BASTEN, Twan, GEILEN, Marc, THEELEN, Bart. Latency Minimization for Synchronous Data Flow Graphs. Proc of the 10th Euromicro Conference on Digital System Design Architectures, Methods and Tools (DSD '07). IEEE Computer Society, Washington, DC, USA, p. 189-196, 2007.

GHEORGHITA, Stefan Valentin, BASTEN, Twan, CORPORAAL, Henk. An Overview of Application Scenario Usage in Streaming-Oriented Embedded System Design, Eindhoven University of Technology, Report number: esr-2006-03, ISSN 1574-9517, 20 May 2006.

GHEORGHITA, Stefan Valentin, BASTEN, Twan, CORPORAAL, Henk. Application scenarios in streaming- oriented embedded system design. IEEE Design \& Test archive. v. 25, n. 6, p. 581-589, 2008.

GRAHAM, Ronald. Bounds for certain multiprocessing anomalies. Bell System Technical Journal v. 45, n. 9, p. 1563-1581, 1966.

GÖSSLER, Gregor, SANGIOVANNI-VINCENTELLI, Alberto. Compositional Modeling in Metropolis, Second International Workshop on Embedded Software, p. 93-107. 2002.

GOVINDARAJAN, Ramaswamy, GAO, Guang, DESAI, Palash. Minimizing buffer requirements under rate-optimal schedule in regular dataflow networks. Journal of VLSI Signal Processing, v. 31, n. 3, p. 207-229, 2002.

HANSSON, Andreas, WIGGERS, Maarten, MOONEN, Arno, GOOSSENS, Kees, BEKOOIJ, Marco. Enabling Application-Level Performance Guarantees in Network-Based Systems on Chip by Applying Dataflow Analysis. IET Computers \& Digital Techniques, v. 3, n. 5, p. 398-412, 2009.

HEALY, Christopher, WHALLEY, David. Tighter Timing Predictions by Automatic Detection and Exploitation of Value-Dependent Constraints. In Proc. 5th IEEE Real-Time Technology and Applications Symposium (RTAS99). p. 79-88, 1999. 
HECKMANN, Reinhold, LANGENBACH, Marc, THESING, Stephan., and WILHELM, Reinhard. The Influence of Processor Architecture on the Design and the Results of WCET Tools. IEEE Proceedings on Real-Time Systems, v. 91, n. 7, p. 1038-1054, 2008.

HENIA, Rafik, ERNST, Rolf. Scenario aware analysis for complex event models and distributed systems. In RTSS '07: Proc of the 28th IEEE International Real-Time Systems Symposium, p. 171180, Washington, DC, USA, 2007.

ISHIWATA, Shunichi, YAMAKAGE, Tomoo, TSUBOI, Yoshiro, SHIMAZAWA, Takayoshi, KITAZAWA, Tomoko, MICHINAKA, Shuji, MIYAMORI, Takashi, OOTOMO, Goichi, MATSUI, Masataka. A single chip MPEG-2 codec based on customizable media embedded processor. IEEE Journal of Solid-State Circuits, v. 38, n. 3, p. 530-540, 2003.

IWASAKI, Hiroe, NAGANUMA, Jiro, NITTA, Koyo, NAKAMURA, Ken, YOSHITOME, Takeshi, OGURA, Mitsuo, NAKAJIMA, Yasuyuki, TASHIRO, Yutaka, ONISHI, Takayuki, IKEDA, Mitsuo, MINAMI, Toshihiro, ENDO, Makoto, YASHIMA, Yoshiyuki. Single-chip MPEG-2 422P@HL CODEC LSI with multi-chip configuration for large scale processing beyond HDTV level. IEEE Transaction on Very Large Scale Integration (VLSI) Systems, v. 15, n. 9, p. 1055 1010, 2007. (In Design, Automation and Test in Europe (DATE), pages 20002-20007, 2003).

JACOBSON Ivar. The use-case construct in object-oriented software engineering. In ScenarioBased Design: Envisioning Work and Technology in System Development, chapter 12, p. 309336. John Wiley \& Sons, NY, USA, 1995.

JANTSCH, Axel. Modeling Embedded Systems and SoC's: Concurrency and Time in Models of Computation. Morgan Kaufmann, San Francisco, CA, 2003.

JERSAK, M.; Richter, K.; and Ernst, R. Performance analysis for complex embedded applications. International Journal of Embedded Systems, Special Issue on Codesign for SoC, 2004.

JIANG, Y. and Liu, Y. Stochastic Network Calculus, Springer-Verlag, Sept. 2008.

KAHN, Giles. The semantics of a simple language for parallel programming. Information Processing 74 - North-Holland, p. 471-475, 1974.

KARP, Richard, MILLER, Raymond. Properties of a model for parallel computations: Determinancy, termination, queueing. SIAM Journal of Applied Mathematics, v. 14, n. 6, p. 13901411, 1966.

KARP, Richard. A characterization of the minimum cycle mean in a digraph. Discrete Mathematics, v. 23, n. 3, p. 309-311, 1978.

KAUNZLI, Simon, HAMANN, Arne, ERNST, Rolf, THIELE, Lothar. Combined approach to system level performance analysis of embedded systems. Proc of the 5th International Conference on Hardware/Software Codesign and System Synthesis. P. 63-68, 2007. 
KEUTZER, Kurt, MALIK, Sharad, MEMBER, Senior, NEWTON, Richard Arthur, RABAEY, Jan M, SANGIOVANNI-VINCENTELLI, Alberto. System-level design: Orthogonalization of concerns and platform-based design. v. 19, n. 12, p. 1523-1543, 2000.

KIENHUIS, Bart, DEPRETTERE, Ed, VISSERS, Kees, VAN DER WOLF, Pieter. An approach for quantitative analysis of application-specific dataflow architectures. In Proceedings of the IEEE International Conference on Application-Specific Systems, Architectures and Processors, p. 338, Washington, DC, USA, 1997.

KRANZLMÜLLER, D.: Event graph analysis for debugging massively parallel programs. PhD thesis, GUP, Joh. Kepler Univ. Linz. http://www.gup.uni-linz.ac.at/ dk/thesis (2000).

KUMAR, A. "Analysis, Design and Management of Multimedia Multiprocessor Systems". PhD thesis. TU Eindhoven, Eindhoven. 2009.

KUMAR, Shashi. On packet switched networks for on-chip communication. In A. Jantsch and H. Tenhunen, editors, Networks on Chip, pages 85-106. Kluwer Academic Publishers, Hingham, MA, USA, 2003.

KUNG, Sun-Yuan, LEWIS, Paul, LO, Sheng-Chun. Performance analysis and optimization of VLSI dataflow arrays. Journal of Parallel Distributed Computing, v. 4, n. 6, p. 592-618, 1987.

LAHIRI, Kanishka; Raghunathan, Anand; Dey, Sujit. 2000. Efficient exploration of the SoC communication architecture design space. In Proceedings of the 2000 IEEE/ACM international conference on Computer-aided design (ICCAD '00). IEEE Press, Piscataway, NJ, USA, 424-430.

LAUWEREINS, Rudy, WAUTER, P. J, ADE, Marleen, PEPERSTRAETE, Jan. Geometric parallelism and cyclo-static data flow in GRAPE-II. Proc 5th International Workshop on Rapid System Prototyping, p. 90-107, 1994.

LE BOUDEC, Jean-Yves, THIRAN Patrick. Network Calculus-A Theory of Deterministic Queuing Systems for the Internet, Online Version of the Book Springer Verlag - LNCS 2050, 2001.

LEE, Edward, MESSERSCHMITT, David. Synchronous dataflow. IEEE Proc. V. 75, n. 9, p. 12351245,1987

LEE, Edward, MESSERSCHMITT, David. Static scheduling of synchronous data flow programs for digital signal processing. IEEE Transactions on Computers, v. 36, n. 1, p. 24-35, 1987.

LEE, Edward. Consistency in dataflow graphs. IEEE Transactions on Parallel and Distributed Systems, v. 2, n. 2, p. 223-235, 1991.

LEE, Edward, SANGIOVANNI-VINCENTELLI, Alberto. A framework for comparing models of computation. IEEE Transactions on Computer-Aided Design of Integrated Circuits and Systems, v. 17, n. 12 , p. 1217-1229, 1998.

LEE, Edward. "Overview of the Ptolemy Project," Technical Memorandum UCB/ERL M03/25, University of California, Berkeley, July 2, 2003. 
LEE, Edward A, NEUENDORFFER, Stephen. Actor-oriented models for codesign: balancing re-use and performance. Formal methods and models for system design, p. 33-56, 2004.

LI, Xianfeng, LIANG, Yun, MITRA, Tulika, ROYCHOUDHURY, Abnik. Chronos: A timing analyzer for embedded software. Sci. Comput. Program. v. 69, n. 1/3, p. 56-67, 2007.

LIM, Sung-Soo, BAE, Young Hyun, JANG, Gyu Tae, RHEE, Byung-Do, MIN, Sang Lyul, PARK, Chang Yun, SHIN, Heonshik, PARK, Kunsoo, MOON, Soo-Mook, KIM, Chong Sang. An Accurate Worst Case Timing Analysis for RISC Processors. IEEE Transactions on Software Engineering v. 21, n. 7, p. 593-604, 1995.

LUNDQVIST, Thomas, STENSTRÖM, Per. Timing Anomalies in Dynamically Scheduled Microprocessors. Proc of the 20th IEEE Real-Time Systems Symposium (RTSS99), p. 12-21, 1999.

MAMAGKAKIS, Stylianos, SOUDRIS, Dimitrios, CATTHOOR, Francky. Middleware design optimization of wireless protocols based on the exploitation of dynamic input patterns. Proc. of the conference on Design, automation and test in Europe, p. 1036-1041, San Jose, CA, USA, 2007.

MARCULESCU, Radu; Umit Y. Ogras, and Nicholas H. Zamora. 2004. Computation and communication refinement for multiprocessor SoC design: A system-level perspective. In Proceedings of the 41st annual Design Automation Conference (DAC '04). ACM, New York, NY, USA, 564-592.

MARKUS Fidler. A Survey of Deterministic and Stochastic Service Curve Models in the Network Calculus IEEE Communications Surveys \& Tutorials, 12(1):59-86, 2010.

MAXIAGUINE, Alexander; Y. Zhu; S. Chakraborty, and W.-F. Wong. Tuning SoC platforms for multimedia processing: Identifying limits and tradeoffs. In CODES+ISSS, Stockholm, Sweden, September 2004.

MAXIAGUINE, Alexander, KÜNZLI, Siomn, THIELE Lothar. Workload Characterization Model for Tasks with Variable Execution Demand. Proc. of the conf. on Design, automation and test in Europe, v. 2 p. 21040, 2004.

MAXIAGUINE, Alexander. Modeling Multimedia Workloads for embedded system design. PhD Thesis, ETH Zurich, October 2005.

METZNER, Alexander. Why model checking can improve wcet analysis. Computer Aided Verification, Lecture Notes in Computer Science, v. 3114, p. 298-301, 2004.

MOREIRA, Orlando, BEKOOIJ, Marco, Self-timed scheduling analysis for real-time applications. EURASIP J. Adv. Sig. Process. 2007.

PAREKH, A. K. and Gallager, R. G. "A generalized processor sharing approach to flow control in integrated services networks: The singlenode case," IEEE/ACM Trans. Netw., vol. 1, no. 3, pp. 344-357, June 1993. 
PHAN, Linh, CHAKRABORTY, Samarjit, THIAGARAJAN, P, S. A multi-mode Real-Time Calculus. In RTSS '08: Proceedings of the 2008 Real-Time Systems Symposium, pages 59-69, Washington, DC, USA, 2008. IEEE Computer Society.

POPLAVKO, Peter, BASTEN, Twan, BEKOOIJ, Marco, VAN MEERBERGEN, Jef, MESMAN, Bart. Task-level timing models for guaranteed performance in multiprocessor networks-on-chip. Procs of the International Conference on Compilers, Architecture, and Synthesis for Embedded Systems, p. 63-72. ACM, 2003.

POPLAVKO, Peter, BASTEN, Twan, VAN MEERBERGEN, Jef. Execution-time prediction for dynamic streaming applications with task-level parallelism. Proc of the 10th Euromicro Conference on Digital System Design Architectures, Methods and Tools, p. 228-235. 2007.

PUSCHNER, Peter, SCHEDL, Anton. Computing maximum task execution times with linear programming techniques. Journal Real-Time Systems, v. 13, n. 1, p. 67-91, 1997.

RAISCH, Jorg. Course Notes: Discrete Event and Hybrid Systems. Version 1.2. Fachgebiet Regelungssysteme Technische Universit at Berlin. Trinity College, Dublin, 2009.

RENFORS, Markku, NEUVO, Ywii. The maximum sampling rate of digital filters under hardware speed constraints. IEEE Transactions on Circuits and Systems, v. 28, n. 3, p. 196-202, 1981.

REISIG Wolfgang, ROZENBERG, Grzegorz. Lectures on Petri Nets, I: Basic Models (Advances in Petri Nets). Lecture Notes in Computer Science, v. 1491, 1998.

REITER, Raymond. Scheduling parallel computations. Journal of the ACM, v. 15, n. 4, p. 590599, 1968.

ROSE compiler infrastructure, Making Compiler Technology Accessible. http://www.rosecompiler.org. Acesso em: 27 ago. 2012.

ROSSON, Mary Beth, (Editor), CARROLL, John, (Editor). Scenario-based design. In The HumanComputer Interaction Handbook: Fundamentals, Evolving Technologies and Emerging Applications, chapter 53, pages 1032-1050. Lawrence Erlbaum Associates, Mahwah, NJ, 2002.

SANGIOVANNI-VINCENTELLI, Alberto, MARTIN, Grant. Platform-based design and software design methodology for embedded systems. IEEE Design \& Test v. 18, n. 6, p. 23-33, 2001.

SCICOSLAB. http://www.scicoslab.org/ último acesso, Novembro de 2012.

SHAW, Alan. Reasoning About Time in Higher-Level Language Software. IEEE Transactions on Software Engineering v. 15, n. 7, p. 875-889, 1989.

SIMON, Imre. Recognizable sets with multiplicities in the tropical semiring, Mathematical foundations of computer science (Carlsbad 1988), Springer Lecture Notes in Computer Science 324 (1988), 107-120.

SIYOUM, Firew; Geilen, Marc; Moreira, Orlando; and Corporaal, Henk. 2012. Worst-case throughput analysis of real-time dynamic streaming applications. In Proceedings of the eighth 
IEEE/ACM/IFIP international conference on Hardware/software codesign and system synthesis (CODES+ISSS '12). ACM, New York, NY, USA, 463-472.

SRIRAM, Sundararajan. BHATTACHARYYA, Shuvra. Embedded Multiprocessors: Scheduling and Synchronization. Marcel Dekker, Inc., New York, NY, USA, 2000.

STAPPERT, Friedhelm, ALTENBERND, Peter. Complete Worst-Case Execution Time Analysis of Straight-line Hard Real-Time Programs. Journal of Systems Architecture v. 46, n. 4, p. 339-355, 2000.

STAPPERT, Friedhelm, ERMEDAHL, Andreas, ENGBLOM, Jakob. Efficient Longest Executable Path Search for Programs with Complex Flows and Pipeline Effects. Proc. 4th International Conference on Compilers, Architecture, and Synthesis for Embedded Systems, p. 132-140, 2001.

STEFANOV, Todor, ZISSULESCU, Claudiu, TURJAN, Alexandru, KIENHUIS, Bart, DEPRETTERE, Ed. System design using Kahn process networks: The Compaan/Laura approach. Proce of the Conference on Design, Automation and Test in Europe. v. 1 p. 10340, 2004.

STEVEN LI, Yau-Tsun, MALIK, Sharad. Performance analysis of embedded software using Implicit Path Enumeration. 32nd Conference on Design Automation, p. 456-461, 1995.

STEVEN LI, Yau-Tsun, MALIK, Sharad, WOLFE, Andrew. Efficient microarchitecture modeling and path analysis for real-time software. Proc of the 16th IEEE Real-Time Systems Symposium (RTSS '95). IEEE Computer Society, Washington, DC, USA. 1995.

STEWART, David. Measuring execution time and real-time performance. Embedded Systems Conference, San Francisco, CA., April 2001.

STILIADIS, D. and Varma A., "Latency-rate servers: A general model for analysis of traffic scheduling algorithms," IEEE/ACM Trans. Netw.,vol. 6, no. 5, pp. 611-624, Oct. 1998.

STOIMENOV, Nikolay. Compositional Design and Analysis of Distributed, Cyclic, and Adaptive Embedded Real-Time Systems - PhD thesis under the supervision of Prof. Dr. Lothar Thiele, Computer Engineering and Networks Laboratory, ETH Zurich, Zurich, Switzerland. TIKSchriftenreihe No. 124. Diss. ETH Zurich No. 19619. 2011.

STRALEN, P. V. "Scenario Based Design Space Exploration", Master's thesis, University of Amsterdam, 2009.

STRIK, Mariano, TIMMER, Adwin, VAN MEERBERGEN, Jef, VAN ROOSTELAAR, Gert-Jan. Heterogeneous multiprocessor for the management of realtime video and graphics streams. IEEE Journal of Solid-State Circuits, v. 35, n. 11, p. 1722-1731, 2000.

STUIJK S.. Design and implementation of a JPEG decoder. Practical Training Report for the Faculty of Electrical Engineering; (ICS/ES); Eindhoven University of Technology. The Netherlands. December 2001. 
STUIJK, Sander, BASTEN, Twan, MESMAN, Bart, GEILEN, Marc. Predictable embedding of large data structures in multiprocessor networks-on-chip. Procs of the conference on Design, Automation and Test in Europe. v. 1, p. 254 - 255 . IEEE, 2005.

STUIJK, Sander, GEILEN, Marc, BASTEN, Twan. Exploring trade-offs in buffer requirements and throughput constraints for Synchronous Dataflow Graphs. Proc of the 43th annual Conference on Design Automation (DAC '06), p. 899-904, San Francisco, California, USA, 2006.

STUIJK, Sander. Predictable Mapping of Streaming Applications on Multiprocessors. Ph.D. dissertation, Eindhoven University of Technology, 2007.

STUIJK, sander, GHAMARIAN, Amir Hossein, THEELEN, Bart, GEILEN, Marc, BASTEN, Twan. FSM-based SADF. MNEMEE internal report, Eindhoven University of Technology, Department of Electrical Engineering, Eindhoven, The Netherlands, December 2008.

TALLA, Deepu, YU-HUNG, Ching, TALLURI, Raj, BRILL, Frank, SMITH, Dvaid BRIER, David, XIONG, Bruce, HUYNH, Derek. Anatomy of a portable digital mediaprocessor. IEEE Micro, v. 24, n. 2, p. 32-39, 2004.

TERUEL, Enrique, CHRZASTOWSKI-WACHTEL, Piotr, COLOM, José Manuel, SILVA, Manuel. On weighted T-systems. Proc13th International Conference on Application and Theory of Petri Nets, p. 348-367. Springer, 1992.

THEELEN, Bart, GEILEN, Marc, BASTEN, Twan, VOETEN, Jeroen, GHEORGHITA, Stefan Valentin, STUIJK, Sander. A scenario-aware dataflow model for combined long-run average and worst-case performance analysis. Proc of the International Conference on Formal Methods and Models for Co-Design. ACM, New York, p. 185-194. 2006.

THEILING, Henrik, FERDINAND, Christian, WILHELM, Reinhard. Fast and precise wcet prediction by separated cache and path analyses. Real-Time Systems, v. 18, n. 2/3, p. 157-179, 2000.

THEILING, Henrik. Control Flow Graphs For Real-Time Systems Analysis. Ph.D. thesis, Universitat des Saarlandes, Saarbr"ucken, Germany. 2002.

THIELE, Lothar, CHAKRABORTY, Samarjit, NAEDELE, Martin. Real-Time Calculus for scheduling hard real-time systems, Proc. IEEE International Symposium on Circuits and Systems, ISCAS, 4, pp. 101-104, 2000.

THIELE, Lothar, STOIMENOV, Nikolay. Modular Performance Analysis of cyclic dataflow graphs. Proc. of the seventh ACM international conf. on Embedded software (EMSOFT '09). p. 127-136, 2009.

WANDELER, Ernesto, THIELE, Lothar. Abstracting functionality for Modular Performance Analysis of hard real-time systems. Proc of the 2005 Asia and South Pacific Design Automation Conference (ASP-DAC '05). ACM, New York, NY, USA, p. 697-702, 2005. 
WANDELER, Ernesto; Maxiaguine, Alexander; and Thiele, Lothar. Quantitative Characterization of Event Streams in Analysis of Hard Real-Time Applications. Real-Time Syst. 29, 2-3 (March 2005), 205-225.

WANDELER, Ernesto, THIELE, Lothar. Real-time interfaces for interface-based design of real-time systems with fixed priority scheduling. Proc of the 5th ACM international conference on Embedded software, EMSOFT '05, p. 80-89, 2005.

WANDELER, Ernesto. Modular Performance Analysis and Interface-Based Design for Embedded Real-Time Systems. PhD thesis, ETH Zurich, September 2006.

WANDELER, Ernesto, THIELE, Lothar. Interface-based design of real-time systems with hierarchical scheduling. Proc of the 12th IEEE Real-Time and Embedded Technology and Applications Symposium, p. 243-252, 2006.

WANDELER, Ernesto, THIELE, Lothar. Real-Time Calculus (RTC) Toolbox. http://www.mpa.ethz.ch/Rtctoolbox. Acesso em: 27 ago. 2012.

WILLIAM J. Palm, Modeling: Analysis and Control of Dynamic Systems. John Wiley \& Sons Inc. January 1983. ISBN-10: 0471058009. ISBN-13: 978-0471058007.

WILHELM, Reinhard, ENGBLOM, Jakob, ERMEDAHL, Andreas, HOLSTI, Niklas, THESING, Stephan, WHALLEY, David, BERNAT, Guillem, FERDINAND, Christian, HECKMANN, Reinhold, MITRA, Tulika, MUELLER, Frank, PUAUT, Isabelle, PUSCHNER, Peter, STACHULAT Jan, STENSTR, Per. The worst-case execution-time problem: overview of methods and survey of tools. ACM Transactions on Embedded Computing Systems v. 7, n. 3, p. 53, 2008.

YANG, Feiteng. "Static Analysis and Task Scheduling for Multi-mode Software-Defined Radio Applications," Master's thesis, 2009.

YANG, Peng, MARCHAL, Paul, WONG, Chun, HIMPE, Stefaan, CATTHOOR, Francky, DAVID, Patrick, VOUNCKX, Johan, LAUWEREINS, Rudy. Managing dynamic concurrent tasks in embedded real-time multimedia systems. In ISSS '02: Proceedings of the 15th international symposium on System Synthesis, p. 112-119, New York, NY, USA, 2002.

YOUNG, Neal, TARJAN, Robert, ORLIN, James. Faster parametric shortest path and minimumbalance algorithms. Networks, v. 21, n. 2, p. 205-221, 1991.

ZHANG, Yina. Evaluation of methods for dynamic time analysis for cc-systems ab. Technical Report, Mälardalen University, August 2005.

ZHU, JUN. Performance Analysis and Implementation of Predictable Streaming Applications on Multiprocessor Systems-on-Chip. Doctoral Thesis. Royal Institute of Technology, Sweden 2010. 


\section{ANEXO I}

\section{I.1. SISTEMAS LINEARES CLÁSSICOS}

Um sistema clássico linear discreto e invariante no tempo é o apresentado na Figura I.1.

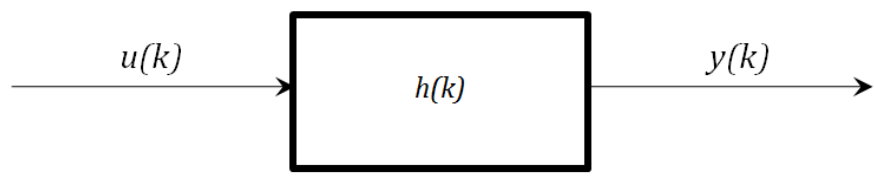

Figura I.1: Sistema Linear de Tempo Discreto

Este sistema é descrito pelo seguinte conjunto de equações diferenciais:

$$
\begin{aligned}
x(k+1) & =A x(k)+B u(k) \\
y(k) & =C x(k)+D u(k)
\end{aligned}
$$

Onde $u(k)$ é a entrada do sistema, $y(k)$ é a saída, e $x(k)$ define as variáveis de estado do sistema linear.

A solução é obtida em duas etapas: primeiro a resposta da variável de estado $x(k)$ é determinada através da solução do conjunto de equações de estado de primeira ordem na Eq.(I.1) e, em seguida, a resposta de estado é substituída nas equações algébricas da saída, na Eq.(I.2) a fim de calcular $y(k)$ [BOOM06].

\section{I.1.1. Resposta de Estado Homogênea}

A resposta de variável de estado de um sistema descrito pela Eq.(I.1) com entrada zero e um conjunto arbitrário de condições iniciais $x(0)$ é a solução de um conjunto de $n$ equações diferenciais homogêneas de primeira ordem:

$$
x(k+1)=A x(k)
$$

É possivel encontrar a solução através de substituições sucessivas. Note-se que $x(1)=A x(0)$ e $x(2)=A x(1)$, desta forma por substituição, obtém-se $x(2)=A^{2} x(0)$. Procedendo deste modo é possivel obter:

$$
x(k)=A^{k} x(0)
$$


A solução é frequentemente escrita como:

$$
x(k)=\Phi(k) x(0)
$$

Onde $\Phi(k)=A^{k}$ é definida como a matriz de transição de estados [BOOM06].

Exemplo: Como um exemplo simples, considere-se o sistema linear discreto e invariável no tempo de primeira ordem, descrito pelas seguintes equações de estado:

$$
\begin{aligned}
x(k+1) & =a x(k)+a(1-a) u(k) \quad k \in \mathbb{Z} \\
y(k) & =x(k)+(1-a) u(k),
\end{aligned}
$$

A equação diferencial de estado homogênea é dada por:

$$
x(k+1)=a x(k)
$$

Daqui resulta que a matriz de transição de estado, de $1 \times 1$, é dada por:

$$
\Phi(k)=A A \cdots A=a \cdot a \cdots a=a^{k}, \quad k>0, \quad k \in \mathbb{Z}
$$

\section{I.1.2. Resposta Forçada}

Para a solução da equação de estado de tempo discreto não-homogênea da Eq(I.1), segue facilmente por indução que:

$$
\begin{aligned}
x(k+2) & =A x(k+1)+B u(k+1) \\
& =A(A x(k)+B u(k))+B u(k+1) \\
& =A^{2} x(k)+A B u(k)+B u(k+1)
\end{aligned}
$$

Procedendo dessa forma é possivel obter:

$$
x(k)=A^{k} x(0)+\sum_{m=0}^{k-1} A^{k-m-1} B u(m)
$$

para $k \geq 1$. Para $k \leq 0$, a soma não contribui para a solução, e, por conseguinte, é possivel multiplicar este termo pela função degrau unitário, $u_{s}(k-1)$, a qual é zero para $k \leq 0$. Desta forma, obtém-se:

$$
x(k)=A^{k} x(0)+\sum_{m=0}^{k-1} A^{k-m-1} B u(m) u_{s}(k-1)
$$


A Eq.(I.8) corresponde à descrição explícita das variáveis de estado das equações descritas pela Eq.(I.1), tal que esta descrição pode ser utilizada para encontrar a resposta total do sistema linear discreto no tempo [BOOM06].

\section{I.1.3. Resposta de Saída do Sistema}

A resposta de saída de um sistema linear discreto no tempo pode ser facilmente derivada por substituição da Eq.(I.8) na Eq.(I.2):

$$
\begin{aligned}
y(k) & =C x(k)+D u(k) \\
& =C\left(A^{k} x(0)+\sum_{m=0}^{k-1} A^{k-m-1} B u(m) u_{s}(k-1)\right)+D u(k) \\
& =C A^{k} x(0)+\sum_{m=0}^{k-1} C A^{k-m-1} B u(m) u_{s}(k-1)+D u(k)
\end{aligned}
$$

Desta forma, a resposta de saída forçada é dada por:

$$
y(k)=\underbrace{C A^{k} x(0)}_{\text {Resposta às condicões iniciais }}+\underbrace{\sum_{m=0}^{k-1} C A^{k-m-1} B u(m) u_{s}(k-1)+D u(k)}_{\text {Resposta à entrada }}
$$

\section{I.1.4. Matriz de Transição de Estados}

A matriz de transição de estados de tempo discreto $\Phi(k)$ tem as seguintes propriedades [BOOM06]:

1. $\Phi(0)=I$

2. $\Phi(-k)=\Phi^{-1}(k)$

3. $\Phi\left(k_{1}\right) \Phi\left(k_{2}\right)=\Phi\left(k_{1}+k_{2}\right)$, e desta forma,

$$
\begin{aligned}
& x\left(k_{2}\right)=\Phi\left(k_{2}\right) x(0)=\Phi\left(k_{2}\right) \Phi\left(-k_{1}\right) x\left(k_{1}\right)=\Phi\left(k_{2}-k_{1}\right) x\left(k_{1}\right) \\
& x\left(k_{2}\right)=\Phi\left(k_{2}-k_{1}\right) x\left(k_{1}\right)
\end{aligned}
$$

Se $A$ é uma matriz diagonal, então, $A^{k}$ é também uma matriz diagonal e cada elemento é a $k$-ésima potência do elemento diagonal correspondente da matriz $A$, isto é, $a_{i i}^{k}$. 


\section{ANEXO II}

\section{II.1. SISTEMAS LINEARES DISCRETOS E VARIANTES NO TEMPO}

Uma descrição geral de um espaço de estado clássico linear e discreto no tempo, de $n$-ésima ordem tem a seguinte forma:

$$
\begin{aligned}
x(k+1) & =A(k) x(k)+B(k) u(k) \\
y(k) & =C(k) x(k)+D(k) u(k)
\end{aligned}
$$

onde $x(k) \in \mathbb{R}^{n}$. Dada a condição inicial $x(0)$ e a sequência de entrada $u(k)$, é de interesse encontrar a sequência de estado, ou trajetória de estado, $x(k)$, bem como a sequência de saída $y(k)$ [BOOM06].

\section{II.1.1. Resposta Homogênea}

Primeiro, considere-se a resposta homogênea, que é a resposta quando $u(k)=0$ para todo $k \in \mathbb{Z}$. A equação da evolução do estado então se reduz a:

$$
x(k+1)=A(k) x(k)
$$

A resposta pode ser obtida diretamente da Eq.(II.2), simplesmente avançandose nas iterações:

$$
\begin{aligned}
x(1) & =A(0) x(0) \\
x(2) & =A(1) x(1) \\
& =A(1) A(0) x(0) \\
x(k) & =A(k-1) A(k-2) \cdots A(1) A(0) x(0)
\end{aligned}
$$

Motivado por (II.3), define-se a matriz de transição de estado variante no tempo [BOOM06], a qual relaciona o estado do sistema homogêneo no tempo $k$ com o estado em um tempo anterior $l$ :

$$
x(k)=\Phi(k, l) x(l) \quad k \geq l
$$

A forma da matriz se segue diretamente a partir de (II.3):

$$
\Phi(k, l)=\left\{\begin{array}{cc}
A(k-1) A(k-2) \cdots A(l), & k>l \geq 0 \\
I, & k=l
\end{array}\right.
$$


Se $A(k-1), A(k-2), \ldots, A(l)$ forem todas matrizes inversiveis, então pode-se usar a matriz de transição de estado para obter $x(k)$ a partir de $x(l)$, mesmo quando $k<l$, mas geralmente assume-se $k \geq l$ ao escrever $\Phi(k, l)$.

As seguintes propriedades da matriz de transição de estado em tempo discreto merecem destaque:

$$
\begin{aligned}
\Phi(k, k) & =I \\
x(k) & =\Phi(k, 0) x(0) \\
\Phi(k+1, l) & =A(k) \Phi(k, l)
\end{aligned}
$$

\section{II.1.2. Resposta Forçada}

Agora, considerando o sistema forçado, ou seja, com uma entrada definida explicitamente, $u(k) \neq 0$, pelo menos para algum $k$, e retomando as Eq.(II.1), obtém-se,

$$
\begin{aligned}
x(1) & =A(0) x(0)+B(0) u(0) \\
x(2) & =A(1) x(1)+B(1) u(1) \\
& =A(1) A(0) x(0)+A(1) B(0) u(0)+B(1) u(1)
\end{aligned}
$$

o que leva a

$$
\begin{aligned}
x(k) & =\Phi(k, 0) x(0)+\sum_{l=0}^{k-1} \Phi(k, l+1) B(l) u(l) \\
x(k) & =\Phi(k, 0) x(0)+\sum_{l=0}^{k-1} \Phi(k, l+1) B(l) u(l) \\
& =\Phi(k, 0) x(0)+\Gamma(k, 0) U(k, 0)
\end{aligned}
$$

onde

$$
\Gamma(k, 0)=[\Phi(k, 1) B(0), \Phi(k, 2) B(1), \cdots, B(k-1)], \quad \mathcal{u}(k, 0)=\left(\begin{array}{c}
u(0) \\
u(1) \\
\vdots \\
u(k-1)
\end{array}\right)
$$

O que a Eq.(II.9) mostra é que a solução do sistema ao longo de $k$ passos tem a mesma forma que a solução sobre um passo, a qual é dada na primeira equação de Eq.(II.1) [BOOM06]. Note-se também que a resposta do sistema é dividida em dois termos: uma depende apenas do estado inicial $x(0)$ e a outro depende apenas da entrada. Estes termos são respectivamente chamados de 
resposta natural, homogênea ou transitória, e de resposta forçada. Note-se que a resposta forçada tem uma forma que lembra uma soma de convolução; esta forma é muitas vezes referida como uma soma de superposição [BOOM06].

Se Eq.(II.9) tem sido indicada simplesmente como uma solução dada, sem qualquer tipo de derivação, então sua validade pode ser verificada através da sua própria substituição recursiva dentro das equações do sistema nas Eq.(II.1) :

$$
\begin{aligned}
x(k+1) & =\Phi(k+1,0) x(0)+\sum_{l=0}^{k} \Phi(k+1, l+1) B(l) u(l) \\
& =\Phi(k+1,0) x(0)+\sum_{l=0}^{k-1} \Phi(k+1, l+1) B(l) u(l)+B(k) u(k) \\
& =A(k)\left[\Phi(k, 0) x(0)+\sum_{l=0}^{k-1} \Phi(k, l+1) B(l) u(l)\right]+B(k) u(k) \\
& =A(k) x(k)+B(k) u(k)
\end{aligned}
$$

Claramente, a Eq.(II.11) satisfaz as equações do sistema na Eq.(II.1). Resta verificar que a solução proposta corresponde ao estado inicial em $k=0$. Então,

$$
x(0)=\Phi(0,0) x(0)=x(0)
$$

o qual completa a verificação.

Se $\mathcal{Y}(k, 0)$ é definida de forma semelhante ao $\mathcal{U}(k, 0)$, então seguindo o tipo de derivação que levou à Eq.(II.9), é possível estabelecer que,

$$
\mathcal{Y}(k, 0)=\Theta(k, 0) x(0)+\Psi(k, 0) \mathcal{U}(k, 0)
$$

para matrizes definidas apropriadamente $\Theta(k, 0)$ e $\Psi(k, 0)$. Mais uma vez, a Eq.(II.13), para a saída ao longo de $k$ passos, tem a mesma forma que a expressão para a saída de um único passo, a qual é dada na segunda equação de Eq.(II.1). 


\section{ANEXO III}

\section{III.1.ESPAÇO DE ESTADO LINEAR EM MAX- PLUS}

Os MoCs descritos por eventos (MoDEs), tais como o grafo de SDF e suas diferentes extensões, podem ser modelados através de um modelo algébrico de Max-Plus, definido da seguinte forma:

$$
\begin{aligned}
x(k+1) & =(A \otimes x(k)) \oplus(B \otimes u(k)) \\
y(k) & =C \otimes x(k)
\end{aligned}
$$

Com $A \in \mathbb{R}_{\varepsilon}^{n \times n}, B \in \mathbb{R}_{\varepsilon}^{n \times m}$ e $C \in \mathbb{R}_{\varepsilon}^{p \times n}$, onde $n$ é o número de atores dentro do modelo, $m$ é o número de entradas e $p$ é o número de saídas [BACCELLIO1]. O vetor $x$ representa as variáveis de estado, $u$ é o vetor de entrada, e $y$ é o vetor de saída do modelo. É importante notar que na Eq.(III.1) os componentes das entradas, saídas, e das variáveis de estado correspondem aos tempos dos diferentes eventos presentes dentro do modelo, de modo que a variável de contagem $k$ corresponde a um contador de eventos.

Devido à analogia destes modelos com os sistemas lineares convencionais invariantes no tempo, um MoDE que pode ser modelado pela Eq.(III.1) é chamado geralmente de modelo linear em Max-Plus invariável no tempo [BACCELLIO1].

O modo tradicional de escrever as equações Eq.(III.1) seria:

$$
\begin{aligned}
x_{i}(k+1) & =\max _{i=1 \ldots n}\left(\left(A_{i 1}+x_{1}(k)\right), \ldots,\left(A_{i n}+x_{n}(k)\right),\left(B_{i 1}+u_{1}(k)\right), \ldots,\left(B+u_{m}(k)\right)\right) \\
y_{i}(k) & =\max _{i=1 \ldots p}\left(\left(C_{i 1}+x_{1}(k)\right), \cdots,\left(x_{i n}+x_{n}(k)\right)\right)
\end{aligned}
$$

Às vezes as equações Eq.(III.1) também são escritas como:

$$
\begin{aligned}
x(k+1) & =A \otimes x(k) \oplus B \otimes u(k) \\
y(k) & =C \otimes x(k)
\end{aligned}
$$

onde entende-se que a "multiplicação" tem prioridade sobre a "soma". No entanto, geralmente este conjunto de equações costuma ser escrito como: 


$$
\begin{aligned}
x(k+1) & =A x(k) \oplus B u(k) \\
y(k) & =C x(k)
\end{aligned}
$$

Esta descrição é mais utilizada devido à semelhança com a notação da álgebra convencional, tal que quando o símbolo $\otimes$ é utilizado, ele também pode ser omitido, como se mostra na Eq.(III.4). Esta prática é exatamente a mesma no que diz em relação aos símbolos de multiplicação ' $X$ ' ou '.' da álgebra convencional.

A solução destas equações permite encontrar a expressão matemática que descreve os tempos dos eventos de saída do MoDE definido pelas equações Eq.(III.1). Primeiro, determina-se o comportamento de entrada-saída do MoDE seguindo uma substituição recursiva em Eq.(III.1) para $k=0,1,2, \ldots$, tal que,

$$
\begin{aligned}
x(1) & =A \otimes x(0) \oplus B \otimes u(0) \\
x(2) & =A \otimes x(1) \oplus B(1) u(1) \\
& =A^{\otimes^{2}} x(0) \oplus A \otimes B \otimes u(0) \oplus B \otimes u(1) \\
& \quad \vdots \quad \vdots
\end{aligned}
$$

o que leva a

$$
x(k)=A^{\otimes^{k}} x(0) \oplus \bigoplus_{i=0}^{k-1} A^{\otimes^{k-1-i}} \otimes B \otimes u(i) \quad \text { para } k=0,1,2, \ldots
$$

Esta Eq.(III.5) corresponde à descrição explícita das variáveis de estado das equações descritas pela Eq.(III.4), tal que esta descrição pode ser utilizada para encontrar a resposta total do modelo linear em Max-Plus invariável no tempo [BACCELLIO1].

Daí que,

$$
y(k)=C \otimes A^{\otimes^{k}} x(0) \oplus \bigoplus_{i=0}^{k-1} C \otimes A^{\otimes^{k-1-i}} \otimes B \otimes u(i) \quad \text { para } k=0,1,2, \ldots \quad \text { (III.6) }
$$

Esta Eq.(III.6) corresponde descrição explícita da resposta total de um modelo linear em Max-Plus invariável no tempo, tal que $y(k)$ descreve os tempos dos eventos de saída do MoDE definido pelas equações Eq.(III.1). 


\section{III.2.TRANSFORMADA Y}

Os sistemas lineares convencionais, com entradas $u(k)$ e saídas $y(k)$, como o mostrado na Figura I.1, têm a forma das Eq.(I.1) e Eq.(I.2), as quais são uma representação de um sistema linear no domínio do tempo discreto [BACCELLIO1]. Sua representação no domínio-z é igual a:

$$
Y(z)=C(z I-A)^{-1} B U(z)
$$

onde $Y(z)$ e $U(z)$ são chamadas de transformada- $z$ de $y(k)$ e $u(k)$, respectivamente, definidas por,

$$
Y(z)=\sum_{i=0}^{\infty} y(i) z^{-i}, \quad U(z)=\sum_{i=0}^{\infty} u(i) z^{-i}
$$

onde é tacitamente assumido que o sistema encontra-se em repouso para $t \leq$ 0 . A matriz $H(z)=C(z I-A)^{-1} B$ é chamada a matriz de transferência do sistema. Aqui I refere-se à matriz identidade na álgebra convencional. A noção de matriz de transferência é especialmente útil quando os subsistemas são combinados para construir sistemas maiores, através de conexões série, paralelo e de realimentação.

No contexto da álgebra de Max-Plus, também existe a transformada- $z$ (ver [BACCELLI01]), mas nela é comum se referir à transformada- $\gamma$, a qual $\gamma$ opera como $z^{-1}$. Por exemplo, a transformada- $\gamma$ de $u(k)$ é definida como:

$$
U(\gamma)=\bigoplus_{i=0}^{\infty} u(i) \otimes \gamma^{i}
$$

e $Y(\gamma)$ e $X(\gamma)$ são definidas da mesma forma.

A multiplicação das Eq.(I.1) e Eq.(I.2) por $\gamma^{k}$ equivale a,

$$
\left.\begin{array}{rl}
\gamma^{-1} x(k+1) \gamma^{k+1} & =A \otimes x(k) \gamma^{k} \oplus B \otimes u(k) \gamma^{k} \\
y(k) \gamma^{k} & =C \otimes x(k) \gamma^{k}
\end{array}\right\}
$$

Se estas equações são somadas com relação a $k=0,1, \cdots$, é possível obter

$$
\left.\begin{array}{rl}
\gamma^{-1} X(\gamma) & =A \otimes X(\gamma) \oplus B \otimes U(\gamma) \oplus \gamma^{-1} x_{0} \\
Y(\gamma) & =C \otimes X(\gamma)
\end{array}\right\}
$$


A primeira dessas equações pode ser resolvida multiplicando-se, no sentido da álgebra de Max-Plus, (seção 4.3.1.1), isto é, somando no sentido convencional, os lados esquerdo e direito por $\gamma$, isto resulta em:

$$
X(\gamma)=\gamma A \otimes X(\gamma) \oplus \gamma B \otimes U(\gamma) \oplus x_{0}
$$

E dado que na álgebra de Max-Plus, a solução de uma equação do tipo $\boldsymbol{X}=A \otimes \boldsymbol{X} \oplus B$ corresponde $\operatorname{com} \boldsymbol{X}=A^{*} \otimes B \quad$ [BACCELLI01], sendo $A^{*}$ a operação Star Kleene ${ }^{27}$, então a solução para $X(\gamma)$ é

$$
X(\gamma)=(\gamma A)^{*}\left(\gamma \otimes B \otimes U(\gamma) \oplus x_{0}\right),
$$

Desta forma, obtém-se $Y(\gamma)=H(\gamma) U(\gamma)$, dado que $x_{0}=\varepsilon$, e onde a matriz de transferência $H(\gamma)$ é definida por:

$$
H(\gamma)=C \otimes(\gamma A)^{*} \otimes \gamma \otimes B
$$

Ou, em notação de Max-Plus abreviada,

$$
\begin{aligned}
H(\gamma) & =C(\gamma A)^{*} \gamma B \\
& =\gamma C B \oplus \gamma^{2} C A B \oplus \gamma^{3} C A^{2} B \oplus \cdots
\end{aligned}
$$

A expressão $Y(\gamma)=H(\gamma) U(\gamma)$ é equivalente na álgebra de Max-Plus a $Y(z)=$ $H(z) U(z)$ na teoria de sistemas convencionais. Desta forma, ao escrever a versão expandida de $H(z)$ em função de $\gamma$ :

$$
\begin{aligned}
& H(z)=C(z I-A)^{-1} B \\
H(z) & =C(z I-A)^{-1} B \\
& =C\left(\frac{1}{\gamma} I-A\right)^{-1} B \\
& =\gamma C(I-\gamma A)^{-1} B \\
& =\gamma C\left(I+\gamma A+\gamma^{2} A^{2}+\cdots\right) B
\end{aligned}
$$

Sendo esta a expressão equivalente no sentido convencional à Eq.(III.12) em Max-Plus [BACCELLIO1].

A matriz de transferência da Eq.(III.12) é definida através de uma série infinita e a convergência depende do valor de $\gamma$. Se a série é convergente para $\gamma=\gamma^{\prime}$, então ela também é convergente para todos os $\gamma$ que sejam menores que $\gamma^{\prime}$. Se a série não converge, ela ainda tem um significado como uma série formal. Igual como na teoria de sistemas convencionais, a matriz de transferência

\footnotetext{
${ }^{27}$ A operação Star Kleene [BACCELLI01] é definida como a soma infinita: $A^{*}=\bigoplus_{n \in N} A^{n}$.
} 
é especialmente útil quando vários subsistemas são combinados para construir sistemas maiores, através de conexões série, paralelo, e de realimentação. Por exemplo, o produto de duas matrizes de transferência (onde tacitamente se assume que os tamanhos destas matrizes são tais que a multiplicação é possivel), é uma nova matriz de transferência, a qual se refere a um sistema que consiste de sistemas originais conectados em série. 